\title{
Warm Water Oxidation Verification - Scoping and Stirred Reactor Tests
}

JC Braley SI Sinkov
CH Delegard

AJ Schmidt

June 2011

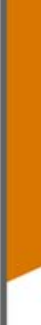

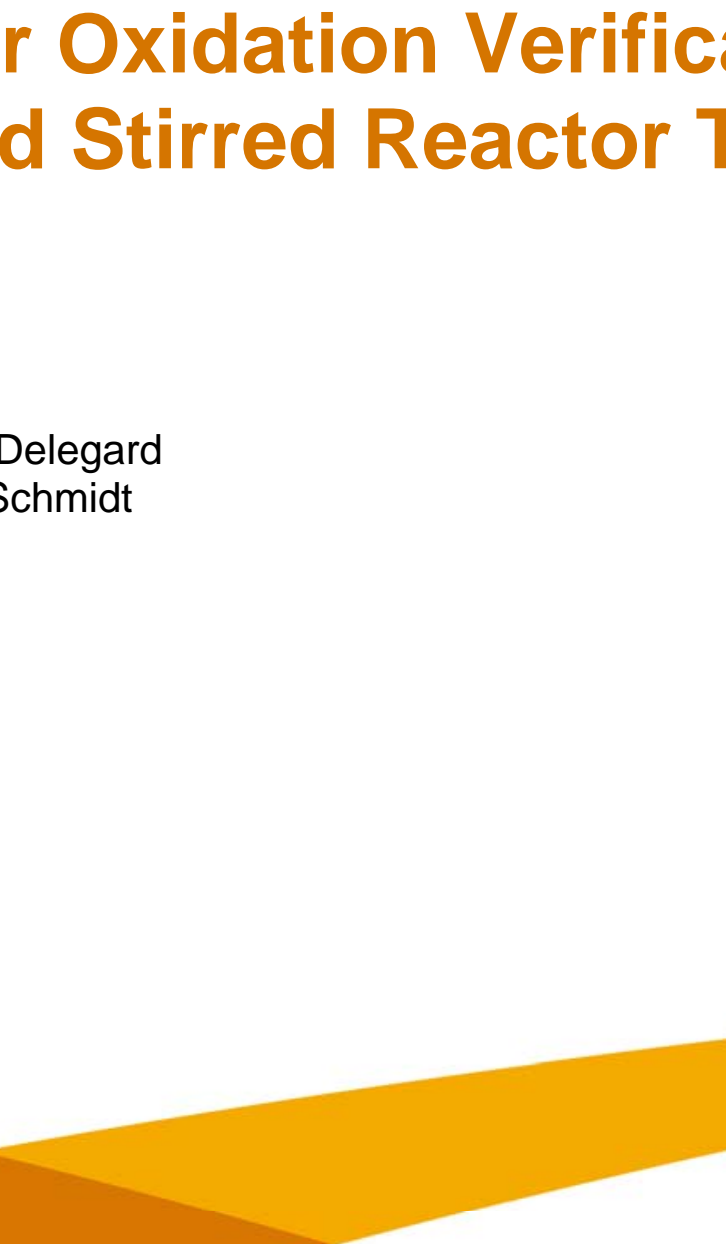

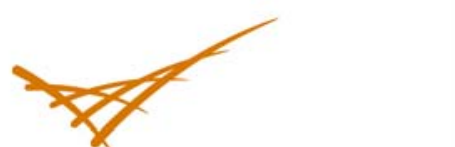

Pacific Northwest

NATIONAL LABORATORY

Proudly Operated by Battelle Since 1965 


\section{DISCLAIMER}

This report was prepared as an account of work sponsored by an agency of the United States Government. Neither the United States Government nor any agency thereof, nor Battelle Memorial Institute, nor any of their employees, makes any warranty, express or implied, or assumes any legal liability or responsibility for the accuracy, completeness, or usefulness of any information, apparatus, product, or process disclosed, or represents that its use would not infringe privately owned rights. Reference herein to any specific commercial product, process, or service by trade name, trademark, manufacturer, or otherwise does not necessarily constitute or imply its endorsement, recommendation, or favoring by the United States Government or any agency thereof, or Battelle Memorial Institute. The views and opinions of authors expressed herein do not necessarily state or reflect those of the United States Government or any agency thereof.

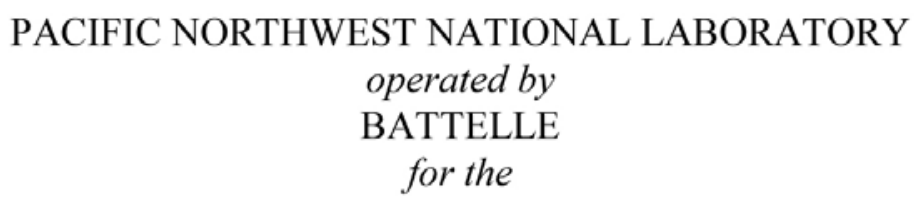

UNITED STATES DEPARTMENT OF ENERGY under Contract DE-AC05-76RL01830

Printed in the United States of America

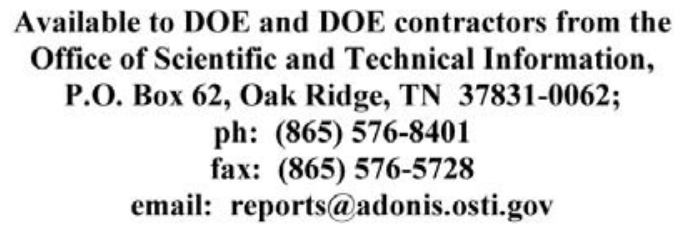

Available to the public from the National Technical Information Service 5301 Shawnee Rd., Alexandria, VA 22312 ph: (800) 553-NTIS (6847)

email: orders@ntis.gov <http://www.ntis.gov/about/form.aspx>

Online ordering: http://www.ntis.gov 
PNNL-20070

53451-RPT16, Rev. 0

\title{
Warm Water Oxidation Verification - Scoping and Stirred Reactor Tests
}

\author{
JC Braley \\ CH Delegard \\ SI Sinkov \\ AJ Schmidt
}

June 2011

Prepared for

the U.S. Department of Energy

under Contract DE-AC05-76RL01830

Pacific Northwest National Laboratory

Richland, Washington 99352 



\section{Summary}

Laboratory-scale scoping and bench-scale stirred reactor tests evaluating the effects of agitation and $\mathrm{pH}$ adjustment on simulant sludge agglomeration and uranium metal oxidation at $\sim 95^{\circ} \mathrm{C}$ were performed under Test Instructions ${ }^{(1,2,3)}$ and as per the Test Plan ${ }^{(4)}$ prepared by AREVA Federal Services, LLC (AREVA). The laboratory-scale scoping testing occurred over a 3-week period, beginning with a 96-hour oxidation rate test completed during the week of October 4-9, 2010, and the stirred thermal testing during the weeks January 10-14, 2011 and January 24-28 2011. The results are reported here.

For this testing, two uranium-containing simulant sludge types were evaluated:

1. A full uranium-containing $\mathrm{K}$ West (KW) Basin container sludge simulant (KW simulant) consisting of nine predominant sludge components.

2. A 50:50 uranium-mole basis mixture of uraninite [U(IV)] and metaschoepite [U(VI)] (50:50 U oxide slurry).

3. Known quantities of uranium metal were added to the simulants in each test.

This study was conducted in support of the Sludge Treatment Project (STP) Phase 2 technology evaluation for the treatment and packaging of K Basin sludge. The STP is managed by CH2M Hill Plateau Remediation Company (CHPRC) for the U.S. Department of Energy. Warm water $\left(\sim 95^{\circ} \mathrm{C}\right)$ oxidation of sludge, followed by immobilization, has been proposed by AREVA and is one of the alternative flowsheets being considered to oxidize uranium metal to eliminate chemical $\mathrm{H}_{2}$ generation during final sludge disposition. Preliminary assessments of warm water oxidation have been conducted, and several issues have been identified that can best be evaluated through laboratory testing. The evaluations documented here were specifically focused on the uranium metal corrosion rates at flowsheet conditions (mixing and simulant matrices) and the issue of the potential formation of high-strength sludge agglomerates at the proposed $95^{\circ} \mathrm{C}$ process operating temperature. Prior hydrothermal tests conducted at $185^{\circ} \mathrm{C}$ produced significant physicochemical changes to genuine sludge, including the formation of monolithic concretions/agglomerates that exhibited shear strengths in excess of $100 \mathrm{kPa}$ (Delegard et al. 2007; Onishi et al. 2011).

For all tests, the uranium metal oxidation rates observed were generally consistent with the predicted nominal Sludge Technical Databook (Schmidt 2010) rate at $95^{\circ} \mathrm{C}$, and the rates were not significantly affected by agitation or $\mathrm{pH}$ adjustment. While the uranium metal oxidation rates in tests with the $\mathrm{KW}$ simulant were a factor of 1.4 to 1.7 greater than the expected Databook rate, this increase falls well within the uncertainty on the Databook rate ( \pm a factor of 3 ).

\footnotetext{
${ }^{1}$ Delegard CH. 2010. “Oxidation of KW Container Sludge Simulant Addendum-Agglomeration with Heating." Test Instruction 53451-TI24, Rev. 1, Addendum, Pacific Northwest National Laboratory, Richland, Washington. ${ }^{2}$ Braley JC. 2010. "Warm Water Oxidation Verification Tests—Runs 1 and 2.” Test Instruction 53451-TI34, Rev. 0, Pacific Northwest National Laboratory, Richland, Washington.

${ }^{3}$ Braley JC. 2011. "Warm Water Oxidation: Stirred Reactor Testing." Test Instruction 53451-TI38, Rev. 0, Pacific Northwest National Laboratory, Richland, Washington.

${ }^{4}$ AREVA Test Plan for Warm Water Oxidation Flowsheet Verification. PLN-3003760-001, AREVA Federal Services, LLC, Richland, Washington.
} 


\section{Results from Laboratory-Scale Scoping Tests}

No strong agglomerate formation was observed in any laboratory-scale scoping tests with the KW simulant, including heating at $95^{\circ} \mathrm{C}$ for 3 weeks. Agitation was shown to be beneficial in minimizing agglomerate formation in tests with the 50:50 U oxide slurry. However, even the strongest solids that formed in the static tests (i.e., no agitation) could be disintegrated with even moderate force.

Sodium hydroxide and sodium phosphate salts were added in some tests to raise the $\mathrm{pH}$ of the supernatant phase to 12. It has been postulated by AREVA that raising the $\mathrm{pH}$ far above the point-of-zero charge of metaschoepite could discourage agglomerate formation. However, it was observed that $\mathrm{NaOH}$ did not provide dispersion significant enough to perceptibly alter the strength of the 50:50 U oxide slurry.

The uranium metal corrosion rates and the U(IV):U(VI) ratios were measured after 96 hours of heating for tests selected in accordance with the Test Plan. The highest uranium metal penetration rates were observed in systems where KW simulant was present and no agitation occurred. These rates were up to $\sim 1.7$ times the nominal rates predicted by the STP rate law as based on extensive review of the technical literature on uranium metal corrosion in anoxic water (Appendix G of Plys and Schmidt 2009). Since agitation generally encouraged the suspension of simulant solids to the supernatant, the somewhat greater corrosion rates indicated that some solid component of the KW simulant (possibly ferrihydrite) encouraged the oxidation of the uranium metal. In the majority of 50:50 U oxide slurry tests, however, uranium metal penetration rates were very close to what is predicted by the STP rate law. In addition, most $\mathrm{U}(\mathrm{IV}): \mathrm{U}(\mathrm{VI})$ ratios were 40:60 and thus indicated that the tests were oxidizing (or at least that oxygen was consumed), given that the initial $\mathrm{U}(\mathrm{IV}): \mathrm{U}(\mathrm{VI})$ ratio was $\sim 50: 50$. The significant exception to this is the reactor test with 50:50 $\mathrm{U}$ oxide stirred slurry where the increase in $\mathrm{U}(\mathrm{VI})$ was less than 1\%.

\section{Results from Bench-Scale Stirred Reactor Testing}

Using information gathered in laboratory-scale scoping tests, the scalability of the warm water oxidation (WWO) process was examined at the 100-g and 200-g level (dry solids basis) for KW containerized simulant and the 50:50 mole basis uraninite/metaschoepite mixture, respectively, using overhead stirring. These two tests were conducted with approximately $200 \mathrm{ml}$ of slurry at 12 to 15 volume percent solids. The testing thus was conducted in a reactor that is more prototypic of the one proposed in the preconceptual flowsheet to help advance the technical readiness of WWO process. Key observations and findings from this work are:

1. A small zone of agglomerated sludge was found in the low shear region just below the impeller (bottom of the reactor vessel) in the testing with the KW containerized simulant. Agglomeration did not occur in the testing with the 50:50 U oxide stirred slurry. Agglomeration can be minimized via reactor/impeller design to eliminate low-shear "dead" zones, but temperature maintenance at $98^{\circ} \mathrm{C}$ or below is of primary importance in applying the WWO sludge treatment to K Basin solids. Further optimization of vessel mixing (e.g., use of a close-clearance impeller design), and application of jacketed sidewall heating, to avoid issues with over-heating sludge at the base of the mixing chamber are recommended.

2. The uranium metal corrosion rates obtained with $\sim 200 \mathrm{~mL}$ slurry in stirred reactor were very comparable to rates obtained in the analogous $3 \mathrm{~mL}$ laboratory-scale scoping tests.

3. Conditions of the stirred reactor tests were more oxidizing for the KW simulant stirred reactor test. In the bench-scale tests a $15 \%$ increase in U(VI) was observed. For the laboratory-scale tests, only a 
$10 \%$ increase in $\mathrm{U}(\mathrm{VI})$ was observed. This may be attributed to more aggressive mixing of the stirred reactor test introducing more oxygen and that the stirred test was continuously open to the atmosphere.

4. Conditions of the stirred reactor tests were less oxidizing for the bench-scale test with 50:50 U oxide slurry, which increased in U(VI) by $1 \%$, compared to the laboratory-scale tests that increased in $\mathrm{U}(\mathrm{VI})$ by $10 \%$.

All U(IV):U(VI) ratios evaluated indicated that test conditions were oxidizing. After considering potential measurement uncertainties, the uranium metal rate enhancement factor for the two matrices is between 1 and 2. The data generated support the use of a rate enhancement factor of 1 for the preconceptual flowsheet.

\section{Overall Observations/Conclusions}

The testing showed that the sludge solids that formed in 96 hours of $\sim 95^{\circ} \mathrm{C}$ heating were generally weak, regardless of agitation and $\mathrm{pH}$ adjustment. However, in the bench-scale test with $\mathrm{KW}$ simulant, a zone of high strength agglomerated material was observed. The simulant representative of settler tank sludge prepared from 50:50 uraninite:metaschoepite exhibited greater strength in the laboratory-scale scoping tests than the multi-component simulant prepared to emulate $\mathrm{KW}$ containerized sludge from SCS-CON-210 and 220). However, neither simulant presented an overwhelming challenge to re-suspension. Agitation did not increase the uranium metal corrosion rate. Of all test conditions evaluated, the greatest corrosion rates were observed for non-agitated KW simulant in the laboratory-scale scoping tests (about 1.7 times the rate predicted by the Databook). The lowest corrosion rate observed occurred in tests conducted with the 50:50 $\mathrm{U}$ oxide slurry under agitated conditions in the laboratory-scale scoping tests ( 0.9 times the Databook rate equation). Oxidation rates for all experiments are well within the uncertainty on the Databook rate ( \pm a factor of 3 ). The rates observed for the larger scale tests with overhead stirring were similar to those observed in the laboratory-scale scoping tests.

Further study of this system is encouraged to:

- investigate the conditions associated with agglomerate formation,

- evaluate the possible role of ferrihydrite and actual sludge matrices on uranium metal oxidation,

- evaluate reactor vessels that may include jacketed sidewall heating and close-clearance mixing, and

- evaluate longer runs analogous to the full length of time anticipated per sludge batch ( $\sim 130$ days). 



\section{Acronyms and Abbreviations}

ALE

AREVA

ASTM

CHPRC

DIW

DOE

EDS

KE Basin

KW Basin

NIST

OIA

OIER

PNNL

PSD

PZC

SEM

STP

TC

UV-Vis

WIPP

WWO

XRD
Fitzner-Eberhardt Arid Lands Ecology Reserve

AREVA Federal Services, LLC

American Society for Testing and Materials

CH2M Hill Plateau Remediation Company

deionized water

U.S. Department of Energy

energy dispersive X-ray spectroscopy

K-East Basin

K-West Basin

National Institute of Standards and Technology

only if agglomerated

organic ion exchange resin

Pacific Northwest National Laboratory

particle-size distribution

point-of-zero charge

scanning electron microscopy

Sludge Treatment Project

thermocouple

ultraviolet visible

Waste Isolation Pilot Plant

warm water oxidation

$\mathrm{X}$-ray diffraction

To maintain clarity in discussion of the testing, the two simulants used in this report will be annotated as "KW simulant" and "50:50 U oxide slurry" to describe the uranium-containing KW containerized sludge simulant and the 50:50 (mole basis) $\mathrm{UO}_{2}: \mathrm{UO}_{3} \cdot 2 \mathrm{H}_{2} \mathrm{O}$, respectively. 



\section{Contents}

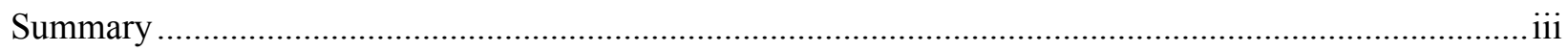

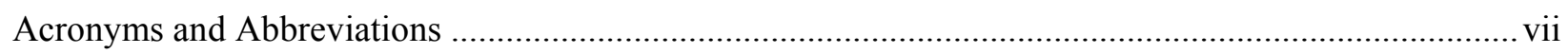

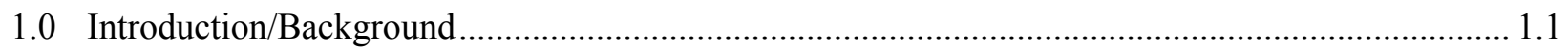

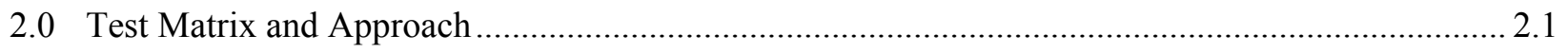

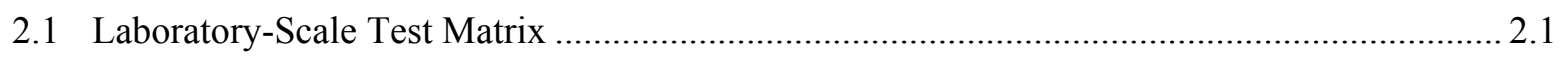

2.2 Simulant Sludge Composition and Preparation................................................................. 2.2

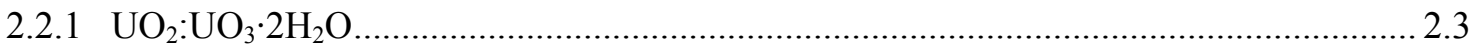

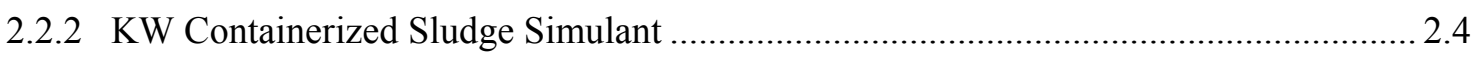

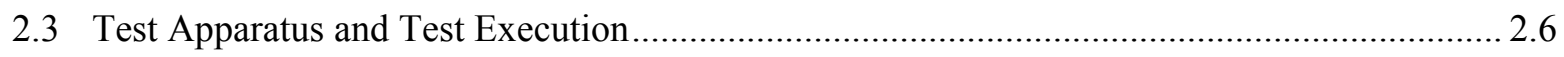

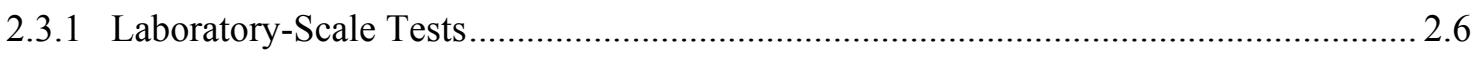

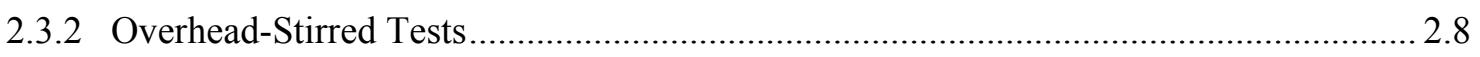

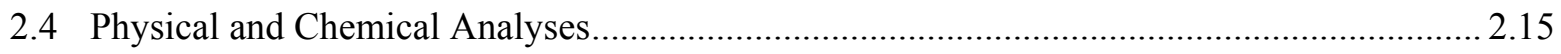

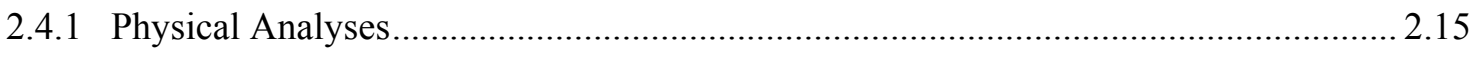

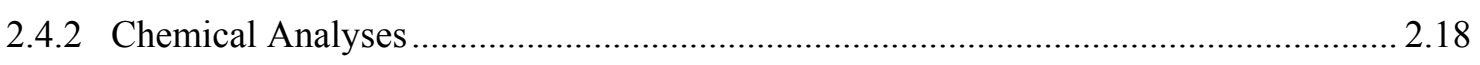

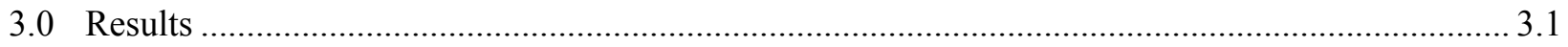

3.1 Uranium Metal Corrosion Rate and Uranium Oxide Redox Analysis .................................. 3.1

3.1.1 Laboratory-Scale Uranium Test Results .............................................................. 3.1

3.1.2 Bench-Scale Uranium Test Results ..................................................................... 3.3

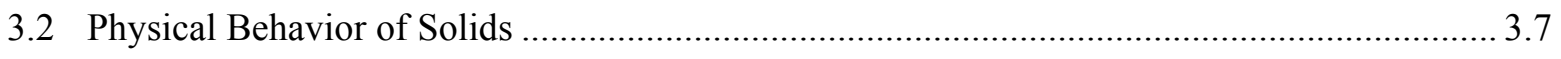

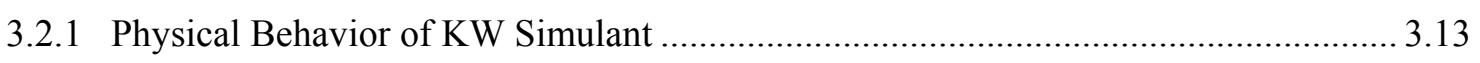

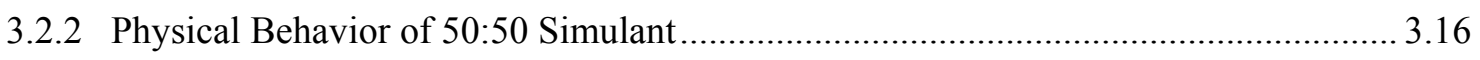

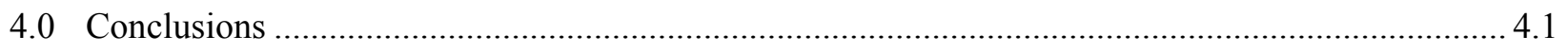

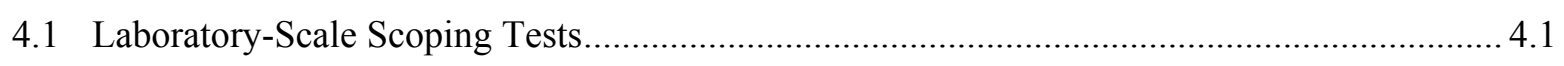

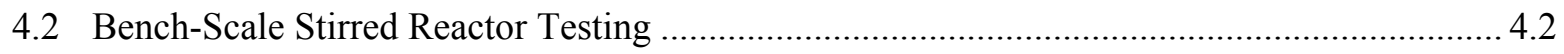

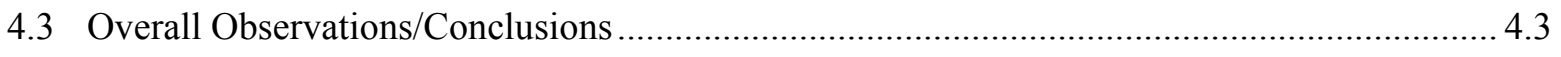

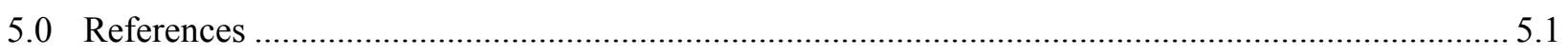

Appendix A Summary of Operating Steps for Laboratory-Scale Warm Water Oxidation Tests ............. A.1

Appendix B Photographs of Test Items Before Initiation of Heating .................................................... 1

Appendix C Photographs of Test Items after 96 Hours of Heating at $95^{\circ} \mathrm{C}$......................................... 1

Appendix D Photographs of Test Items Following Completion of Two-Week Settling Period.............. D.1

Appendix E Scanned Electron Micrographs of Test Items ................................................................... 1 


\section{Figures}

2.1. Left: Customized $50 \mathrm{~mL}$ Centrifuge Tube Used in Tests for Solids Heating and Containment. Right: Test Setup for Agitated Samples.

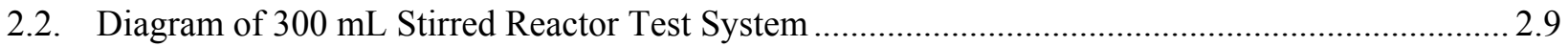

2.3. Photograph of $300 \mathrm{~mL}$ Stirred Reactor Test System............................................................ 2.10

2.4. Photograph of Tungsten and Steel Grit Particles Used in Shakedown Testing of $300 \mathrm{~mL}$ Reactor.

2.5. Photograph of Modified Impeller Used to Minimize Dead Zone Formation................................ 2.15

2.6. Spatula Used to Probe Sludge Solids ....................................................................................... 2.16

3.1. SEM Images of Uranium Metal Beads Relevant to Stirred Reactor Testing ................................ 3.4

3.2. Photographic Images of Uranium Metal Beads Relevant to Stirred Reactor Testing ..................... 3.5

3.3. (a) Stratified KW Simulant Observed After 72-Hour Settling Period. (b) Composition of Sludge Heel.

3.4. The Effects of $\mathrm{pH}$ Adjustment on KW Simulant Tests: Tests 1 and 2 Are Duplicates and Representative of Samples Without pH Adjustment................................................................. 3.8

3.5. Unique Morphology of 50:50 Uranium Oxide Slurry Mixtures After 96 Hours of Heating ......... 3.17

3.6. The Effects of Agitation on 50:50 UO $\mathrm{U}_{\mathrm{x}}$ Slurry: Tests 9 and 21 Indicate Agitated and Static

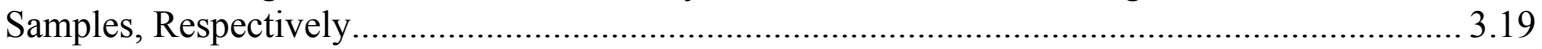

3.7. The Breakdown Possibilities of Plate-Like Solids After Prolonged (2-wk) Heating.................... 3.20

3.8. Photographic and SEM Comparison of Initial and Final Compositions of 50:50 Uranium

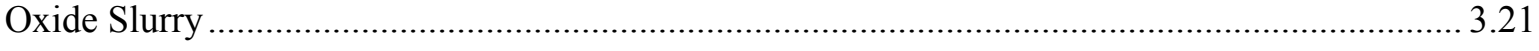

3.9. Average Volume \% PSD of Sample 50:50 Uranium Oxide Slurry Before WWO Treatment....... 3.22

3.10. Average Volume \% PSD of 50:50 Uranium Oxide Slurry After WWO Treatment (96 hr at $95^{\circ} \mathrm{C}$ in stirred reactor). 


\section{Tables}

2.1. Test Matrix for Warm Water Treatment Laboratory-Scale Scoping Study-Effects of Agitation and $\mathrm{pH}$ on Agglomeration and Uranium Metal Oxidation 2.2

2.2. Basis and Composition of KW Containerized Simulant Sludge .................................................. 2.6

2.3. Summary of Nominal WWO Stirred Reactor Tests ................................................................ 2.11

2.4. Nominal 100-g Basis KW Container Sludge Simulant ............................................................. 2.12

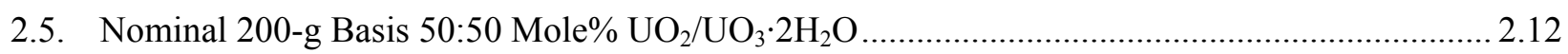

2.6. Summary of Malvern MS2000 Instrument Information and Parameters Used for Sample Analysis.

3.1. Uranium Oxidation Information After 96-Hour Heating for Both Uranium Metal and 50:50 Uranium Oxide Slurry.... 3.2

3.2. Uranium Oxidation Information After 96-Hour Heating for Stirred Reactor Testing .................... 3.7

3.3. Complete $\mathrm{pH}$ Data for All Laboratory-Scale Tests Performed for WWO Scoping ......................... 3.9

3.4. Test Heights Before Heating and After Heating for 96 Hours .................................................. 3.10

3.5. Observations From Warm Water Heating With Initial Agitation .............................................. 3.11

3.6. Observations From Warm Water Heating Without Agitation (Static) .......................................... 3.12

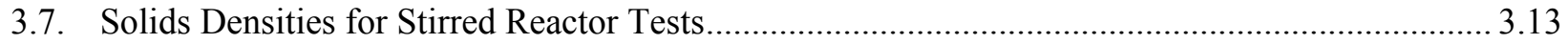

3.8. Summary of Selected Percentile Values Describing Particle Size Distribution............................. 3.23 



\subsection{Introduction/Background}

The function of the warm water oxidation (WWO) system is to oxidize solid uranium metal $\left(\mathrm{U}_{(0)}\right)$ in anoxic $\sim 95^{\circ} \mathrm{C}$ water to form uranium (IV) dioxide $\left(\mathrm{U}_{(\mathrm{IV})} \mathrm{O}_{2}\right)$ and hydrogen gas $\left(\mathrm{H}_{2}\right)$ :

$$
\mathrm{U}_{(0)}+2 \mathrm{H}_{2} \mathrm{O} \rightarrow \mathrm{U}_{(\mathrm{IV})} \mathrm{O}_{2}+2 \mathrm{H}_{2(\mathrm{~g})}
$$

The reaction rate is surface-area limited and occurs isotropically such that, for a given temperature, the penetration depth through the corroding uranium metal is proportional to time. Based on the reaction rate equation provided in the Sludge Databook (Schmidt 2010), the extinction time for a baseline $1 / 4$-inch $(6350-\mu \mathrm{m})$ diameter uranium metal sphere is 39 hours at $185^{\circ} \mathrm{C}$ (i.e., the penetration rate is $\sim 81 \mu \mathrm{m} /$ hour) while the same particle under the WWO temperature of $95^{\circ} \mathrm{C}$ is estimated to take 130 days to oxidize to extinction (penetration rate is $\sim 1 \mu \mathrm{m} /$ hour). Previous testing at $185^{\circ} \mathrm{C}$ and at temperatures from $\sim 40$ to $95^{\circ} \mathrm{C}$ verified that the oxidation proceeded according to known rates (Delegard et al. 2007; Delegard and Schmidt 2009). For these reasons, similar adherence to the known rate law is expected for the $95^{\circ} \mathrm{C}$ WWO process.

The primary goal of the WWO is to oxidize most, if not all, of the uranium metal contained in the sludge before its disposal to the Waste Isolation Pilot Plant (WIPP) and thus eliminate the chemical generation of hydrogen gas by the reaction of uranium metal with water during transit. Besides uranium metal, the sludge contains a number of non-uranium constituents and uranium compounds that may react or dissolve to some extent at the process temperature. By WWO processing, new phases may form by chemical reaction of the sludge components. Precipitation through loss of water, by subsequent cooling of the product to ambient temperature, or through crystal growth, by way of Ostwald ripening, then may cement particles together. It is suspected that these mechanisms may have been responsible for high-uranium-content sludge, with a composition similar to that expected for sludge from the settler tanks, to produce a solid product with a shear strength in excess of $100 \mathrm{kPa}$ during $\sim 28$-month storage at $\sim 34^{\circ} \mathrm{C}$ in a radiological hot cell (Delegard et al. 2005; Wells et al. 2009). Material of this strength would not be readily transportable from the WWO process vessel in a loss-of-agitation event for the follow-on processing steps. The agglomeration of high-uranium sludge to a shear strength of $\sim 120$ to $170 \mathrm{kPa}$ also was observed by its hydrothermal processing at $185^{\circ} \mathrm{C}$ for 7 to 10 hours (Delegard et al. 2007) and was thought to be due to a similar mechanism.

Agitation during the WWO process may 1) prevent the formation of agglomerates, 2) promote the breakup of agglomerates once formed, and thus 3) decrease the strength of the heated product. Agitation also may enhance the uranium oxidation rate by two mechanisms. First, agitation would serve to disrupt the sludge blanketing that has been credited with decreasing the uranium metal oxidation rate observed in previous testing (Schmidt et al. 2003; Delegard and Schmidt 2009). Agitating the sludge during the oxidation process also may abrade uranium metal particle surfaces with the effect of removing the protective oxide layers from the metal to increase reaction rates.

It is expected that the WWO process will also affect the chemistry and physical properties, including the shear strength, of the other sludge components. Chemical alterations of sludge components occur during hydrothermal treatment, but the extent of such reactions in the simulated sludge under warm water oxidation is not known. For instance, it has been shown that mixtures formed by $\mathrm{UO}_{2}$ oxidation contain metaschoepite, $\mathrm{UO}_{3} \cdot 2 \mathrm{H}_{2} \mathrm{O}$, and tend to higher-strengths (Delegard et al. 2011; Hill 2010). 
Sludge components, such as metaschoepite, ferrihydrite, goethite, and gibbsite, also can dehydrate by heating and aging. It is known that metaschoepite does not alter when heated in air to $65^{\circ} \mathrm{C}$, but forms "dehydrated schoepite," $\mathrm{UO}_{3} \cdot 0.8 \mathrm{H}_{2} \mathrm{O}$, when heated in air at $105^{\circ} \mathrm{C}$ and does not undergo further change when heated to $150^{\circ} \mathrm{C}$ (Sowder et al. 1999). Dehydrated schoepite was observed in the hydrothermal alteration of metaschoepite-bearing genuine sludge at $185^{\circ} \mathrm{C}$ (Delegard et al. 2007). Ferrihydrite, formally $\mathrm{Fe}_{2} \mathrm{O}_{3} \cdot 1.8 \mathrm{H}_{2} \mathrm{O}$, ages under even dry room temperature conditions to form goethite, $\alpha-\mathrm{FeOOH}$, and hematite, $\mathrm{Fe}_{2} \mathrm{O}_{3}$ (Sinkov et al. 2010) and was found to hydrothermally alter to hematite at $185^{\circ} \mathrm{C}$ (Delegard et al. 2007). Goethite itself dehydrates with aging in water and heat to form hematite. Gibbsite, $\alpha-\mathrm{Al}(\mathrm{OH})_{3}$, dehydrates in air between $150^{\circ} \mathrm{C}$ and $200^{\circ} \mathrm{C}$ to form boehmite, $\gamma$-AlOOH (Rivas Mercury et al. 2006) and alters to boehmite under $185^{\circ} \mathrm{C}$ hydrothermal conditions (Delegard et al. 2007). The hydrated precursor phases of metaschoepite, goethite, and gibbsite all have been observed in genuine sludge and are important components in sludge simulants. Ferrihydrite, though likely present in sludge from mild steel corrosion, itself has a diffuse X-ray diffraction (XRD) pattern and would be difficult to observe in complex sludge matrices.

As a predecessor to the current testing, limited laboratory-scale scoping tests were performed to examine the behavior of $\mathrm{UO}_{2} / \mathrm{UO}_{3} \cdot 2 \mathrm{H}_{2} \mathrm{O}$ and $\mathrm{KW}$ simulant at $96^{\circ} \mathrm{C}$ (96-hour test) under static gas conditions (summarized in Section 3.2 of Delegard et al. 2011). No uranium metal was included in these tests. Comparing the XRD scans of the unheated and heated samples showed no evidence of dehydration reactions or changes in material phases, although changes in peak intensities were noted. No peaks attributable to dehydrated schoepite or to boehmite were observed. The hydrated precursor compounds of metaschoepite, goethite, and gibbsite remained present in the heated products.

It is hypothesized that maintaining the uranium metal oxidation reaction at a $\mathrm{pH}$ substantially higher than the point-of-zero charge (pzc) may minimize agglomeration in the WWO process. This is because, under such conditions, the colloidal particles exhibit zero zeta potential (i.e., the particles remain stationary in an electric field) while maintaining minimum stability (i.e., have maximum dispersion and minimum flocculation rates). These two effects would combine to minimize the viscosity of the slurry dispersion. Studies of pure $\mathrm{UO}_{2}$ and of sludge indicate that the $\mathrm{pH}$ of the pzc is in the range of 4 to 6 (Olsson et al. 2002; Makenas et al. 1996, 1997, 1998).

Based on these considerations, laboratory-scale scoping tests ( $\sim 3 \mathrm{~mL}$ settled sludge solids) were undertaken to understand better the WWO process operated at $95^{\circ} \mathrm{C}$. Studies were performed using two types of simulant sludge - one containing only uranium oxide and another containing uranium oxide with other key sludge components. Because of the potential role of agitation on sludge strength and the uranium metal corrosion rate, tests were conducted with and without agitation. Tests also were conducted with and without agents added to raise the $\mathrm{pH}$ above the pzc. The agents tested were sodium hydroxide and sodium phosphate solutions. Besides raising $\mathrm{pH}$, sodium phosphate also was investigated to determine if it could increase the uranium metal oxidation rate as had been shown in a single aqueous solution test that contained disodium phosphate (Sinkov et al. 2010).

Bench-scale ( $\sim 200 \mathrm{~mL}$ slurry) $95^{\circ} \mathrm{C}$ tests of the WWO process then were performed under prototypic overhead-stirred conditions using the same two simulant sludges but with no $\mathrm{pH}$ amendments. The uranium corrosion rates, sludge agglomeration characteristics, and uranium oxide oxidation rates were measured and compared with the observations made for the laboratory-scale tests. 
The laboratory-scale scoping and bench-scale overhead-stirred testing described here were designed to provide insight into the nature of the chemical reactions, the effects of compositional and process variations, and the effectiveness of various strategies to mitigate agglomerates that may be formed during the WWO process. The specific objectives of the testing, as articulated in the AREVA Federal Services, LLC (AREVA) Test Plan (Hagerty 2010), are described below:

- Determine the rate of uranium metal oxidation in simulated sludge in the WWO process and compare this with the established rate equation.

- Determine if, at the temperature conditions of the WWO process, problematic agglomerates form.

- Determine the effect of agitation during the oxidation process on the formation of agglomerates.

- Determine if the agitation will adequately break up agglomerates once they are formed in the oxidation process.

- Determine if an extended soak time at the WWO temperature $\left(95^{\circ} \mathrm{C}\right)$ will cause the formation of agglomerates.

- Determine if agitation affects the uranium metal reaction rate at WWO process conditions.

- Determine if altering the $\mathrm{pH}$ of the simulant changes the formation of agglomerates or impacts other factors (e.g., uranium metal oxidation rate).

- Determine the scalability of an optimized WWO process.

Section 2.0 of this report will describe the WWO test matrix, test materials (uranium-containing simulants), test equipment, and experimental methods. Results and data derived from the testing will be presented in Section 3.0. The presented laboratory-scale scoping test data will include uranium metal corrosion rates and uranium oxide oxidation state analyses evaluated after the first 96 hours of testing, as well as the physical behavior of the simulants throughout the 3-week test duration. Analogous observations arising from the overhead-stirred tests also are presented in Section 3.0. Section 4.0 summarizes the conclusions from the testing. A brief summary of experimental steps is provided in Appendix A, and Appendices B, C, D, and E include supplemental photographs or images that document the physical appearance of the test items at various steps within the test sequence. 



\subsection{Test Matrix and Approach}

A balanced matrix of 27 small-scale experiments (laboratory-scale scoping tests) was performed to address the specific test objectives outlined in Section 1.0 (Introduction/Background). Of these 27 experiments, 22 were conducted at the nominal $95^{\circ} \mathrm{C} \mathrm{WWO}$ temperature, half with agitation and half without agitation. The remaining 5 tests were run static at room temperature as controls. Within each experimental set, tests were run with full K-West $(\mathrm{KW})$ container sludge simulant $(\sim 3 \mathrm{~mL}$ volume; $4.15 \mathrm{~g}$ ), with $\sim 50: 50$ (mole basis) $\mathrm{UO}_{2}: \mathrm{UO}_{3} \cdot 2 \mathrm{H}_{2} \mathrm{O}(\sim 3 \mathrm{~mL}$ volume; $\sim 5 \mathrm{~g})$ simulant and under varied $\mathrm{pH}$ environments (from near neutral $\mathrm{pH}$ to higher $\mathrm{pHs}$ attained with $\mathrm{NaOH}$ or $\mathrm{Na}_{3} \mathrm{PO}_{4}$ ). The laboratory-scale tests were followed by two single bench-scale $(\sim 200 \mathrm{~mL})$ tests using the same two sludge simulant compositions without $\mathrm{pH}$ amendment. These latter tests were each run at a nominal $95^{\circ} \mathrm{C}$ WWO temperature and were continuously agitated by an overhead-driven impeller.

The composition of KW container sludge simulant is broadly representative of sludge that had been present on the floor and pits of the KW Basin that is now held in engineered containers SCS-CON-210 and 220. The KW container simulant is also similar to, but higher in uranium content than, the KE-originating sludge that is held in engineered containers SCS-CON-240, 250, and 260. The 50:50 $\mathrm{UO}_{2}: \mathrm{UO}_{3} \cdot 2 \mathrm{H}_{2} \mathrm{O}$ represents sludge that originated from the settler tubes in the KW Basin and is now present in container SCS-CON-230.

To enhance solids agitation provided by the side-to-side action of the test apparatus, the materials in the laboratory-scale tests were held in capped $50 \mathrm{~mL}$ polypropylene centrifuge tubes that had been modified from their original cone shape to have flat bottoms. The larger scaled, overhead-stirred tests were conducted in a $\sim 300 \mathrm{~mL}$, round-bottom, glass vessel. The vessel had four vertical baffles that prevented vortices from forming during stirring. The stirrer rotor directed flow downward.

Following the treatments according to the various test parameters of sludge type, heating time, agitation, and $\mathrm{pH}$ amendment, the test items were examined to determine changes in the solids volume and strength, appearance, uranium oxide oxidation state distribution, and uranium metal corrosion rate.

The following sections describe the test approach. Section 2.1 describes the laboratory-scale test matrix. Section 2.2 outlines the preparation and composition of the simulant sludges. Section 2.3 describes the test apparatus and test execution. The means used to characterize the materials after testing are outlined in Section 2.4.

\subsection{Laboratory-Scale Test Matrix}

The test matrix and its rationale were developed by AREVA Federal Services LLC, in collaboration with Pacific Northwest National Laboratory (PNNL) scientists and engineers and are presented in the associated Test Plan (Hagerty 2010). The test matrix for the laboratory-scale scoping evaluation is provided in Table 2.1, and a summary of the test operating steps is included in Appendix A. The balanced test matrix was designed to make evident the effects of sludge type, agitation, heating, and $\mathrm{pH}$ amendment by $\mathrm{NaOH}$ and $\mathrm{Na}_{3} \mathrm{PO}_{4}$ on sludge-material strength and uranium metal corrosion rate. 
Table 2.1. Test Matrix for Warm Water Treatment Laboratory-Scale Scoping Study-Effects of Agitation and $\mathrm{pH}$ on Agglomeration and Uranium Metal Oxidation

\begin{tabular}{|c|c|c|c|c|c|c|}
\hline \multicolumn{7}{|c|}{ MultiTherm Run \#1-All samples agitated and heated to $95^{\circ} \mathrm{C}$ for 96 hours. } \\
\hline Sample ID\# & Matrix $^{(a)}$ & pH Adj. & Slump Test \#1 & Slump Test \#2 & Re-agitation? & U Metal Analysis \\
\hline 1 & KW Simulant & No & Post 96 hours & No & No & Post 96 hours \\
\hline 2 & KW Simulant & No & No & Post 2 wk at 95 & Yes & No \\
\hline 3 & KW Simulant & $\mathrm{NaOH}: 12$ & Post 96 hours & No & No & Post 96 hours \\
\hline 4 & KW Simulant & $\mathrm{NaOH}: 12$ & No & Post 2 wk at 95 & Yes & No \\
\hline 5 & KW Simulant & No & No & Post 2 wk at 25 & Yes & No \\
\hline 6 & KW Simulant & $\mathrm{NaOH}: 12$ & No & Post $2 w k$ at 25 & Yes & No \\
\hline 7 & KW Simulant & $\mathrm{Na}_{3} \mathrm{PO}_{4}: 12$ & Post 96 hours & No & No & Post 96 hours \\
\hline 8 & $50: 50 \mathrm{UO}_{2} / \mathrm{UO}_{3}$ & No & Post 96 hours & No & No & Post 96 hours \\
\hline 9 & $50: 50 \mathrm{UO}_{2} / \mathrm{UO}_{3}$ & No & No & Post 2 wk at 95 & Yes & No \\
\hline 10 & $50: 50 \mathrm{UO}_{2} / \mathrm{UO}_{3}$ & $\mathrm{NaOH}: 12$ & Post 96 hours & No & No & Post 96 hours \\
\hline 11 & $50: 50 \mathrm{UO}_{2} / \mathrm{UO}_{3}$ & No & No & Post 2 wk at 25 & Yes & No \\
\hline 12 & TC & - & - & - & - & - \\
\hline \multicolumn{7}{|c|}{ MultiTherm Run \#2-No samples agitated. All samples heated to $95^{\circ} \mathrm{C}$ for 96 hours. } \\
\hline Sample ID\# & Matrix $^{(a)}$ & pH Adj. & Slump Test \#1 & Slump Test \#2 & Re-agitation? & U Metal Analysis \\
\hline 13 & KW Simulant & No & Post 96 hours & No & OIA $^{(b)}$ & Post 96 hours \\
\hline 14 & KW Simulant & No & No & Post 2 wk at 95 & Yes & No \\
\hline 15 & KW Simulant & $\mathrm{NaOH}: 12$ & Post 96 hours & No & OIA $^{(b)}$ & Post 96 hours \\
\hline 16 & KW Sin & $\mathrm{NaOH}: 12$ & No & Post 2 wk at 95 & Yes & No \\
\hline 17 & KW Sim & No & No & Post $2 \mathrm{wk}$ & Yes & No \\
\hline 18 & KW Simulant & NaOH: 12 & No & Post 2 wk at 25 & Yes & No \\
\hline 19 & KW Simulant & $\mathrm{Na}_{3} \mathrm{PO}_{4}: 12$ & Post 96 hours & No & OIA $^{(b)}$ & Post 96 hours \\
\hline 20 & $50: 50 \mathrm{UO}_{2} / \mathrm{UO}_{3}$ & No & Post 96 hours & No & OIA $^{(b)}$ & Post 96 hours \\
\hline 21 & $50: 50 \mathrm{UO}_{2} / \mathrm{UO}_{3}$ & No & No & Post 2 wk at 95 & Yes & No \\
\hline 22 & $50: 50 \mathrm{UO}_{2} / \mathrm{UO}_{3}$ & NaOH: 12 & Post 96 hours & No & OIA $^{(b)}$ & Post 96 hours \\
\hline 23 & $50: 50 \mathrm{UO}_{2} / \mathrm{UO}_{3}$ & No & No & Post 2 wk at 25 & Yes & No \\
\hline 24 & TC & - & - & - & - & - \\
\hline \multicolumn{7}{|c|}{ Run \#1 and \#2 ambient temperature controls (No heating OR agitation). Only Re-agitate if agglomerated. } \\
\hline Sample ID\# & Matrix $^{(a)}$ & pH Adj. & Slump Test \#1 & Slump Test \#2 & Re-agitation? & U Metal Analysis \\
\hline Control 1 & KW Simulant & No & Post 96 hours & Post $2 w k$ & -- & No \\
\hline Control 2 & KW Simulant & $\mathrm{NaOH}: 12$ & Post 96 hours & Post $2 w k$ & -- & No \\
\hline Control 3 & KW Simulant & $\mathrm{Na}_{3} \mathrm{PO}_{4}: 12$ & Post 96 hours & Post $2 w k$ & -- & No \\
\hline Control 4 & $50: 50 \mathrm{UO}_{2} / \mathrm{UO}_{3}$ & No & Post 96 hours & Post $2 w k$ & -- & No \\
\hline Control 5 & $50: 50 \mathrm{UO}_{2} / \mathrm{UO}_{3}$ & $\mathrm{NaOH}: 12$ & Post 96 hours & Post $2 w k$ & -- & No \\
\hline
\end{tabular}

(a) All samples contain uranium metal except for the cells reserved for thermocouple (TC) and controls.

(b) OIA-Only if agglomerated.

\subsection{Simulant Sludge Composition and Preparation}

Two types of simulant sludge were prepared for use in the laboratory-scale and bench-scale testing. The first type is the $\sim 50: 50$ mole basis mix of $\mathrm{UO}_{2}: \mathrm{UO}_{3} \cdot 2 \mathrm{H}_{2} \mathrm{O}$. The second type, $\mathrm{KW}$ containerized sludge simulant, included $\mathrm{UO}_{2}$ and $\mathrm{UO}_{3} \cdot 2 \mathrm{H}_{2} \mathrm{O}$ in the 50:50 mole ratio but also included ferrihydrite, gibbsite, Fitzner-Eberhardt Arid Lands Ecology (ALE) Reserve sand, Purolite NRW37 organic ion exchange resin (OIER), mordenite inorganic ion exchanger, water, and Optimer 7194 Plus flocculating agent.

In the laboratory-scale scoping tests, uranium metal was added at the concentration prescribed in the simulant makeup (i.e., $3.6 \mathrm{wt} \%$ - dry simulant basis). In the bench-scale testing, the concentration of uranium metal used was reduced to allow for near quantitative recovery of the partially reacted uranium 
beads during post-test examinations. Confirmation of the uranium metal reaction behavior and reaction rate was achievable with the reduced uranium metal concentration. Agglomeration behavior is not expected to be significantly influenced by the $U$ metal content (within the range of interest), as it is small with respect to the total uranium oxide concentration.

\subsection{1 $\mathrm{UO}_{2}: \mathrm{UO}_{3} \cdot 2 \mathrm{H}_{2} \mathrm{O}$}

The $\mathrm{UO}_{2}: \mathrm{UO}_{3} \cdot 2 \mathrm{H}_{2} \mathrm{O}$ material was prepared by oxidizing $\mathrm{UO}_{2}$ in water slurry with pure oxygen. The $\mathrm{UO}_{2}$ [oxidation state of $\mathrm{U}(\mathrm{IV})$ ] starting material was prepared in 2007 under PNNL direction by Manufacturing Sciences Corporation of Oak Ridge, Tennessee, by reaction of high-purity (99.96 wt\%) uranium metal turnings in $\sim 60{ }^{\circ} \mathrm{C}$ water. The source uranium metal was $0.19 \%{ }^{235} \mathrm{U}$ (i.e., of depleted enrichment). The $\mathrm{UO}_{2}$ has been stored underwater in closed jars since preparation to prevent further oxidation. Previous characterization showed this material to be nearly stoichiometric $\mathrm{UO}_{2}$ and to have a nominal 6-nm-diameter particle size with smaller particles and larger agglomerates (Sinkov et al. 2008).

PNNL staff prepared the target $50 \% \mathrm{U}(\mathrm{IV})$ and $50 \% \mathrm{U}(\mathrm{VI})$ oxidation state $\mathrm{UO}_{2}: \mathrm{UO}_{3} \cdot 2 \mathrm{H}_{2} \mathrm{O}$ mixtures by oxidizing $\mathrm{UO}_{2}$ with sparging oxygen gas through the slurry at room temperature until the desired 50:50 mole \% composition ( $\pm 5 \%$ ) was reached. Preparations of the U(IV):U(VI) mixtures were conducted within applicable test instructions used in prior simulant preparations. ${ }^{(1)}$ The actual uranium oxidation state distributions and the concentrations of total uranium and U(IV) and U(VI) in the slurries were determined according to an internal PNNL analytical procedure. ${ }^{(2)}$

The $\mathrm{UO}_{2}: \mathrm{UO}_{3} \cdot 2 \mathrm{H}_{2} \mathrm{O}$ simulant also contained uranium metal of natural enrichment and in the form of nearly spherical beads. Previous energy-dispersive spectroscopy showed aluminum and iron present in small but nonquantifiable concentrations. Analyses by spectrophotometry of a solution produced by quantitatively dissolving a portion of the metal in nitric acid showed the uranium concentration to be $99.7 \mathrm{wt} \%$. Carbon also is present at about 73 parts per million parts of uranium (Delegard et al. 2004). Subsequent analyses of the dissolved metal by kinetic phosphorescence for the purpose of using this material as a uranium metal standard in analyses of $\mathrm{K}$ Basin sludge under an internal PNNL procedure ${ }^{(3)}$ showed the uranium concentration in the beads to be $100 \pm 1 \%$.

The uranium metal beads were cleaned of uranium oxide surface corrosion before they were used in the experiments. This was done by immersing the beads in $\sim 6 \mathrm{M} \mathrm{HNO}_{3}$ at room temperature until the beads became visibly shiny. The chemicals used in the cleaning were reagent grade. The cleaning solutions in each case were discarded and the cleaned beads rinsed with deionized water (DIW) and air-dried. The number of beads used varied from 17 to 22 in each small-scale test and represented $3.6 \mathrm{wt} \%$ of the dry sludge solids. The number of beads used in the overhead-stirred test was 118 for the $\mathrm{UO}_{2}: \mathrm{UO}_{3} \cdot 2 \mathrm{H}_{2} \mathrm{O}$ simulant and represented $0.21 \mathrm{wt} \%$ of the dry sludge solids (as compared to the simulant

\footnotetext{
${ }^{1}$ Delegard CH. 2010. “Oxidation of KW Container Sludge Simulant.” TI 53451-TI24, Rev. 1, Pacific Northwest National Laboratory, Richland, Washington.

Delegard CH. 2010. "Oxidation of KW Container Sludge Simulant; Addendum-Agglomeration with Heating." TI 53451-TI24, Rev. 1, Addendum, Pacific Northwest National Laboratory, Richland, Washington.

${ }^{2}$ Delegard CH. 2009. Sample Preparation and Analysis for Determining Uranium Oxide Oxidation States in K Basin Sludges. RPG-CMC-255, Rev. 0, Pacific Northwest National Laboratory, Richland, Washington. ${ }^{3}$ Jones SA. 2009. Sample Preparation for Determination of Uranium Metal Concentration in Sludge. RPG-CMC-107, Rev. 1, Pacific Northwest National Laboratory, Richland, Washington.
} 
target of $3.6 \mathrm{wt} \%)$. Beads were individually selected for roundness and were sieved to pass an 841-micron sieve (\#25 sieve, ASTM E-11) but be retained on a 707-micron sieve (\#20 sieve, ASTM E-11). Based on $19.1-\mathrm{g} / \mathrm{cm}^{3}$ uranium metal density, the average bead diameter was about $780 \mu \mathrm{m}$. About $0.092 \mathrm{~g}$ of beads were used for each heated small-scale test and $\sim 0.4 \mathrm{~g}$ for the bench-scale overhead-stirred test. The target quantity of dry 50:50 uranium oxide solids in each small-scale test was $2.459 \mathrm{~g}$ and $193.2 \mathrm{~g}$ in the overhead-stirred test. [Note: The uranium metal particles in genuine K Basin sludge will likely have a layer of uranium oxide present when the sludge is treated in a WWO process. At $95^{\circ} \mathrm{C}$, it is not expected that the oxide layer will result in a prolonged induction period that would delay the onset of anoxic corrosion of the underlying uranium metal.]

\subsubsection{KW Containerized Sludge Simulant}

The KW containerized sludge simulant components were $\mathrm{UO}_{2}$ and $\mathrm{UO}_{3} \cdot 2 \mathrm{H}_{2} \mathrm{O}$ (present in 50 \pm 5:50 \pm 5 mole ratio), ferrihydrite, gibbsite, ALE sand, Purolite NRW37 OIER, mordenite inorganic ion exchanger, water, Optimer 7194 Plus flocculating agent, and uranium metal beads. The ferrihydrite $\left[\mathrm{Fe}_{5} \mathrm{O}_{7}(\mathrm{OH}) \cdot 4 \mathrm{H}_{2} \mathrm{O}\right.$, expressed more simply as $\left.\mathrm{Fe}_{2} \mathrm{O}_{3} \cdot 1.8 \mathrm{H}_{2} \mathrm{O}\right]$ and other iron (hydr)oxides, such as goethite and hematite ( $\mathrm{FeOOH}$ and $\mathrm{Fe}_{2} \mathrm{O}_{3}$, respectively), in $\mathrm{KW}$ containerized sludge arise from the corrosion of mild steel structural components. Gibbsite and other aluminum hydroxide $\left[\mathrm{Al}(\mathrm{OH})_{3}\right]$ components arise from aluminum component corrosion. The Hanford sand was in-blown into the basins from the surrounding soil while the ion exchange media, including Purolite NRW37 organic ion exchange resin and Norton Zeolon 900 (mordenite) inorganic ion exchanger, were used in maintaining K Basin water quality and their presence in the sludge is due to inadvertent process losses. The flocculating agent was used to control particle dispersion and improve settling during sludge solids transfer operations.

The vendor analyzed the ferrihydrite, identified as ferric oxide hydroxide (Shepherd Chemical Company), by XRD and determined that it was poorly crystalline 6-line ferrihydrite. Subsequent XRD analysis by PNNL showed that no observable 6-line ferrihydrite was present and that the solids had transformed to goethite and hematite (Sinkov et al. 2010). Tests of the $\mathrm{pH}$ of slurries of this material have shown it to be alkaline (i.e., $\mathrm{pH} \sim 12$ ). Because the alkalinity could affect simulated sludge properties, the ferrihydrite was washed with DIW several times before use by repeated sequential steps of water addition, stirring, settling, and decanting, followed by room-temperature air-drying once the $\mathrm{pH}$ became less than 8 .

The aluminum hydroxide used in testing was "Onyx Classica," OC1000 (Almatis) and has been identified by PNNL XRD to be gibbsite.

The finely granular to powdery Hanford blow sand used in the testing was collected from ALE in July 2007 between mileposts 9 and 10 on the south side of Washington State Highway 240, about 12 miles south of the KW Basin. According to XRD analysis (Sinkov et al. 2010), the sand contained quartz $\left(\mathrm{SiO}_{2}\right)$, anorthite $\left(\mathrm{CaAl}_{2} \mathrm{Si}_{2} \mathrm{O}_{8}\right)$, microcline $\left(\mathrm{KAlSi}_{3} \mathrm{O}_{8}\right)$, mica $\left[\mathrm{KFe}_{3}\left(\mathrm{Al}_{0.24} \mathrm{Fe}_{0.76} \mathrm{Si}_{3}\right) \mathrm{O}_{10}(\mathrm{OH})_{2}\right]$, and aegerine $\left(\mathrm{Fe}_{0.5185} \mathrm{Al}_{0.4185} \mathrm{Ca}_{0.466} \mathrm{Na}_{0.534} \mathrm{Si}_{2} \mathrm{O}_{6}\right)$. Non-crystalline or glassy phases found locally in basalt are ubiquitous in the Hanford soils, but are not seen by XRD.

The mordenite used in the testing is sodium mordenite LZM-5 from UOP, LLC. This material was selected to substitute for the Norton Zeolon 900 mordenite because Norton Zeolon 900 is no longer commercially available. The dry LZM-5, nominally $\mathrm{Na}_{6} \mathrm{Al}_{6} \mathrm{Si}_{42} \mathrm{O}_{96}$, is equivalent to $\mathrm{NaAlSi}_{7} \mathrm{O}_{16}$, for a Si:Al mole ratio of 7.0 (Ramachandran et al. 2005). The wt\% of Si and $\mathrm{Al}$ are 39.1 and 5.4, respectively. For comparison, the chemical composition of Zeolon 900 (containing 98\% mordenite) is reported to have 
the formula $\mathrm{Na}_{2} \mathrm{Al}_{2} \mathrm{Si}_{10} \mathrm{O}_{24}$ for a Si:Al mole ratio of $5.0^{(1)}$ while Zeolon $900 \mathrm{H}$ (the hydrogen form of Zeolon 900$)$ is $32.1 \mathrm{wt} \% \mathrm{Si}$ and $6.9 \mathrm{wt} \% \mathrm{Al}$ for the $\mathrm{Si}: \mathrm{Al}$ mole ratio of $4.5 .^{(2)}$

The OIER used in the sludge simulant is Purolite NRW37, a 40:60 (by volume) mixture of strong acid cation (NRW100) and strong base anion (NRW400) resin. This is the same resin that was used to control water quality in the K Basins. ${ }^{(3)}$

Optimer 7194 Plus flocculating agent was used during KE Basin sludge consolidation operations and, on a more limited scale, on the KE and KW sludge transfer operations. The Optimer 7194 Plus flocculating agent used in preparing the simulant was obtained from the Nalco distributor as a concentrate. A 0.5 -wt $\%$ dispersion in water of the Optimer agent was prepared, and the diluted Optimer was introduced to the water-suspended sludge solids according to the manufacturer's recommendations and in concentrations corresponding to the cumulative values added to K Basin sludge.

The uranium metal used in this testing was taken from the same population of 707- to 841- $\mu \mathrm{m}$ natural enrichment near spherical beads as used in the $\mathrm{UO}_{2}: \mathrm{UO}_{3} \cdot 2 \mathrm{H}_{2} \mathrm{O}$ tests and were cleaned in the same manner with $\mathrm{HNO}_{3}$ solution. The number of beads used varied from 17 to 22 in each small-scale test, representing $3.6 \mathrm{wt} \%$ of the dry sludge solids. The overhead-stirred test used 124 beads, representing $0.41 \mathrm{wt} \%$ of the dry sludge solids.

The simulated KW containerized sludge composition used in testing, shown in Table 2.2, was derived from the composition of a physical/chemical simulant used in previous testing (Burbank 2010). The sludge component quantities required to prepare the 2.551-g (dry basis) portions used in each $\mathrm{KW}$, containerized sludge, small-scale test are shown in the right-most column. Except for uranium metal, the sludge component proportions were the same in the overhead-stirred test as in the small-scale tests. The total dry sludge quantity used in the overhead-stirred test was $96.8 \mathrm{~g}$. To provide uniform composition in each experiment, the simulated sludge components were prepared from their respective ingredients individually for each test rather than taken as a portion of a larger batch.

For all tests requiring adjustment to $\mathrm{pH} 12$, either $0.2 \mathrm{M} \mathrm{NaOH}(1.2 \mathrm{~mL})$ or $0.2 \mathrm{M} \mathrm{Na}_{3} \mathrm{PO}_{4}(2.4 \mathrm{~mL})$ was added before the beginning of the settling period. The $\mathrm{pH}$ values were determined by taking a $0.5 \mathrm{~mL}$ aliquot of test supernatant and measuring the $\mathrm{pH}$ with a calibrated $\mathrm{Ag} / \mathrm{AgCl} \mathrm{pH}$ electrode.

\footnotetext{
${ }^{1}$ Hastings TW. 1997. FAX communication to I Papp, May 19, 1997, Zeolyst International, Valley Forge, Pennsylvania.

${ }^{2}$ Pool KH, CH Delegard, AJ Schmidt, and KL Silvers. 1998. "Results from Test 1, 'Acid Digestion of Zeolite and Hydrated Iron Oxide in Proportions Representative of Analyzed Sludge Materials'." Letter Report 28510-04 to Duke Engineering \& Services, Hanford, January 1998, Pacific Northwest National Laboratory, Richland, Washington.

${ }^{3}$ The OIER used in the K Basins, mixed bed cation/anion resin Purolite NRW37, is composed of 60 vol\% anion resin NRW400 and 40 vol\% NRW100 cation resin (Purolite 2007). These resins were designed to withstand high radiation doses for power reactor water decontamination. Therefore, ion exchange capacity loss due to radiolytic or chemical degradation is unlikely. However, some ion exchange capacity for OIER in the containerized sludge present in the KW Basin likely is occupied by calcium, sodium, and carbonate (and chemically trace radionuclides such as cesium-137 and strontium-90) from previous treatment of the $\mathrm{K}$ Basin waters and subsequent exposure. Vendor specifications show that the anion exchange capacity of pure NRW400 resin is $1.0 \mathrm{eq} / \mathrm{L}$ on a wet volume basis (Purolite 2007). Because NRW400 is $60 \mathrm{vol} \%$ of the NRW37 mixed bed resin used in the K Basins, the anion uptake capacity of pure mixed resin is $0.6 \mathrm{eq} / \mathrm{L}$.
} 
Table 2.2. Basis and Composition of KW Containerized Simulant Sludge

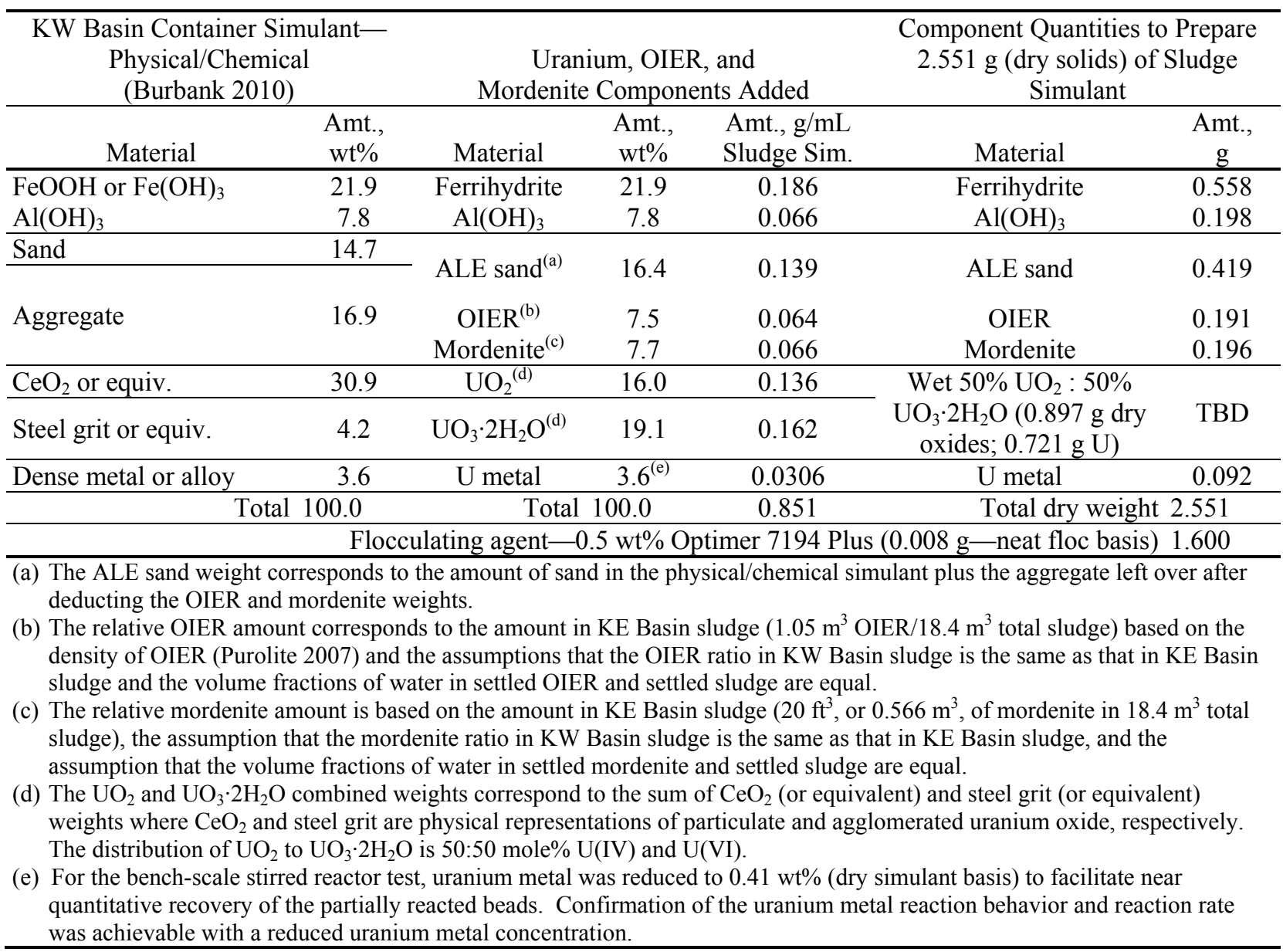

\subsection{Test Apparatus and Test Execution}

The experimental apparatus and test execution for the laboratory-scale tests are described in Section 2.3.1. The apparatus design and test parameters for the overhead-stirred experiments are described in Section 2.3.2.

\subsubsection{Laboratory-Scale Tests}

The laboratory-scale testing occurred in $50 \mathrm{~mL}$ centrifuge tubes that were modified to have flat bottoms. The flat-bottomed cones were prepared by pressing the pointed bottom of a conventional $50 \mathrm{~mL}$ polypropylene centrifuge tube to a flat, hot surface. Laboratory-scale scoping tests were conducted to evaluate the mixing intensity achieved with the MultiTherm ${ }^{\circledR}$, temperature-controlled agitator and its side-to-side action at 1000 cycles per minute using $15 \mathrm{~mL}$, conical bottom, centrifuge cones. This testing demonstrated that with non-radioactive simulant slurries (sand, iron hydroxide, ceric oxide, and zinc metal beads), reasonable mixing, as shown by movement and suspension of solids, was not achieved with the conical bottom tubes. However, all solids moved with the flat-bottomed, $50 \mathrm{~mL}$ cones. Excess supernatant water was added to the centrifuge tubes to make sure that the samples remained saturated. After loading, the samples were gently mixed and allowed to settle for several days. 
A flattened, $50 \mathrm{~mL}$, centrifuge tube and definitions of the markings used are shown in Figure 2.1. This figure also shows the agitator/heat block (MultiTherm ${ }^{\mathrm{TM}}$; Benchmark) used for the agitated samples. The non-agitated samples were heated in a thermostatted oven. The temperatures in the heat block and oven were controlled by power supplies regulated with calibrated thermocouples.
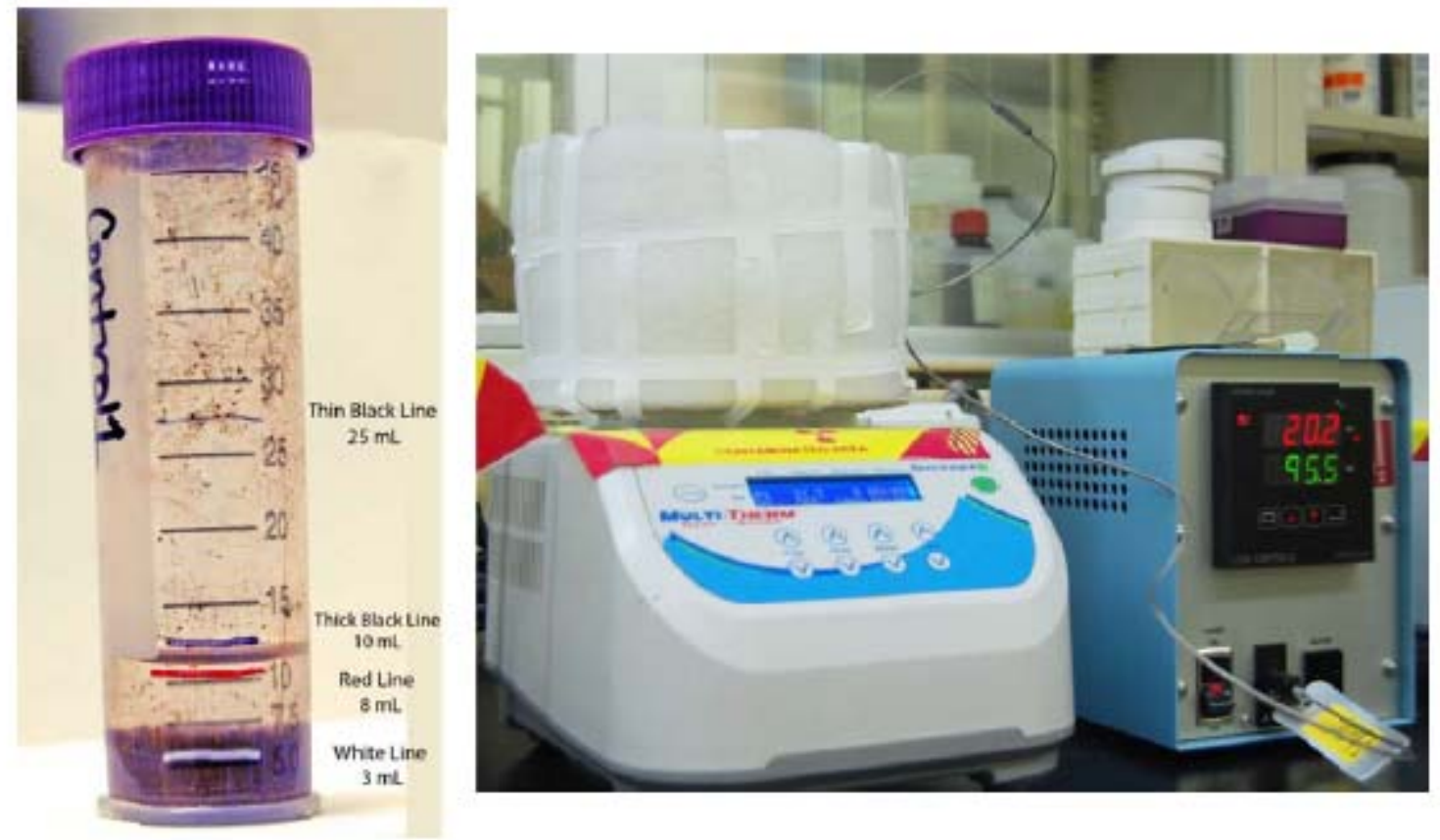

Figure 2.1. Left: Customized $50 \mathrm{~mL}$ Centrifuge Tube Used in Tests for Solids Heating and Containment. The markings on the tube indicate new calibration points for the vessel as determined with calibrated pipettes. The white line indicates the anticipated volume of the simulated sludge. The red line indicates the initial fill volume. The thick black line indicates the initial fill volume suggested for these tests. The thin black line indicates the final fill volume used. Right: Test Setup for Agitated Samples. Foam insulation surrounds the aluminum-heating block containing agitated tests. A thermocouple pierced the foam and was inserted in a flattened, $50 \mathrm{~mL}$, centrifuge tube containing DIW that occupied a spot in the heating block.

For the laboratory-scale tests, the MultiTherm ${ }^{\mathrm{TM}}$ shaker was set to its maximum value (1000 rpm) to agitate the appropriate samples. Agitation was provided in an orbital, counter-clockwise direction and provided no vertical jostling. The orbital motion amplitude is $\sim 2 \mathrm{~mm}$. The highest temperature provided by the MultiTherm ${ }^{\mathrm{TM}}$ mixer was $100^{\circ} \mathrm{C}$. In the absence of insulation, the contents of the $50 \mathrm{~mL}$ test vessels would only reach $92^{\circ} \mathrm{C}$. To provide the temperatures desired for the investigation, the aluminum heating block was surrounded by foam insulation. Preliminary tests were also performed before the run to evaluate the level of agitation the samples would receive. It was observed that the splash zone of the test was $5 \mathrm{~mL}$ higher than the non-agitated supernatant volume.

On October 4, 2010, samples for WWO were heated using either a MultiTherm ${ }^{\mathrm{TM}}$ shaker for samples to be agitated $\left(96.0^{\circ} \mathrm{C} \pm 0.2^{\circ} \mathrm{C}\right)$ or an oven for the static tests $\left(95.3^{\circ} \mathrm{C} \pm 0.6^{\circ} \mathrm{C}\right)$. Uncertainties on temperature readings are determined as one standard deviation in four measurements. Initially, the power oscillations for the static oven-heated samples shifted the temperature between $92^{\circ} \mathrm{C}$ and $98^{\circ} \mathrm{C}$. On the third day of heating, the power setting was adjusted to only submit the samples to temperature oscillations 
from $93.5^{\circ} \mathrm{C}$ to $96.5^{\circ} \mathrm{C}$. For agitated samples, centrifuge cones were inserted into individual, $50 \mathrm{~mL}$, aluminum heating blocks that were present in the MultiTherm ${ }^{\mathrm{TM}}$. The samples were agitated at the maximum setting of the MultiTherm ${ }^{\mathrm{TM}}$ shaker, $1000 \mathrm{rpm}$. All samples were held at temperature for 96 hours and, because the caps were vented, were exposed passively to air exchange. Controls 1 through 5 were capped tightly and maintained at room temperature.

After the first round of heating, select tests were allowed to settle under static conditions for another 2 weeks. Depending on the prescription of the test instruction, samples either were heated in the oven at $95^{\circ} \mathrm{C}$ or were maintained at ambient temperature. After this prolonged settling period, samples were agitated for 5 minutes using the MultiTherm ${ }^{\mathrm{TM}}$ shaker at $1000 \mathrm{rpm}$ at ambient temperature.

\subsubsection{Overhead-Stirred Tests}

The bench-scale tests were performed in a stirred reactor that is more prototypical of the one proposed in the preconceptual flowsheet (see Figure 2.2 and Figure 2.3). The constant agitator stir rate was $\sim 550$ revolutions per minute, and the flow was directed downward in the reactor vessel. For the denser 50:50 uranium oxide slurry, the agitation rate was raised to $1000 \mathrm{rpm}$ for 5 minutes twice daily to help move all regions of the slurry. The vessel was constructed of glass and had a roughly spherical shape but with four vertical baffles formed in the glass walls to enhance the mixing and prevent vortexing. The vessel also was fitted with an air-cooled condenser to prevent internal pressurization but still limit evaporative water loss. Slurry levels were observed daily and the water losses made up as required. The KW simulant test required a $30 \mathrm{~mL}$ addition of water every 24 hours to maintain the target percent solids volume. The 50:50 uranium oxide slurry test required 10 to $15 \mathrm{~mL}$ of water every 24 hours. Experimental conditions for the large-scale stirred reactor testing are shown in Table 2.3.

The reactor was heated by a heating mantle, and the temperature was maintained by a thermocouple feedback control to the power supply. The thermocouple was placed in the agitated simulant sludge. For the large-scale, 50:50 uraninite: metaschoepite investigation, a passive thermocouple was also inserted between the heating mantle and reactor vessel to provide an indication of the temperature gradient across the reactor vessel bottom. (Note, this passive thermocouple is not shown in Figure 2.2.) 


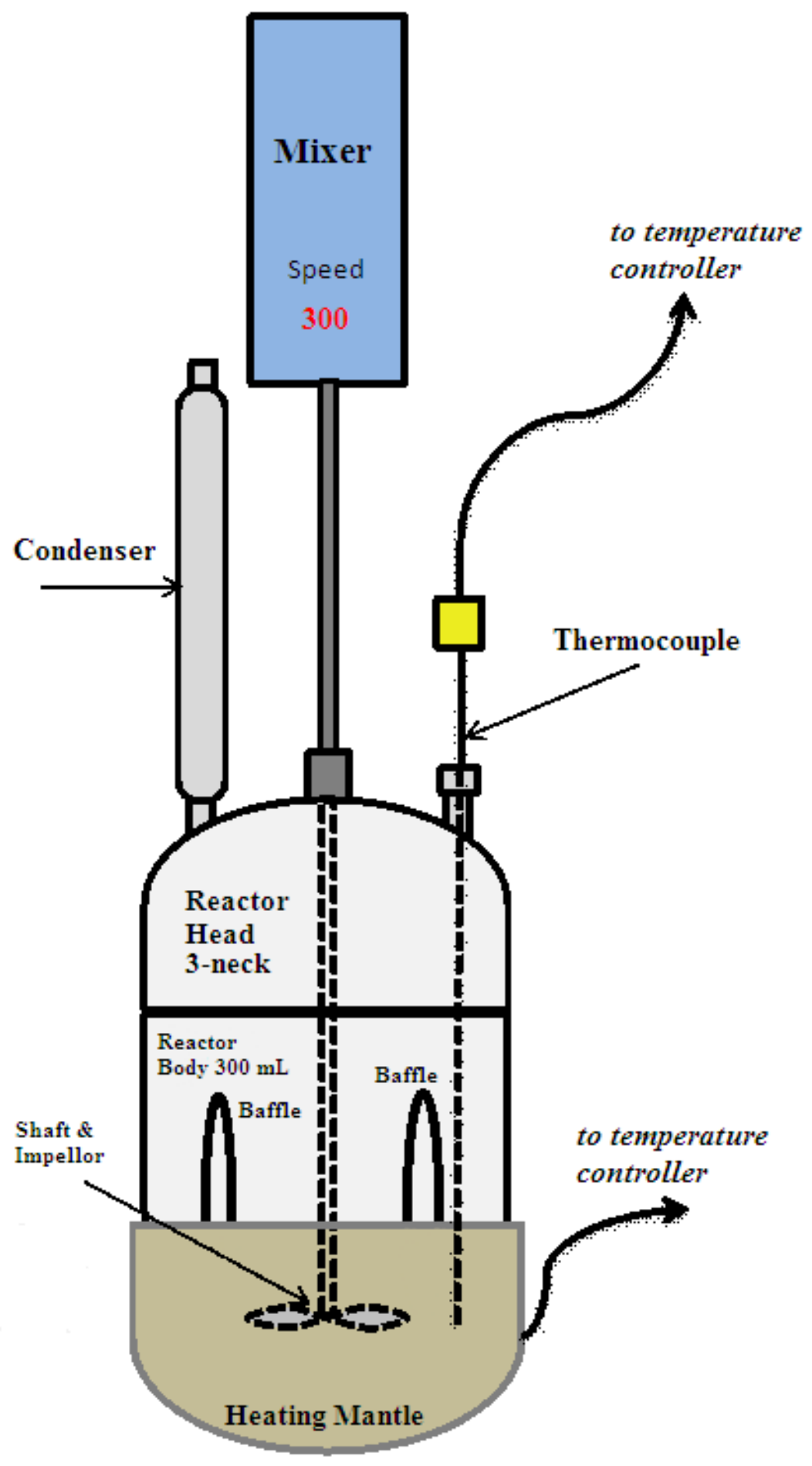

Figure 2.2. Diagram of $300 \mathrm{~mL}$ Stirred Reactor Test System 


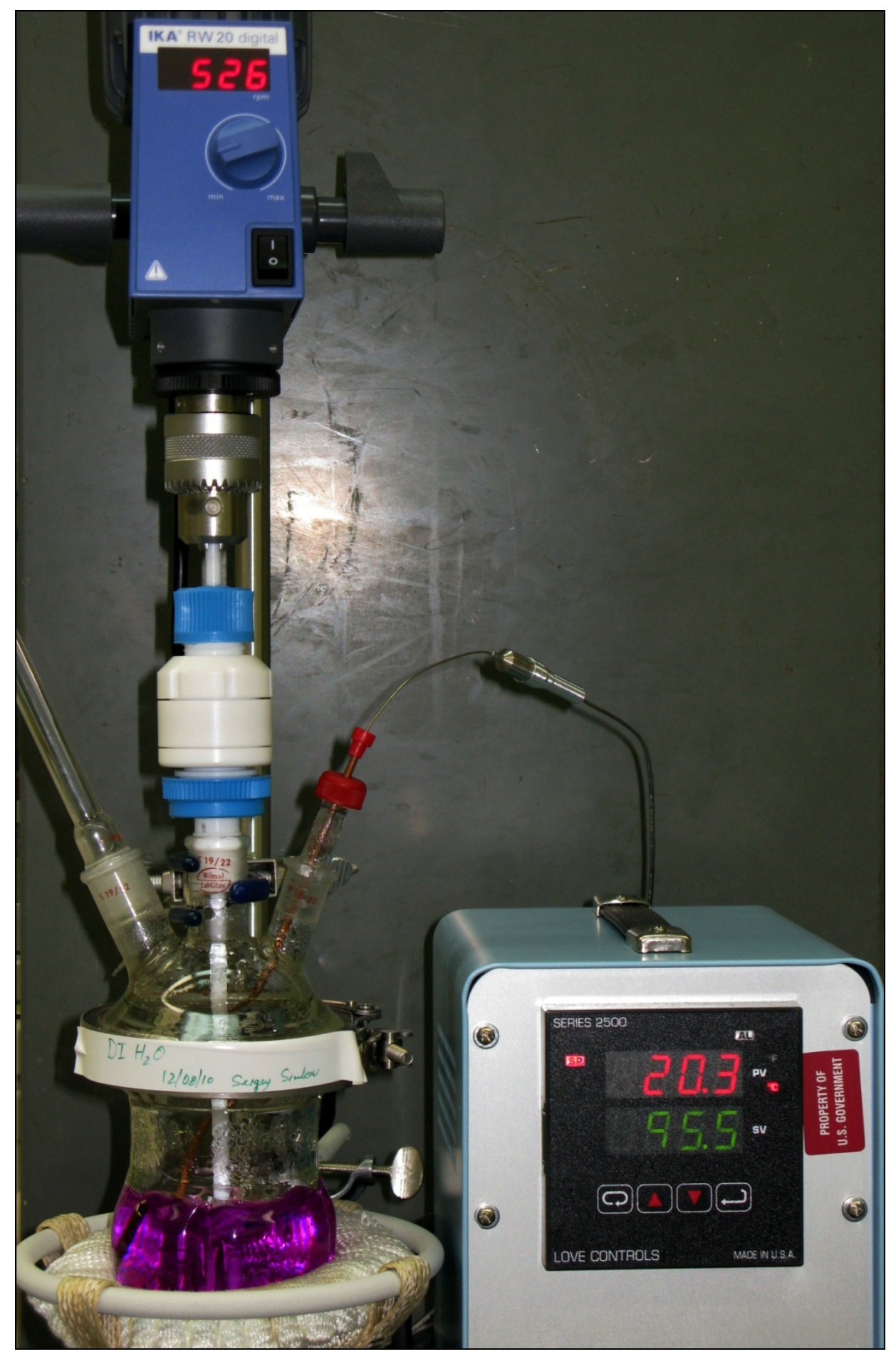

Figure 2.3. Photograph of $300 \mathrm{~mL}$ Stirred Reactor Test System 
Table 2.3. Summary of Nominal WWO Stirred Reactor Tests

\begin{tabular}{|c|c|}
\hline Test Parameter & Description \\
\hline Test Material & $\begin{array}{l}\text { Primary Test: uranium-containing KW container simulant (Table } 2.4) \text { and } 50( \pm 5) \mathrm{mole} \% \\
\mathrm{UO}_{2} / 50( \pm 5) \text { mole } \% \mathrm{UO}_{3} \cdot 2 \mathrm{H}_{2} \mathrm{O} \text { slurry ( } \\
\text { Table 2.5) }\end{array}$ \\
\hline \multicolumn{2}{|r|}{ Stirred Reactor System (see Figures 2.2 and 2.3) } \\
\hline Reaction Vessel & Glass, $300 \mathrm{~mL}$ spherical vessel, $87 \mathrm{~mm} \mathrm{OD}$, with four mixing indents/baffles \\
\hline Reactor Head & Glass, 3 necks; for agitator shaft (center), condenser, and thermocouple \\
\hline Condenser & Glass, $10 \mathrm{~mm}$ ID, $200 \mathrm{~mm}$ length straight tube air condenser \\
\hline Stirrer/Agitator & IKA RW20, 60 to $2000 \mathrm{rpm}$, speed display, push-through agitator shaft \\
\hline Impeller & PTFE, screw propeller, $40 \mathrm{~mm}$ diameter \\
\hline Heating & Electric heating mantle \\
\hline \multicolumn{2}{|r|}{ Test Conditions } \\
\hline Test Slurry & $\begin{array}{l}\text { Nominally, } 100 \text {-g (dry basis); } 15 \% \text { solids ( } 165 \text { to } 220 \mathrm{~mL} \text { slurry) for } \mathrm{KW} \text { container simulant } \\
\text { or } 200 \text {-g (dry basis); } 12 \mathrm{vol} \% \text { solids for } 50: 50 \mathrm{UO}_{2} / \mathrm{UO}_{3} \cdot 2 \mathrm{H}_{2} \mathrm{O}\end{array}$ \\
\hline Temperature & $95 \pm 3^{\circ} \mathrm{C}$ \\
\hline Agitation Intensity & $\begin{array}{l}\text { Sufficient to achieve off-bottom movement/suspension of granulated tungsten, }-12,+20 \\
\text { mesh, }\left(841 \text { to } 1680 \mu \mathrm{m} ; \rho \approx 19 \mathrm{~g} / \mathrm{cm}^{3}\right) \text {; was determined to be } 550 \mathrm{rpm} \text { for } \mathrm{KW} \text { simulant test, } \\
550 \mathrm{rpm} \text { plus } 5 \text { minute, } 1000 \mathrm{rpm} \text { bursts twice daily for the } 50: 50 \mathrm{U} \text { oxide slurry }\end{array}$ \\
\hline Test Duration & 96 hours \\
\hline \multicolumn{2}{|r|}{ Test Measurements } \\
\hline Pre-Test & $\begin{array}{l}\text { Reactor dimensions, impeller location, settled and total slurry mass and volume, } \mathrm{pH} \text {, } \\
\text { photograph }\end{array}$ \\
\hline During Test & Monitor and log rpm, temperature, slurry level, observations \\
\hline Post-Test & $\begin{array}{l}\text { Settled and total slurry volume, density, } \mathrm{pH} \text {, photograph, U metal conc., U oxidation state, } \\
\text { and shear strength via vane rheometry, as warranted. }\end{array}$ \\
\hline
\end{tabular}

After the simulant was prepared for the bench-scale stirred reactor system, water was added or removed to achieve the target 12 to $15 \mathrm{vol} \%$ solids and was near $15-20 \mathrm{vol} \%$ solids at the end of the oxidation process. The solids particle volume of nominal $100 \mathrm{~g}$, KW container simulant is estimated to be $\sim 32.4 \mathrm{~cm}^{3}$. In the WWO process, the reactor may also serve to concentrate dilute feeds by evaporation. Testing was started at a solids concentration of about $15 \mathrm{vol} \%$, with a total slurry volume of $200 \mathrm{~mL}$, and periodic water additions were made to avoid concentrating the slurry to greater than $20 \%$. The total slurry volumes to achieve $20 \mathrm{vol} \%$ and $15 \mathrm{vol} \%$ solids are approximately $160 \mathrm{~mL}$ and $215 \mathrm{~mL}$, respectively (see Table 2.4).

The nominal solids simulant volume of 200-g of 50:50 mole $\% \mathrm{UO}_{2} / \mathrm{UO}_{3} \cdot 2 \mathrm{H}_{2} \mathrm{O}$ uranium oxide is estimated to be $\sim 29.4 \mathrm{~cm}^{3}$. The total slurry volumes to achieve $20 \mathrm{vol} \%$ and $15 \mathrm{vol} \%$ solids for this simulant are approximately $146 \mathrm{~mL}$ and $196 \mathrm{~mL}$, respectively (see Table 2.5).

Due to the initial difficulty in lofting the 200 -g of $50: 50$ mole $\% \mathrm{UO}_{2} / \mathrm{UO}_{3} \cdot 2 \mathrm{H}_{2} \mathrm{O}$ uranium oxide simulant, a further $50 \mathrm{~mL}$ addition of water was provided immediately after testing began to create a suspendable slurry. This increased the slurry volume to $\sim 250 \mathrm{~mL}$, which reduced the solids concentration to $12 \mathrm{vol} \%$. The solids concentration was maintained at this level for the rest of the test. 
Table 2.4. Nominal 100-g Basis KW Container Sludge Simulant

\begin{tabular}{|c|c|c|c|}
\hline Component & $\begin{array}{c}\text { Grams (or } \\
\left.w^{0} \%\right)\end{array}$ & $\begin{array}{c}\text { Particle } \\
\text { Density, } \mathrm{g} / \mathrm{cm}^{3}\end{array}$ & $\begin{array}{c}\text { Solid Vol, } \\
96.8{\mathrm{~g}, \mathrm{~cm}^{3}}^{3}\end{array}$ \\
\hline Ferrihydrite & 21.9 & 3.02 & 7.25 \\
\hline $\mathrm{Al}(\mathrm{OH})_{3}$ & 7.8 & 2.42 & 3.22 \\
\hline ALE sand & 16.4 & 2.65 & 6.18 \\
\hline OIER & 7.7 & 1.122 & 6.86 \\
\hline Mordenite & 7.5 & 2.13 & 3.52 \\
\hline $\mathrm{UO}_{2}$ & 16.0 & 11.31 & 1.42 \\
\hline $\mathrm{UO}_{3} \cdot 2 \mathrm{H}_{2} \mathrm{O}$ & 19.1 & 4.87 & 3.92 \\
\hline U metal (Nominal $3.6 \mathrm{wt} \%$; actual $\left.0.41 \mathrm{wt}^{0} \%\right)^{(\mathrm{a})}$ & 0.4 & 19 & 0.02 \\
\hline Total & 96.8 & & 32.4 \\
\hline Mean Particle Density of U-Containing KW Simulant & & 2.99 & $\mathrm{~g} / \mathrm{cm}^{3}$ \\
\hline Volume of 20 vol\% slurry & & 162 & $\mathrm{~mL}$ \\
\hline Volume of 15 vol\% slurry & & 216 & $\mathrm{~mL}$ \\
\hline Slurry volume range in test & & 150 to 200 & $\mathrm{ml}$ \\
\hline \multicolumn{4}{|c|}{$\begin{array}{l}\text { (a) Note: On a dry component basis, the uranium-containing } \mathrm{KW} \text { container simulant is specified to contain } 3.6 \mathrm{~g} \text { uranium metal, } \\
\text { preferably as } \mathrm{U} \text { metal beads with a nominal diameter between } 500 \text { and } 1000 \mu \mathrm{m} \text {. As nominal } 700-\mu \mathrm{m} \text { diameter spheres, } 3.6 \mathrm{~g} \\
\text { is approximately } 1000 \text { beads. A quantitative recovery of } 1000 \text { partially oxidized } \mathrm{U} \text { metal beads at the end of the reaction } \\
\text { period is not practical. Therefore, a lower uranium metal content (i.e., } 100 \mathrm{U} \text { metal beads with } \sim 0.4 \mathrm{~g} \text { of } \mathrm{U} \text { metal) was used } \\
\text { for testing. }\end{array}$} \\
\hline
\end{tabular}

The initial test duration with heating was 4 days (96 hours). This duration allowed the tests to be completed within one working week and was consistent with a reasonably bounding duration for loss of agitation in a WWO process for the tests that were performed under static conditions. In comparison to the 4-day test duration, the batch time for a WWO process at $95^{\circ} \mathrm{C}$ may be as long as 130 days. The 130 -day period is the time required to react a $1 / 4$-in.-diameter $(6350-\mu \mathrm{m})$ uranium metal particle to extinction at $95^{\circ} \mathrm{C}$ based on the Sludge Databook rate equation with a rate enhancement factor of 1 (Schmidt 2010). The time to react to extinction a $600-\mu \mathrm{m}$ uranium metal particle, such as would be present in Settler Sludge, at $95^{\circ} \mathrm{C}$ is approximately 12 days.

Table 2.5. Nominal 200-g Basis 50:50 Mole $\% \mathrm{UO}_{2} / \mathrm{UO}_{3} \cdot 2 \mathrm{H}_{2} \mathrm{O}$

\begin{tabular}{|c|c|c|c|}
\hline Component & $\mathrm{Wt} \%$ & $\begin{array}{l}\text { Particle Density, } \\
\mathrm{g} / \mathrm{cm}^{3}\end{array}$ & $\begin{array}{l}\text { Solid Vol, } \\
96.8{\mathrm{~g}, \mathrm{~cm}^{3}}^{2}\end{array}$ \\
\hline $\mathrm{UO}_{2}$ & 88.0 & 11.31 & 7.78 \\
\hline $\mathrm{UO}_{3} \cdot 2 \mathrm{H}_{2} \mathrm{O}$ & 104.8 & 4.87 & 21.54 \\
\hline U metal (Nom: $3.6 \%)^{(\mathrm{a})}$ & 0.2 & 19 & 0.02 \\
\hline Total & 193.2 & & 29.3 \\
\hline Mean Particle Density of 50:50 U Oxide Simulant & & 6.60 & $\mathrm{~g} / \mathrm{cm}^{3}$ \\
\hline Volume of 20 vol\% slurry & & 146 & $\mathrm{~mL}$ \\
\hline Volume of 15 vol $\%$ slurry & & 196 & $\mathrm{~mL}$ \\
\hline Slurry volume range in test & & 200 to 250 & $\mathrm{ml}$ \\
\hline \multicolumn{4}{|c|}{$\begin{array}{l}\text { (a) Note: On a dry component basis, the U-containing } 50: 50 \mathrm{UO}_{2} / \mathrm{UO}_{3} \cdot 2 \mathrm{H}_{2} \mathrm{O} \text { simulant is specified to contain } 7.2 \mathrm{~g} \text { uranium meta } \\
\text { preferably as } \mathrm{U} \text { metal beads with a nominal diameter between } 500 \text { and } 1000 \mu \mathrm{m} \text {. As nominal } 700-\mu \mathrm{m} \text { diameter spheres, } 7.2 \mathrm{~g} \\
\text { is approximately } 2000 \text { beads. A quantitative recovery of } 2000 \text { partially oxidized } \mathrm{U} \text { metal beads at the end of the reaction } \\
\text { period is not practical. Therefore, a lower uranium metal content (e.g., } 100 \mathrm{U} \text { metal beads with } \sim 0.4 \mathrm{~g} \text { of } \mathrm{U} \text { metal) was used } \\
\text { for testing. }\end{array}$} \\
\hline
\end{tabular}

The mixer used for large-scale testing was set to its maximum value of $550 \mathrm{rpm}$ for continuous usage. Additional agitation was determined appropriate for the 50:50 uraninite:metaschoepite when zones of little to no mixing were observed. To provide the added agitation, the mixing speed was increased to 
$1000 \mathrm{rpm}$ twice daily for 5 minutes. Additional insulation was not required to attain internal vessel temperatures of $95^{\circ} \mathrm{C}$. Preliminary mix testing was performed using tungsten and steel grit particles (Figure 2.4). Mix testing indicated that optimal impeller placement was towards the bottom of the vessel; however, quiescent ("dead") zones still occurred in the reactor vessel bottom when 10-g of steel grit was present. To address this, the impeller was modified by strapping a small magnetic stir bar to the bottom of the impeller using Teflon tape (Figure 2.5). This provided an additional $0.5 \mathrm{~cm}$ of length to the impeller, allowing it to mix material at the curved reactor bottom.

On January 14, 2011, and January 21, 2011, heating was initiated for large-scale tests of the KW containerized and 50:50 uraninite:metaschoepite simulants, respectively. The temperature was maintained at $95.5^{\circ} \mathrm{C} \pm 0.1^{\circ} \mathrm{C}$ for both tests. The passive, external thermocouple used in the 50:50 uraninite:metaschoepite test, which was placed between the heating mantle and the glass reactor bottom, read $135^{\circ} \mathrm{C} \pm 5^{\circ} \mathrm{C}$ during periods of continuous 550-rpm mixing. When the 50:50

uraninite:metaschoepite was mixed at $1000 \mathrm{rpm}$, the reading of the active thermocouple would drop to $92^{\circ} \mathrm{C} \pm 0.5^{\circ} \mathrm{C}$, and the passive thermocouple would read as high as $230^{\circ} \mathrm{C}$ as the heating mantle was driven to attain $95^{\circ} \mathrm{C}$ in the simulated sludge slurry. The temperature would re-stabilize within 10 minutes of returning the mixer setting to $550 \mathrm{rpm}$. 


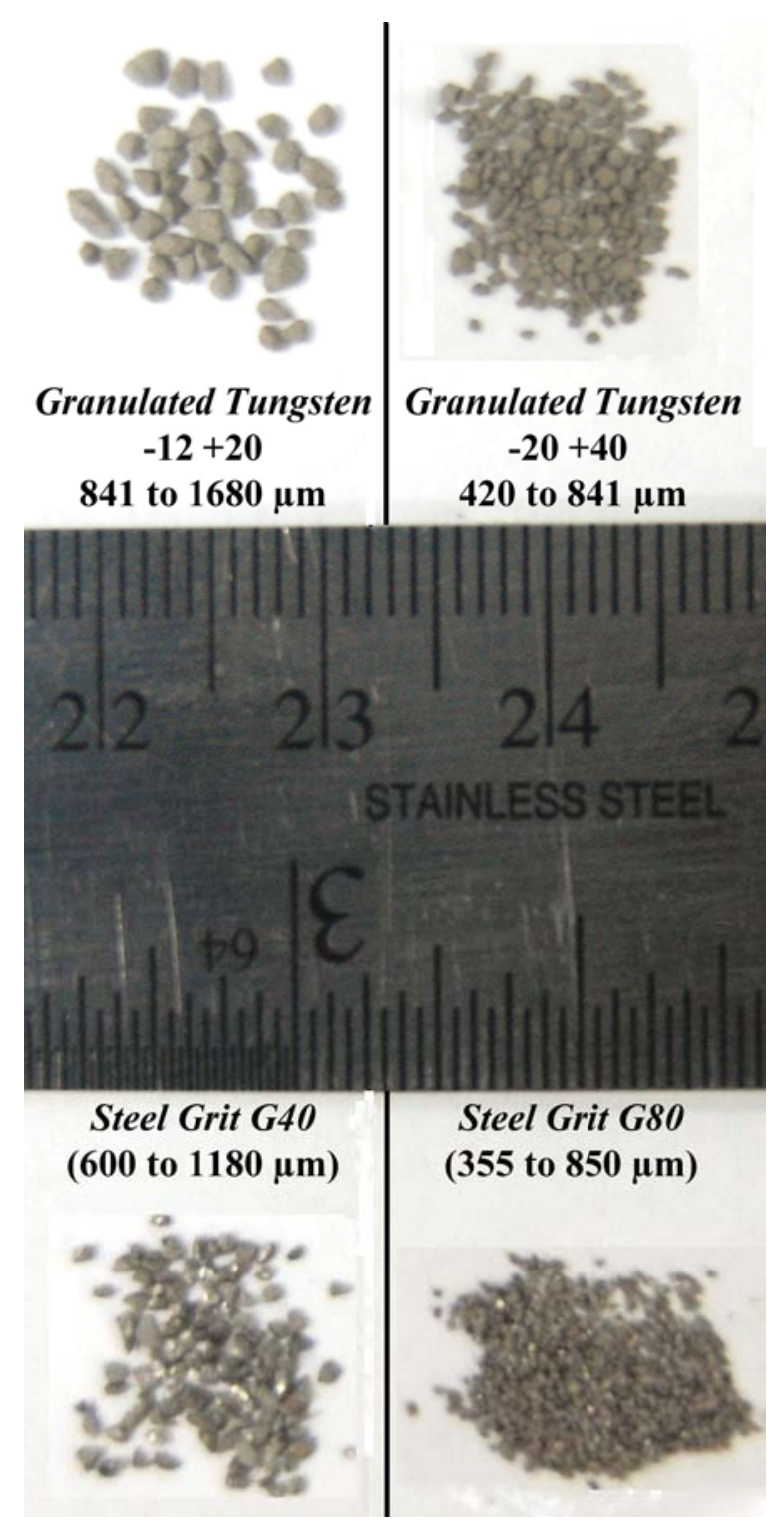

Figure 2.4. Photograph of Tungsten and Steel Grit Particles Used in Shakedown Testing of $300 \mathrm{~mL}$ Reactor. Ruler included to provide an indication of sample sizes. 


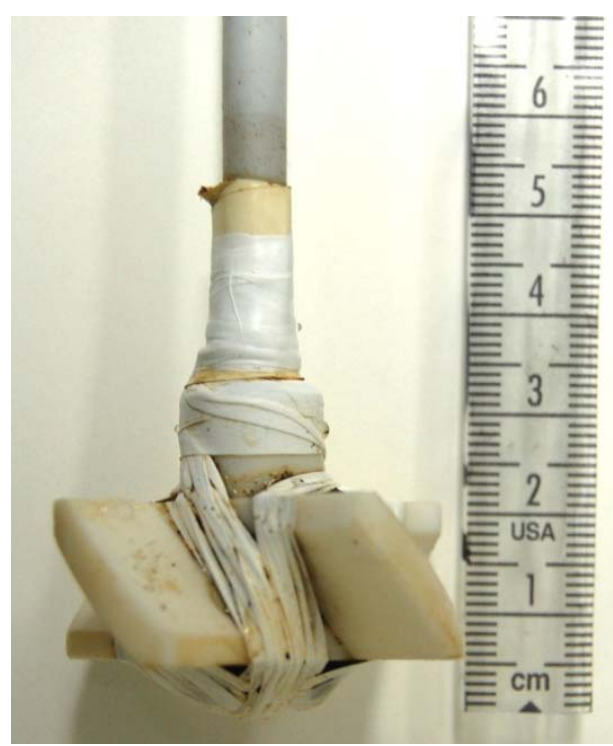

Figure 2.5. Photograph of Modified Impeller Used to Minimize Dead Zone Formation. Ruler included to provide an indication of impeller dimensions.

\subsection{Physical and Chemical Analyses}

Physical and chemical testing of the simulant sludges was performed. The physical testing included appearance, settled solids volume (and thus density), and rheology by probing and slumping when tilted. The chemical testing included $\mathrm{pH}$ measurement, determination of uranium-oxide oxidation state, and determination of uranium metal corrosion rate.

\subsubsection{Physical Analyses}

For the laboratory-scale scoping tests, digital images were taken of all samples both before and after the prescribed testing. The captured images are helpful in establishing settled solids levels and in making side-by-side visual comparisons of the test items. The densities of the settled solids were determined before and after heating and agitation using the known densities of the individual components and their determined volumes. Volumes were provided from solids heights using the calibration equation determined experimentally where

$$
\text { Known Height }(\mathrm{cm}) \times 4.791 \pm 0.03(\mathrm{~mL} / \mathrm{cm})-0.483 \pm 0.04(\mathrm{~mL})=\text { Volume }(\mathrm{mL})
$$

At the end of the initial 4-day test intervals, the strengths of the solids were qualitatively assessed by slump testing and probing with a spatula:

1. Slump test - The test vessel was turned on its side and observed to determine if the sludge bed flowed/slumped. The amount of time required to initiate slumping was noted (up to 5 minutes).

2. Strength test $-\mathrm{A} \sim 6.0$-g mass spatula ( $\sim 14-\mathrm{cm}$ long and similar to the image, Figure 2.6 ) was stood vertically on its metal end. It was determined whether the structure of the sludge beds provided sufficient strength to support the spatula. 


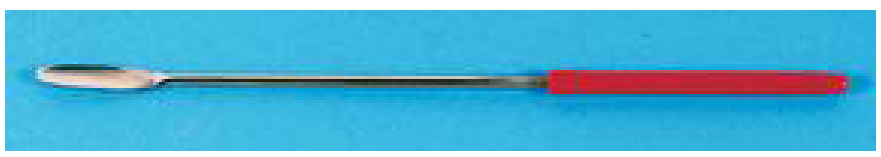

Figure 2.6. Spatula Used to Probe Sludge Solids

A description of the general consistency of the settled sludge solid (beyond its capability to support the spatula's weight) was also obtained by stirring and probing.

\subsubsection{Scanning Electron Microscopy and Energy Dispersive X-ray Spectroscopy}

The air-dried uranium sample was transferred with a triangular Q-tip onto carbon tape supported by an aluminum pedestal mount. The sample mount was cleanly removed from the fume hood and transferred to the scanning electron microscopy (SEM) workstation. The sample mount was carbon-coated to enhance conductivity. The sample was analyzed with the radiation-shielded Amray Model 1610T SEM according to RPL-611A-SEM, Scanning Electron Microscope Examinations. ${ }^{(1)}$ Micrographs were taken at various magnifications with secondary electron imaging (10 kV to $20 \mathrm{kV})$ as well as backscatter electron imaging $(20 \mathrm{kV})$. Selected sample areas were also evaluated by energy dispersive X-ray spectroscopy (EDS) for elemental identification with qualitative composition.

\subsubsection{Particle Size Distribution Analyses}

For WWO testing conducted in the stirred reactor with a 50:50 mole $\% \mathrm{UO}_{2} / \mathrm{UO}_{3} \cdot 2 \mathrm{H}_{2} \mathrm{O}$ slurry, significant changes in solids strength, morphology, and settling after the 96-hour heating period were observed. Therefore, subsamples of the initial (pre-test, Sample ID: PSD U-50:50) and final (post-test, Sample ID: PSD U-50:50) were collected to evaluate potential changes in the material particle size distribution (PSD). The PSD of sludge before and after WWO is important to the design and operation of slurry retrieval and transport systems. Additionally, this PSD data can be used to provide insights on how WWO treatment may affect the respirable fraction of sludge particulate.

Particle size distributions were determined under procedure RPL-COLLOID-01 Rev. 1, Particle Size Analysis Using Malvern MS2000, using a Malvern Mastersizer 2000 (Malvern Instruments Ltd., Worcestershire, UK) particle size analyzer equipped with a Hydro $\mu \mathrm{P}$ dispersion unit. The size analyzer instrument software (Mastersizer 2000 Version 5.60, Malvern Instruments, Ltd., Copyright 2009) was used to calculate the PSD as fractional volume contribution versus particle diameter from the laser diffraction patterns measured by the instrument using Mie scattering theory (see instrument manual and Malvern product literature for additional information). Based on the equipment specifications, particles with diameters between 0.02 and 2000 micrometers $(\mu \mathrm{m})$ can be analyzed by the Malvern Mastersizer 2000; however, the ability of the Hydro $\mu \mathrm{P}$ dispersion unit to suspend and detect greater than $\sim 150 \mu \mathrm{m}$ diameter components (and/or high density materials) is a challenge for the instrument.

For the radiological Malvern Mastersizer 2000 size analysis system installed in RPL/302, performance checks involve measuring the PSD of a particle size standard traceable to NIST. The standard consists of polydispersed silica particles with diameters falling primarily between 1-10 $\mu \mathrm{m}$ or

\footnotetext{
${ }^{1}$ The routine performance check was not conducted per schedule. Details of the investigation are described in K Basin Occurrence Form 52578-1-19-10.
} 
10-100 $\mu \mathrm{m}$. In accordance with procedure RPL-COLLOID-01, Rev. 1, the median value $\left(\mathrm{D}_{50}\right)$ of three standard measurements should deviate less than a target value of $10 \%$ from the certified value together with its standard deviation unless other criteria are provided by the manufacturer of the standard material. The results from this measurement were compared to the standard's certificate of analysis provided by the supplier, and the acceptable performance of the size analyzer was confirmed.

Size analysis using the Malvern Mastersizer 2000 system requires specification of operating parameters such a flow cell flow rate and sonication level and analysis parameters such as particle and suspending refractive indices. PSD parameter evaluations were conducted for both $\mathrm{K}$ Basin simulants (Burns et al. 2009) and actual K Basin sludge samples (Fiskum et al. 2009). These evaluations provided the basis for the parameter values used for the $50: 50 \mathrm{~mole} \% \mathrm{UO}_{2} / \mathrm{UO}_{3} \cdot 2 \mathrm{H}_{2} \mathrm{O}$ PSD measurements, as shown in Table 2.6. The parameters derived in Burn et al. (2009) and Fiskum et al. (2009) were used for the current sample analysis. However, sonication at full power (100\%) during initial sample measurements appeared to result in the formation of agglomerates and/or bubbles. As a result, sonication power was reduced $50 \%$ in an attempt to eliminate bubble/aggregate formation.

For the analyses, sample slurries were subsampled using a transfer pipette with a clipped tip (to minimize size exclusion bias). The slurry was mixed and solids suspended by rapid transfer in and out of the transfer pipette. Then a sample was collected and transferred into the Hydro $\mu \mathrm{P}$ dispersion. One drop was transferred for each aliquot for both samples and in situ dilution was still required to obtain satisfactory obscuration values for sample analysis. The sampled material was analyzed three times for PSD and then drained from the system. The results from three aliquots ( 9 measurements) were combined to obtain a representative PSD of each sample.

Table 2.6. Summary of Malvern MS2000 Instrument Information and Parameters Used for Sample Analysis

\begin{aligned} & \hline Analyzer: MS2000 \\ & \hline Measurement Principle: Laser diffraction (Mie scattering) \\ & \hline Analyzer Accessory: Hydro $\mu \mathrm{P} \\ &$ Serial Number: MAL100406 \\ & \hline Measurement Range: 0.02 to $150 \mu \mathrm{m}$ with accessory \\ & Type: Flow cell system with continuously variable and independent pump and ultrasound \\ & Capacity: $20 \mathrm{~mL} \\ &$\hline Software Version/Date: $5.6 / 1998-2009 \\ &$ Ultrasound Power: 0 to $20 \mathrm{~W}$ (variable), used 100\% for 2 minutes and then measured \\ & Pump Speed: $2000 \mathrm{RPM} \\ &$\hline Particle Refractive Index: 2.42 \\ & Particle Absorbance: 1 \\ & Particle Shape: Irregular \\ & Measurement Times: 1) After 1 minute (unsonicated) recirculating, 2) and after a 1-minute sonication \\ & period at 50\% sonication power, and 3) after 1 minute recirculation post sonication \\ & \hline\end{aligned}




\subsubsection{Chemical Analyses}

Supernatant samples were collected before and after heating from each test for $\mathrm{pH}$ measurement. The $\mathrm{pH}$ measurements were made with a $\mathrm{pH}$ electrode calibrated with commercial buffer solutions.

Samples of settled solids not being examined in prolonged settling tests were treated with $85 \%$ (concentrated) $\mathrm{H}_{3} \mathrm{PO}_{4}$ containing $0.14 \mathrm{M} \mathrm{H}_{2} \mathrm{SO}_{4}$. This reagent has been found to be effective in dissolving the non-metallic uranium oxide solids and still preserving the uranium oxidation state distribution (Sinkov et al. 2008). This reagent also dissolves ferrihydrite and $\mathrm{Al}(\mathrm{OH})_{3}$ but is not effective for silicates and the OIER and does not dissolve the uranium metal. Eight milliliters of the $\mathrm{Na}_{2} \mathrm{SO}_{4} / \mathrm{H}_{3} \mathrm{PO}_{4}$ reagent was required to dissolve the uranium phases for the $\mathrm{KW}$, containerized sludge simulant, laboratory-scale tests. For the 50:50 UO $\mathrm{UO}_{2}: \mathrm{UO}_{3} \cdot 2 \mathrm{H}_{2} \mathrm{O}$ slurry tests, $11 \mathrm{~mL}$ of acid was required because of the higher uranium content. Most of the solids only required an hour or two at $80^{\circ} \mathrm{C}$ to complete the dissolution. Solids dissolution required more time for samples containing the added sodium hydroxide. Test 3 took the longest to dissolve, requiring approximately 10 hours of heating. The reason for this is not immediately clear, but adding $\mathrm{NaOH}$ did encourage solids suspension to a greater degree than the other test conditions investigated (i.e., no added $\mathrm{NaOH}$ or $\mathrm{Na}_{3} \mathrm{PO}_{4}$ ). This uniform suspension may have inhibited the dissolution of the uranium by the phosphoric acid.

After the solids were dissolved, solution aliquots were obtained for spectrophotometric ultraviolet-visible (UV-Vis) analysis of the $\mathrm{U}(\mathrm{IV}) / \mathrm{U}(\mathrm{VI})$ ratio according to an established procedure developed for K Basin sludge characterization. ${ }^{(1)}$ The solution aliquots $(180 \mu \mathrm{L})$ were diluted with $1.2 \mathrm{~mL}$ of the $\mathrm{H}_{3} \mathrm{PO}_{4} / \mathrm{Na}_{2} \mathrm{SO}_{4}$ reagent to obtain solutions of $<1$ absorbance unit quantitation limit.

After solids dissolution, all liquid was removed, the solids were heel rinsed in DIW, and the uranium metal beads, which are not appreciably attacked by the $\mathrm{H}_{3} \mathrm{PO}_{4} / \mathrm{Na}_{2} \mathrm{SO}_{4}$ reagent, were hand-selected from the undissolved residue. These residues included OIER, mordenite, and sand. In all laboratory-scale tests, the number of uranium metal beads retrieved was equivalent to the number initially put in a given test. For the stirred reactor tests, the number of beads retrieved was lower than the initial number, but nearly all were found. The amount of corrosion for all beads was pro-rated based on those beads that were retrieved. The retrieved uranium metal beads were leached with $\mathrm{H}_{3} \mathrm{PO}_{4} / \mathrm{N}_{2} \mathrm{SO}_{4}$, washed, dried, and weighed. The difference between the mass of uranium metal initially in the system and the mass of uranium metal after heating is the mass of uranium metal oxidized to $U(I V)$ in the form of $\mathrm{UO}_{2}$. All uranium metal mass measurements were performed with a 5-place balance. Uranium metal corrosion rates were calculated based on the metal weight loss, the reasonable estimate that the uranium metal beads were approximately the same spherical starting size because they had been selected by sieving, the density of the uranium metal, and the time of exposure to the heated conditions.

${ }^{1}$ Delegard CH. 2009. Sample Preparation and Analysis for Determining Uranium Oxide Oxidation States in K Basin Sludges. RPG-CMC-255, Rev. 0, Pacific Northwest National Laboratory, Richland, Washington. 


\subsection{Results}

The laboratory-scale WWO verification tests, Runs 1 and 2, (scoping tests) were designed to evaluate the oxidation behavior of uranium metal and solids rheology (agglomeration) in two different simulated sludges under agitated and non-agitated conditions at $95^{\circ} \mathrm{C}$ at non-adjusted and alkaline-adjusted $\mathrm{pH}$. The two large-scale stirred reactor tests were performed to determine the sludge agglomeration and uranium metal corrosion behaviors under more prototypic stirring conditions. The simulants used in both tests were 1) uranium-containing KW container simulant and 2) a 50:50 (mole basis) mixture $\mathrm{UO}_{2}: \mathrm{UO}_{3} \cdot 2 \mathrm{H}_{2} \mathrm{O}$ (uraninite/metaschoepite) slurry.

For WWO laboratory-scale scoping verification runs, room-temperature control tests were conducted in parallel for comparison to determine the effects of heating. A total of 27 separate test items were included within the test matrix. For large-scale, stirred reactor testing, two separate test items were examined. Results from the testing are provided in this section. In Section 3.1, results from specific tests to evaluate the effects of agitation and $\mathrm{pH}$ control on uranium metal and uranium oxide are presented. The effects of the test parameters are provided in Section 3.2.

For the control experiments, no changes in slumping characteristics or settled solids height were observed during the course of the experiment for the entirety of the 3-week experiment.

\subsection{Uranium Metal Corrosion Rate and Uranium Oxide Redox Analysis}

The uranium metal corrosion rate and uranium oxide oxidation state analyses for the laboratory-scale and overhead-stirred tests are provided in Sections 3.1.1 and 3.1.2, respectively.

\subsubsection{Laboratory-Scale Uranium Test Results}

As described in the laboratory-scale test matrix (Table 2.1) and Appendix C of the AREVA test plan, a number of experiments were terminated after 96 hours of $95^{\circ} \mathrm{C}$ heating to evaluate the effect of the test parameters on uranium metal corrosion and uranium oxide oxidation. Based on the assumed spherical bead geometry, the Sludge Databook reaction rate equation predicts that after 96 hours at the $\sim 96^{\circ} \mathrm{C}$ test conditions, the original $\sim 780-\mu \mathrm{m}$ diameter beads would have reacted to an $\sim 530-\mu \mathrm{m}$ diameter. This isotropic size reduction corresponds to $\sim 50 \%$ mass reduction. Beads of the expected $530-\mu \mathrm{m}$ terminal size can be identified and physically separated from other sludge simulant components; hence, uranium metal corrosion rates from Tests 1 and 2 were determined by isolating the residual uranium metal beads, weighing them, and comparing these weights with their initial total weights. Results from determining the rate of uranium metal corrosion are given in Table 3.1. Comparisons of the measured rates to the rate predicted by the Sludge Databook rate equation are also provided in Table 3.1.

The uranium metal corrosion rates in the tests were essentially equal to or greater than the rate predicted by the Sludge Databook rate equation, with rate enhancement/comparison factors ranging from about 0.90 to 1.74 . The rate comparison factors (measured/predicted) fall well within the $95 \%$ confidence range established for the Databook rate equation [i.e., 0.33 (low) and 3 (high)]. It is important to note that no rate inhibition (i.e., rate comparison factor less that 1.0) was observed for any of the static tests. In other prior experiments, WWO tests were conducted with genuine sludge samples and irradiated uranium 
metal fuel particles at various temperatures $\left(33,40,60,80\right.$, and $\left.95^{\circ} \mathrm{C}\right)$. Observed rates averaged 0.42 times the STP rate with the rate inhibition speculated to be caused by sludge-blanketing/mass-transfer resistances (Schmidt et al. 2003). No evidence of corrosion rate inhibition, such as might be caused by sludge blanketing, was observed in Runs 1 and 2. However, no comparative laboratory-scale tests containing only uranium metal beads in the absence of sludge were conducted in the present experimental set.

Table 3.1. Uranium Oxidation Information After 96-Hour Heating for Both Uranium Metal and 50:50 Uranium Oxide Slurry. Agitated tests and static tests were conducted at $96.0^{\circ} \mathrm{C} \pm 0.2^{\circ} \mathrm{C}$ and $95.3^{\circ} \mathrm{C} \pm 0.6^{\circ} \mathrm{C}$, respectively. The initial $\mathrm{U}(\mathrm{IV}): \mathrm{U}(\mathrm{VI})$ composition was 50:50.

\begin{tabular}{|c|c|c|c|c|c|c|c|c|c|}
\hline Matrix & \multicolumn{2}{|l|}{ Test } & $\begin{array}{c}\text { Initial } \\
\mathrm{pH}\end{array}$ & $\begin{array}{c}\text { Avg. Final } \\
\mathrm{pH}^{(\mathrm{a})}\end{array}$ & $\begin{array}{l}\text { Salt for } \mathrm{pH} \\
\text { Adj }\end{array}$ & $\begin{array}{c}\text { Final } \\
\% \mathrm{U}(\mathrm{VI})\end{array}$ & $\begin{array}{l}\text { Absolute } \\
\text { Change in } \\
\% \text { U(VI) }\end{array}$ & $\begin{array}{l}\text { Corr. Rate } \\
(\mu \mathrm{m} / \mathrm{h})\end{array}$ & $\begin{array}{c}\text { Ratio of Measured } \\
\text { Corr. Rate to Predicted } \\
\text { Corr. Rate }\end{array}$ \\
\hline \multirow{3}{*}{$\begin{array}{c}\text { KW } \\
\text { Simulant }\end{array}$} & 1 & \multirow{5}{*}{ 焉 } & 7 & 8.4 & none & 59.7 & 9.7 & 1.554 & 1.42 \\
\hline & 3 & & 12 & 9.1 & $\mathrm{NaOH}$ & 73.9 & 23.9 & 1.524 & 1.40 \\
\hline & 7 & & 12 & 8.4 & $\mathrm{Na}_{3} \mathrm{PO}_{4}$ & 61.5 & 11.5 & 1.519 & 1.39 \\
\hline \multirow{2}{*}{$50: 50$} & 8 & & 7 & 9.4 & none & 59.6 & 9.6 & 1.037 & 0.95 \\
\hline & 10 & & 12 & 8.7 & $\mathrm{NaOH}$ & 62.2 & 12.2 & 0.981 & 0.90 \\
\hline \multirow{3}{*}{$\begin{array}{c}\text { KW } \\
\text { Simulant }\end{array}$} & 13 & \multirow{5}{*}{ 苞 } & 7 & 9.3 & none & 60.4 & 10.4 & 1.812 & 1.73 \\
\hline & 15 & & 12 & 9.1 & $\mathrm{NaOH}$ & 59.0 & 9.0 & 1.821 & 1.74 \\
\hline & 19 & & 12 & 9.4 & $\mathrm{Na}_{3} \mathrm{PO}_{4}$ & 56.2 & 6.2 & 1.429 & 1.37 \\
\hline \multirow{2}{*}{$50: 50$} & 20 & & 7 & 8.7 & none & 58.5 & 8.5 & 1.366 & 1.31 \\
\hline & 22 & & 12 & 8.8 & $\mathrm{NaOH}$ & 57.1 & 7.1 & 1.047 & 1.00 \\
\hline \multicolumn{10}{|c|}{ Sludge Technical Databook ${ }^{(b)}$ Corrosion Rate Predictions } \\
\hline \multicolumn{3}{|c|}{ Temperature $\left({ }^{\circ} \mathrm{C}\right)$} & & $\begin{array}{l}\text { rrosion Rate } \\
(\mu \mathrm{m} / \mathrm{h})\end{array}$ & \multicolumn{5}{|c|}{ Condition } \\
\hline \multicolumn{2}{|c|}{92.0} & & & 0.854 & \\
\hline \multirow{2}{*}{\multicolumn{3}{|c|}{$\begin{array}{l}95.3 \\
96.0\end{array}$}} & & 1.045 & \multicolumn{5}{|c|}{ Average Temperature for Static Tests $1,3,7,8$, and 10} \\
\hline & & & & 1.090 & \multicolumn{5}{|c|}{ Average Temperature for Agitated Tests $13,15,19,20$, and 22} \\
\hline \multicolumn{3}{|c|}{98.0} & & 1.229 & & & & & \\
\hline \multicolumn{3}{|c|}{104.0} & & 1.747 & & & & & \\
\hline
\end{tabular}

(a) Of duplicate tests.

(b) The Sludge Technical Databook (Schmidt 2010) reaction rate of uranium metal with anoxic liquid water, expressed as a linear penetration rate (depth of uranium metal reacted per unit time), is as follows: $\log _{10} \mathrm{rate}, \mu \mathrm{m} / \mathrm{h}=9.694-3565 / \mathrm{T}$ where $\mathrm{T}$ is temperature in $\mathrm{K}$.

Data from the static and agitated KW simulant samples (Table 3.1) indicate that uranium metal corrosion rates were statistically indistinguishable with the average static test corrosion rate $=1.69 \pm 0.22 \mu \mathrm{m} / \mathrm{h}$ and the average agitated test corrosion rate $=1.53 \pm 0.02 \mu \mathrm{m} / \mathrm{h}$. Errors are reported as one standard deviation of the mean. The marginally lower rates in the agitation tests may have been because agitation would increase dissolved oxygen concentrations, thus imposing slightly oxic conditions that would inhibit uranium metal corrosion. This explanation is speculative and the effect, in any event, is small.

The $\mathrm{pH}$ adjustments also had little or no effect on uranium metal corrosion rates. This can be seen by comparing the results of tests within groupings $(1,3,7),(8,10),(13,15,19)$, and $(20,22)$, which differ only in the $\mathrm{pH}$. For example, in the static tests with KW simulant, the rate observed in test $19\left(\mathrm{Na}_{3} \mathrm{PO}_{4}\right)$ was about $20 \%$ lower than the tests with $\mathrm{NaOH}$ addition (Test 15 ) and the test without $\mathrm{pH}$ adjustment (Test 13). In the static tests with the 50:50 uranium oxide slurry, Test 22 with $\mathrm{NaOH}$ addition exhibited a rate $\sim 20 \%$ lower than the otherwise equivalent Test 20 with no $\mathrm{pH}$ adjustment. Complete $\mathrm{pH}$ data, shown 
in Table 3.1, suggest that the lack of a significant $\mathrm{pH}$ effect on corrosion may be because buffering reactions (perhaps by absorbed carbon dioxide) lowered the target $\mathrm{pH} 12$ to values little different from the $\sim 7.5$ to $9.5 \mathrm{pH}$ of the tests without $\mathrm{NaOH}$ or $\mathrm{Na}_{3} \mathrm{PO}_{4}$ amendments.

Tests conducted with the KW simulant had higher uranium metal corrosion rates than tests conducted with the 50:50 uranium oxide slurry. The average corrosion rate of the six tests in Table 3.1 with the KW simulant is $1.61 \mu \mathrm{m} / \mathrm{h}$; in comparison, the average uranium metal corrosion rate for the four tests with the 50:50 uranium oxide slurry was $1.11 \mu \mathrm{m} / \mathrm{h}$. The increase in corrosion rate for the $\mathrm{KW}$ simulant samples indicates that a solid component, possibly ferrihydrite, may be serving as a redox shuttle or as a redox agent for the oxidation of uranium metal. In the absence of iron, the oxidation of uranium metal is generally consistent with the nominal Databook rate. For the 50:50 uranium oxide slurry, only Test 20 differs appreciably from the nominal Databook rate and was $30 \%$ faster.

The results of oxidation state distributions of oxidized uranium species, analyzed by ultraviolet visible (UV-Vis) spectrophotometry as prescribed by RPG-CMC-255, are provided in Table 3.1. In general, a 10\% (absolute) increase in the presence of U(VI) was observed. A $20 \%$ increase in U(VI) content was observed for Test 3, which was agitated and adjusted to $\mathrm{pH} 12$ using $\mathrm{NaOH}$. The reason for the increased U(VI) formation in Test 3 relative to the other tests is unknown.

\subsubsection{Bench-Scale Uranium Test Results}

The penetration rates for the KW simulant $(1.74 \mu \mathrm{m} / \mathrm{h})$ and $50: 50 \mathrm{U}$ oxide slurry $(1.42 \mu \mathrm{m} / \mathrm{h})$ fall within 0.6 and $8.0 \%$, respectively, of the rates observed for the analogous laboratory-scale static runs. The similar uranium metal corrosion rates within the bench-scale and laboratory-scale testing may indicate that the uranium metal beads remained mostly static under the impeller during testing. Considering the difficulty encountered lofting $10 \mathrm{~g}$ of steel grit from the reactor bottom, the stagnation of uranium metal in the bench-scale stirred tests seems reasonable.

Because uranium metal was consistently oxidized at a faster rate in the KW simulant compared to the 50:50 uranium oxide slurry simulant, photographic and SEM images of $U$ metal beads before heating and after heating in the two simulants were obtained to probe the possibility of different oxidation mechanisms. SEM images of a starting uranium metal bead and product beads from the two tests are shown in Figure 3.1. Additional SEM images are captured in Appendix E. Also, the surfaces of the uranium metal bead surfaces were examined with EDS. Only uranium and oxygen were identified through EDS, and the differences in element compositions between the uranium metal surfaces did not seem statistically significant. The U:O ratio was determined to be 79.3:20.7 \pm 0.5 for the three samples.

The optical image (Figure 3.2a) shows that a blue interference oxide coating is refracted from the surface of beads prior to any oxidative contact and the SEM image shows the surface to be smooth (Figure 3.1a). The SEM images indicate that the surface structure of oxidized uranium beads depends on the type of simulant present during the 96-hour oxidation process. It is seen that beads from oxidation in the KW simulant become faceted during the oxidation process (Figure 3.2b) and have a relatively smooth surface with concave conchoidal divots, that mimic knapped stone, and small raised striations (Figure 3.1b). However, since the beads in the stirred reactor $\mathrm{KW}$ simulant test were recovered from the robust sludge heel (see Section 3.2.1.2), it is not believed that the beads experienced significant abrasion or chipping from sand. 


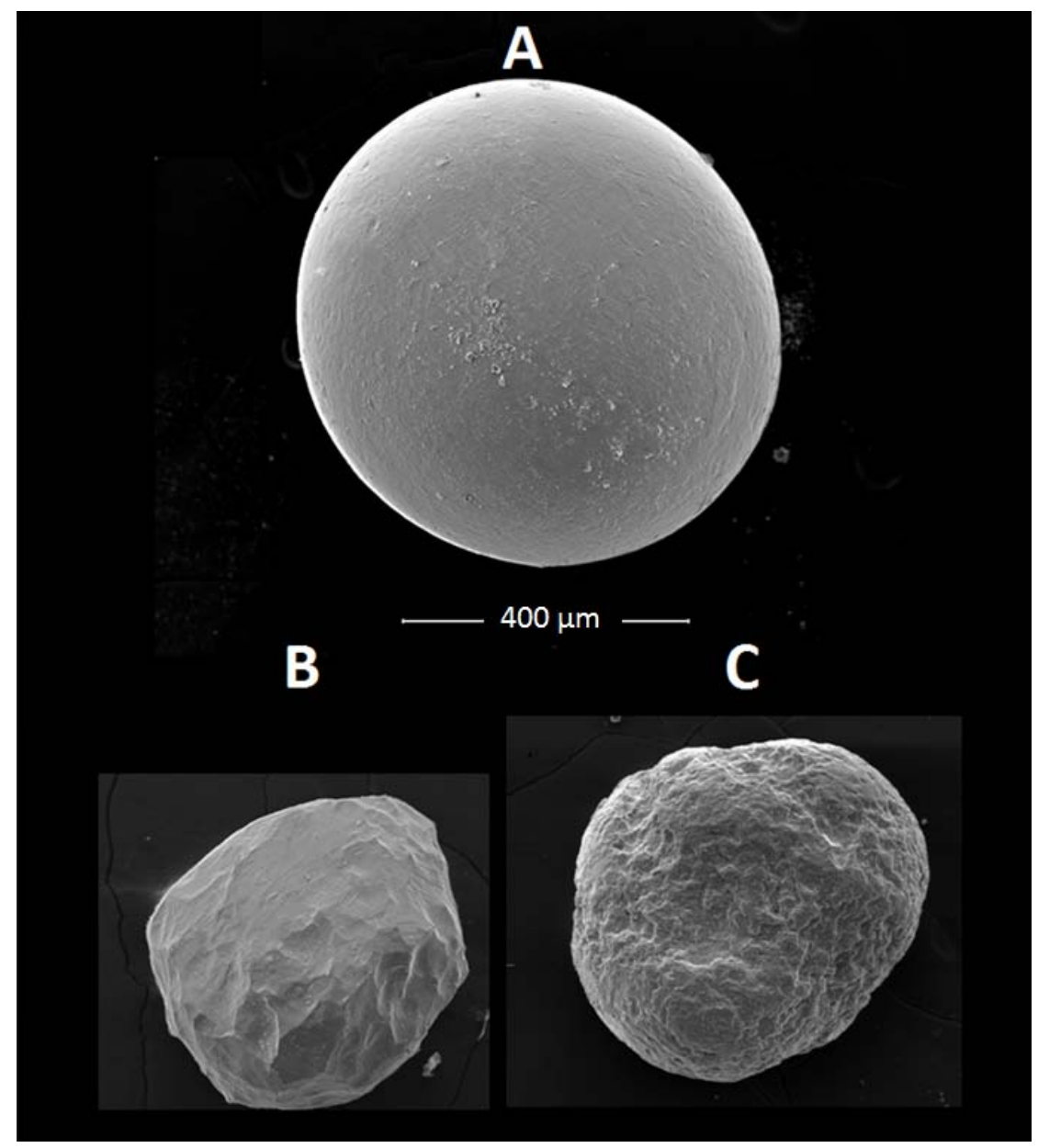

Figure 3.1. SEM Images of Uranium Metal Beads Relevant to Stirred Reactor Testing. Images are scaled with respect to each other. A) Initial uranium metal bead condition. B) Bead after 96-hour, $95^{\circ} \mathrm{C}$ heating in $\mathrm{KW}$ simulant. C) Bead after 96 -hour, $95^{\circ} \mathrm{C}$ heating in $50: 50$ uranium oxide slurry. 

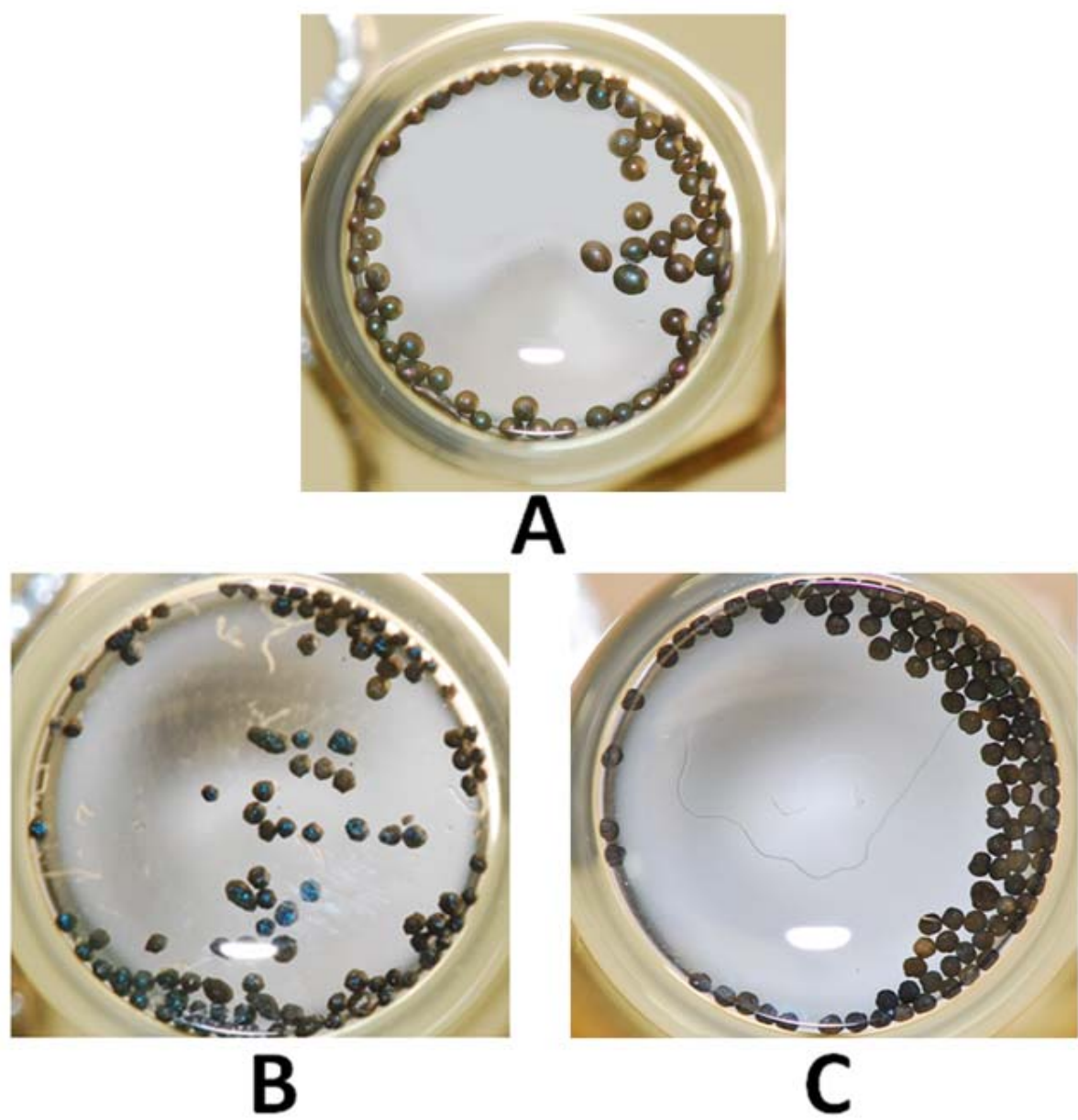

Figure 3.2. Photographic Images of Uranium Metal Beads Relevant to Stirred Reactor Testing. The left side displays photographic images obtained from the bottom of a $2 \mathrm{~mL}$ vial. A) Initial uranium metal bead condition. B) Beads after 96 -hour, $95^{\circ} \mathrm{C}$ heating in $\mathrm{KW}$ simulant. C) Beads after 96 -hour, $95^{\circ} \mathrm{C}$ heating in 50:50 uranium oxide slurry.

In contrast to the relatively smooth surface observed initially for a $U$ metal bead or after contact with the KW simulant, beads oxidized in 50:50 uranium oxide media have a very rugged, pitted, and layered surface (Figure 3.1c). Optical photographs of 50:50 uranium oxide beads are consistent with the SEM images (Figure 3.2c). The surface coarseness, evident in the SEM images, prevents the beads from reflecting light in a fashion comparable to new beads or the beads from the KW simulant test with their rough surface making them black-body light absorbers. Considering the difficulty in lofting the heavy 50:50 uranium oxide slurry, it is most likely the beads experienced a largely static environment (see Section 2.0).

The differences in uranium metal bead surfaces produced between the KW simulant tests and the 50:50 uranium oxide tests may be from the presence of ferrihydrite in the KW simulant. Studies of the oxidation of $\mathrm{UO}_{2}$ in soil environments show that ferrihydrite, $\mathrm{Fe}_{5} \mathrm{O}_{7}(\mathrm{OH}) \cdot 4 \mathrm{H}_{2} \mathrm{O}$, in comparison with less hydrated and more crystalline goethite, $\mathrm{FeOOH}$, or hematite, $\mathrm{Fe}_{2} \mathrm{O}_{3}$, encourages $\mathrm{UO}_{2}$ oxidation to more soluble U(VI) species (Ginder-Vogel et al. 2006). Uraninite forms as an oxide coating during the oxidation of uranium metal, allowing the uranium metal oxidation process to be somewhat self-protecting. Accelerated removal of the oxide layer through oxidation would perpetuate a fresh 
surface for oxidation, ultimately encouraging an expedited oxidation rate compared to the 50:50 uranium oxide stirred reactor test, which contained no ferrihydrite.

Due to the high specificity of uraninite oxidation with ferrihydrite at near neutral $\mathrm{pHs}$ as compared with goethite or hematite, uranium metal corrosion in the presence of aged real sludge having a lower fraction of ferrihydrite than the simulant used in the present testing may not be as fast as the KW simulant case and may more closely mimic the results of the 50:50 uranium oxide tests.

The uranium oxidation state distributions in the samples from the stirred reactor testing also differed significantly from those found in the laboratory-scale tests of their respective simulants. Three stratified layers emerged after 72-hours of quiescent settling for the KW simulant (Figure 3.3). A sample was obtained from each layer for $U$ oxide oxidation analysis. In contrast, the 50:50 U oxide slurry was homogenous post-test; therefore, only one sample was obtained for oxidation state analysis.

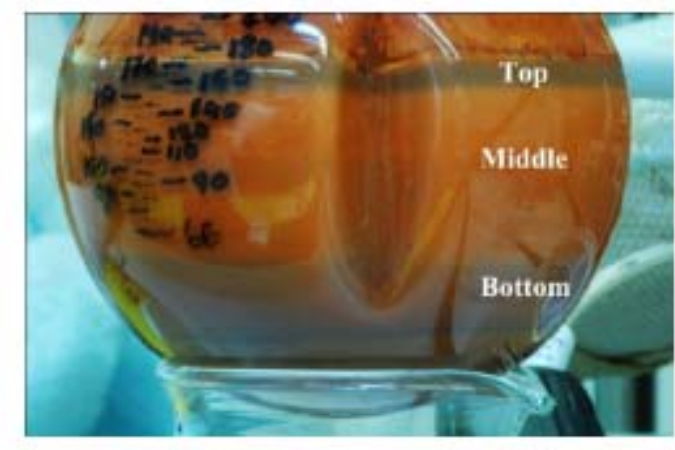

a

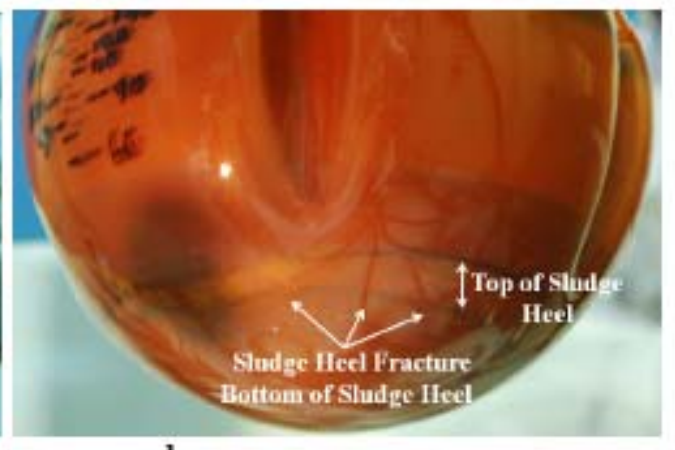

b

Figure 3.3. (a) Stratified KW Simulant Observed After 72-Hour Settling Period. Samples for UV-Vis analysis were aliquoted from the top, middle, and bottom phases. (b) Composition of Sludge Heel. The top layer of the sludge heel slumps readily and separately from the bottom of the sludge heel. The "sludge heel fracture" delineates the slumping solids from solids of sufficient strength. The solids strength of the sludge heel bottom is estimated at $150 \mathrm{kPa}$.

Oxidation state analysis of the KW simulant in stirred reactor testing indicated highly oxidizing conditions were present, as the increase in U(VI) was at least $20 \%$ in each of the sampled layers (Table 3.2). The U(VI) fraction in the post-test settled slurry the extent of U(VI) oxidation in the layers increased with proximity to the surface of the simulant. The faster settling U(IV) particles in the bottom layer were likely larger, with less surface area per unit mass, and thus, were less readily oxidized.

The data also indicate that even though no measures were taken to exclude atmospheric and dissolved oxygen, the uranium metal corrosion in the present testing is well modeled by anoxic aqueous kinetics. The time required for the full transition from relatively low uranium metal corrosion rates under oxic conditions to the more rapid rates under anoxic corrosion conditions is difficult to predict but clearly decreases with increasing temperature, as shown in early testing of uranium metal corrosion in water (Mollison et al. 1945). The transition to the more rapid anoxic corrosion rates is gradual at temperatures below $80^{\circ} \mathrm{C}$, but is reached almost instantaneously at $80^{\circ} \mathrm{C}$ and $100^{\circ} \mathrm{C}$ in these prior tests. In the present testing conducted at $95^{\circ} \mathrm{C}$, the oxic kinetics and its lower rates were practically excluded and rapid anoxic corrosion were established rapidly. 
The uranium 50:50 oxide slurry oxide composition showed remarkable resistance to oxidation with $<1 \%$ increase in U(VI). This behavior is significantly different than the batch scale tests, which showed an average $\mathrm{U}(\mathrm{VI})$ increase of $9 \pm 2 \%$ and may indicate better oxygenation in the relatively shallow laboratory-scale tests.

The WWO flowsheet incorporates an assumption that a rate enhancement factor of 1 can be used to estimate required processing times. The data highlighted in Table 3.1 and Table 3.2 support this assumption (i.e., no evidence of rate inhibition). Therefore, the uranium metal corrosion rate and uranium oxide redox analysis observed in this section support the current WWO flowsheet uranium metal corrosion rate assumption.

Table 3.2. Uranium Oxidation Information After 96-Hour Heating for Stirred Reactor Testing. Tests were performed at $95.5^{\circ} \mathrm{C} \pm 0.1^{\circ} \mathrm{C}$. The initial $\mathrm{U}(\mathrm{IV}): \mathrm{U}(\mathrm{VI})$ composition was 55:45.

\begin{tabular}{|c|c|c|c|c|c|c|}
\hline Matrix & $\begin{array}{c}\text { Initial } \\
\mathrm{pH}\end{array}$ & $\begin{array}{l}\text { Final } \\
\mathrm{pH}\end{array}$ & $\begin{array}{c}\text { Final } \\
\% \mathrm{U}(\mathrm{VI})^{(\mathrm{a})}\end{array}$ & $\begin{array}{l}\text { Absolute } \\
\text { Change in } \\
\% \mathrm{U}(\mathrm{VI})\end{array}$ & $\begin{array}{l}\text { Corr. Rate } \\
(\mu \mathrm{m} / \mathrm{h})\end{array}$ & $\begin{array}{c}\text { Ratio of Exp. Corr. Rate to } \\
\text { Lit. Corr. Rate }\end{array}$ \\
\hline $\begin{array}{c}\text { KW } \\
\text { Simulant }^{(b)}\end{array}$ & 8.33 & 6.96 & $\begin{array}{c}\text { Top-73.8 } \\
\text { Middle-70.1 } \\
\text { Bottom-65.7 }\end{array}$ & $\begin{array}{c}\text { Top-28.8 } \\
\text { Middle-25.1 } \\
\text { Bottom-20.7 }\end{array}$ & 1.74 & 1.64 \\
\hline $50: 50^{(\mathrm{c})}$ & 7.36 & 8.04 & 45.7 & 0.7 & 1.42 & 1.34 \\
\hline \multicolumn{7}{|c|}{ Sludge Technical Databook Corrosion Rate Predictions, Schmidt 2010} \\
\hline \multicolumn{2}{|c|}{ Temperature $\left({ }^{\circ} \mathrm{C}\right)$} & \multicolumn{2}{|c|}{$\begin{array}{l}\text { Corrosion Rate } \\
\qquad(\mu \mathrm{m} / \mathrm{h})\end{array}$} & \multicolumn{3}{|c|}{ Condition } \\
\hline \multicolumn{2}{|c|}{92.0} & \multicolumn{2}{|c|}{0.854} & \\
\hline \multicolumn{2}{|c|}{95.5} & \multicolumn{2}{|c|}{1.058} & \multicolumn{3}{|c|}{ Average temperature for stirred tests } \\
\hline \multicolumn{2}{|c|}{102.5} & \multicolumn{2}{|c|}{1.601} & & & \\
\hline \multicolumn{2}{|c|}{104.0} & \multicolumn{2}{|c|}{1.747} & & & \\
\hline \multicolumn{7}{|c|}{$\begin{array}{l}\text { (a) See Figure } 3.4 \text { for visual indication of the discussed phases. } \\
\text { (b) The slurry volume for the KW simulant stirred reactor study varied from } 150-200 \mathrm{~mL} \text { total volume. } \\
\text { (c) The slurry volume for the 50:50 uranium oxide slurry stirred reactor study varied from } 200-250 \mathrm{~mL} \text { total volume. }\end{array}$} \\
\hline
\end{tabular}

\subsection{Physical Behavior of Solids}

The physical behavior of solids at WWO conditions was evaluated by visual observations and measurements and by conducting simple strength tests by slump and probing. Results from these observations and assessments are presented in this section.

For the laboratory-scale scoping tests, specific notes of observations and solids phenomenological composition regarding test heights and densities are found in Table 3.1 through Table 3.4. Information on the densities of the large-scale test sludge is found in Table 3.7. Although photos were obtained for all samples, specific pictures are highlighted within the main body of this report to illustrate observed phenomena (Figure 3.1 through Figure 3.4). All other photos not specifically discussed within the main body of the report can be found in Appendices B, C, and D. The physical behaviors of the KW simulant are described in Section 3.2.1 and the 50:50 simulant in Section 3.2.2. 

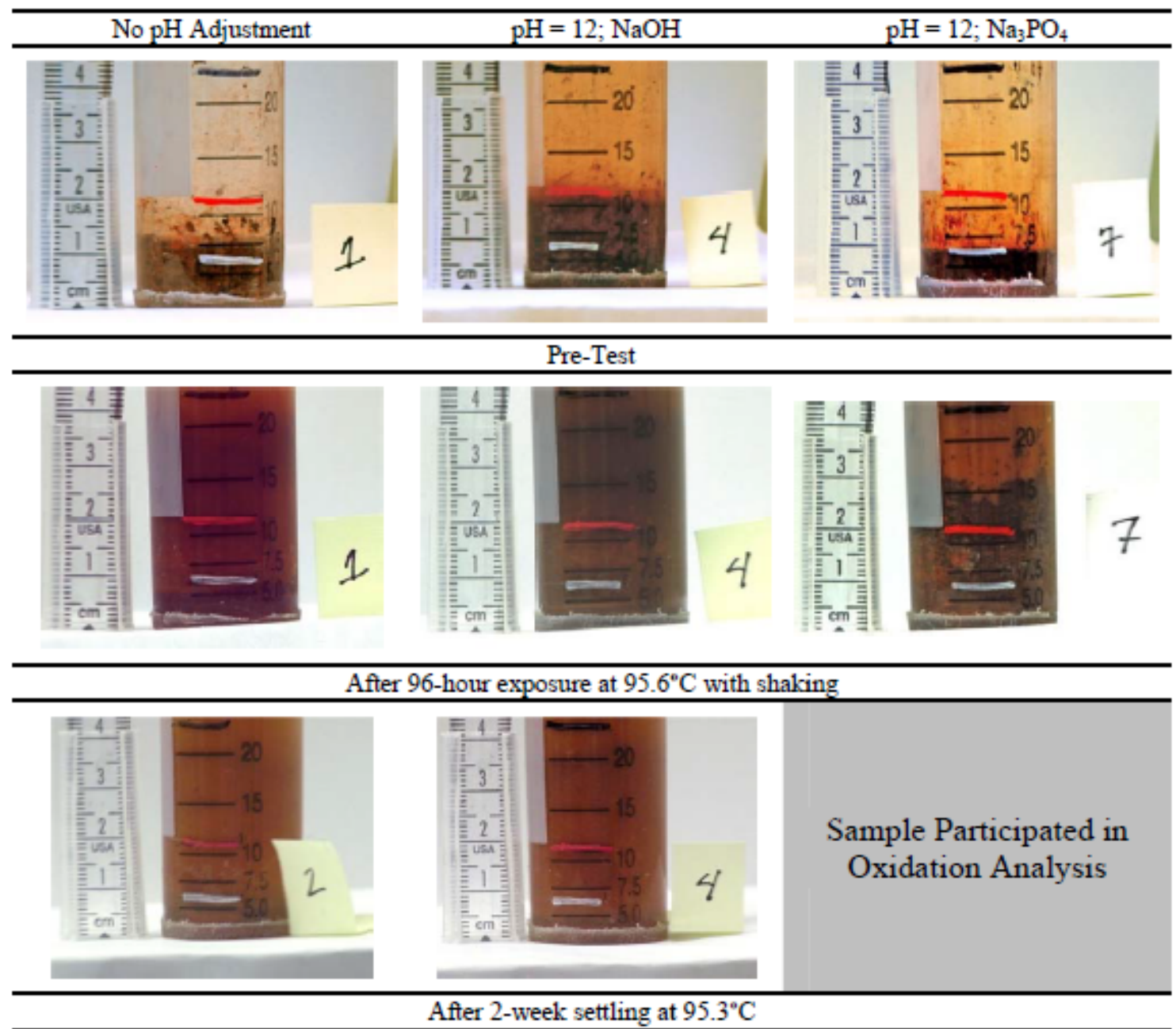

Figure 3.4. The Effects of $\mathrm{pH}$ Adjustment on KW Simulant Tests: Tests 1 and 2 Are Duplicates and Representative of Samples Without $\mathrm{pH}$ Adjustment. The $\mathrm{pH}$ was adjusted to 12 using $\mathrm{NaOH}$ and $\mathrm{Na}_{3} \mathrm{PO}_{4}$ for Tests 4 and 7, respectively. All tests were agitated during the initial 96-hour heating. The white line, red line, and thick black line represent 3,8 , and $20 \mathrm{~mL}$ volumes. 
Table 3.3. Complete pH Data for All Laboratory-Scale Tests Performed for WWO Scoping

\begin{tabular}{|c|c|c|c|c|c|c|}
\hline Test & & Solid Composition & Salt & $\begin{array}{c}\text { Initial } \mathrm{pH} \\
\text { (Post 3-day settling) }\end{array}$ & Final $\mathrm{pH}$ & Final pH Time \\
\hline 1 & \multirow{11}{*}{ 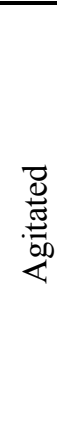 } & KW Simulant & None & 8.19 & 8.41 & $96 \mathrm{~h}$ \\
\hline 2 & & KW Simulant & None & 8.41 & 7.91 & $2 \mathrm{wk}$ \\
\hline 3 & & KW Simulant & $\mathrm{NaOH}$ & 9.43 & 9.09 & $96 \mathrm{~h}$ \\
\hline 4 & & KW Simulant & $\mathrm{NaOH}$ & 9.46 & 7.93 & $2 \mathrm{wk}$ \\
\hline 5 & & KW Simulant & None & 9.05 & 7.50 & $2 \mathrm{wk}$ \\
\hline 6 & & KW Simulant & $\mathrm{NaOH}$ & 9.41 & 7.81 & $2 \mathrm{wk}$ \\
\hline 7 & & KW Simulant & $\mathrm{Na}_{3} \mathrm{PO}_{4}$ & 9.88 & 8.42 & $96 \mathrm{~h}$ \\
\hline 8 & & 50:50 U Slurry & None & 9.15 & 9.39 & $96 \mathrm{~h}$ \\
\hline 9 & & 50:50 U Slurry & None & 8.65 & 8.25 & $2 \mathrm{wk}$ \\
\hline 10 & & 50:50 U Slurry & $\mathrm{NaOH}$ & 8.92 & 8.75 & $96 \mathrm{~h}$ \\
\hline 11 & & 50:50 U Slurry & None & 8.77 & 8.14 & $2 \mathrm{wk}$ \\
\hline 13 & \multirow{11}{*}{ 氙 } & KW Simulant & None & 8.25 & 9.27 & $96 \mathrm{~h}$ \\
\hline 14 & & KW Simulant & None & 8.87 & 7.94 & $2 \mathrm{wk}$ \\
\hline 15 & & KW Simulant & $\mathrm{NaOH}$ & 11.27 & 9.07 & $96 \mathrm{~h}$ \\
\hline 16 & & KW Simulant & $\mathrm{NaOH}$ & 8.90 & 7.93 & $2 \mathrm{wk}$ \\
\hline 17 & & KW Simulant & None & 8.88 & 7.71 & $2 \mathrm{wk}$ \\
\hline 18 & & KW Simulant & $\mathrm{NaOH}$ & 11.30 & 7.91 & $2 \mathrm{wk}$ \\
\hline 19 & & KW Simulant & $\mathrm{Na}_{3} \mathrm{PO}_{4}$ & 9.39 & 9.45 & $96 \mathrm{~h}$ \\
\hline 20 & & 50:50 U Slurry & None & 8.93 & 8.69 & $96 \mathrm{~h}$ \\
\hline 21 & & 50:50 U Slurry & None & 8.65 & 8.13 & $2 \mathrm{wk}$ \\
\hline 22 & & 50:50 U Slurry & $\mathrm{NaOH}$ & 8.61 & 8.81 & $96 \mathrm{hr}$ \\
\hline 23 & & 50:50 U Slurry & None & 8.86 & 8.42 & $2 \mathrm{wk}$ \\
\hline Control 1 & \multirow{5}{*}{ 窇 } & KW Simulant & None & 8.43 & 8.21 & $2 \mathrm{wk}$ \\
\hline Control 2 & & KW Simulant & $\mathrm{NaOH}$ & 9.42 & 9.15 & $2 \mathrm{wk}$ \\
\hline Control 3 & & KW Simulant & $\mathrm{Na}_{3} \mathrm{PO}_{4}$ & 9.56 & 9.3 & $2 \mathrm{wk}$ \\
\hline Control 4 & & 50:50 U Slurry & None & 8.55 & 8.32 & $2 \mathrm{wk}$ \\
\hline Control 5 & & 50:50 U Slurry & $\mathrm{NaOH}$ & 8.91 & 8.65 & $2 \mathrm{wk}$ \\
\hline
\end{tabular}


Table 3.4. Test Heights Before Heating and After Heating for 96 Hours. Grey-shaded rows indicate samples with only uranium slurry present. All other tests include KW simulant.

\begin{tabular}{|c|c|c|c|c|c|c|c|}
\hline \multicolumn{4}{|c|}{ Agitated } & \multicolumn{4}{|c|}{ Static } \\
\hline $\begin{array}{l}\text { Test and } \\
\text { Conditions }\end{array}$ & $\begin{array}{c}\text { Pre-Test } \\
\text { Height } \\
(\mathrm{cm})\end{array}$ & $\begin{array}{l}\text { Pre-Test } \\
\text { Density } \\
(\mathrm{g} / \mathrm{mL})\end{array}$ & $\begin{array}{l}\text { Post 96-Hour } \\
\text { Height }(\mathrm{cm})\end{array}$ & $\begin{array}{c}\text { Test and } \\
\text { Conditions }\end{array}$ & $\begin{array}{c}\text { Pre-Test } \\
\text { Height } \\
(\mathrm{cm})\end{array}$ & $\begin{array}{l}\text { Pre-Test } \\
\text { Density } \\
(\mathrm{g} / \mathrm{mL})\end{array}$ & $\begin{array}{l}\text { Post 96-Hour } \\
\text { Height }(\mathrm{cm})\end{array}$ \\
\hline $1, \mathrm{pH}=7$ & 1.15 & 1.4 & $0.55, \mathrm{D}^{(\mathrm{b})}$ & $13, \mathrm{pH}=7$ & 1.15 & 1.4 & $0.75, \mathrm{D}^{(\mathrm{b})}$ \\
\hline $2, \mathrm{pH}=7$ & 1.15 & 1.4 & $0.35, \mathrm{D}^{(\mathrm{b})}$ & $14, \mathrm{pH}=7$ & 1.05 & 1.4 & $0.55, \mathrm{D}^{(\mathrm{b})}$ \\
\hline $\begin{array}{c}3, \mathrm{pH}=12 \\
\mathrm{NaOH}\end{array}$ & 1.55 & 1.3 & N.D. ${ }^{\text {(a) }}$ & $\begin{array}{c}15, \mathrm{pH}=12 \\
\mathrm{NaOH}\end{array}$ & 0.93 & 1.5 & $0.45, \mathrm{D}^{(\mathrm{b})}$ \\
\hline $\begin{array}{c}4, \mathrm{pH}=12 \\
\mathrm{NaOH}\end{array}$ & 1.75 & 1.3 & $0.15, \mathrm{D}^{(\mathrm{b})}$ & $\begin{array}{c}16, \mathrm{pH}=12 \\
\mathrm{NaOH}\end{array}$ & 0.86 & 1.6 & $0.65, \mathrm{D}^{(\mathrm{b})}$ \\
\hline $5, \mathrm{pH}=7$ & 1.05 & 1.6 & N.D. ${ }^{\text {(a) }}$ & $17, \mathrm{pH}=7$ & 1.15 & 1.4 & $0.65, \mathrm{D}^{(\mathrm{b})}$ \\
\hline $\begin{array}{c}6, \mathrm{pH}=12 \\
\mathrm{NaOH}\end{array}$ & 1.25 & 1.4 & $0.35, \mathrm{D}^{(\mathrm{b})}$ & $\begin{array}{c}18, \mathrm{pH}=12 \\
\mathrm{NaOH}\end{array}$ & 0.85 & 1.6 & $0.45, \mathrm{D}^{(\mathrm{b})}$ \\
\hline $\begin{array}{c}7, \mathrm{pH}=12 \\
\mathrm{Na}_{3} \mathrm{PO}_{4}\end{array}$ & 0.7 & 2.0 & N.D. ${ }^{\text {(a) }}$ & $\begin{array}{c}19, \mathrm{pH}=12 \\
\mathrm{Na}_{3} \mathrm{PO}_{4}\end{array}$ & 0.65 & 1.8 & 0.65 \\
\hline $8, \mathrm{pH}=7$ & 0.75 & 2.2 & 0.95 & $20, \mathrm{pH}=7$ & 0.75 & 2.2 & $1.05, \mathrm{~V} . \mathrm{F}^{(\mathrm{c})}$ \\
\hline $9, \mathrm{pH}=7$ & 0.75 & 2.2 & 0.85 & $21, \mathrm{pH}=7$ & 0.65 & 2.3 & 1.65, V.F. $^{(\mathrm{c})}$ \\
\hline $\begin{array}{c}10, \mathrm{pH}=12 \\
\mathrm{NaOH}\end{array}$ & 0.75 & 2.2 & $0.45, \mathrm{D}^{(\mathrm{b})}$ & $\begin{array}{c}22, \mathrm{pH}=12 \\
\mathrm{NaOH}\end{array}$ & 0.75 & 2.2 & 0.75 \\
\hline $11, \mathrm{pH}=7$ & 0.75 & 2.2 & 1.05 & $23, \mathrm{pH}=7$ & 0.75 & 2.2 & 1.65, V.F. ${ }^{(\mathrm{c})}$ \\
\hline
\end{tabular}

(a) Abbreviation N.D. indicates solid presence was "Not Discernable."

(b) Abbreviation $D$ indicates significant sample "Dispersion" observed.

(c) Abbreviation V.F. indicates "Void Formation." 
Table 3.5. Observations From Warm Water Heating With Initial Agitation

\begin{tabular}{|c|c|c|c|c|}
\hline \multirow[b]{2}{*}{ Test } & \multicolumn{2}{|r|}{ Post 96 Hours } & \multicolumn{2}{|r|}{ Post Additional 2 Weeks } \\
\hline & $\begin{array}{c}\text { Temp } \\
{ }^{\circ} \mathrm{C}\end{array}$ & Observations & $\begin{array}{c}\text { Temp } \\
{ }^{\circ} \mathrm{C}\end{array}$ & Observations \\
\hline $\begin{array}{c}1 \\
\mathrm{pH}=7 \\
\text { KW Sim. }\end{array}$ & 95.6 & $\begin{array}{l}\text { No foam; very hard to see settled solids. Solids } \\
\text { that were present were very soft and unable to } \\
\text { support weight of vertically positioned spatula. } \\
\text { Slumping observed after a couple of minutes. }\end{array}$ & - & - \\
\hline $\begin{array}{c}2 \\
\mathrm{pH}=7 \\
\text { KW Sim. }\end{array}$ & 95.6 & $\begin{array}{l}\text { No foam, redder than duplicate Test } 1 . \text { Same } \\
\text { sludge composition to Test } 1 .\end{array}$ & 95.3 & $\begin{array}{l}\text { Visible settled sludge. Gas release when opened. } \\
\text { Noticeably firmer, but still slumps within } 2 \\
\text { minutes and responds well to agitation. }\end{array}$ \\
\hline $\begin{array}{c}3 \\
\mathrm{pH}=12 \\
\mathrm{NaOH} \\
\text { KW Sim. }\end{array}$ & 95.6 & $\begin{array}{l}\text { No foam; Test } 3 \text { looks like Test } 1 \text { in color. More } \\
\text { than } 95 \% \text { of the solids were suspended, which } \\
\text { prevented assessment of solids morphology. } \\
\text { Solids slumped within } 3 \text { minutes. }\end{array}$ & - & - \\
\hline $\begin{array}{c}4 \\
\mathrm{pH}=12 \\
\mathrm{NaOH} \\
\text { KW Sim. }\end{array}$ & 95.6 & $\begin{array}{l}\text { No foam and duplicate appearance to Test } 3 \text {. } \\
\text { Some solids left at bottom. Slumping observed } \\
\text { after } 1 \text { minute. }\end{array}$ & 95.3 & $\begin{array}{l}\text { All solids visually appear in suspended state. Gas } \\
\text { release upon opening. Some solids found during } \\
\text { poke test and tilting. Responds well to agitation, } \\
\text { and slumping observed within } 3 \text { minutes. }\end{array}$ \\
\hline $\begin{array}{c}5 \\
\mathrm{pH}=7 \\
\text { KW Sim. }\end{array}$ & 95.6 & $\begin{array}{l}\sim 2 \text { to } 3 \mathrm{~mL} \text { of foam. The top } 5 \mathrm{~mL} \text { of the tube } \\
\text { are redder in color. Few solids are } \\
\text { distinguishable as a settled layer, but the bottom } \\
\text { layer is darker. Material on the walls of the } \\
\text { container is thin and slick. }\end{array}$ & 25 & $\begin{array}{l}\text { All solids are suspended with the exception of } \\
\text { sand. }\end{array}$ \\
\hline $\begin{array}{c}6 \\
\mathrm{pH}=12 \\
\mathrm{NaOH} \\
\text { KW Sim. }\end{array}$ & 95.6 & $\begin{array}{l}\text { Few bubbles at top; reddish upper layer. All } \\
\text { solids are in solution. }\end{array}$ & 25 & $\begin{array}{l}\text { All solids are suspended with the exception of } \\
\text { sand. }\end{array}$ \\
\hline $\begin{array}{c}7 \\
\mathrm{pH}=12 \\
\mathrm{Na}_{3} \mathrm{PO}_{4} \\
\text { KW Sim. }\end{array}$ & 95.6 & $\begin{array}{l}\text { Few bubbles, stripes on side walls. Solids form } \\
\text { but are fractured into chunks. Consistency } \\
\text { similar to wet topsoil. Slumping observed after } \\
5 \text { minutes. }\end{array}$ & - & - \\
\hline $\begin{array}{c}8 \\
\mathrm{pH}=7 \\
50: 50 \mathrm{U} \\
\text { Slurry }\end{array}$ & 95.6 & $\begin{array}{l}\text { Approximately } 5 \mathrm{~mL} \text { of foam with fractured } \\
\text { lavender solids. Slightly turbid. Behaved largely } \\
\text { as a fine powder, but a relatively monolithic } \\
\text { chunk was found in the middle of the powder } \\
\text { during poke testing. A small fraction of solids } \\
\text { shows initial dispersion when tube is tilted for } \\
\text { slump test, but no further slumping is observed. }\end{array}$ & 一 & - \\
\hline $\begin{array}{c}9 \\
\mathrm{pH}=7 \\
50: 50 \mathrm{U} \\
\text { Slurry }\end{array}$ & 95.6 & $\begin{array}{l}\text { Approximately } 5 \mathrm{~mL} \text { of foam with fractured } \\
\text { lavender solids. Very soft and behaves like wet } \\
\text { powder. Slumping behavior identical to Test } 8 .\end{array}$ & 95.3 & $\begin{array}{l}\text { Gas release. Chunky agglomerate formation in } \\
\text { appearance, but could be fractured with moderate } \\
\text { effort. Does support the full weight of the spatula. } \\
\text { Began to break apart to fine powder solids when } \\
\text { agitated. For powders that were present, the } \\
\text { slumping behavior was identical to Tests } 8 \text { and } 9 \\
\text { after } 96 \text { hours of heating. Monolithic samples } \\
\text { remaining after agitation and never slumped. }\end{array}$ \\
\hline $\begin{array}{c}10 \\
\mathrm{pH}=12 \\
\mathrm{NaOH} \\
50: 50 \mathrm{U} \\
\text { Slurry }\end{array}$ & 95.6 & $\begin{array}{l}\text { Approximately } 2 \mathrm{~mL} \text { of foam with lighter upper } \\
\text { lavender layer and dark gray lower layer solids. } \\
\text { More turbid than Tests } 8 \text { and } 9 . \text { Felt a bit like } \\
\text { dried-out clay. No slumping observed. }\end{array}$ & - & - \\
\hline $\begin{array}{c}11 \\
\mathrm{pH}=7 \\
50: 50 \mathrm{U} \\
\text { Slurry }\end{array}$ & 95.6 & $\begin{array}{l}\text { Approximately } 2 \mathrm{~mL} \text { of foam with solids slightly } \\
\text { cracked. All solids are the same color. Slump } \\
\text { test was not performed to allow observation of } \\
\text { crack irregularity for } 2 \text {-week test. Mild shifting } \\
\text { ( } \sim 45 \text { degree tilts) did not disturb crack. }\end{array}$ & 25 & $\begin{array}{l}\text { Part powder and part chunky after agitation. Does } \\
\text { not slump after } 5 \text { minutes. Fracture no longer } \\
\text { observed. Settling caused some collapse of voids. }\end{array}$ \\
\hline
\end{tabular}


Table 3.6. Observations From Warm Water Heating Without Agitation (Static)

\begin{tabular}{|c|c|c|c|c|}
\hline & & Post 96 Hours & & Post Additional 2 Weeks \\
\hline Test & $\begin{array}{c}\text { Temp } \\
{ }^{\circ} \mathrm{C}\end{array}$ & Observations & $\begin{array}{c}\text { Temp } \\
{ }^{\circ} \mathrm{C}\end{array}$ & Observations \\
\hline $\begin{array}{c}13 \\
\mathrm{pH}=7 \\
\text { KW Sim. }\end{array}$ & 95.3 & $\begin{array}{l}\text { Approximately } 2 \mathrm{~mL} \text { of foam, and supernatant } \\
\text { is turbid. Fairly soft (cake batter-like } \\
\text { consistency). Slumps after } 2 \text { minutes. }\end{array}$ & - & - \\
\hline $\begin{array}{c}14 \\
\mathrm{pH}=7 \\
\text { KW Sim. }\end{array}$ & 95.3 & $\begin{array}{l}\text { Approximately } 2.5 \mathrm{~mL} \text { of froth, and supernatant } \\
\text { is turbid. Reasonable settling. The solids are } \\
\text { very soft (comparable to Test } 9 \text { ). Slumping is } \\
\text { observed after } 1 \text { minute. }\end{array}$ & 95.3 & $\begin{array}{l}\text { Gas release upon opening. Opening the tube did } \\
\text { not result in depressurization or wide-scale } \\
\text { bubble release. Not a lot of solids present, but } \\
\text { those present are fairly soft. Readily suspends } \\
\text { with post-test agitation and slumps after } 2 \\
\text { minutes. }\end{array}$ \\
\hline $\begin{array}{c}15 \\
\mathrm{pH}=12 \\
\mathrm{NaOH} \\
\mathrm{KW} \mathrm{Sim}\end{array}$ & 95.3 & $\begin{array}{l}\text { Nearly no bubbles, and supernatant is turbid. } \\
\text { There is reasonable settling, and solids are fairly } \\
\text { soft. Slumps within } 1 \text { to } 2 \text { minutes. }\end{array}$ & - & - \\
\hline $\begin{array}{c}16 \\
\mathrm{pH}=12 \\
\mathrm{NaOH} \\
\mathrm{KW} \mathrm{Sim}\end{array}$ & 95.3 & $\begin{array}{l}\text { Few bubbles and packed about the same as } \\
\text { Tests } 13 \text { and } 14 \text {. Harder than Test } 9 \text {, but still } \\
\text { relatively soft. Slumps after } 2 \text { minutes. }\end{array}$ & 95.3 & $\begin{array}{l}\text { Gas release. Solids present are still pretty soft. } \\
\text { Slumps within } 2 \text { minutes. }\end{array}$ \\
\hline $\begin{array}{c}17 \\
\mathrm{pH}=7 \\
\text { KW Sim. }\end{array}$ & 95.3 & $\begin{array}{l}\text { Approximately } 1 \mathrm{~mL} \text { of bubbles, similar } \\
\text { packing and turbidity to Tests } 13,14 \text {, and } 16 . \\
\text { Slumps between } 1 \text { and } 2 \text { minutes. }\end{array}$ & 25 & $\begin{array}{l}\text { Many solids present, and they are pretty soft. } \\
\text { Slumps after } 3 \text { minutes. }\end{array}$ \\
\hline $\begin{array}{c}18 \\
\mathrm{pH}=12 \\
\mathrm{NaOH} \\
\text { KW Sim. }\end{array}$ & 95.3 & $\begin{array}{l}\text { Approximately } 1 \mathrm{~mL} \text { of bubbles, similar } \\
\text { packing and turbidity to Tests } 15 \text { and } 16 .\end{array}$ & 25 & $\begin{array}{l}\text { Many solids present, and they are pretty soft. } \\
\text { Slumps after } 3 \text { minutes. }\end{array}$ \\
\hline $\begin{array}{c}19 \\
\mathrm{pH}=12 \\
\mathrm{Na}_{3} \mathrm{PO}_{4} \\
\text { KW Sim. }\end{array}$ & 95.3 & $\begin{array}{l}\text { Approximately } 2 \mathrm{~mL} \text { of bubbles, similar in color } \\
\text { and turbidity to } \mathrm{NaOH} \text {-free samples. Slumps } \\
\text { within a couple of minutes. }\end{array}$ & - & - \\
\hline $\begin{array}{c}20 \\
\mathrm{pH}=7 \\
50: 50 \mathrm{U} \\
\text { Slurry }\end{array}$ & 95.3 & $\begin{array}{l}\text { No foam layer and almost clear solution. Solids } \\
\text { are piled like rubble. Robust composition that } \\
\text { supports the weight of the spatula. }\end{array}$ & - & - \\
\hline $\begin{array}{c}21 \\
\mathrm{pH}=7 \\
50: 50 \mathrm{U} \\
\text { Slurry }\end{array}$ & 95.3 & $\begin{array}{l}\text { Spalled layers, clear solution with no bubbles. } \\
\text { No slump observed within 5-minute window. }\end{array}$ & 95.3 & $\begin{array}{l}\text { Still very hard, and large plates move } \\
\text { independently of one another upon adjustment. } \\
\text { Large voids are present, and it appears possible } \\
\text { for gas bubbles to become trapped in voids. } \\
\text { Solids are quite monolithic, but the beginnings } \\
\text { of breakdown are observed after } 5 \text { minutes of } \\
\text { agitation. The solids break down to the powders } \\
\text { observed in Tests } 8 \text { and } 9 \text {. }\end{array}$ \\
\hline $\begin{array}{c}22 \\
\mathrm{pH}=12 \\
\mathrm{NaOH} \\
50: 50 \mathrm{U} \\
\text { Slurry }\end{array}$ & 95.3 & $\begin{array}{l}\text { Approximately } 2 \mathrm{~mL} \text { of foam with a slightly } \\
\text { turbid supernate. The solids have formed into a } \\
\text { rounded blob. Solids still very hard. }\end{array}$ & - & - \\
\hline $\begin{array}{c}23 \\
\mathrm{pH}=7 \\
50: 50 \mathrm{U} \\
\text { Slurry }\end{array}$ & 95.3 & $\begin{array}{l}\text { Few bubbles, clear solution, and fractured } \\
\text { rubble solids are present that are similar to Test } \\
21 \text {. }\end{array}$ & 25 & $\begin{array}{l}\text { Solids are somewhat softer than immediately } \\
\text { after } 96 \text {-hour heating. This indicates that } \\
\text { monolithic formation may be reversible over } \\
\text { storage at cooler temperatures. There is no } \\
\text { observable slump, but some breakdown is } \\
\text { observed after 5-minute agitation. }\end{array}$ \\
\hline
\end{tabular}


Table 3.7. Solids Densities for Stirred Reactor Tests

\begin{tabular}{ccc}
\hline \multicolumn{3}{c}{ Stirred Reactor Test } \\
\hline Test & Pre-Test Density $(\mathrm{g} / \mathrm{mL})$ & Post-Test Density $(\mathrm{g} / \mathrm{mL})$ \\
\hline KW Simulant & 1.61 & $1.11^{\text {(a) }}$ \\
50:50 U Oxide Slurry & 1.54 & 1.55 \\
\hline (a) & Significant dispersion of the KW simulant prevented discernment of the supernatant layer from the settled solids; \\
\multicolumn{2}{l}{ therefore the post-test density is the average density of the entire test volume. } \\
\hline
\end{tabular}

\subsubsection{Physical Behavior of KW Simulant}

\subsubsection{Laboratory-Scale Scoping Tests}

Before heating, $\mathrm{pH}$ adjustments were found to have an indiscernible impact on solids settling (Table 3.4). The largest determiner in sludge density prior to heating appears to be the flocculating agent. During the preparation of the simulants, the flocculating agent was not homogenously dispersed - even upon aggressive mixing. Therefore, a similar sludge mass may vary in density by approximately $10 \%$ depending on the cohesion of the flocculating agent with the sludge solids. The influence of $\mathrm{Na}_{3} \mathrm{PO}_{4}$ on sludge density does seem to overwhelm the variability imparted by the flocculating agent. The settled densities of the $\mathrm{NaOH}$ and non-salt adjusted simulants were $1.4 \pm 0.1 \mathrm{~g} / \mathrm{mL}$ (error $1 \sigma$ and based on the standard deviation). The settled densities of the $\mathrm{Na}_{3} \mathrm{PO}_{4}$ adjusted simulants were $1.9 \pm 0.2$ (error $1 \sigma$ and based on the relative percent difference). Since most of the solids dispersed into the supernatant phase in these tests upon heating, these initial room-temperature observations are the most informative on the impact of $\mathrm{pH}$ adjustment to the settled-solids volume.

Upon heating, fine, opaque, red-brown suspensions were observed for the $\mathrm{KW}$ simulant sludges in all tests. For the KW simulant samples containing sodium hydroxide, the solids suspension in agitated tests was effectively complete such that no settled heel was observed (Figure 3.3). The opacity of the suspension also obscured observations of any potential voids within the settled slurry. Consequently, the accuracy of settled-sludge volume measurement was degraded. Because of unevenness in the solid-liquid surface, difficulties in observing the settled layers, the presence of solids in suspension in the supernatant liquid, and lacunae in the settled solids, the settled volumes could only be measured on a best-effort basis using real-time visual observation and review of photographs taken as the tubes were rotated through $90^{\circ}$ steps. Based on the photo reviews, uncertainties in settled-solids volumes were estimated to be about $30 \%$ or more (including parallax error) so that the post-test settled density accuracy is estimated to be approximately $\pm 50 \%$ (relative).

The level of suspension seemed to vary, even between duplicate tests, so it is not inherently clear what factors encourage simulant suspension. One factor that could be contributing to the poor suspension reproducibility observed between duplicate samples is uniformity in applying the flocculating agent. In the KW simulant make-up, uniformly coating the KW simulant solids with flocculating agent using current methods is challenging. Uneven distribution of the flocculating agent would certainly affect the suspension of simulant solids. If $\mathrm{NaOH}$ reacts with the flocculating agent, this could cause increased suspension of simulant solids into the $\mathrm{NaOH}$ supernatant compared to a supernatant with no added salts.

The voids within the sludge were not easily observable for KW simulant tests because of the opaque rust-brown and non-settling suspension frequently formed in the supernatant (Figure 3.6). The color and the nonsettling, very finely particulate character of the suspension is consistent with the hematite, $\mathrm{Fe}_{2} \mathrm{O}_{3}$, 
and goethite, $\mathrm{FeOOH}$, present from the aging of the ferrihydrite component used to prepare the simulant sludge (see Appendix A of Sinkov et al. 2010 for XRD analysis of the ferrihydrite starting material).

For all tests conducted with the KW simulant, the solid materials slumped and did not support the spatula mass during post-test examinations at either the 96-hour or the 2-week time interval. Only very minor differences in solids consistency were observed for the various conditions tested. Some resistance was encountered when the spatula contacted the sand, a component of the simulant, which, by touch, had apparently and expectedly settled to the bottom. For these KW simulant tests, however, gentle rocking of the centrifuge cone resulted in sample suspension and mobilization of this sand layer.

Consistent with the test matrix, after the initial 96 hours of heating, tests were terminated or continued for an additional 2 weeks at elevated or room temperature. For the tests subjected to an additional 2 weeks of static heating at $95^{\circ} \mathrm{C}$, a slightly stiffer consistency was observed relative to the samples allowed to settle at room temperature. KW simulant adjusted with $\mathrm{Na}_{3} \mathrm{PO}_{4}$ had the most robust solids observed of the KW simulant tests. The $\mathrm{Na}_{3} \mathrm{PO}_{4}$-amended material had a uniform consistency similar to wet topsoil.

Post-test evaluation included placing the samples back into the MultiTherm ${ }^{\mathrm{TM}}$ gyratory shaker set at 1000 cycles per minute for 5 minutes. This agitation encouraged further suspension of solids material into the supernatant regardless of the initial $\mathrm{pH}$ of the aqueous phase. None of the settled solids could support the weight of the 6.0 -g spatula, and slumping was observed for all materials within 3 minutes.

Overall, the testing showed that:

- No strong agglomerates were formed for the KW simulant at any of the conditions tested.

- The length of heating increases the strength of the KW simulant solids, but the agglomeration is minimal enough to maintain desirable physical characteristics for up to 2 weeks at $95^{\circ} \mathrm{C}$.

- Slumping was observed in all tests during post-test evaluations.

- Agitation expedited solids dispersion to the supernatant, but results indicate that given enough time, KW simulant solids can migrate into suspension even under static conditions. The amount of time required for dispersion is probably largely dependent on the coating of the flocculating agent.

- For the tests after heating, increasing the $\mathrm{pH}$ using $\mathrm{NaOH}$ encourages solids dispersion, whereas using $\mathrm{Na}_{3} \mathrm{PO}_{4}$ enhances the consolidation of solids (Figure 3.3). Given enough time, even the non-pH-adjusted samples will disperse. The amount of time required for dispersion is probably largely dependent on the coating of the flocculating agent.

- Current data indicate no potential benefit to solids or oxidation characteristics related to $\mathrm{pH}$ adjustment.

\subsubsection{Bench-Scale Stirred Reactor Test for KW Simulant}

For stirred reactor testing, solids stratification was observed after the 72 -hour period at $\sim 95^{\circ} \mathrm{C}$ (Figure 3.5a). The top layer was easily collected for UV-Vis analysis using a 1-mm bore diameter pipette. This layer had low solids content and settling suspended material did not occur. No resistance within the layer was observed, and the material flowed like water. The second layer was also collected for UV-Vis analysis using a 1-mm bore pipette. The texture was similar to thin paint. The third layer was 
too thick to sample using a 1-mm pipette. A larger, 2-mm bore pipette was successful in acquiring UV-Vis samples. The sample consistency of the third layer was similar to thick paint. The top, middle and bottom constituted 20,65, $40 \mathrm{~mL}$, respectively ( $125 \mathrm{~mL}$ total). The final bottom layers, constituting $25 \mathrm{~mL}$, were removed with a wide-bore pipette to enable uranium metal bead recovery.

The densities of the stirred reactor solids are noted in Table 3.7 for both the KW simulant and 50:50 uranium oxide slurry tests. For the KW simulant, removing stratified layers revealed a sludge heel comprising two portions (Figure 3.5a). The top portion of the sludge heel constituted 20 to $25 \mathrm{~mL}$ and could be removed with a large bore pipette. This material slumped within 3 minutes. The sludge heel bottom $(\sim 25 \mathrm{~mL})$ was composed of material with substantial strength. Using soil strength terminology, the material would be described as Stiff to Very Stiff, indicating it could be indented slightly by thumb (Clayton 1995; British Standard 1999), indicating that the shear strength would be between 100 and $200 \mathrm{kPa}$. Probing indicated a spatula could be pressed into the material with force.

The substantial strength of the sludge heel observed in the KW simulant was not observed in any of the previous laboratory-scale tests. A series of events is postulated to explain the presence of the agglomerated material.

1. Mixing of the solids at the bottom of the reactor was insufficient to prevent agglomeration. This is supported by the observation of a dead zone (little or no mixing) observed in shakedown testing conducted with G-10 steel grit in $150 \mathrm{ml}$ DI water.

2. The agglomerated material may have served as a barrier to heat transfer, potentially resulting in slightly higher temperatures in the agglomerated region. Since the temperature-controlling thermocouple was about $5 \mathrm{~cm}$ from the reactor bottom (i.e., within the bulk slurry), greater temperatures at the base of the reactor supplied by the heating mantle may have been required to drive $95^{\circ} \mathrm{C}$ at the thermocouple site.

To assess the possibility of a significant temperature gradient, a second (passive) thermocouple was inserted between the heating mantle and exterior of the reactor vessel for the 50:50 $\mathrm{U}$ oxide stirred test. During initial vessel heating for this test, the passive thermocouple read temperatures as high as $280^{\circ} \mathrm{C}$. Once the testing temperature of $95^{\circ} \mathrm{C}$ was reached, the external thermocouple would read $190^{\circ} \mathrm{C} \pm 10^{\circ} \mathrm{C}$.

Uranium metal oxidation rates in the stirred reactor case are consistent with temperatures at the base of the reactor reaching as high as $104^{\circ} \mathrm{C}$; however, expedited metal oxidation in the $\mathrm{KW}$ simulant study was most likely encouraged by both ferrihydrite solubilization of uranium oxide and a slight temperature excursion (note: boiling in the reactor vessel was not observed). It is useful to compare the measured uranium metal penetration to estimate the reaction temperature based on the Databook corrosion rate equation for the stirred reactor test with 50:50 uranium oxide test, where no agglomeration was observed. Here the uranium metal penetration rate is consistent with the reactor vessel having reached $102.5^{\circ} \mathrm{C}$ (at a rate enhancement factor of 1 ). Taking all factors into consideration a rate enhancement factor of 1 is reasonable for the WWO process. 
Given the observation of the agglomerated region at the base of the reactor and the temperature gradient across the base of the glass reactor, several considerations for reactor vessel design are suggested:

- Use close-clearance impeller designs to prevent dead-zones.

- Develop a means to measure the temperature at the internal base of the reactor to prevent overheating of sludge.

- Investigate sidewall reactor heating to prevent sludge/simulant accumulation and potential overheating at the reactor bottom where the heaviest solids collect-ultimately forming a heat sink.

Overall, the larger-scale, stirred reactor testing showed that:

- Agglomeration can occur in zones were mixing is poor. Robust close-clearance impeller designs are likely to prevent agglomeration.

- The uranium corrosion rate obtained in the $200 \mathrm{~mL}$ stirred reactor was very comparable to rates obtained in the $3 \mathrm{~mL}$ (laboratory scale) scoping tests.

- Upon consideration of potential measurements uncertainties, the uranium metal rate enhancement factor for the $\mathrm{KW}$ simulant matrix examined at $95^{\circ} \mathrm{C}$ is between 1 and 2 . The data generated support the use of a rate enhancement factor of 1 for the preconceptual flowsheet rather than $0.33^{1}$.

\subsubsection{Physical Behavior of 50:50 Simulant}

\subsubsection{Laboratory-Scale Tests}

The solids morphology of 50:50 uranium oxide slurry tests was highly dependent on agitation, as illustrated in Figure 3.5. For agitated slurry tests, the primary solids product visible at the top and side surface of the settled material was a very fine powder. However, within the settled material, some solid agglomerates could be present that exhibit a different morphology and strength. That is, the agitation produced by the MultiTherm ${ }^{\mathrm{TM}}$ may have only been able to agitate a portion of the solid. Due to the heterogeneity of the solid matrix after heating, settled-density estimates are based on the bulk volume and include variable void volumes. During post-test evaluations, only a small fraction of the solids present in these tests flowed during the slump testing.

The 50:50 uranium oxide slurry solids morphology was highly irregular in the static tests and seemed to form rubble-like chunks or irregularly stacked plates with voids between the plates (Figure 3.5). Agglomeration and void formation were observed within 24 hours at $96^{\circ} \mathrm{C}$. In some instances, large voids producing a $300 \%$ increase in bulk solids volume formed within 1 day of heating. Some of these

\footnotetext{
${ }^{1}$ Note that warm water oxidation testing of size-sieved irradiated uranium metal fuel from $\mathrm{N}$ Reactor in the presence and absence of overlying burdens of actual K Basin sludge has been performed (Schmidt et al. 2003). The testing, run at $\sim 40,60,80$, and $95^{\circ} \mathrm{C}$, showed uranium metal corrosion rates somewhat lower than predicted based upon the STP Databook rate. Rates observed for the crushed irradiated N Reactor fuel without sludge were from 1- to 10-times lower (about a factor of 3, overall) than the rates predicted based on the surveyed technical literature for non-irradiated uranium corrosion. Data for tests with sludge overburden were more scattered but the sludge was shown to further lower rates in comparison with analogous sludge-free tests (Schmidt et al. 2003).
} 
voids were observed to trap gas bubbles. Previous sludge simulants tested have displayed the same gas release, even in the absence of uranium metal. This indicates that the bubbles were largely a product of exsolution and separation of dissolved and entrained air. The air, driven from solution, expanded when the samples were heated to test temperatures. Solids that formed plates trapped more gas than the solids that formed chunks. The shear strengths of the slurry solids likely influenced whether plate versus rubble formed in the solids. Table 3.4 notes the heights measured for all tests before and after heating. The presence of voids or significant sample dispersion is also noted. No slumping was observed in these tests.
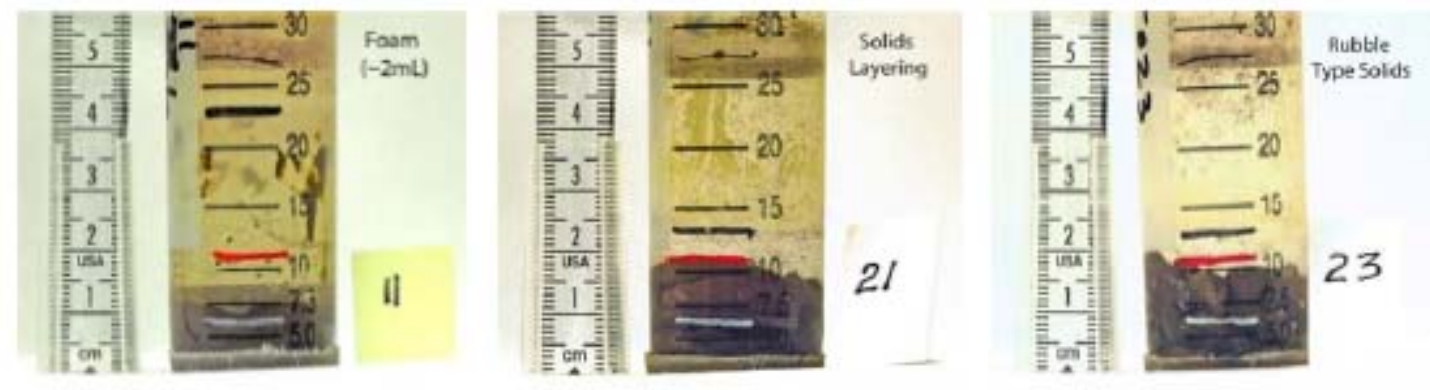

Figure 3.5. Unique Morphology of 50:50 Uranium Oxide Slurry Mixtures After 96 Hours of Heating. None of the samples were $\mathrm{pH}$ adjusted before heating. Test 11 (Left) was agitated during the first interval. The crack in the fine solids maintained over the course of agitation provides an indication that the fine and relatively weak solids actually contain a microstructure. Foamed bubbles are present at the top of the supernatant. Test 21 (Center) was a static heated test. The plates formed would move independently of each other and did begin to break down after prolonged (2-week) settling at room temperature (not shown). Test 23 (Right) is another static heated test. Here the solids more closely represent rocks or rubble.

Following the second interval of the test, the solids behavior of the 50:50 uranium oxide slurry samples varied between samples. Samples agitated in the initial interval, and then allowed to sit at room temperature for 2 weeks, maintained the loose, powder-like consistency observed after the initial 4-day heating/agitation period. However, very little slumping was observed. Samples that were initially agitated with heating and then further heated $\left(95^{\circ} \mathrm{C}\right)$ under static conditions for 2 weeks began to take on the solids stiffness and strength observed for the samples that were not agitated during the first interval. For these tests, the solids shape did not morph into plates or clumps that had been observed for other static and heated samples, but during static heating, the solids compressed to about half of their mean settled volume before heating. Figure 3.6 illustrates the differences in solids morphology for an agitated test (Test 9) and a static test (Test 21) and the changes that occurred during the 2-week settling interval. No $\mathrm{pH}$ adjustments were made to Tests 9 and 21 .

Solids composition and uranium metal oxidation results showed no dependence on $\mathrm{pH}$ for the range investigated in this study ( $\mathrm{pH}$ 6-12). During heating, the supernatant of the $\mathrm{NaOH}$ tests did have some fine particulates present that appeared to be dispersed uranium oxide; however, the dispersion was not significant enough to affect the solids height.

No morphological changes beyond those observed after the first interval were observed for samples that were initially heated under static conditions and then allowed to sit at room temperature. 
After post-test agitation, even the stiffest solids showed signs of breakdown for all 50:50 uranium oxide slurry tests. This indicates that the monolithic plate and chunk formation are reversible with physical perturbation.

For agitated 50:50 uranium slurry samples, the solids had insufficient strength to support the mass of vertically positioned spatula. However, the material exhibited sufficient strength that it did not slump. In contrast, the static 50:50 uranium slurry tests did not slump, and the solids surface exhibited sufficient strength to support the spatula. Additional resistance was observed when the spatula was pushed into the sludge. The resistance was consistent at all depths, indicating that the entire sample had agglomerated homogeneously rather than forming a surface crust that was harder than the underlying material. After probing, Test 21 was aggressively agitated by shaking at hour intervals using the MultiTherm ${ }^{\mathrm{TM}}$. This agitation eroded and suspended the fines. The relatively weak nature of the agglomerates formed from the 50:50 uranium slurry tests is consistent with observations noted in the precursor scoping test (Delegard et al. 2011). Photos of the disintegration of the monolithic plate that agglomerated as a function of agitation time are presented in Figure 3.7.

Overall, the 50:50 uranium slurry laboratory-scale scoping tests were mechanically stronger than the KW simulant materials. In addition, for the 50:50 uranium slurry:

- Monolithic agglomeration was observed within 24 hours at $95^{\circ} \mathrm{C}$, without agitation.

- With agitation, a soft, granular bed that was readily suspendible was formed during heating. Continued heating, without agitation, resulted in sludge consolidation and strength increases.

- The adjustment to a higher solution $\mathrm{pH}$ did not prohibit monolith formation in static tests.

- For all tests with the 50:50 slurry, post-test agitation and mixing resulted in significant erosion of any agglomerates that formed. 


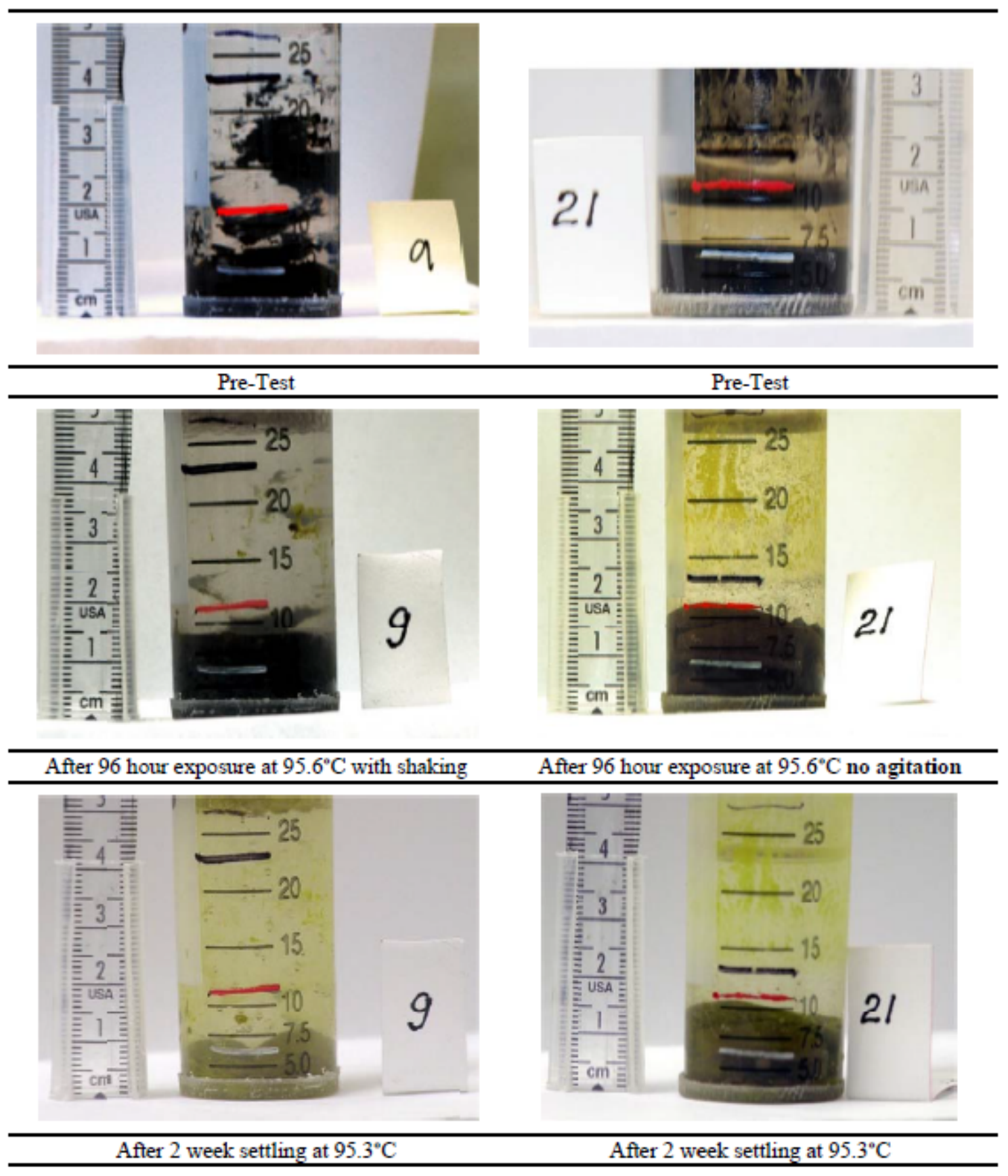

Figure 3.6. The Effects of Agitation on 50:50 $\mathrm{UO}_{\mathrm{x}}$ Slurry: Tests 9 and 21 Indicate Agitated and Static Samples, Respectively. The $\mathrm{pH}$ was not adjusted for any samples. The white line, red line, and thin black line represent 3,8, and $25 \mathrm{~mL}$ volumes. For tests 9 and 21, the thick black line represents 20 and $10 \mathrm{~mL}$, respectively. 

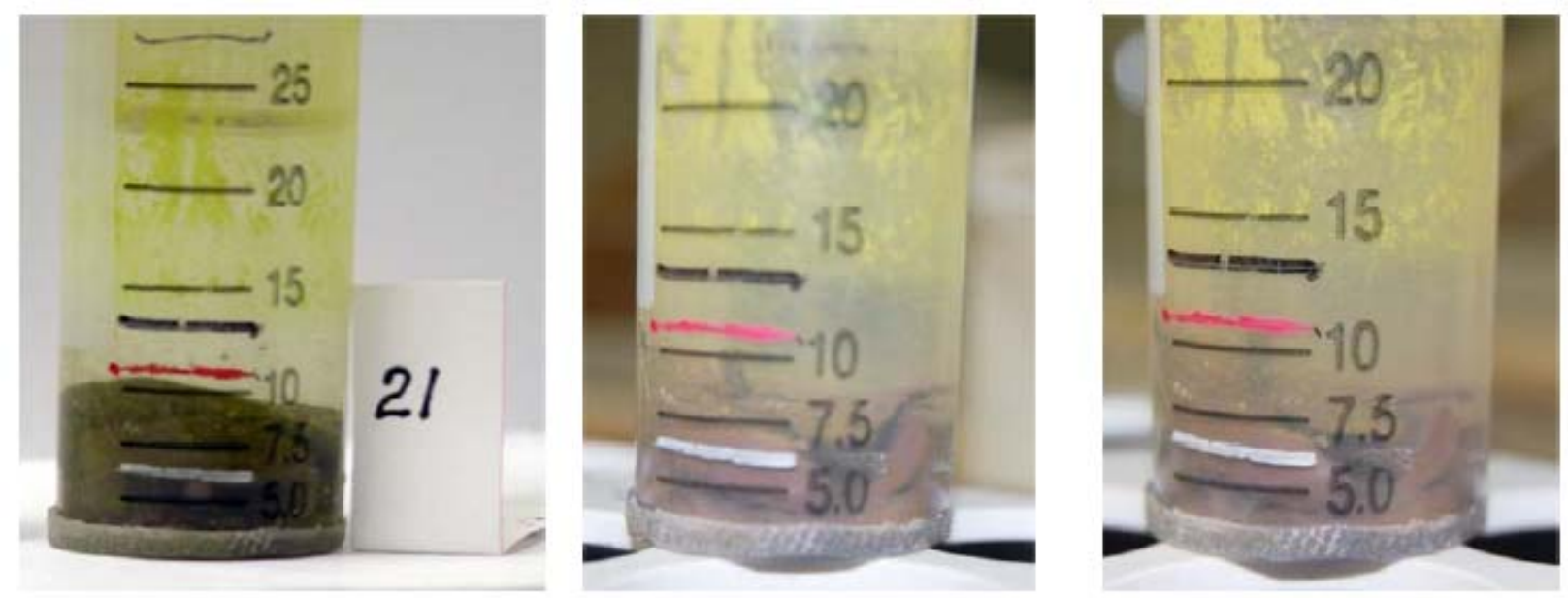

Figure 3.7. The Breakdown Possibilities of Plate-Like Solids After Prolonged (2-wk) Heating. From left to right: immediately post heating; after 1 hour of agitation; after 2 hours of agitation.

\subsubsection{Large-Scale Stirred Reactor Test}

The solids morphology of 50:50 uranium oxide slurry from the stirred reactor test closely matched the solids of the 50:50 uranium oxide slurry batch testing. The primary solids product visible throughout the settled material was a very fine but rapidly settling particulate. The 50:50 uranium oxide slurry did require dilution from 15 vol\% solids to 12 vol\% solids, but unlike batch testing, no solid agglomerates were identified. The lack of solids agglomerates indicates successful agitation of the $12 \mathrm{vol} \%$ dense uranium material. The issues associated with mixing the $15 \mathrm{vol} \%$ solids material implies that $12 \mathrm{vol} \%$ may be a practical upper limit for 50:50 uranium oxide solids volume during a WWO treatment using this sort of mixing apparatus. During the post-test slump examination, the material in the stirred reactor testing flowed immediately, indicating a likely shear strength of less than several hundred $\mathrm{Pa}$ (Russell et al. 2010). The spatula immediately sank to the bottom of the solids on its own weight. Figure 3.8 compares the photographic and SEM appearances (SEM image is $40 \mu \mathrm{m}$ width) of the 50:50 uranium oxide starting material and the final product. EDS data were also obtained in concert with SEM images, and atomic compositions are noted within the relevant SEM image.

SEM and EDS analysis indicates that the physical differences between the two materials have more to do with physical structure than atomic composition. The atomic compositions for the initial and final uranium oxide data are nearly identical. This would be in agreement with UV-Vis oxide speciation analysis captured in Table 3.2, where very little difference in the uraninite to metaschoepite ratio, reflected as the $\mathrm{U}(\mathrm{IV}): \mathrm{U}(\mathrm{VI})$ ratio, was observed before and after heating for 96 hours at $95^{\circ} \mathrm{C}$. Larger plates are observed in the initial 50:50 uranium oxide (Figure 3.8c) compared to the particulate matter (Figure 3.8d) observed after heating. This more irregular particulate matter may be less likely to engage in interfacial plate-to-plate interactions, and this would lead to the decrease in shear strength observed in the 50:50 uranium oxide after heating.

Figure 3.9 and Figure 3.10 summarize the volume contribution \% PSD at 1 minute of recirculation, during sonication, and post sonication for the U-50:50 test samples, before and after WWO treatment respectively. The values represent averages of the results obtained from 9 measurements performed on 3 aliquots from the respective samples. The untreated U-50:50 slurry analyzed was readily homogenized 
such that particles were free flowing when pulsed with the transfer pipette. The untreated solids did not clump. However, large granular material was detected when mixing the solids before analysis. This observation is consistent with the increased fraction of particles in the $100 \mu \mathrm{m}$ range seen in the PSD given in Figure 3.9. In contrast, the treated U-50:50 material analyzed formed a creamy, sticky slurry that was difficult to homogenize relative to the untreated sample. The treated material did not feel as gritty when mixing with the transfer pipette. This observation is consistent with the reduced fraction of $100 \mu \mathrm{m}$ population particles in treated PSD (Figure 3.10) relative to the untreated PSD (Figure 3.9).

A summary of a select number of percentiles is given in Table 3.8 for the two PSD samples. The table provides a brief overview of the particle sizes present and in particular, in the tails of the PSD. Comparison of the SEM images with PSD results provides reasonable agreement.

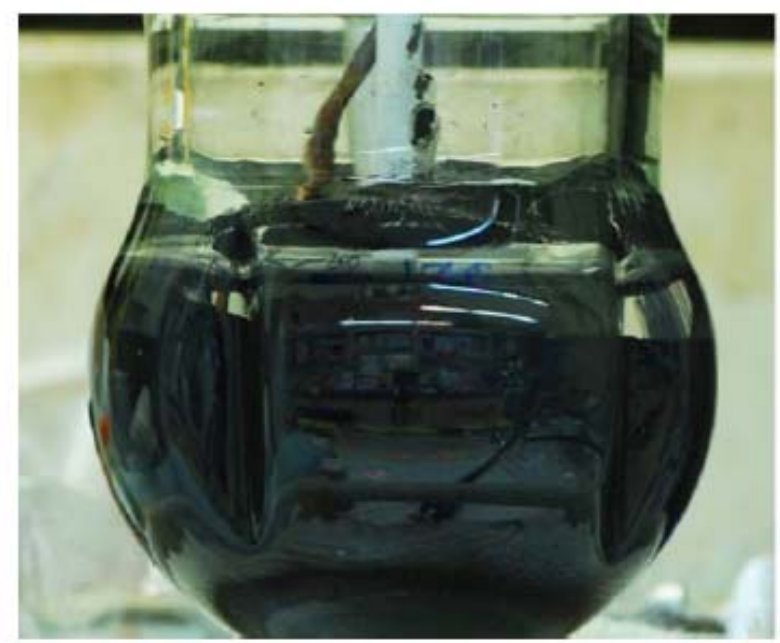

A

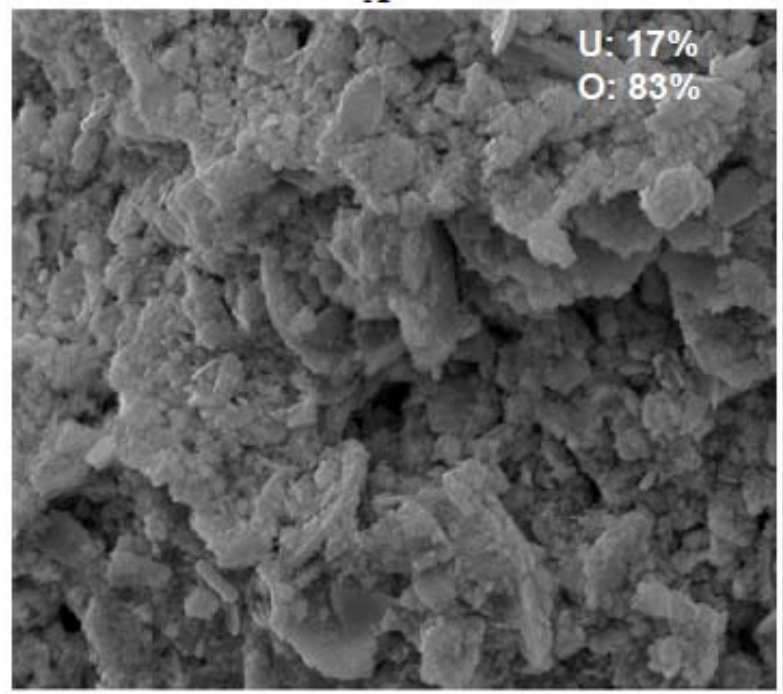

C

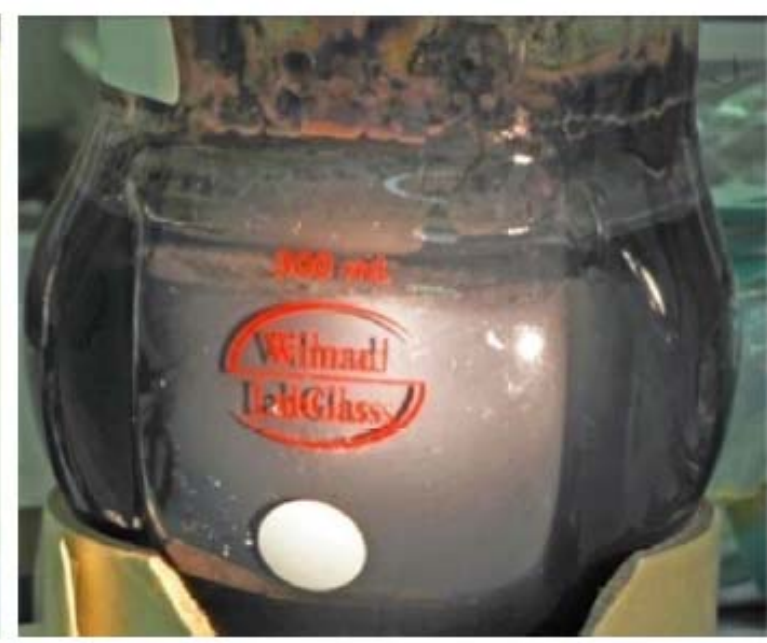

B

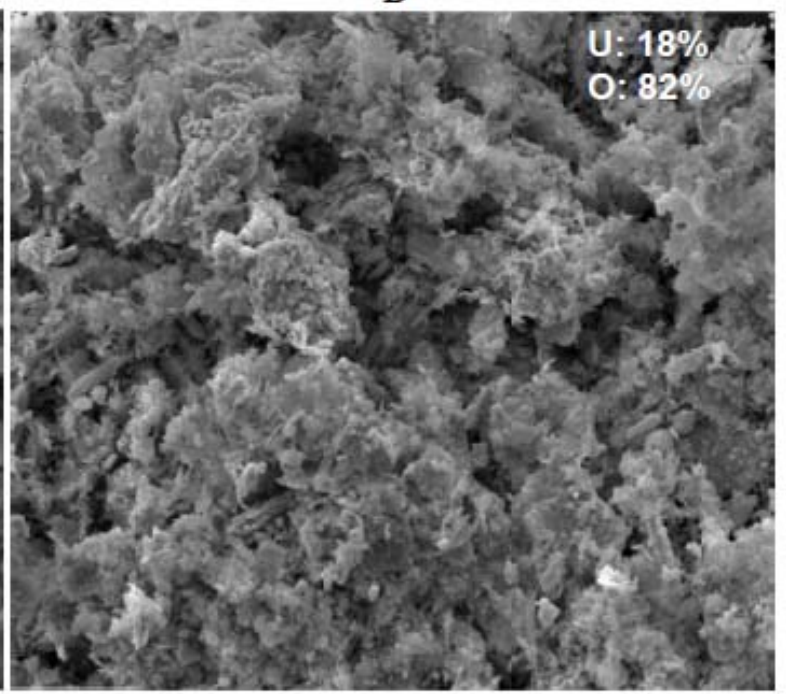

D

Figure 3.8. Photographic and SEM Comparison of Initial and Final Compositions of 50:50 Uranium Oxide Slurry. (a) Photograph of initial oxide slurry; (b) photograph of oxide slurry after 96-hour heating at $95^{\circ} \mathrm{C}$; (c) SEM image of initial oxide slurry at $40 \mu \mathrm{m}$ full width; (d) SEM image of final oxide slurry after 96 -hour heating at $95^{\circ} \mathrm{C}$ at $40 \mu \mathrm{m}$ full width (Note the presence of fine particulate ridges in the final product). 


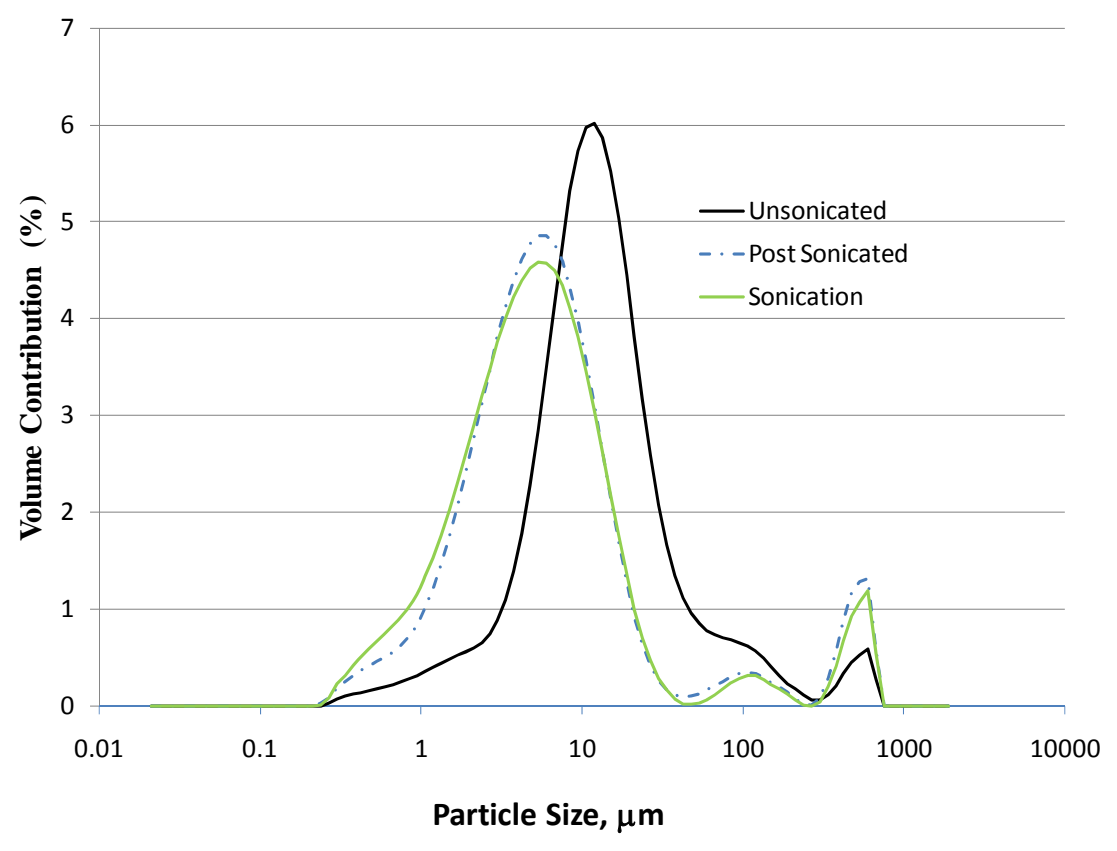

Figure 3.9. Average Volume \% PSD of Sample 50:50 Uranium Oxide Slurry Before WWO Treatment. Figure Note: PSD is based on the average of 9 PSD measurements generated from 3 aliquots of sample PSD U-50:50.

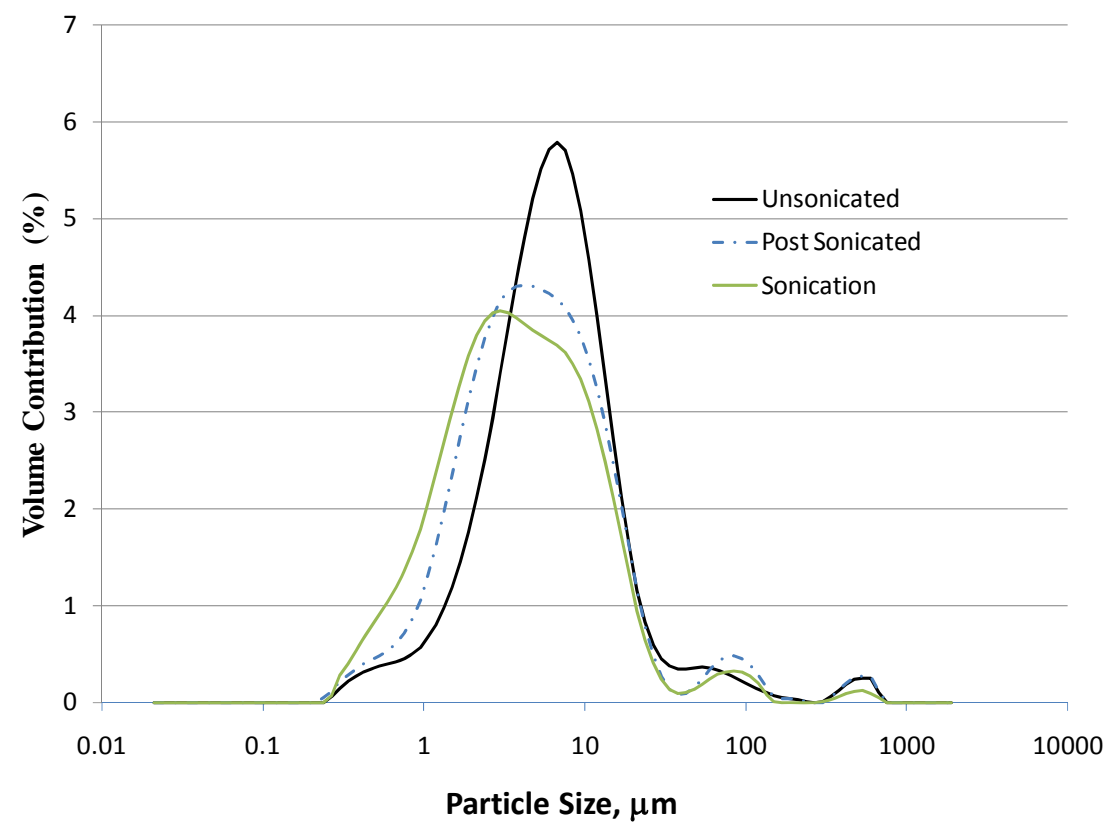

Figure 3.10. Average Volume \% PSD of 50:50 Uranium Oxide Slurry After WWO Treatment ( $96 \mathrm{hr}$ at $95^{\circ} \mathrm{C}$ in stirred reactor). Figure Note: PSD is based on the average of 9 PSD measurements generated from 3 aliquots of sample PSD U-50:50 Final. 
Table 3.8. Summary of Selected Percentile Values Describing Particle Size Distribution

\begin{tabular}{|c|c|c|c|c|c|c|}
\hline \multirow{2}{*}{ Percentile } & \multicolumn{3}{|c|}{$\begin{array}{c}\text { Before WWO, } \mu \mathrm{m} \\
\text { (PSD U-50:50 Initial) }\end{array}$} & \multicolumn{3}{|c|}{$\begin{array}{l}\text { After WWO Treatment, } \mu \mathrm{m} \\
\text { (PSD U-50:50 Final) }\end{array}$} \\
\hline & $\begin{array}{l}\text { 1-min } \\
\text { Recirc. }\end{array}$ & Sonication & $\begin{array}{c}\text { Post } \\
\text { Sonication }\end{array}$ & $\begin{array}{l}\text { 1-min } \\
\text { Recirc. }\end{array}$ & Sonication & $\begin{array}{c}\text { Post } \\
\text { Sonication }\end{array}$ \\
\hline $\mathrm{d}(0.01)$ & 0.64 & 0.39 & 0.42 & 0.45 & 0.38 & 0.40 \\
\hline $\mathrm{d}(0.05)$ & 2.1 & 0.77 & 0.96 & 1.17 & 0.65 & 0.89 \\
\hline $\mathrm{d}(0.10)$ & 3.9 & 1.23 & 1.52 & 1.88 & 0.97 & 1.34 \\
\hline $\mathrm{d}(0.50)$ & 12.0 & 5.08 & 5.48 & 6.15 & 3.83 & 4.79 \\
\hline $\mathrm{d}(0.90)$ & 49.7 & 20.3 & 27.2 & 17.6 & 14.7 & 17.3 \\
\hline $\mathrm{d}(0.95)$ & 110 & 319 & 413 & 33.0 & 21.3 & 40.6 \\
\hline $\mathrm{d}(0.99)$ & 546 & 605 & 608 & 409 & 106 & 431 \\
\hline
\end{tabular}





\subsection{Conclusions}

\subsection{Laboratory-Scale Scoping Tests}

In the laboratory-scale scoping tests, heating at $95^{\circ} \mathrm{C}$ for 4 days resulted in physicochemical changes to both the uranium oxide simulant and the KW container sludge simulant. Color changes, possibly indicative of phase or particle size changes, were observed after heating. These observations were made for the 22 parametric laboratory-scale tests and for the two bench-scale, overhead-stirred tests.

After heating, agglomeration and significant increase in strength were observed for the 50:50 $\mathrm{UO}_{2}: \mathrm{UO}_{3} \cdot 2 \mathrm{H}_{2} \mathrm{O}$ material in static, laboratory-scale scoping Tests 20 through 23 . Physical changes were evident within 24 hours of heating. However, much of the agglomerate structure could be eroded with aggressive spatula mixing or partially eroded with further agitation. This is in agreement with observations made of agitated 50:50 UO $\mathrm{UO}_{2}: \mathrm{UO}_{3} \cdot 2 \mathrm{H}_{2} \mathrm{O}$ material in Tests 8 through 11 , where all solids were eroded to fine particulates over the course of the 96-hour heating.

Under the conditions tested, the KW container sludge simulant did not form agglomerates of significant strength. In many instances, the solid dispersed to the supernatant phase. Adding sodium hydroxide expedited the solids dispersion, whereas sodium phosphate largely retarded solids dispersion. Based on these contrasting solids behaviors, it appears that the solution anion plays a more significant role in solids constitution than the solution $\mathrm{pH}$, which changed from the target $\mathrm{pH} 12$ at the beginning of testing to 7.5 to 9.5 values observed for tests without $\mathrm{pH}$ amendment. At the same time, the increased dispersion of fines provided no substantial improvements with respect to uranium metal corrosion rates or mitigation of agglomerate formation.

The uranium metal oxidation rates observed in the laboratory-scale tests were generally consistent with the predicted nominal Sludge Technical Databook (Schmidt 2010) rate at $95^{\circ} \mathrm{C}$, and the rates were not significantly affected by agitation or $\mathrm{pH}$ adjustment. While the uranium metal oxidation rates in tests with the KW simulant were a factor of 1.4 to 1.7 greater than the expected Databook rate, this increase falls well within the uncertainty on the Databook rate ( \pm a factor of 3 ). The corrosion of uranium metal in the $50: 50 \mathrm{UO}_{2}: \mathrm{UO}_{3} \cdot 2 \mathrm{H}_{2} \mathrm{O}$ slurry was about 1.1 times the Databook rate, indicating that the 50:50 mixture has little impact on the corrosion chemistry of uranium metal. The $\sim 1.7$-fold corrosion rate increase in uranium metal oxidation found for the KW container sludge simulant suggests that a simulant component, potentially ferrihydrite, serves as a redox shuttle or as a redox agent to facilitate the oxidation of uranium metal.

Overall, the laboratory-scale testing showed that the sludge solids that formed in 96 hours of $\sim 95^{\circ} \mathrm{C}$ heating were weak, regardless of agitation and $\mathrm{pH}$ adjustment. The simulant representative of settler tank sludge and prepared from 50:50 uraninite:metaschoepite exhibited greater strength than the multi-component simulant prepared to emulate KW containerized sludge. However, neither presented a significant challenge to re-suspension. Agitation did not increase the uranium metal corrosion rate. Of all test conditions evaluated, the greatest corrosion rates were observed for non-agitated KW simulant (about 1.7 times the rate predicted by the Databook). The lowest corrosion rate observed occurred in tests conducted with the 50:50 U oxide slurry under agitated conditions (0.9 times the Databook rate). Oxidation rates for all experiments are well within the uncertainty on the Databook rate ( \pm a factor of 3 ). 
For $\mathrm{K}$ Basin samples where there is a significant presence of $50: 50 \mathrm{UO}_{2}: \mathrm{UO}_{3} \cdot 2 \mathrm{H}_{2} \mathrm{O}$, agitation is recommended to prevent the agglomerate formation of notable strength. However, even without agitation, the agglomerates formed from 50:50 UO $\mathrm{UO}_{2}: \mathrm{UO}_{3} \cdot 2 \mathrm{H}_{2} \mathrm{O}$ in the laboratory-scale tests were easily dispersed. Even under extended soak times (simulating an unexpected halt in processing), $\mathrm{KW}$ simulant agglomerates still slumped. Agglomerates may form in static systems with high 50:50 $\mathrm{UO}_{2}: \mathrm{UO}_{3} \cdot 2 \mathrm{H}_{2} \mathrm{O}$ content, but agitation can break up agglomerates once they have formed.

The observed solids rheology and U metal oxidation rates near to Databook rates in the case of the 50:50 simulant and 1.4- to 1.7 times the Databook rate for the KW simulant indicated that the WWO process was ready for larger scale testing.

\subsection{Bench-Scale Stirred Reactor Testing}

Like the laboratory-scale tests, the bench-scale testing also was performed for 96 hours at $\sim 95^{\circ} \mathrm{C}$. The tests were run in an overhead-stirred, round-bottomed reactor with downward impeller-driven flow and four vertical baffles added to enhance mixing and diminish vortexing. Impeller clearance at the reactor bottom was minimized to help decrease regions of low shear (so-called "dead" zones). This tested stirred reactor system was more prototypic of WWO flowsheet process design in comparison to the configuration used from the laboratory-scale scoping tests.

During testing, a region of low or no simulant particulate movement was observed to be present just under the impeller in the KW simulant test. As a result, a small lens of compact solid material (simulant agglomerate) formed and was found to have a consistency that is described as stiff to very stiff in soil mechanics, corresponding to a shear strength of 100 to $200 \mathrm{kPa}$. Because sludge above this level underwent greater shear rates, it remained fluid and slumped readily during post-test evaluations. Therefore, better mixing, perhaps by a close-clearance mixing, is suggested to maintain fluid sludge movement in KW simulant-like materials to minimize agglomeration. The greater density of the 50:50 $\mathrm{UO}_{2}: \mathrm{UO}_{3} \cdot 2 \mathrm{H}_{2} \mathrm{O}$ slurry required a decrease in solids volume from $15 \%$ to $12 \%$. This decrease in solids volume allowed the 50:50 slurry to remain fluid throughout the entire test duration.

In the two bench-scale tests, the uranium metal corrosion rates for the KW simulant and the 50:50 sludge were comparable with the rates observed in the analogous laboratory-scale tests. The uranium metal in the 50:50 simulant corroded at rates near those projected by the Sludge Treatment Project (STP) rate law. The uranium metal in the KW simulant corroded at rates about 1.6 times that of the rate law (at $95^{\circ} \mathrm{C}$ ). The uranium corrosion rate observations for the two simulants at two different scales support the use of a rate enhancement factor of 1 for the WWO preconceptual flowsheet.

To help understand the reasons for the differing corrosion rate behavior between the two simulant matrices, optical photographic and SEM images were gathered of uranium metal beads of the starting uranium metal and the metal after contact with the two simulants. The starting uranium metal beads were found to be smoothly spherical with little surface texture. In contrast, the uranium metal after exposure to the KW simulant had a scalloped surface with small raised strips, and the metal after exposure to the 50:50 simulant was rough and pitted. Although the rougher surface uranium metal from the 50:50 test would be expected to have the greater corrosion rate because of its higher surface area, the greater rate actually was observed for the uranium metal in the KW simulant. The greater rate and the smoother, though scalloped, surface texture of the metal from the KW simulant compared with the 50:50 sludge 
suggests that iron in the form of ferrihydrite in the KW simulant likely was acting as a redox shuttle to both accelerate the uranium metal corrosion reaction and smooth the corroding metal surface. This attribution remains speculative, however.

\subsection{Overall Observations/Conclusions}

Overall, the testing showed that the sludge solids that formed in 96 hours of $\sim 95^{\circ} \mathrm{C}$ heating tended to be weak. However, the exception is that the simulant representative of settler tank sludge prepared from $\sim 50: 50$ uraninite:metaschoepite exhibited greater strength in the laboratory-scale scoping tests than the multi-component simulant prepared to emulate KW containerized sludge from SCS-CON-210 and 220. However, neither simulant presented an overwhelming challenge to re-suspension. Agitation did not increase the uranium metal corrosion rate. Of all test conditions evaluated, the greatest corrosion rates were observed for non-agitated KW simulant in the laboratory-scale scoping tests (about 1.7 times the rate predicted by the Databook). The lowest corrosion rate observed occurred in tests conducted with the 50:50 U oxide slurry under agitated conditions in the laboratory-scale scoping tests $(0.9$ times the Databook rate equation). Oxidation rates for all experiments are well within the uncertainty on the Databook rate ( \pm a factor of 3 ). The rates observed for the larger scale tests with overhead stirring were similar to those observed in the laboratory-scale scoping tests.

Further study of this system is encouraged to:

- target the reaction temperature associated with agglomerate formation,

- evaluate the possible role of ferrihydrite and actual sludge matrices in uranium metal oxidation,

- evaluate additional optimization of the reactor vessel that may include jacketed sidewall heating and close-clearance impeller designs, and

- evaluate longer runs analogous to the full length of time anticipated per sludge batch ( $\sim 130$ days) to scope solids behavior and ensure robustness of prototype mixing vessel. 



\subsection{References}

British Standard. 1999. Code of Practice for Site Investigations. BS 5930:1999, Table 13 and Section 41.3.1, British Standards Institute, London, United Kingdom.

Burbank D. 2010. Sludge Simulant Strategy and Design Basis. PRC-STP-00034, Rev. 1, CH2M HILL Plateau Remediation Company, Richland, Washington.

Burns CA, M Luna, AJ Schmidt. 2009. Characterization of Settler Tank and KW Container Sludge Simulants. PNNL-18408, Pacific Northwest National Laboratory, Richland, Washington.

Clayton CRI, MC Matthews, and NE Simons. 1995. Site Investigation, $2^{\text {nd }}$ edition, chapter 2, pages 7-10, Blackwell Science, Cambridge, Massachusetts. Accessed March 13, 2011, at http://www.geotechnique.info/.

Delegard CH, SI Sinkov, AJ Schmidt, RC Daniel, and CA Burns. 2011. Effect of Time, Heat and Oxygen on K Basin Sludge Agglomeration, Strength and Solids Volume. PNNL-20100, Pacific Northwest National Laboratory, Richland, Washington.

Delegard CH and AJ Schmidt. 2009. Uranium Metal Reaction Behavior in Water, Sludge, and Grout Matrices. PNNL-17815, Rev. 1, Pacific Northwest National Laboratory, Richland, Washington. Accessed December 1, 2010, at http://www.pnl.gov/main/publications/external/technical_reports/PNNL17815rev1.pdf.

Delegard CH, AJ Schmidt, RL Sell, SI Sinkov, SA Bryan, SR Gano, and BM Thornton. 2004. Final Report-Gas Generation Testing of Uranium Metal in Simulated K Basin Sludge and in Grouted Sludge Waste Forms. PNNL-14811, Pacific Northwest National Laboratory, Richland, Washington. Accessed December 1, 2010, at http://www.pnl.gov/main/publications/external/technical_reports/PNNL-14811.pdf.

Delegard CH, AP Poloski, AJ Schmidt, and JW Chenault. 2005. Characterization of Compaction and Dryout Properties of KE Basin Sludge During Long-Term Storage. PNNL-15092, Pacific Northwest National Laboratory, Richland, Washington. Accessed December 1, 2010, at http://www.pnl.gov/main/publications/external/technical_reports/PNNL-15092.pdf.

Delegard CH, AJ Schmidt, and BM Thornton. 2007. Hydrothermal Testing of K Basin Sludge and N Reactor Fuel at Sludge Treatment Project Operating Conditions. PNNL-16496, Pacific Northwest National Laboratory, Richland, Washington. Accessed December 1, 2010, at http://www.pnl.gov/main/publications/external/technical_reports/PNNL-16496.pdf.

Ginder-Vogel M, CS Criddle, and S Fendorf. 2006. "Thermodynamic Constraints on the Oxidation of Biogenic $\mathrm{UO}_{2}$ by $\mathrm{Fe}(\mathrm{III})$ (hydr)oxides.” Environmental Science and Technology 40:3544-3550.

Hagerty K. 2010. AREVA Test Plan for Warm Water Oxidation Flowsheet Verification. PLN-3003760-001, AREVA Federal Services, LLC, Richland, Washington.

Hill SR. 2010. Consolidation of K Basin Sludge Data and Experiences on Agglomerate Formation. PRC-STP-00274, Rev. 1, CH2M Hill Plateau Remediation Company, Richland, Washington. 
Makenas BJ, TL Welsh, RB Baker, DR Hansen, and GR Golcar. 1996. Analysis of Sludge from Hanford K East Basin Floor and Weasel Pit. WHC-SP-1182, Westinghouse Hanford Company, Richland, Washington.

Makenas BJ, TL Welsh, RB Baker, EW Hoppe, AJ Schmidt, J Abrefah, JM Tingey, PR Bredt, and GR Golcar. 1997. Analysis of Sludge from Hanford K East Basin Canisters. HNF-SP-1201, Duke Engineering and Services Hanford, Inc., Richland, Washington.

Makenas BJ, TL Welsh, RB Baker, GR Golcar, PR Bredt, AJ Schmidt, and JM Tingey. 1998. Analysis of Sludge from Hanford K West Basin Canisters. HNF-1728, Rev. 0, Fluor Daniel Hanford, Richland, Washington.

Mollison WA, GC English, and F Nelson. 1945. Corrosion of Uranium in Distilled Water. CT-3055, University of Chicago, Chicago, Illinois.

Olsson M, AM Jakobsson, and Y Albinsson. 2002. "Surface Charge Densities of Two Actinide(IV) Oxides: $\mathrm{UO}_{2}$ and $\mathrm{ThO}_{2}$." Journal of Colloid and Interface Science 256:256-261.

Onishi Y, EBK Baer, J Chun, ST Yokuda, AJ Schmidt, SA Sande, and WC Buchmiller. 2011. Development of K-Basin High-Strength Homogeneous Sludge Simulants and Correlations Between Unconfined Compressive Strength and Shear Strength. PNNL-20048, Pacific Northwest National Laboratory, Richland, Washington. Accessed March 15, 2011, at http://www.pnl.gov/main/publications/external/technical_reports/PNNL-20048.pdf.

Plys MG and AJ Schmidt. 2009. Supporting Basis for Spent Nuclear Fuel Project Sludge Technical Databook. SNF-7765, Rev. 3D, CH2M Hill Plateau Remediation Company, Richland, Washington.

Purolite. 2007. "Product Data Sheets for NRW37, NRW100, and NRW400." The Purolite Company, Bala Cynwyd, Pennsylvania. Accessed November 11, 2010, at http://www.purolite.com/RelId/606306/ProductID/161/isvars/default/productzoom.htm (NRW37, mixed bed); http://www.purolite.com/RelId/606306/ProductID/49/isvars/default/productzoom.htm (NRW100, cation); and http://www.purolite.com/RelId/606306/ProductID/44/isvars/default/productzoom.htm (NRW400, anion).

Ramachandran CE, BA Williams, JA van Bokhoven, and JT Miller. 2005. "Observation of a Compensation Relation for $n$-hexane Adsorption in Zeolites with Different Structures: Implications for Catalytic Activity." Journal of Catalysis 233:100-108.

Rivas Mercury JM, P Pena, AH de Aza, D Sheptyakov, and X Turrillas. 2006. "On the Decomposition of Synthetic Gibbsite Studied by Neutron Thermodiffractometry." Journal of the American Ceramic Society 89(12):3728-3733.

Russell RL, DE Rinehart, PA Gauglitz, J Chun and AJ Schmidt. 2010. Results of Kaolin Clay Slump Testing. PNNL-19713, Pacific Northwest National Laboratory, Richland, Washington.

Schmidt AJ. 2010. Spent Nuclear Fuel Project Technical Databook, Vol 2, Sludge. HNF-SD-SNF-TI-015, Revision 14B, Fluor Hanford Company, Richland, Washington. 
Schmidt AJ, CH Delegard, SA Bryan, MR Elmore, RL Sell, KL Silvers, SR Gano, and BM Thornton. 2003. Gas Generation from K East Basin Sludges and Irradiated Metallic Uranium Fuel Particles - Series III Testing. PNNL-14346, Pacific Northwest National Laboratory, Richland, Washington. Accessed December 1, 2010, at http://www.pnl.gov/main/publications/external/technical_reports/PNNL-14346.pdf.

Sinkov SI, CH Delegard, and AJ Schmidt. 2008. Preparation and Characterization of Uranium Oxides in Support of the K Basin Sludge Treatment Project. PNNL-17678, Pacific Northwest National Laboratory, Richland, Washington. Accessed December 1, 2010, at http://www.pnl.gov/main/publications/external/technical_reports/PNNL-17678.pdf.

Sinkov SI, CH Delegard, and AJ Schmidt. 2010. Mitigation of Hydrogen Gas Generation from the Reaction of Water with Uranium Metal in K Basin Sludge. PNNL-19135, Pacific Northwest National Laboratory, Richland, Washington. Accessed December 1, 2010, at http://www.pnl.gov/main/publications/external/technical_reports/PNNL-19135.pdf.

Sowder AG, SB Clark, and RA Fjeld. 1999. "The Transformation of Uranyl Oxide Hydrates: The Effect of Dehydration on Synthetic Metaschoepite and Its Alteration to Becquerelite." Environmental Science and Technology 33(20):3552-3557.

Wells BE, CW Enderlin, PA Gauglitz, and RA Peterson. 2009. Assessment of Jet Erosion for Potential Post-Retrieval K-Basin Settled Sludge. PNNL-18831, Pacific Northwest National Laboratory, Richland, Washington. Accessed March 14, 2011, at http://www.pnl.gov/main/publications/external/technical_reports/PNNL-18831.pdf. 

Appendix A

Summary of Operating Steps for Laboratory-Scale Warm Water Oxidation Tests 



\section{Appendix A - Summary of Operating Steps for Laboratory-Scale Warm Water Oxidation Tests}

Testing was conceived, planned, approved, and executed during a less than 2-week time window, and existing test material was used. The test approach selected (see below) was appropriate to achieve the testing objectives within the time constraints.

- Label twenty-nine, $50 \mathrm{~mL}$, screw-cap tops with centrifuge cones and flattened bottoms as Test 1 through 24 and Control 1 through 5. Tare-weigh the cones and note the tare weights and date in the Log Sheet.

- Stir the thickened $\mathrm{UO}_{2} / \mathrm{UO}_{3} \cdot 2 \mathrm{H}_{2} \mathrm{O}$ slurry from the bottom to make it homogeneous. Add $\sim 5 \mathrm{~g}$ $(\sim 3.3 \mathrm{~mL})$ of thickened $\mathrm{UO}_{2} / \mathrm{UO}_{3} \cdot 2 \mathrm{H}_{2} \mathrm{O}$ slurry and reweigh for tests that will only contain the 50:50 uranium slurry. For tests that will contain the KW simulant, add $\sim 1.3 \mathrm{~g}$ of thickened $\mathrm{UO}_{2} / \mathrm{UO}_{3} \cdot 2 \mathrm{H}_{2} \mathrm{O}$ slurry. Record the weights and the balance information.

- Add DIW to all tests to provide a $25 \mathrm{~mL}$ total volume. Shake cones to mix contents and rotate the cones to wash down the walls and settle the solids overnight.

- Collect $\sim 0.5 \mathrm{~mL}$ of supernatant solution from each test cone and place into labeled vials.

- Measure and record the weights of each test cone and the settled solids and total (upper water) volumes.

- Introduce Tests 1 through 11 and 13 through 23 into the MultiTherm Shaker or the oven. Adjust the temperature to $95^{\circ} \mathrm{C}$; begin agitation and record the date and time.

- On at least a daily basis, record the temperature (average temperature will be determined at the end of testing). Also record settled-solids volume levels in each tube and make sure that supernatant water and water-bath levels are maintained. Add water as necessary.

- After at least 4 days of heating, remove the test items from the heat. Upon cooling, weigh each item and record solids and water levels with weights.

- Capture photographic images of the test items as deemed appropriate by the Cognizant scientist. Print and include in the test instruction as appropriate.

- Remove a $\sim 0.5 \mathrm{~mL}$ portion of solution from each heated test and add to labeled vials.

- Using a spatula or other device, probe the solids in each centrifuge cone (including the control tests) and record observations of the strengths of solids. Also examine the slumping characteristics.

- Measure the $\mathrm{pH}$ of the "before" and "after" solutions collected and record the data.

- For tests intended for oxidation analysis, dissolve solids using 8 to $10 \mathrm{~mL}$ of $85 \%$ $\mathrm{Na}_{3} \mathrm{PO}_{4} / 0.14 \mathrm{Na}_{2} \mathrm{SO}_{4}$ solution and heat to $80^{\circ} \mathrm{C}$. Once all solids except the sand and ion exchange resin have dissolved, remove the solution and analyze it using UV-Vis for U(IV):U(VI) ratios.

- Hand-select uranium metal beads from the remaining ion exchange resin and sand. Weigh the collected uranium metal and calculate penetration rates based on the difference between the initial mass and the final mass.

- Tests not participating in oxidation analysis will continue to settle for an additional 2 weeks at either ambient or heated conditions as prescribed by the test instruction. At the end of the settling, analyze the solids composition through poke and slump tests. 



\section{Appendix B}

\section{Photographs of Test Items Before Initiation of Heating}

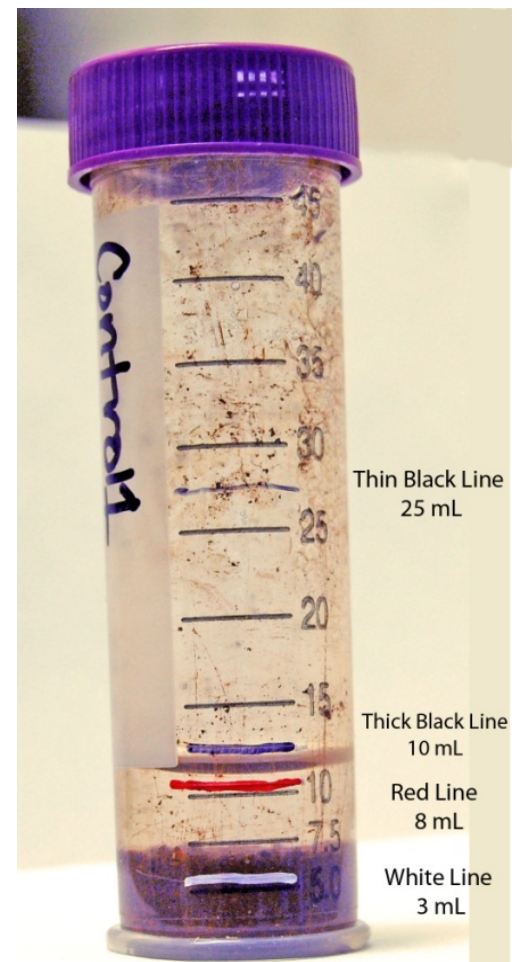

Note: The markings on the centrifuge tubes in these photos in this appendix indicate new calibration points for the vessel as determined with calibrated pipettes. The white line indicates the anticipated volume of the simulated sludge. The red line indicates the initial fill volume. The thick black line indicates the initial fill volume suggested for these tests. The thin black line indicates the final fill volume used. 



\section{Appendix B - Photographs of Test Items Before Initiation of Heating}

Note: Test identification numbers appear in each photograph. These test identification numbers correspond to the test matrix conditions as shown in Table B.1.

Table B.1. Test Matrix for Warm Water Treatment Laboratory-Scale Scoping Study-Effects of Agitation and $\mathrm{pH}$ on Agglomeration and Uranium Metal Oxidation

\begin{tabular}{|c|c|c|c|c|c|c|}
\hline \multicolumn{7}{|c|}{ MultiTherm Run \#1-All samples agitated and heated to $95^{\circ} \mathrm{C}$ for 96 hours. } \\
\hline Smpl ID\# & Matrix $^{(a)}$ & pH Adj. & Slump Test \#1 & Slump Test \#2 & Reagitation? & U Metal Analysis \\
\hline 1 & KW Simulant & No & Post 96 hours & No & No & Post 96 hours \\
\hline 2 & KW Simulant & No & No & Post 2 wk at 95 & Yes & No \\
\hline 3 & KW Simulant & $\mathrm{NaOH}: 12$ & Post 96 hours & No & No & Post 96 hours \\
\hline 4 & KW Simulant & $\mathrm{NaOH}: 12$ & No & Post 2 wk at 95 & Yes & No \\
\hline 5 & KW Simulant & No & No & Post $2 w k$ at 25 & Yes & No \\
\hline 6 & KW Simulant & $\mathrm{NaOH}: 12$ & No & Post 2 wk at 25 & Yes & No \\
\hline 7 & KW Simulant & $\mathrm{Na}_{3} \mathrm{PO}_{4}: 12$ & Post 96 hours & No & No & Post 96 hours \\
\hline 8 & $50: 50 \mathrm{UO}_{2} / \mathrm{UO}_{3}$ & No & Post 96 hours & No & No & Post 96 hours \\
\hline 9 & $50: 50 \mathrm{UO}_{2} / \mathrm{UO}_{3}$ & No & No & Post 2 wk at 95 & Yes & No \\
\hline 10 & $50: 50 \mathrm{UO}_{2} / \mathrm{UO}_{3}$ & $\mathrm{NaOH}: 12$ & Post 96 hours & No & No & Post 96 hours \\
\hline 11 & $50: 50 \mathrm{UO}_{2} / \mathrm{UO}_{3}$ & No & No & Post $2 w k$ at 25 & Yes & No \\
\hline 12 & $\mathrm{TC}$ & - & - & - & - & - \\
\hline \multicolumn{7}{|c|}{ MultiTherm Run \#2-No samples agitated. All samples heated to $95^{\circ} \mathrm{C}$ for 96 hours. } \\
\hline Smpl ID\# & Matrix $^{(a)}$ & pH Adj. & Slump Test \#1 & Slump Test \#2 & Reagitation? & U Metal Analysis \\
\hline 13 & KW Simulant & No & Post 96 hours & No & OIA $^{(\mathrm{b})}$ & Post 96 hours \\
\hline 14 & KW Simulant & No & No & Post 2 wk at 95 & Yes & No \\
\hline 15 & KW Simulant & $\mathrm{NaOH}: 12$ & Post 96 hours & No & OIA $^{(\mathrm{b})}$ & Post 96 hours \\
\hline 16 & KW Simulant & $\mathrm{NaOH}: 12$ & No & Post 2 wk at 95 & Yes & No \\
\hline 17 & KW Simulant & No & No & Post 2 wk at 25 & Yes & No \\
\hline 18 & KW Simulant & $\mathrm{NaOH}: 12$ & No & Post $2 w k$ at 25 & Yes & No \\
\hline 19 & KW Simulant & $\mathrm{Na}_{3} \mathrm{PO}_{4}: 12$ & Post 96 hours & No & OIA $^{(\mathrm{b})}$ & Post 96 hours \\
\hline 20 & $50: 50 \mathrm{UO}_{2} / \mathrm{UO}_{3}$ & No & Post 96 hours & No & OIA $^{(b)}$ & Post 96 hours \\
\hline 21 & $50: 50 \mathrm{UO}_{2} / \mathrm{UO}_{3}$ & No & No & Post 2 wk at 95 & Yes & No \\
\hline 22 & $50: 50 \mathrm{UO}_{2} / \mathrm{UO}_{3}$ & $\mathrm{NaOH}: 12$ & Post 96 hours & No & OIA $^{(\mathrm{b})}$ & Post 96 hours \\
\hline 23 & $50: 50 \mathrm{UO}_{2} / \mathrm{UO}_{3}$ & No & No & Post 2 wk at 25 & Yes & No \\
\hline 24 & $\mathrm{TC}$ & - & - & - & - & - \\
\hline \multicolumn{7}{|c|}{ Run \#1 and \#2 ambient temperature controls (No heating OR agitation). Only reagitate if agglomerated. } \\
\hline Smpl ID\# & Matrix $^{(a)}$ & pH Adj. & Slump Test \#1 & Slump Test \#2 & Reagitation? & U Metal Analysis \\
\hline Control 1 & KW Simulant & No & Post 96 hours & Post $2 \mathrm{wk}$ & - & No \\
\hline Control 2 & KW Simulant & $\mathrm{NaOH}: 12$ & Post 96 hours & Post $2 \mathrm{wk}$ & - & No \\
\hline Control 3 & KW Simulant & $\mathrm{Na}_{3} \mathrm{PO}_{4}: 12$ & Post 96 hours & Post $2 \mathrm{wk}$ & - & No \\
\hline Control 4 & $50: 50 \mathrm{UO}_{2} / \mathrm{UO}_{3}$ & No & Post 96 hours & Post $2 w k$ & - & No \\
\hline Control 5 & $50: 50 \mathrm{UO}_{2} / \mathrm{UO}_{3}$ & $\mathrm{NaOH}: 12$ & Post 96 hours & Post 2wk & - & No \\
\hline
\end{tabular}




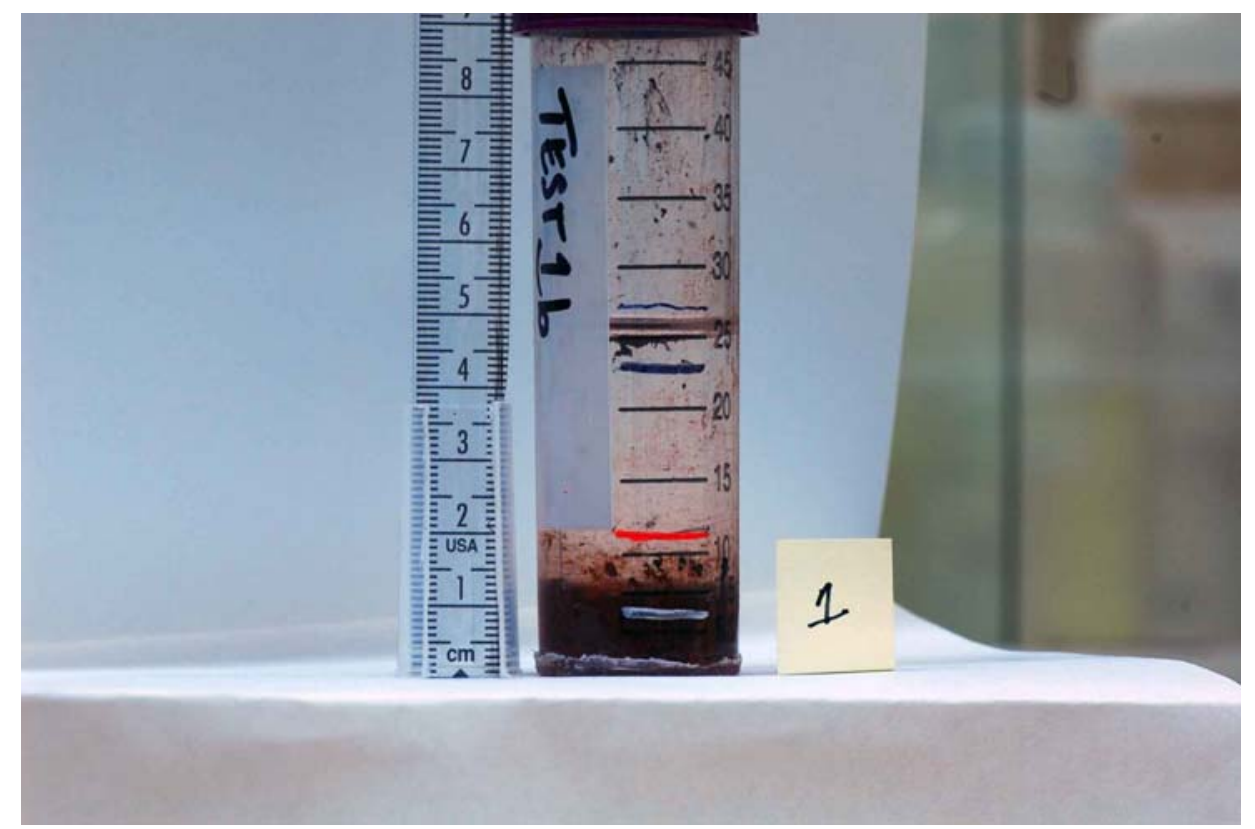

Figure B.1. Agitated-No $\mathrm{pH}$ Adjustment-KW Simulant

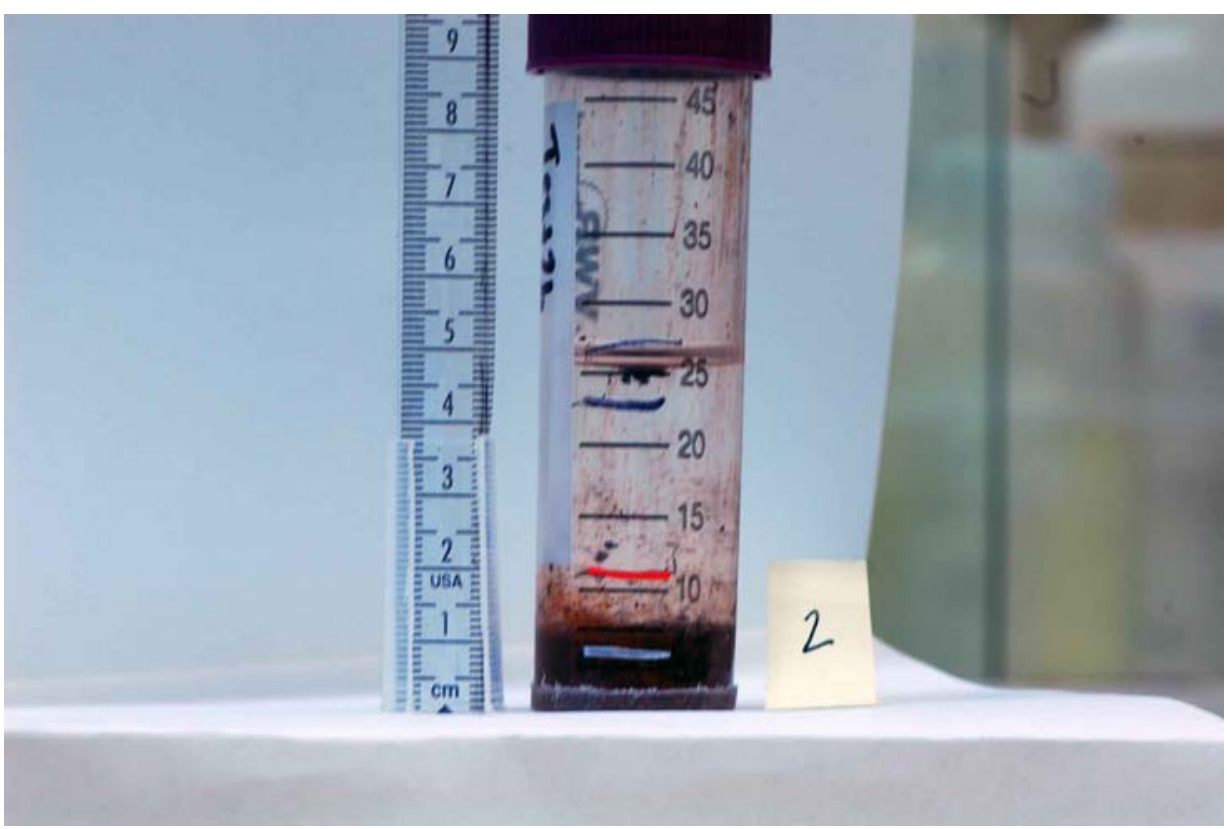

Figure B.2. Agitated-No pH Adjustment-KW Simulant 


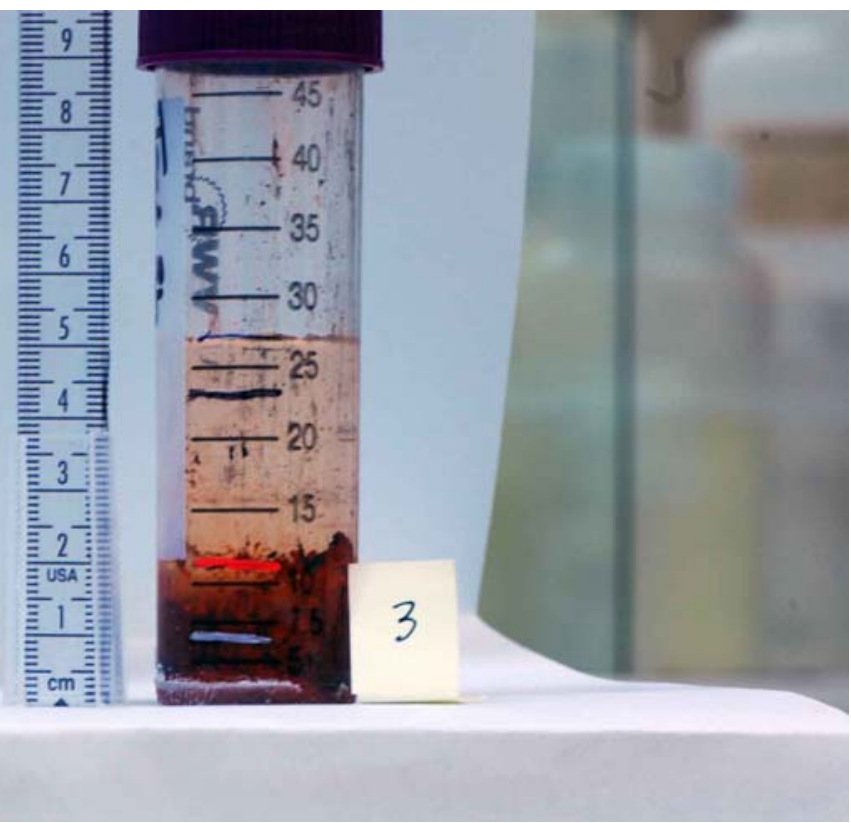

Figure B.3. Agitated-Solution $\mathrm{pH}$ Raised to 12 Using $\mathrm{NaOH}-\mathrm{KW}$ Simulant

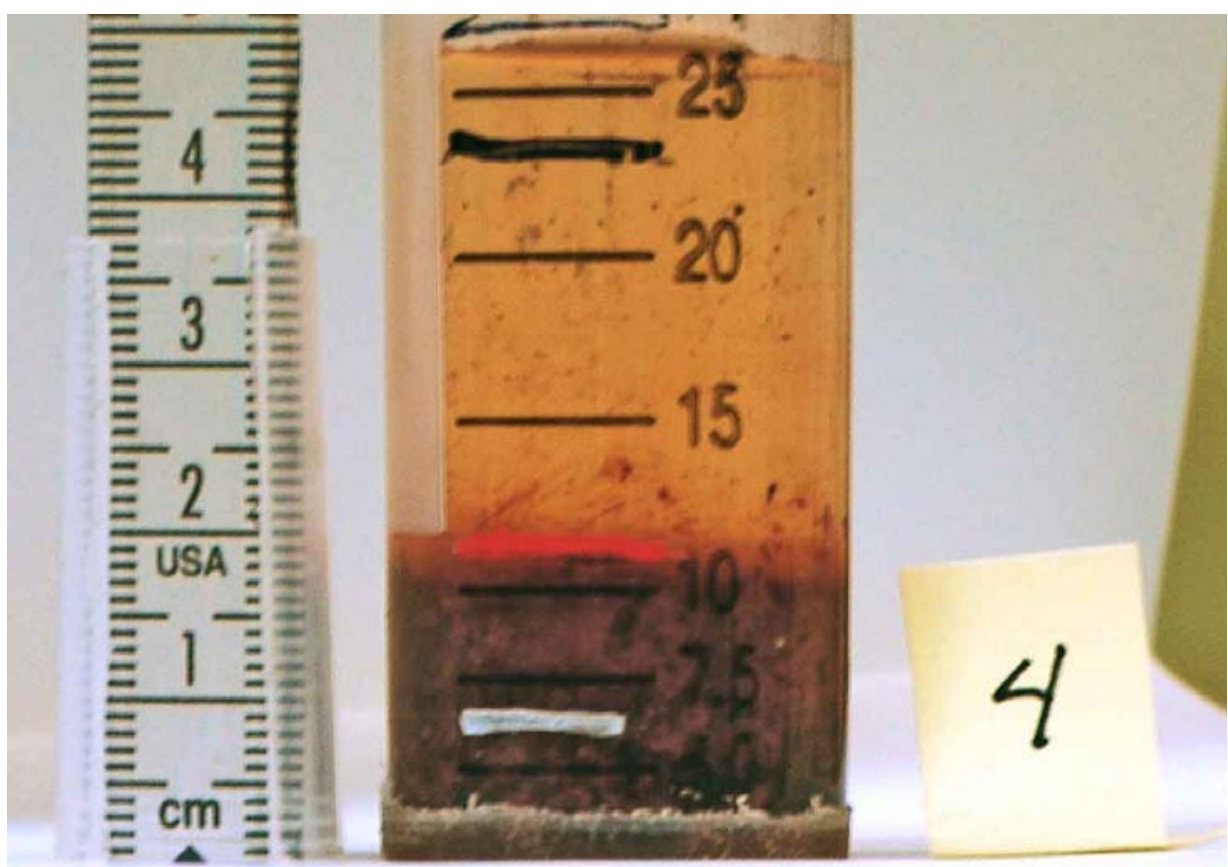

Figure B.4. Agitated-Solution $\mathrm{pH}$ Raised to 12 Using $\mathrm{NaOH}-\mathrm{KW}$ Simulant 


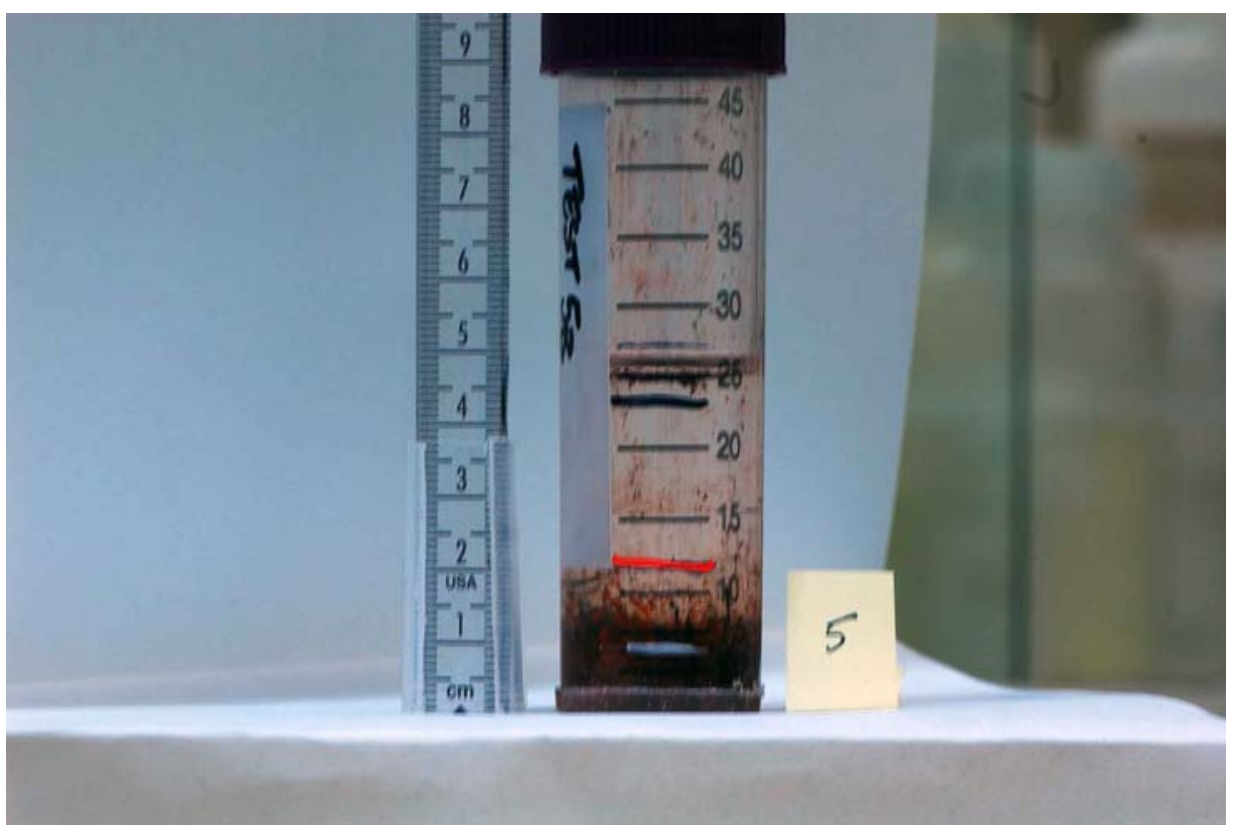

Figure B.5. Agitated-No pH Adjustment-KW Simulant

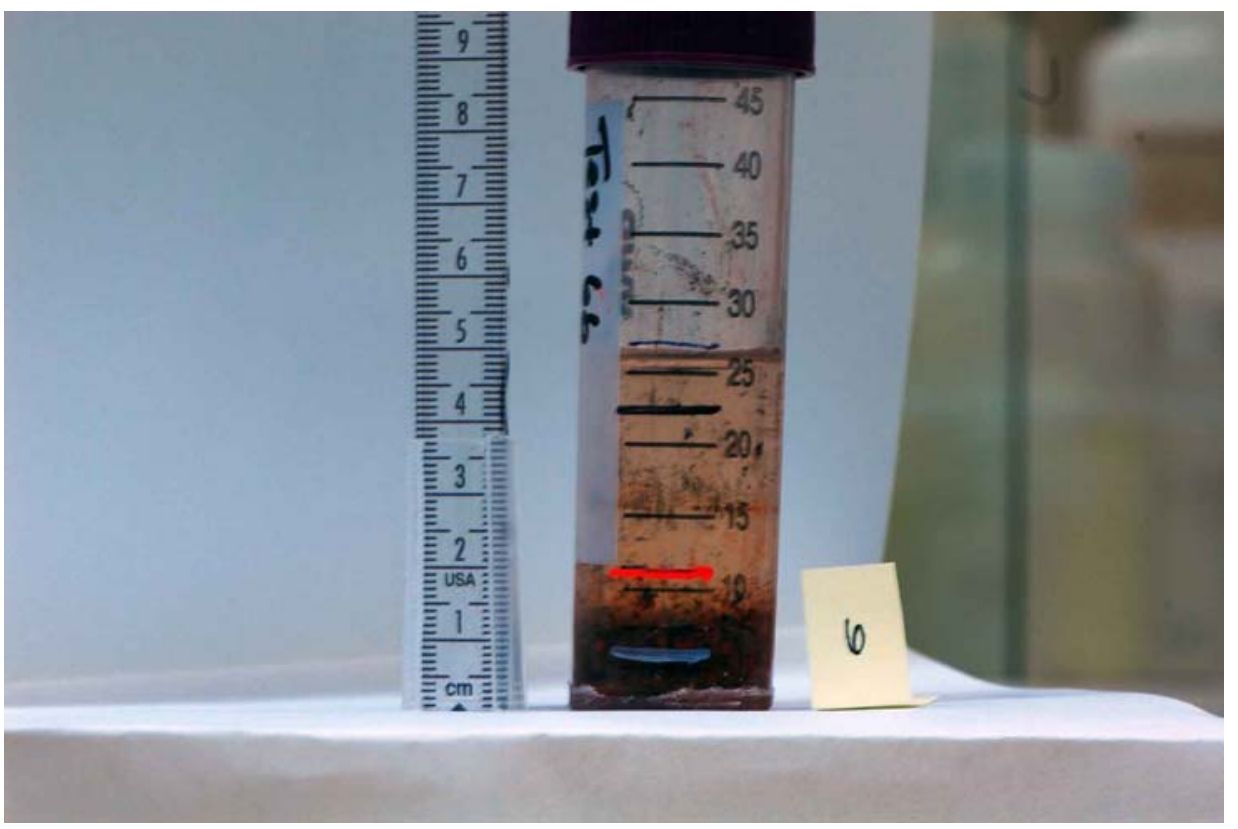

Figure B.6. Agitated - Solution $\mathrm{pH}$ Raised to $12 \mathrm{Using} \mathrm{NaOH}-\mathrm{KW}$ Simulant 


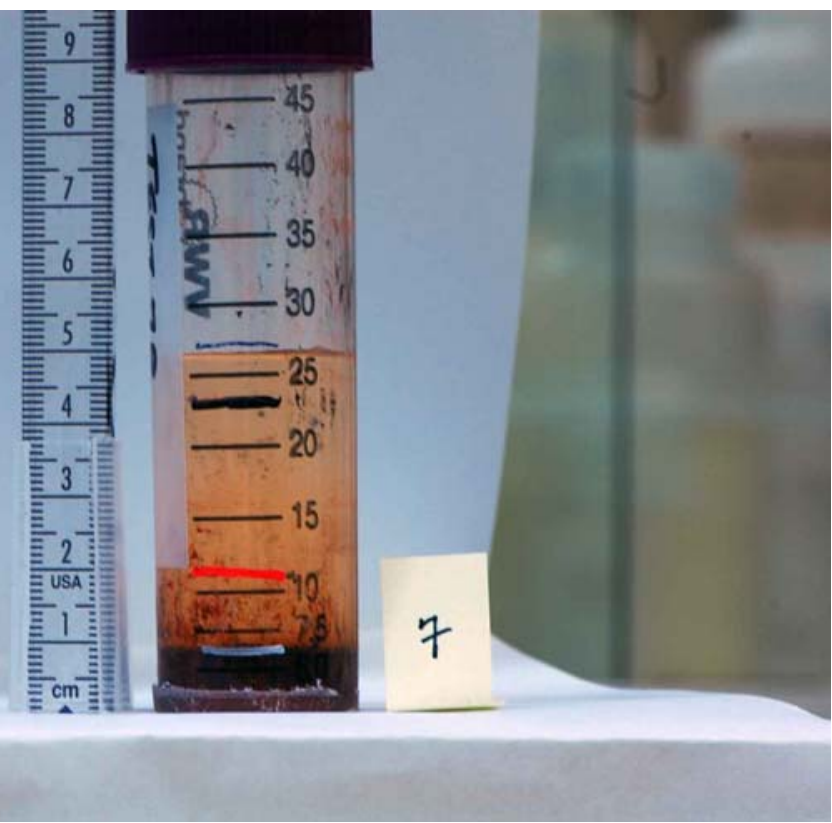

Figure B.7. Agitated-Solution $\mathrm{pH}$ Raised to 12 Using $\mathrm{Na}_{3} \mathrm{PO}_{4}-\mathrm{KW}$ Simulant

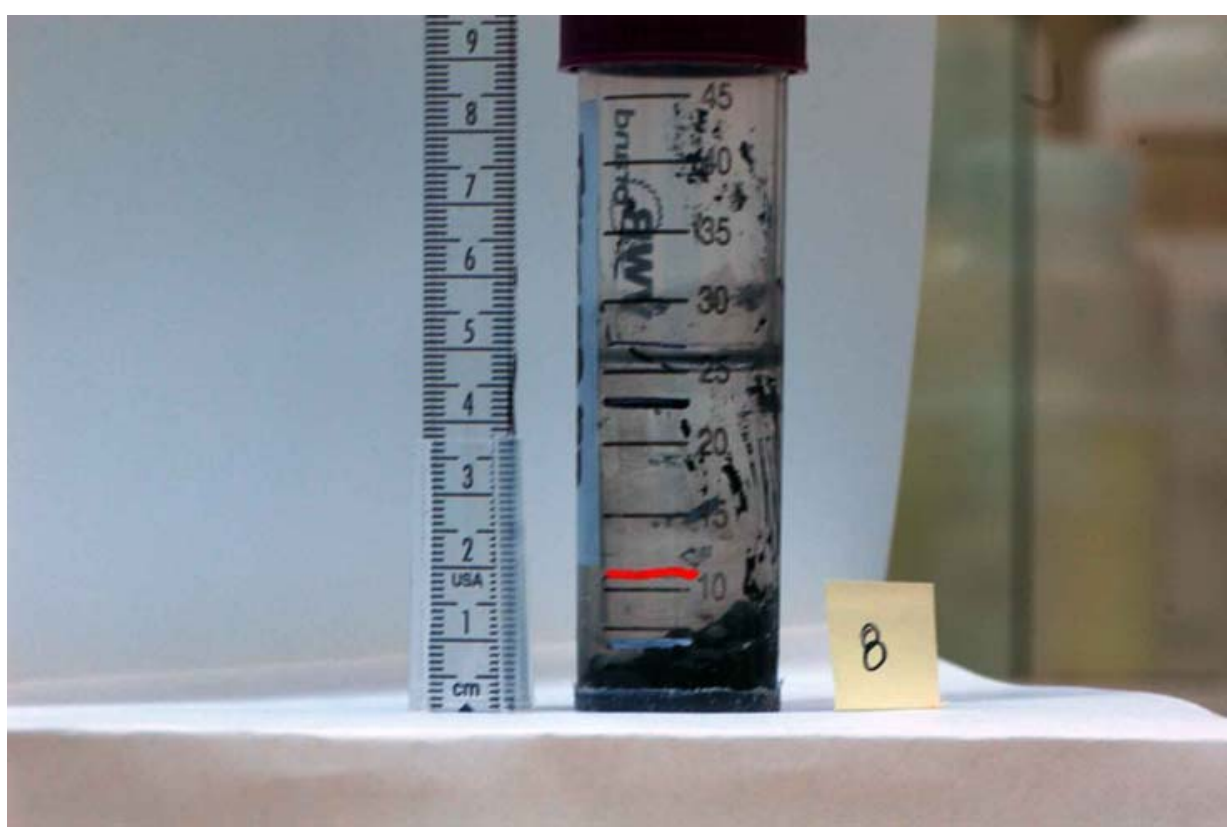

Figure B.8. Agitated-No pH Adjustment-50:50 Uranium Oxide Slurry 


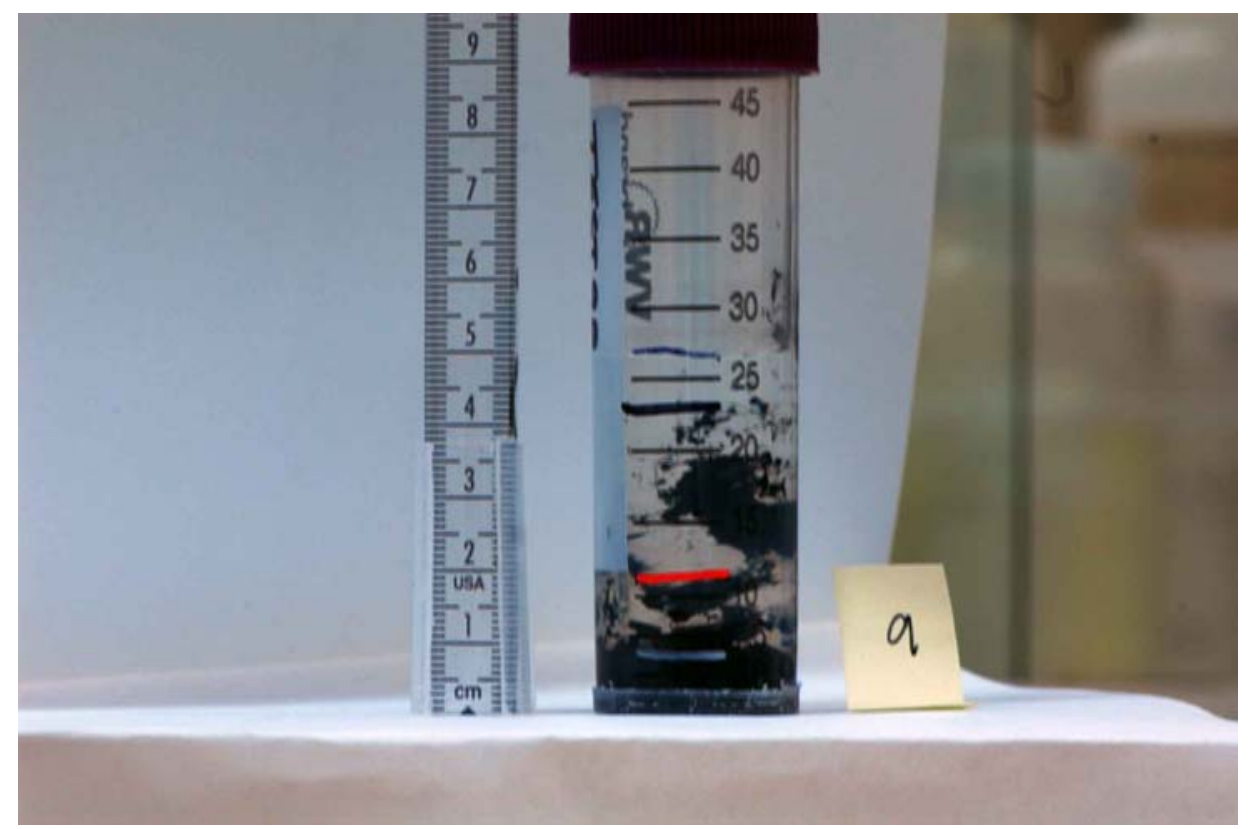

Figure B.9. Agitated-No pH Adjustment-50:50 Uranium Oxide Slurry

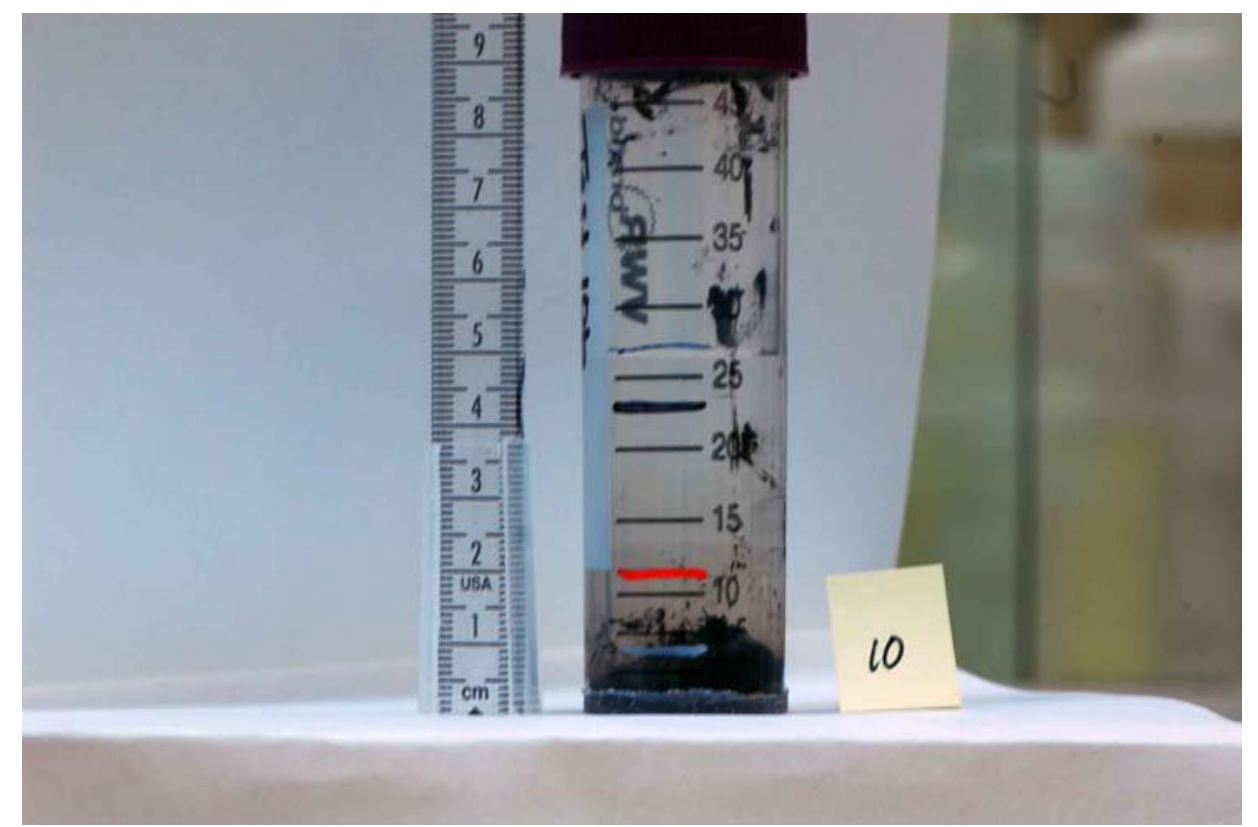

Figure B.10. Agitated—Solution $\mathrm{pH}$ Raised to 12 Using $\mathrm{NaOH}-50: 50$ Uranium Oxide Slurry 

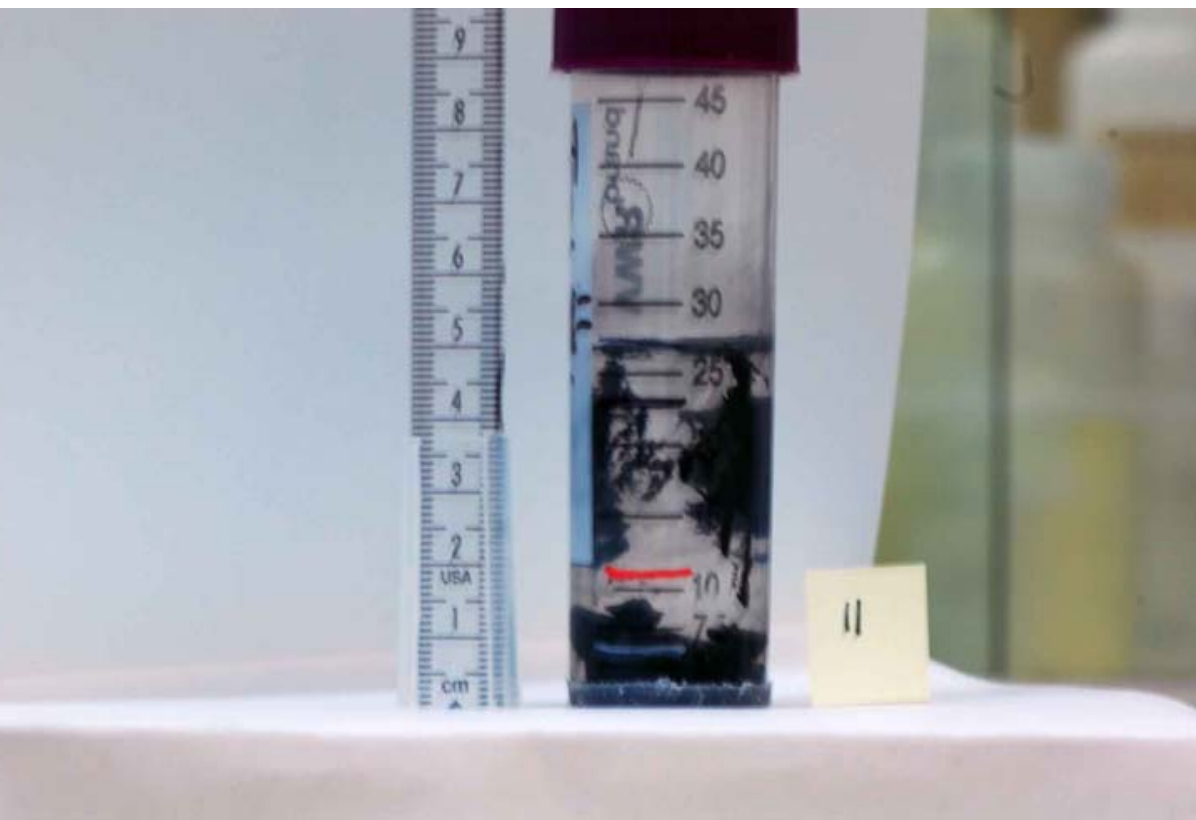

Figure B.11. Agitated—No pH Adjustment—50:50 Uranium Oxide Slurry

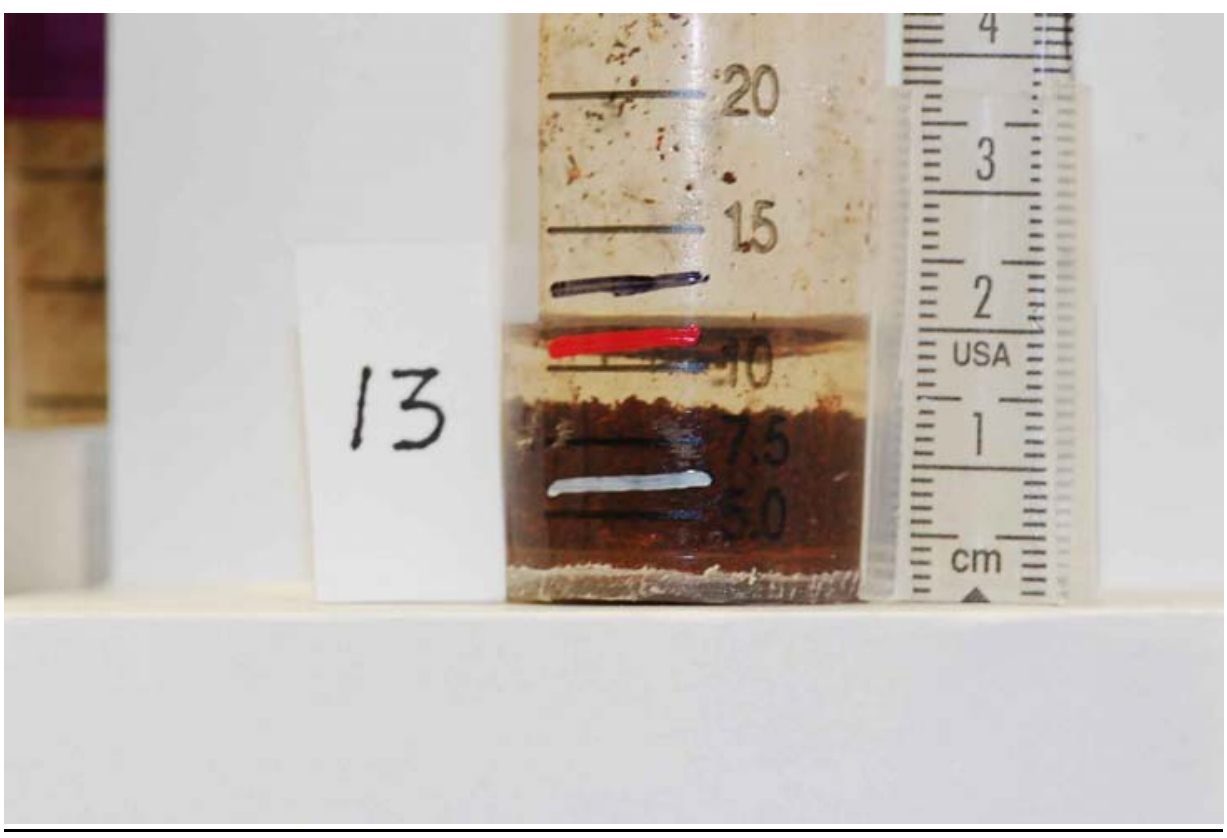

Figure B.12. Static-No pH Adjustment-KW Simulant 


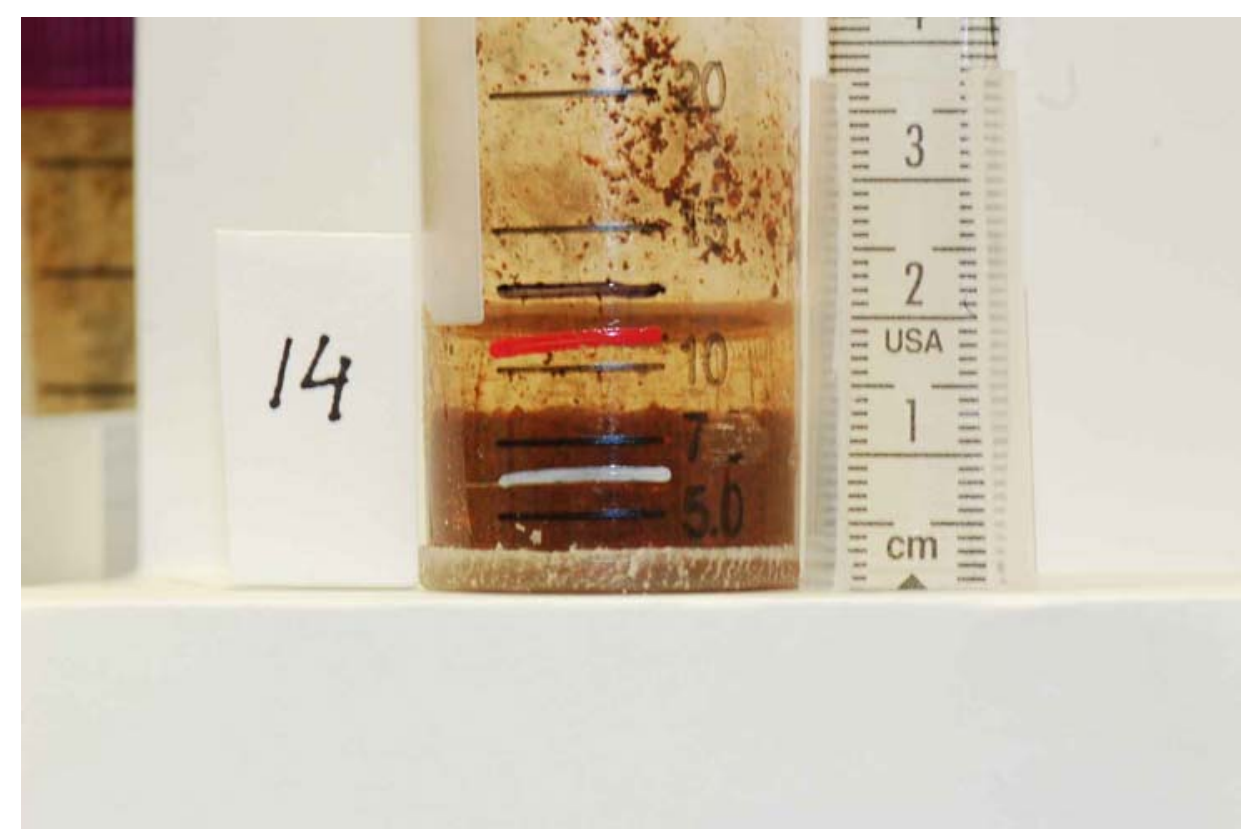

Figure B.13. Static - No pH Adjustment-KW Simulant

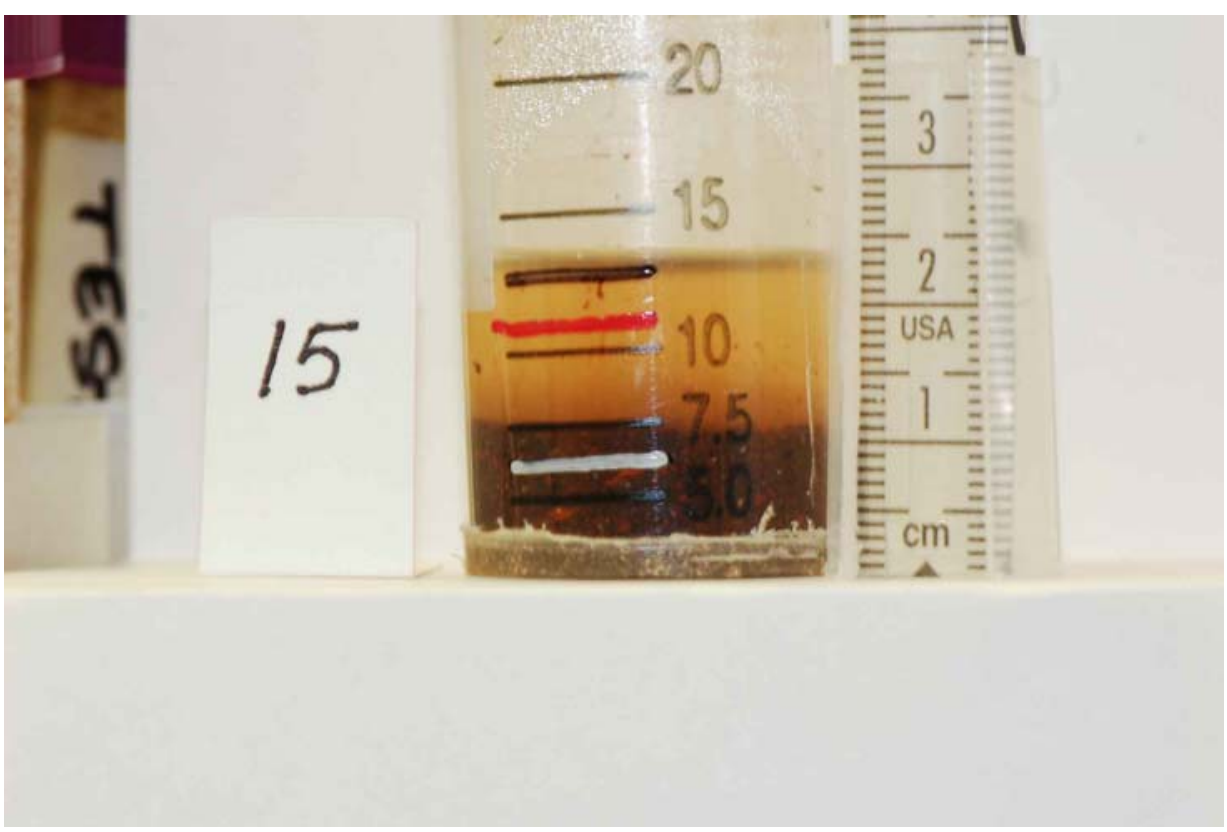

Figure B.14. Static—Solution $\mathrm{pH}$ Raised to 12 Using $\mathrm{NaOH}-\mathrm{KW}$ Simulant 


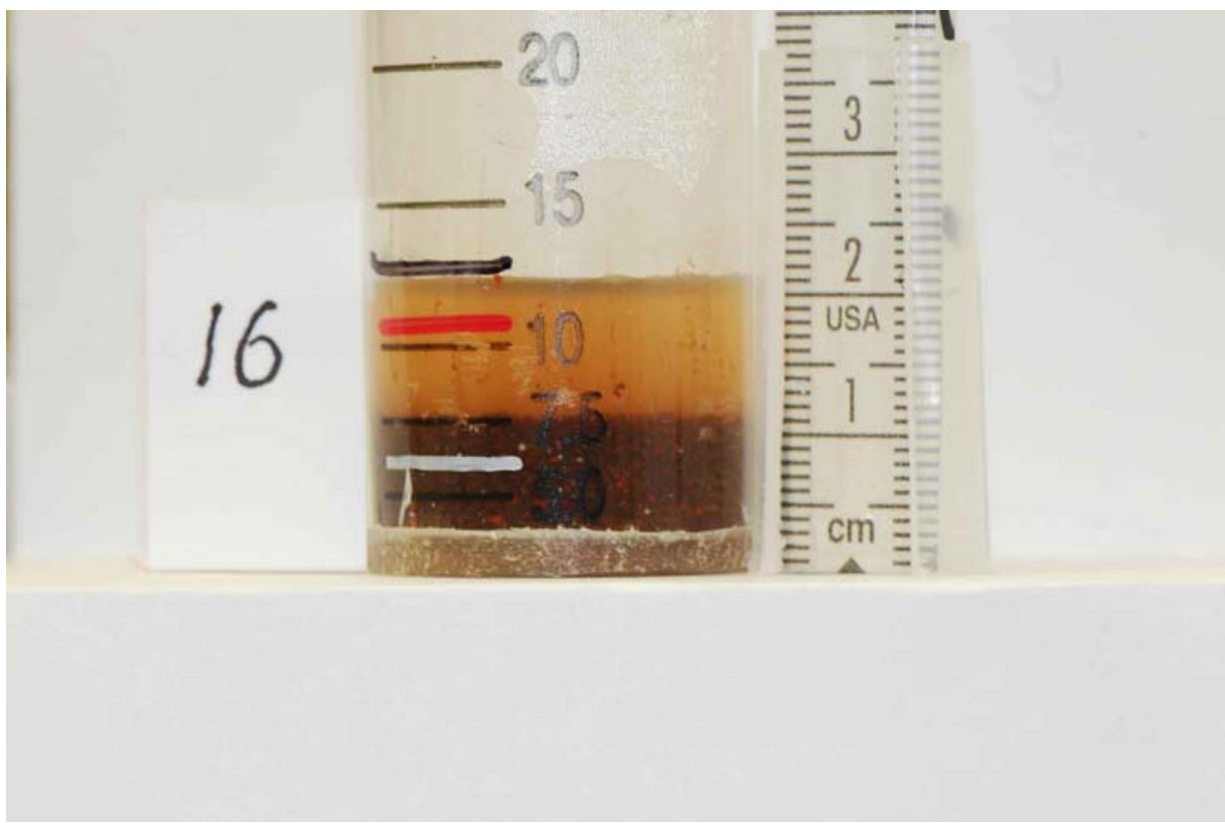

Figure B.15. Static - Solution pH Raised to 12 Using $\mathrm{NaOH}-\mathrm{KW}$ Simulant

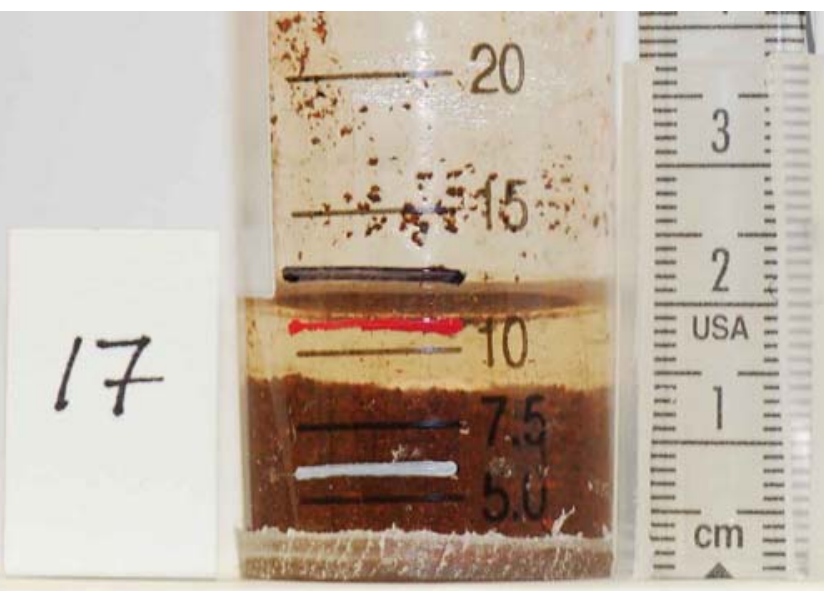

Figure B.16. Static - No pH Adjustment-KW Simulant 


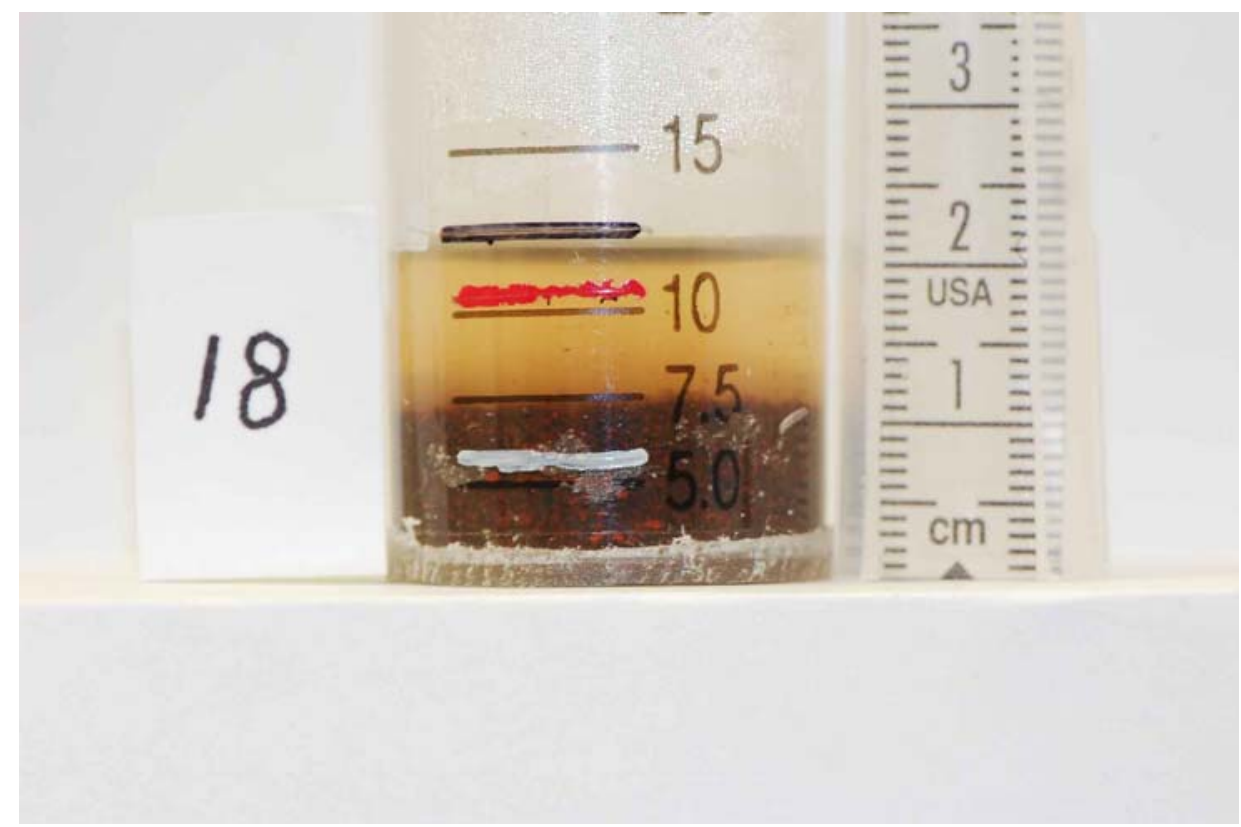

Figure B.17. Static-Solution $\mathrm{pH}$ Raised to 12 Using $\mathrm{NaOH}-\mathrm{KW}$ Simulant

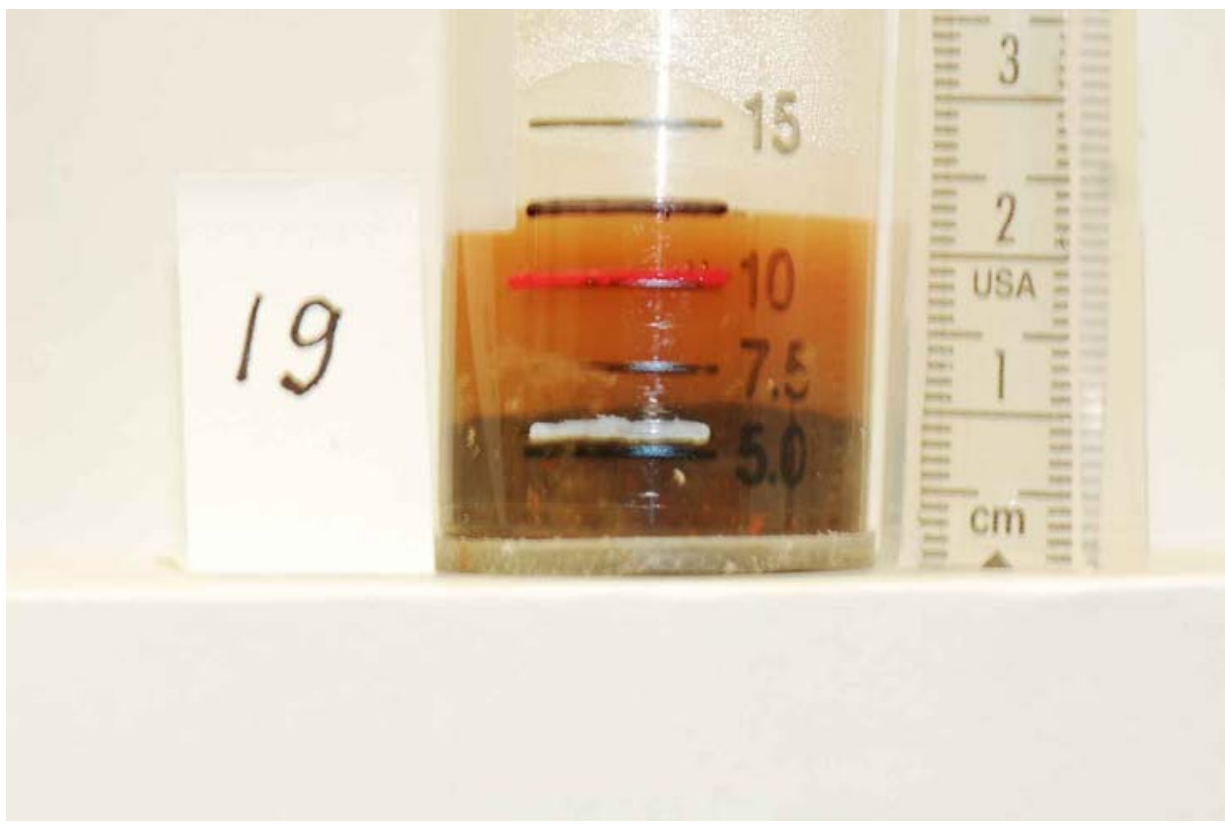

Figure B.18. Static- Solution pH Raised to 12 Using $\mathrm{Na}_{3} \mathrm{PO}_{4}-\mathrm{KW}$ Simulant 


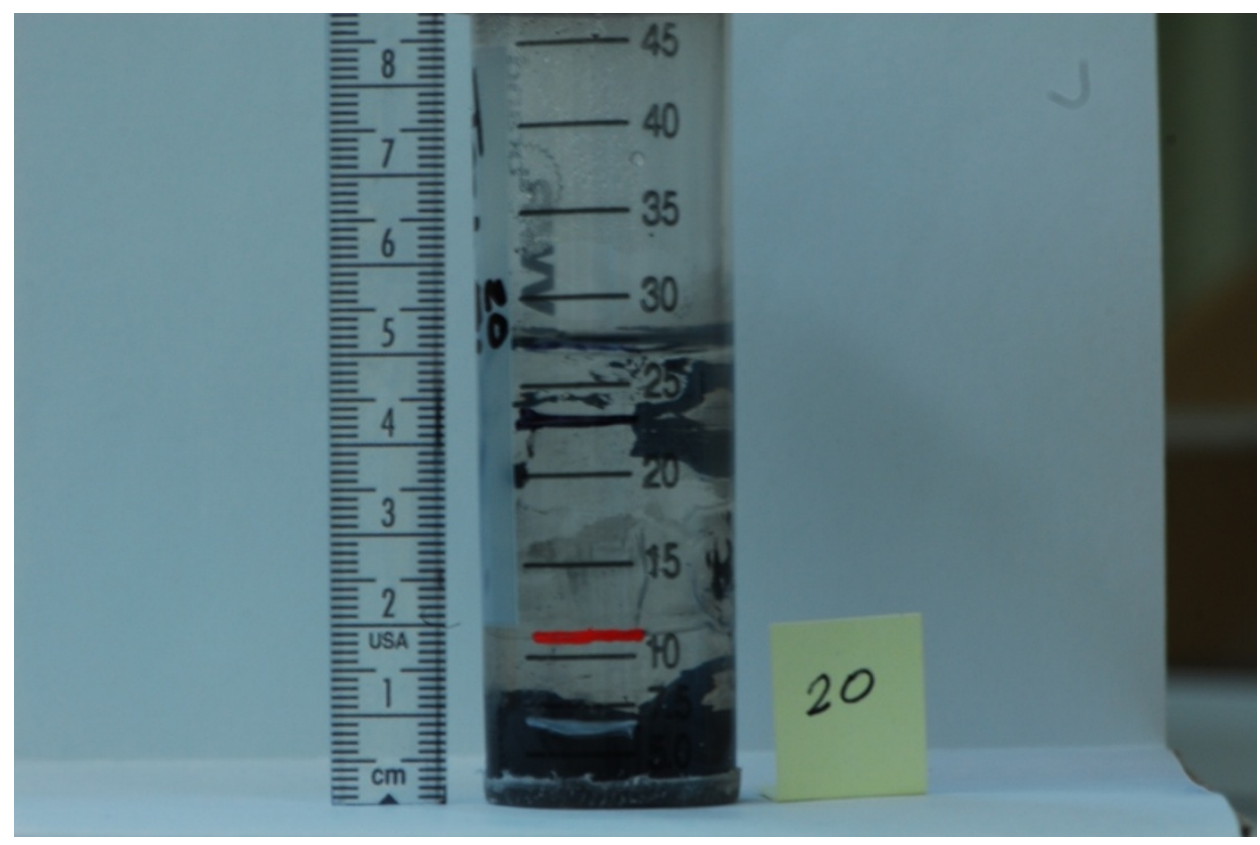

Figure B.19. Static — No pH Adjustment—50:50 Uranium Oxide Slurry

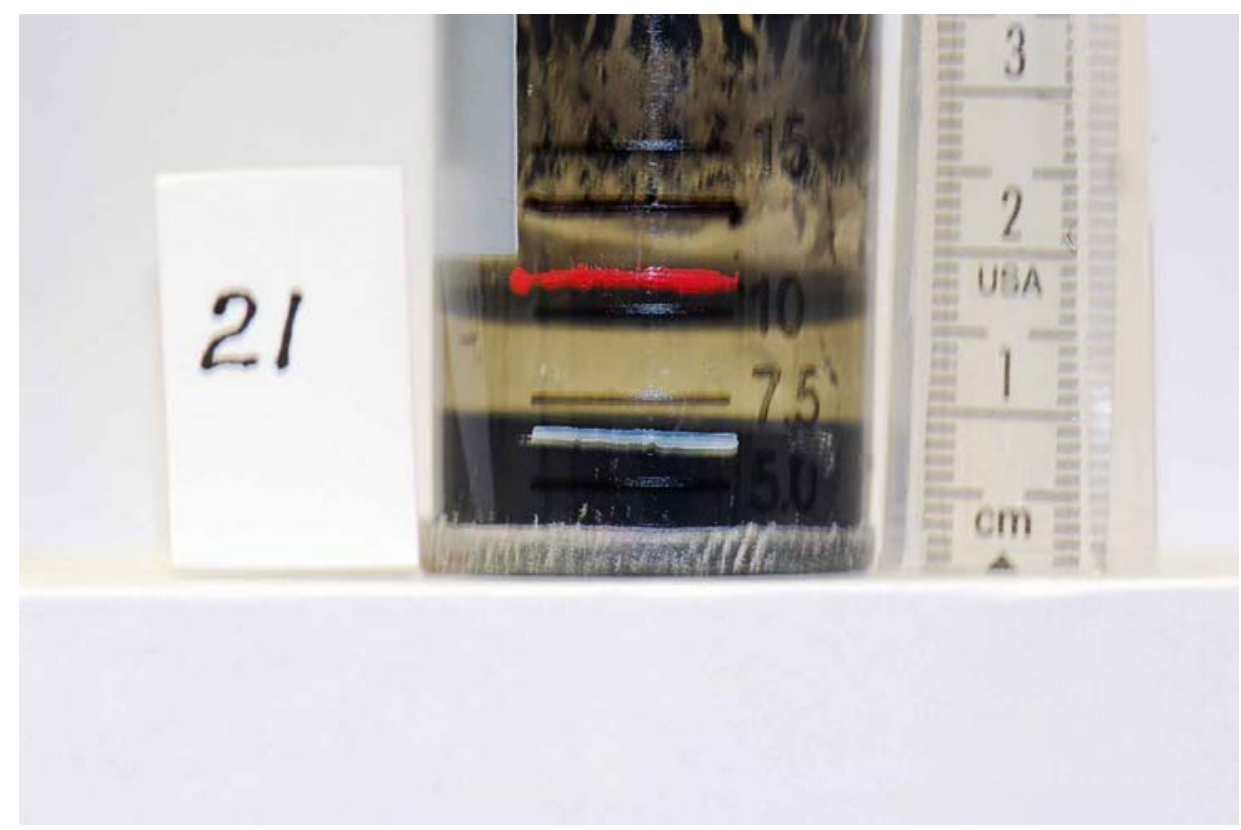

Figure B.20. Static—No pH Adjustment-50:50 Uranium Oxide Slurry 


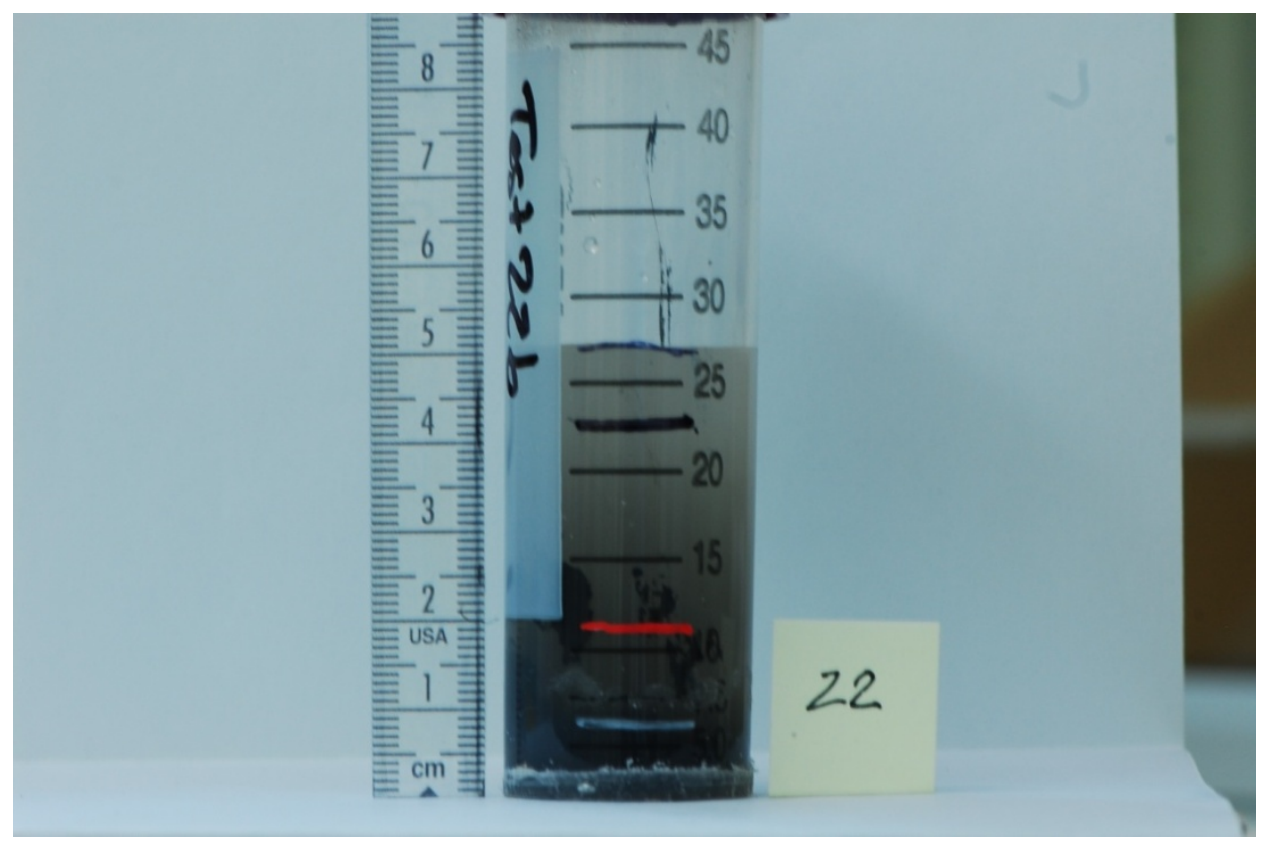

Figure B.21. Static - pH Raised to 12 Using $\mathrm{NaOH}-50: 50$ Uranium Oxide Slurry

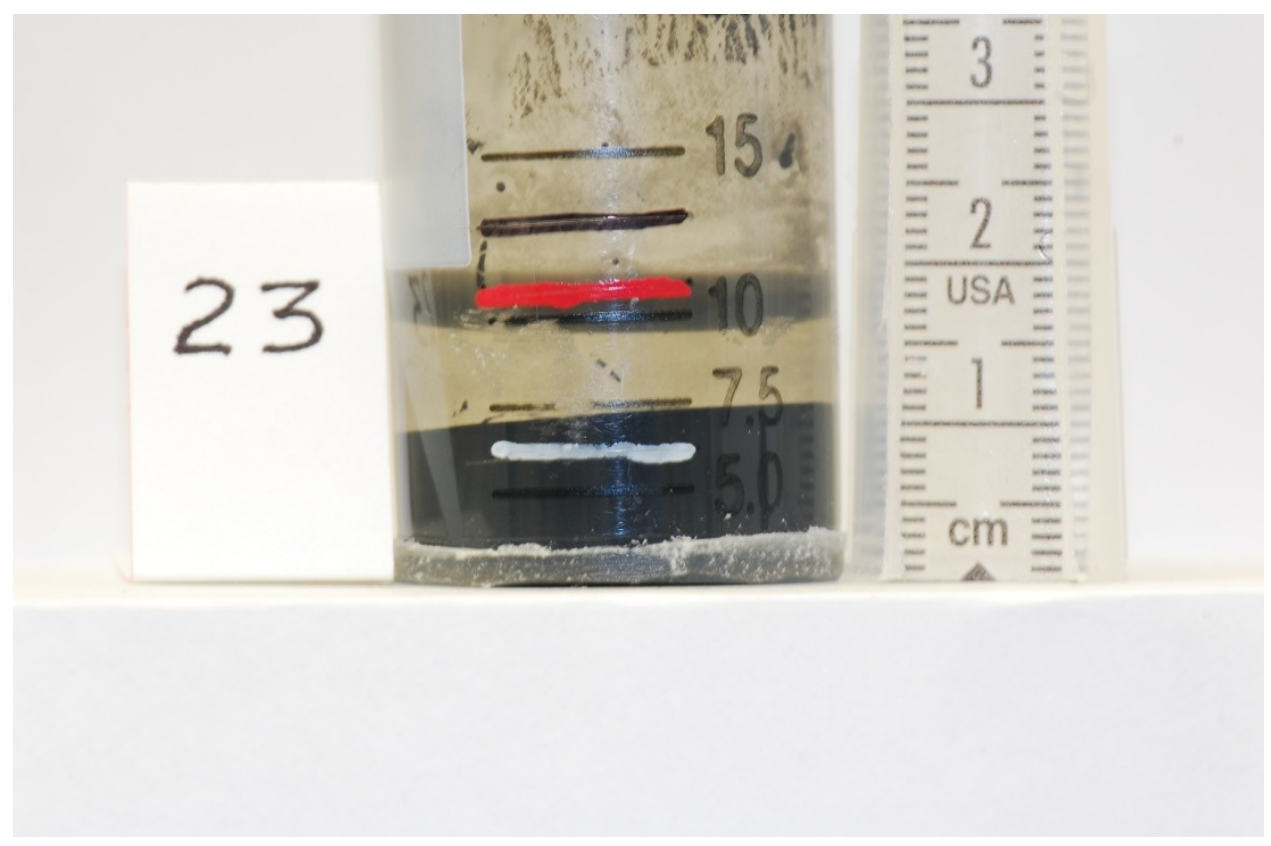

Figure B.22. Static—No pH Adjustment—50:50 Uranium Oxide Slurry 


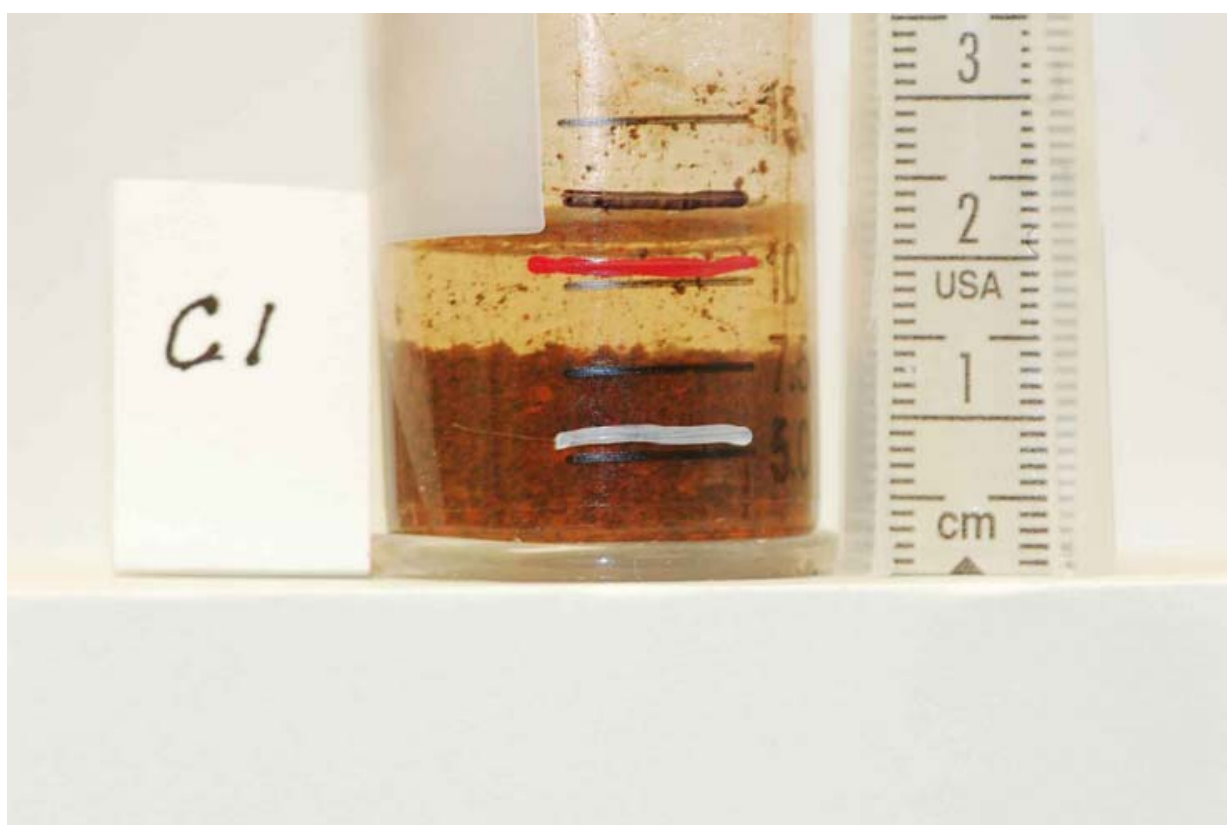

Figure B.23. Control—-No pH Adjustment-KW Simulant

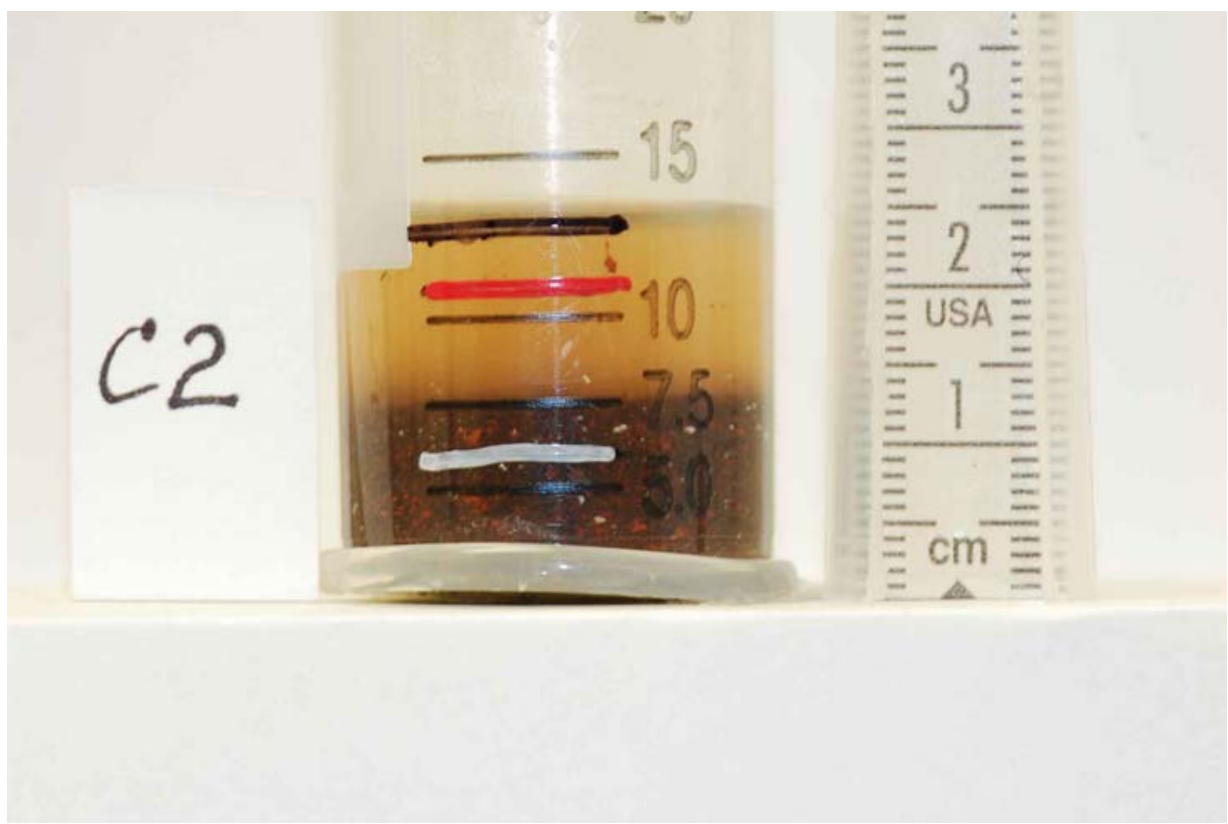

Figure B.24. Control- $\mathrm{pH}$ Raised to 12 Using $\mathrm{NaOH}-\mathrm{KW}$ Simulant 


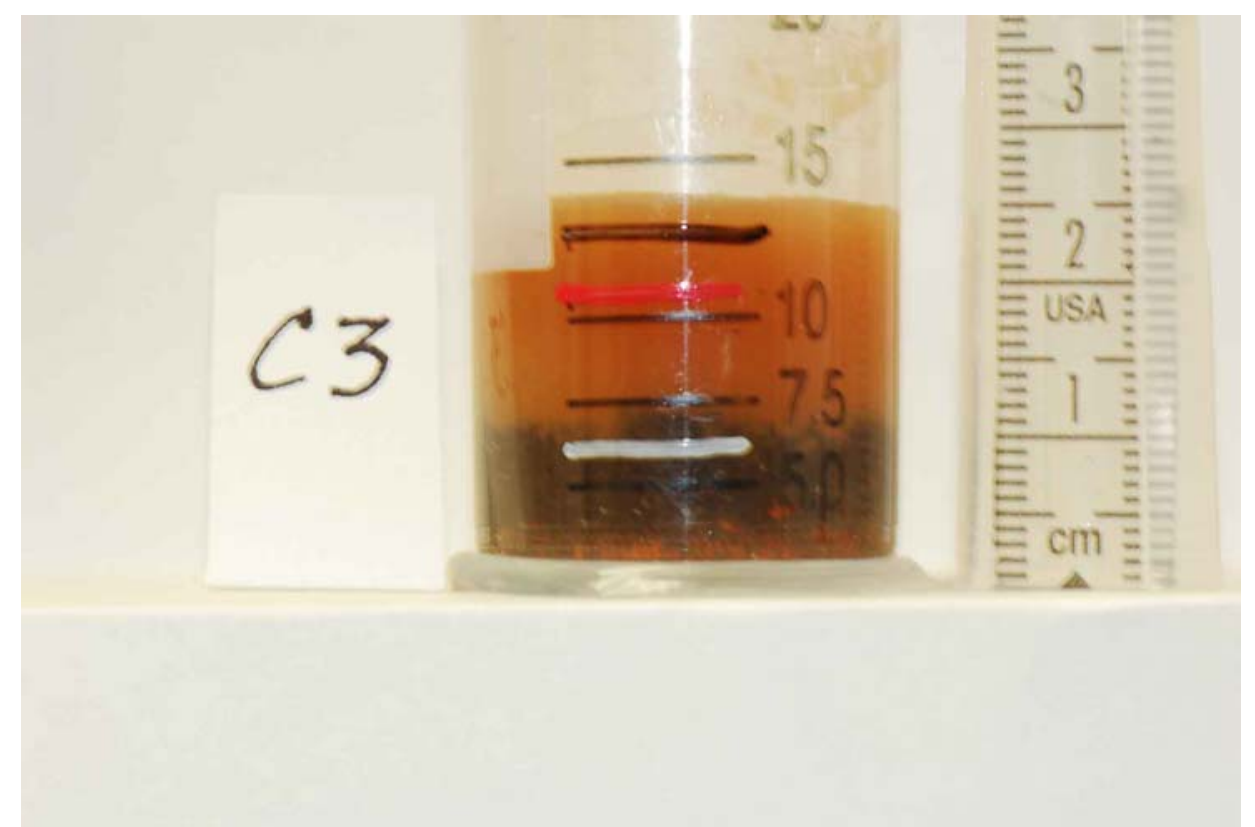

Figure B.25. Control $-\mathrm{pH}$ Raised to 12 Using $\mathrm{Na}_{3} \mathrm{PO}_{4}-\mathrm{KW}$ Simulant

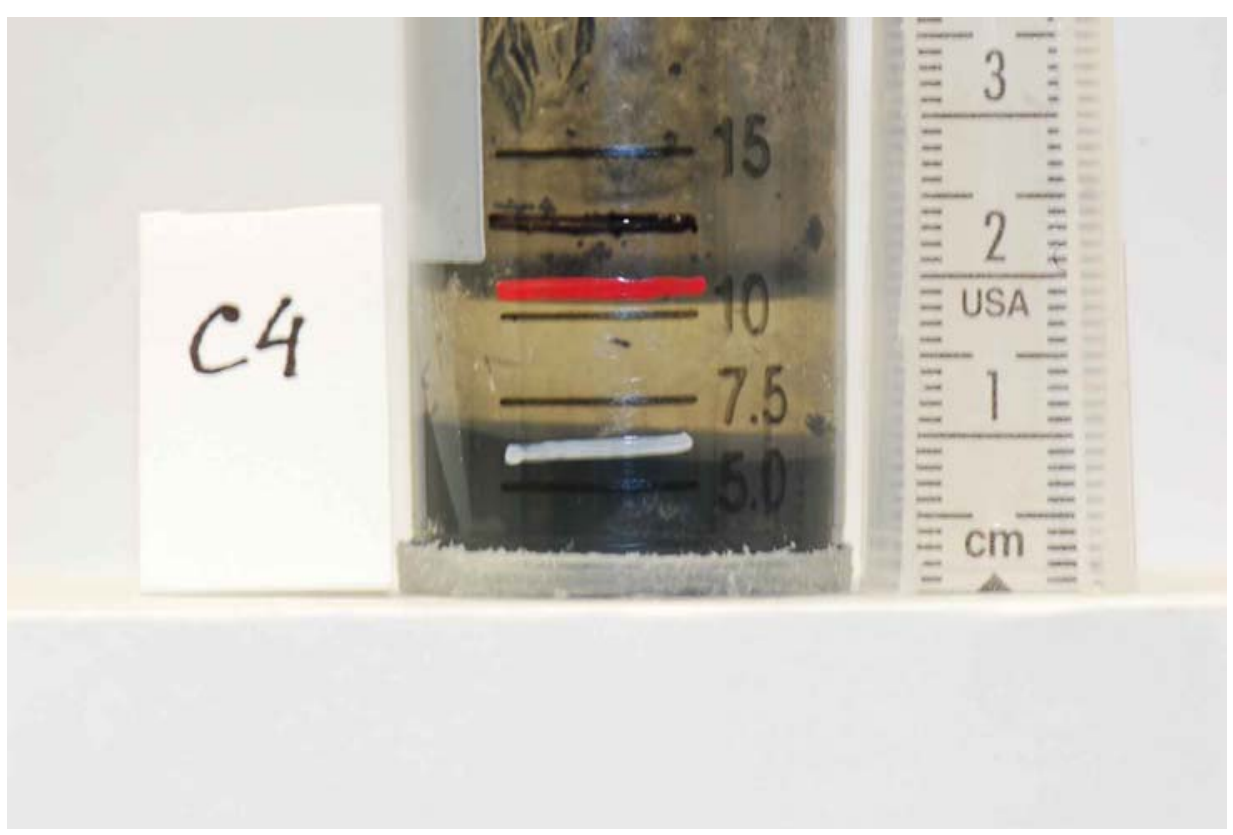

Figure B.26. Control—No pH Adjustment-50:50 Uranium Oxide Slurry 


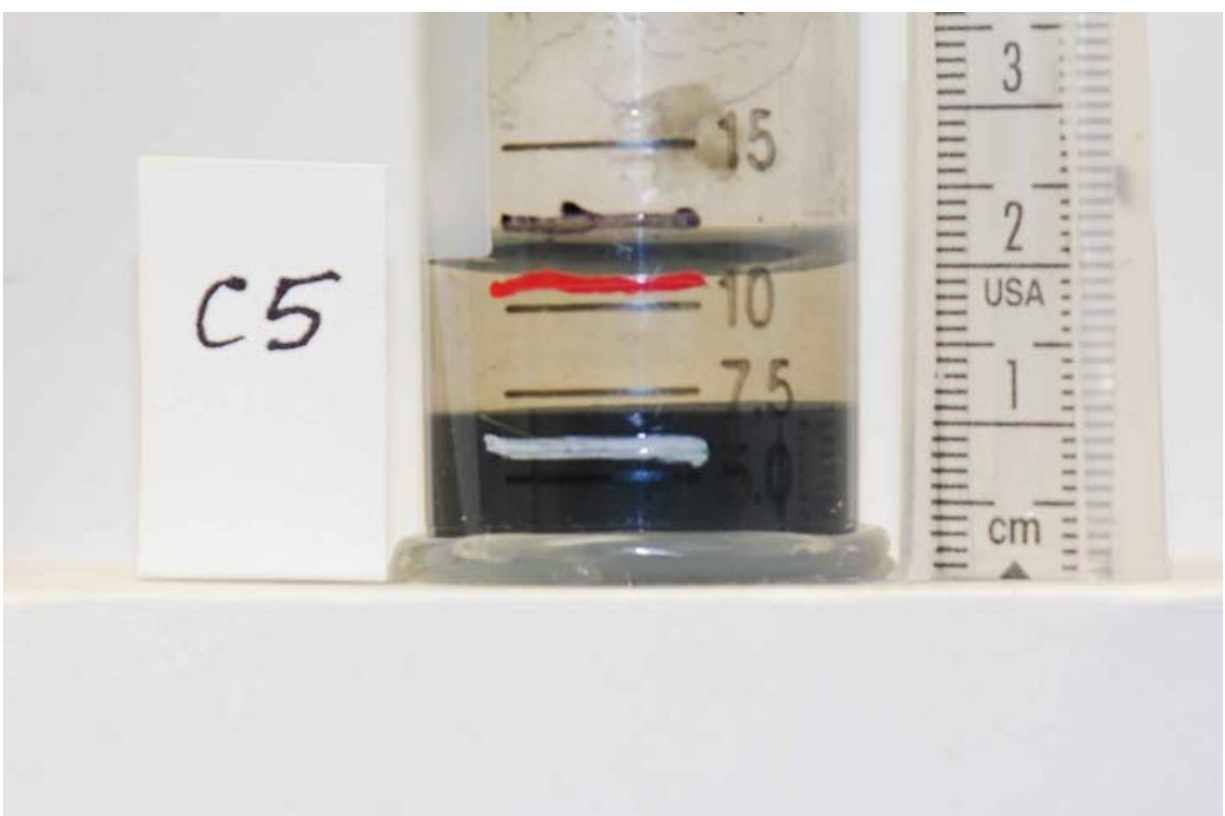

Figure B.27. Control $-\mathrm{pH}$ Raised to 12 Using $\mathrm{NaOH}-50: 50$ Uranium Oxide Slurry 



\section{Appendix C}

\section{Photographs of Test Items after 96 Hours of Heating at $95^{\circ} \mathrm{C}$}

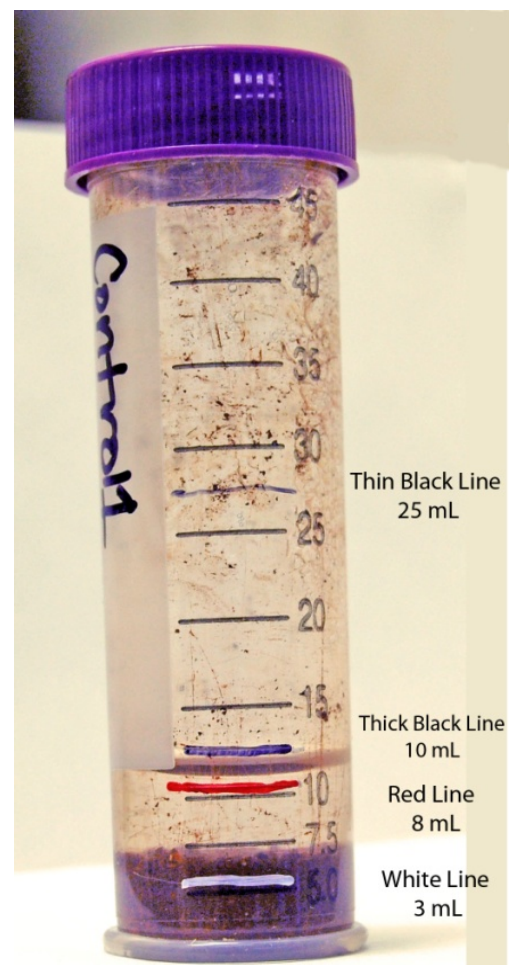

Note: The markings on the centrifuge tubes in these photos in this appendix indicate new calibration points for the vessel as determined with calibrated pipettes. The white line indicates the anticipated volume of the simulated sludge. The red line indicates the initial fill volume. The thick black line indicates the initial fill volume suggested for these tests. The thin black line indicates the final fill volume used. 



\section{Appendix C - Photographs of Test Items after 96 Hours of Heating at $95^{\circ} \mathrm{C}$}

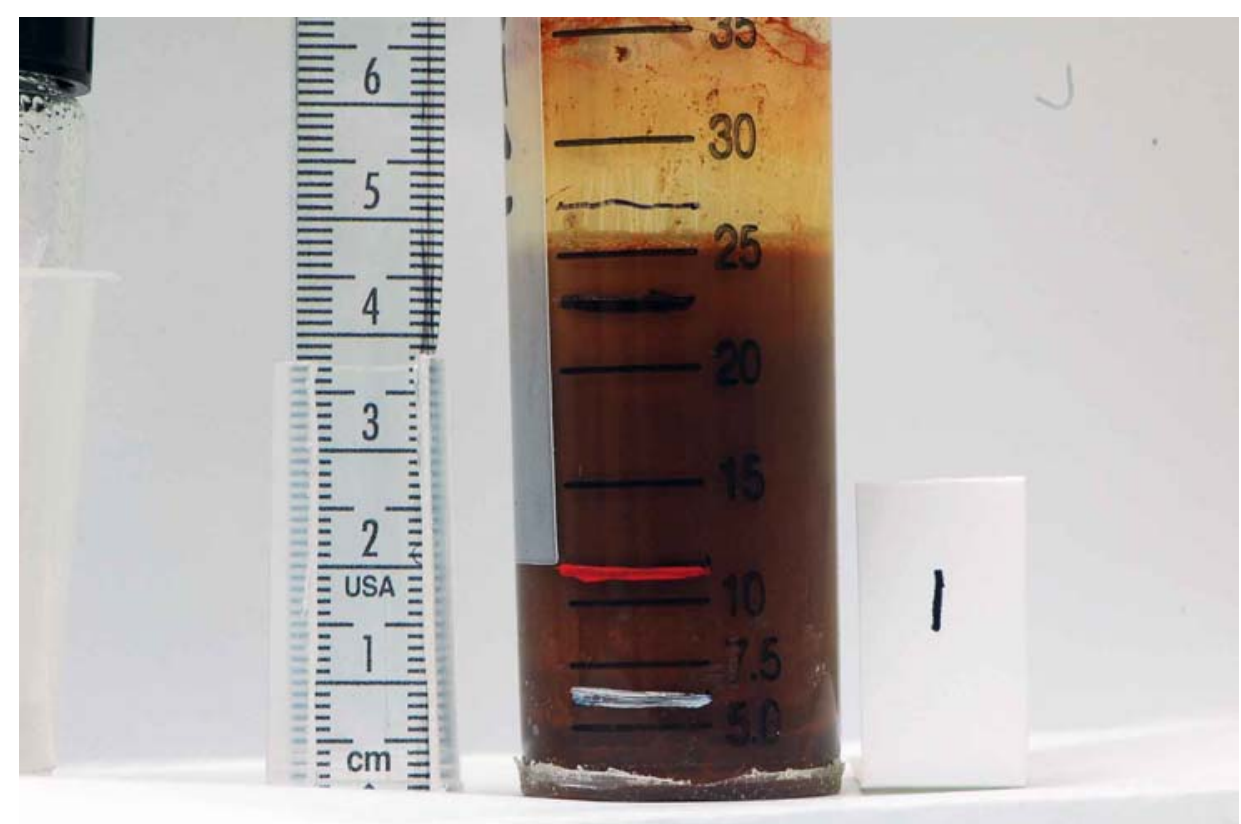

Figure C.1. Agitated-No pH Adjustment-KW Simulant

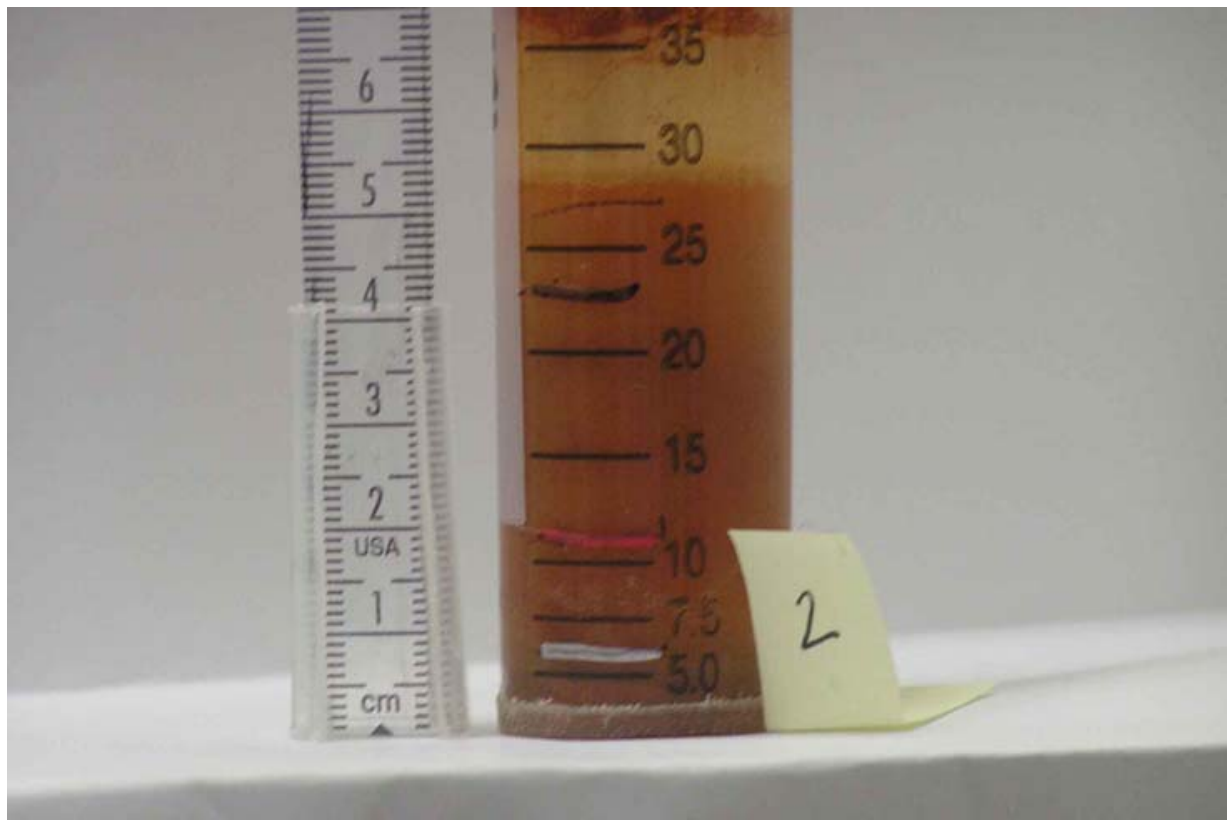

Figure C.2. Agitated-No pH Adjustment-KW Simulant 


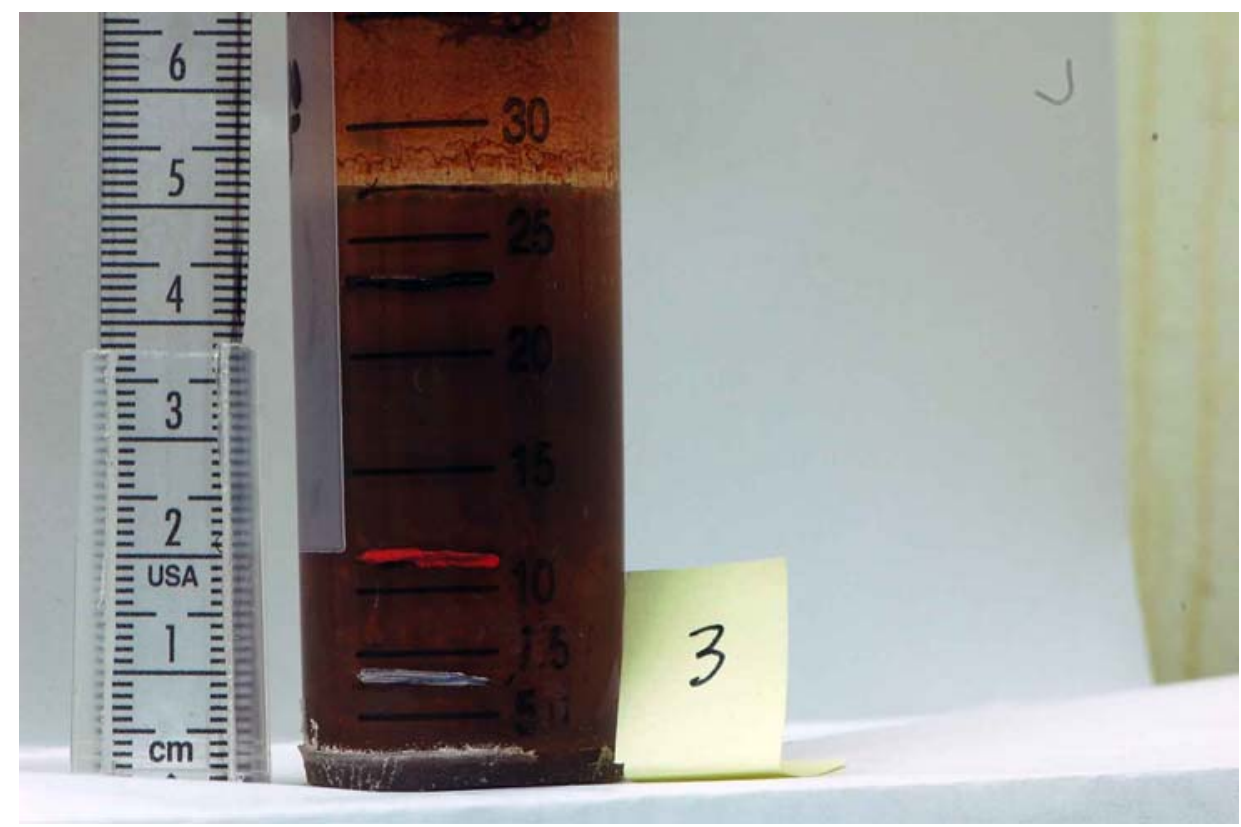

Figure C.3. Agitated- $-\mathrm{pH}$ Raised to 12 Using $\mathrm{Na}_{3} \mathrm{PO}_{4}-\mathrm{KW}$ Simulant

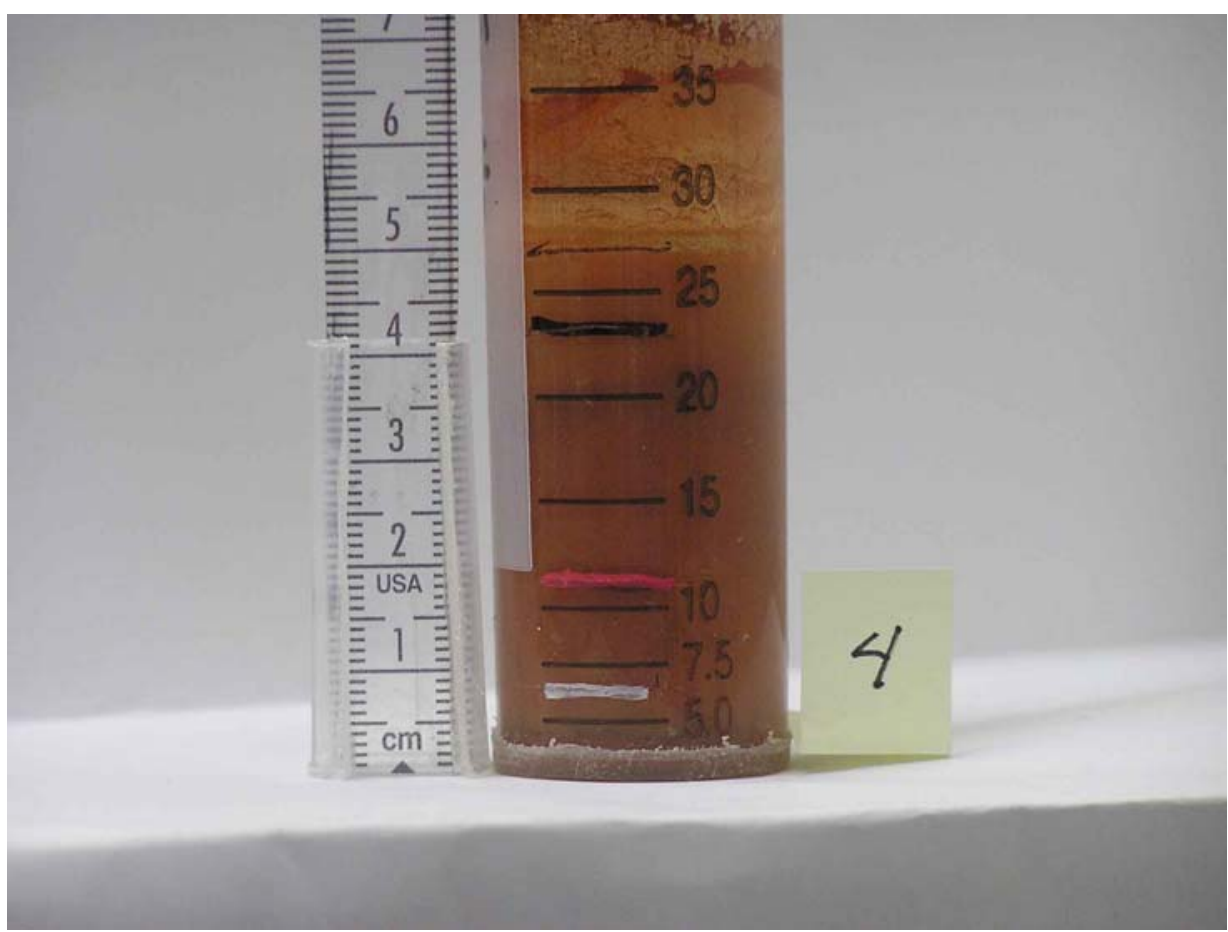

Figure C.4. Agitated- $\mathrm{pH}$ Raised to 12 Using $\mathrm{Na}_{3} \mathrm{PO}_{4}-\mathrm{KW}$ Simulant 


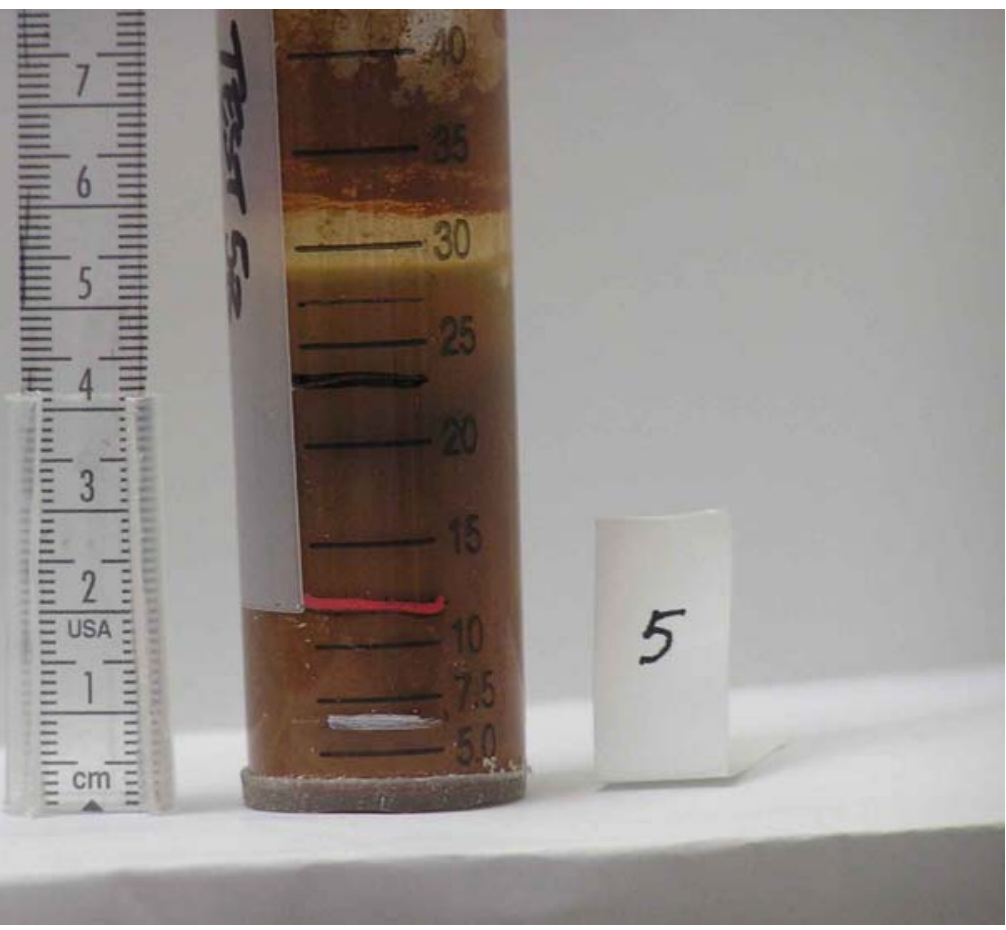

Figure C.5. Agitated-No pH Adjustment-KW Simulant

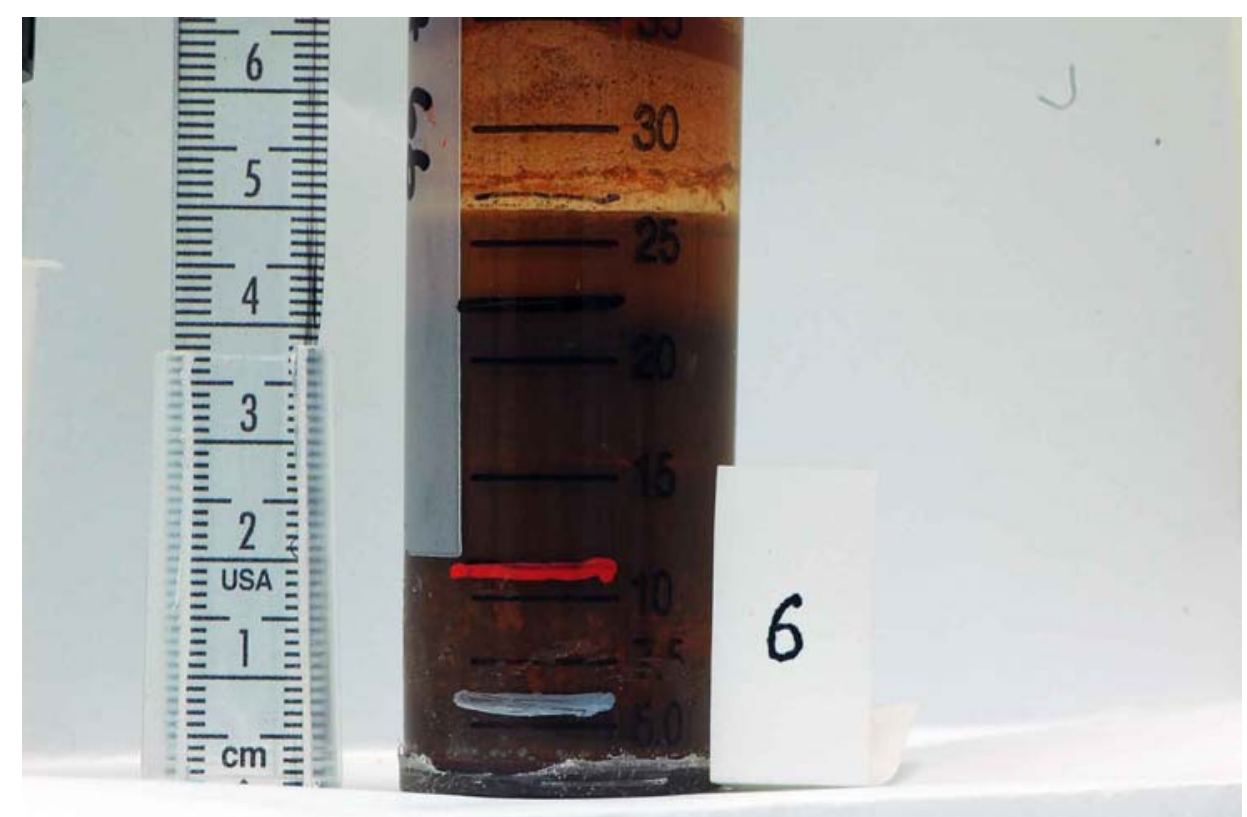

Figure C.6. Agitated- $-\mathrm{pH}$ Raised to 12 Using $\mathrm{NaOH}-\mathrm{KW}$ Simulant 


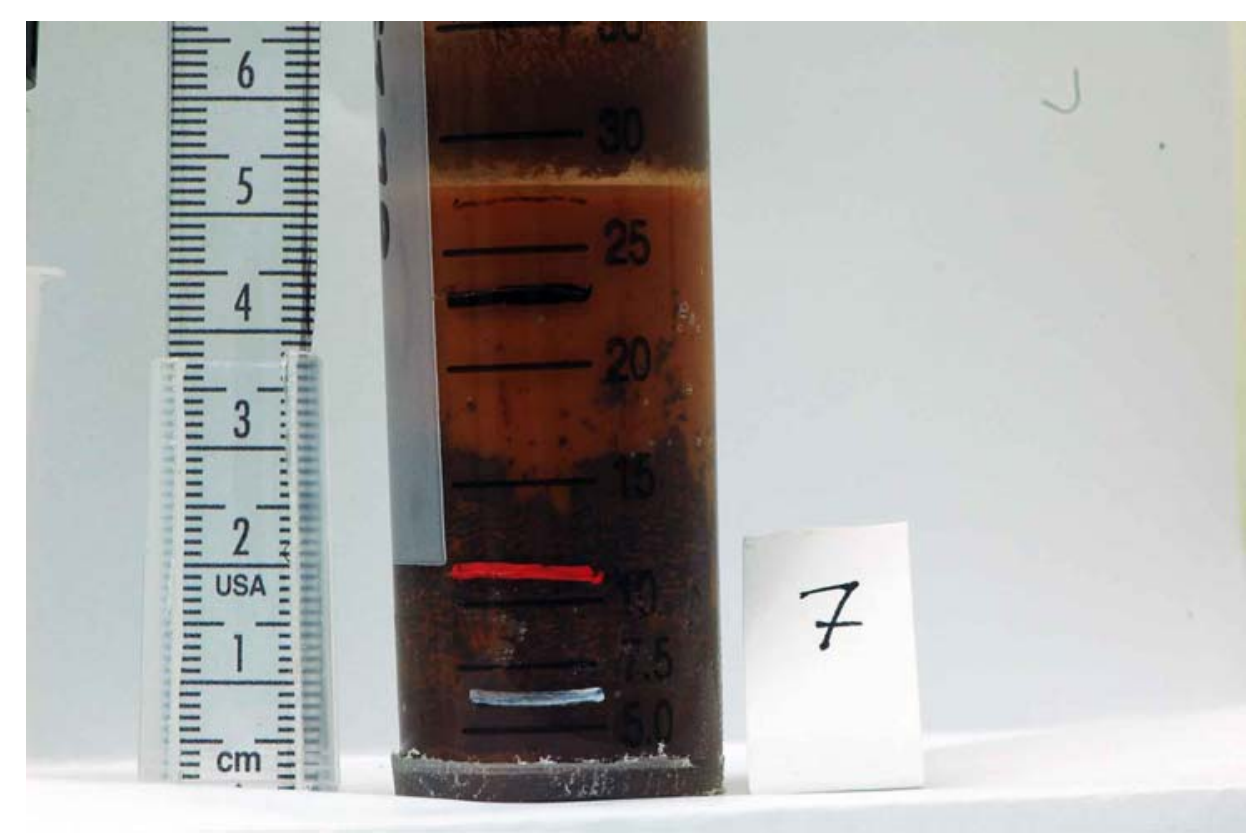

Figure C.7. Agitated- $-\mathrm{pH}$ Raised to 12 Using $\mathrm{Na}_{3} \mathrm{PO}_{4}-\mathrm{KW}$ Simulant

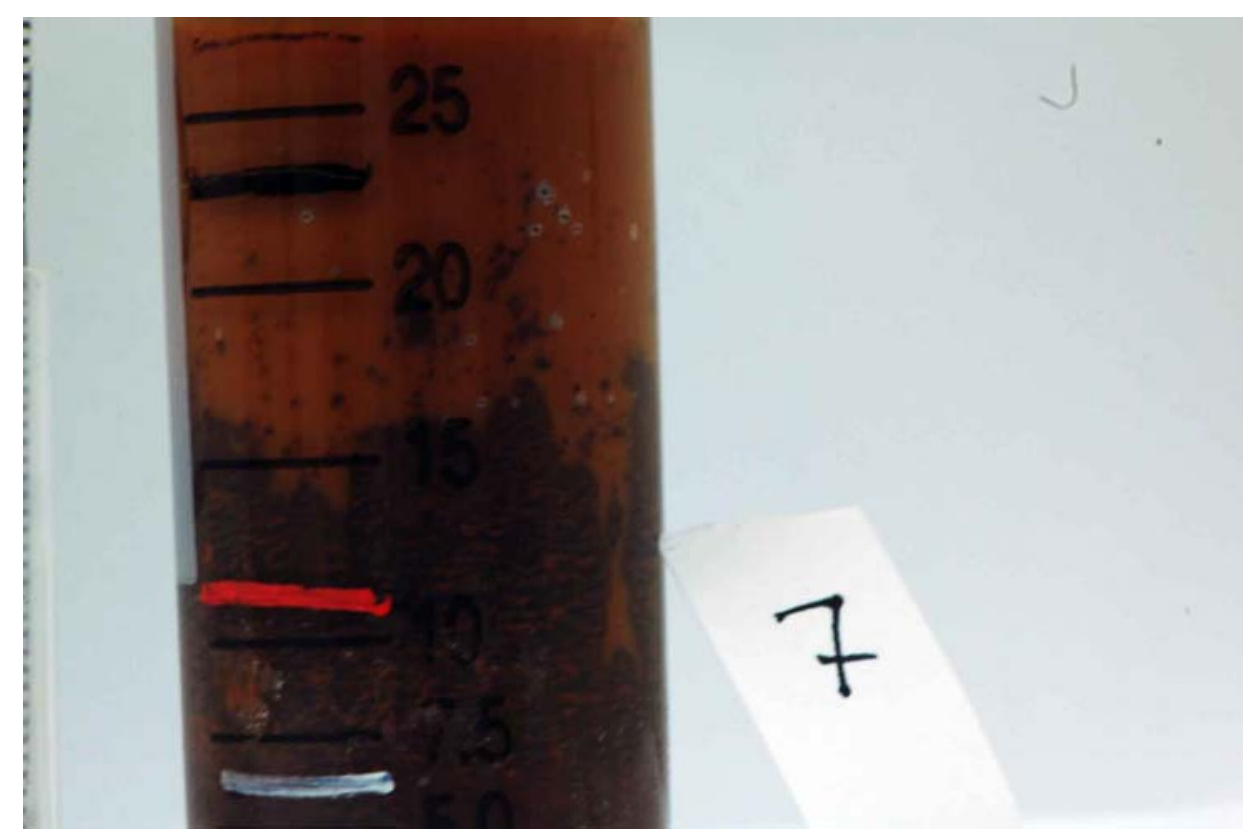

Figure C.8. Agitated- $\mathrm{pH}$ Raised to 12 Using $\mathrm{Na}_{3} \mathrm{PO}_{4}-\mathrm{KW}$ Simulant 


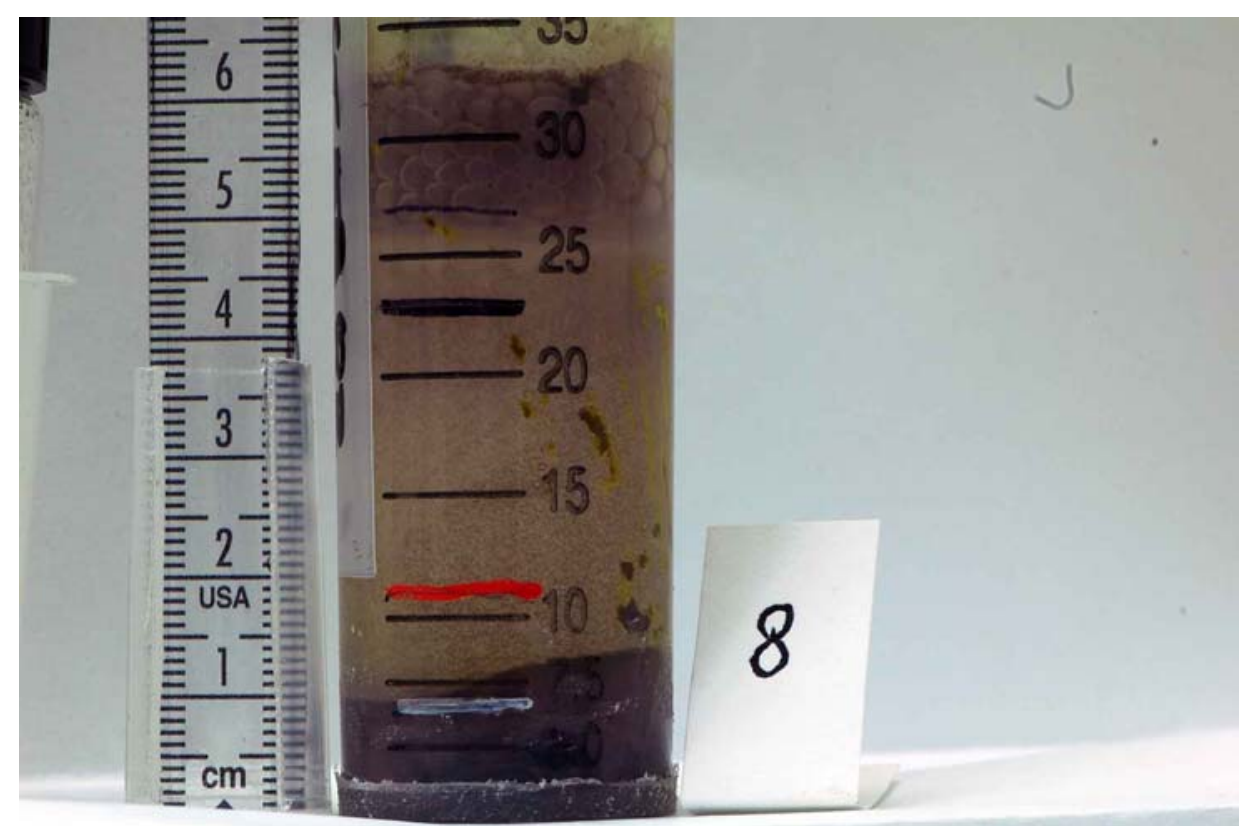

Figure C.9. Agitated-No pH Adjustment-50:50 Uranium Oxide Slurry

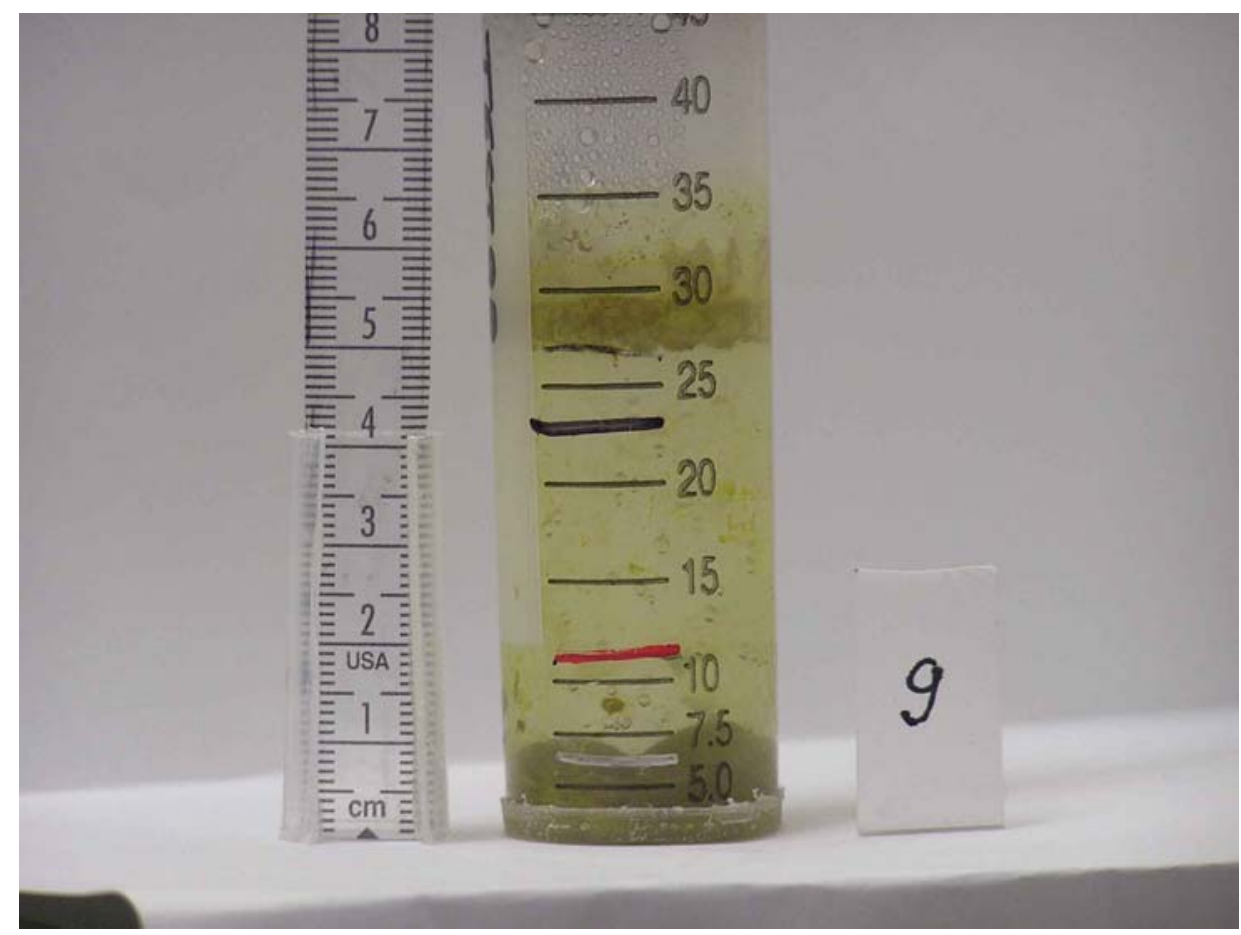

Figure C.10. Agitated—No pH Adjustment—50:50 Uranium Oxide Slurry 


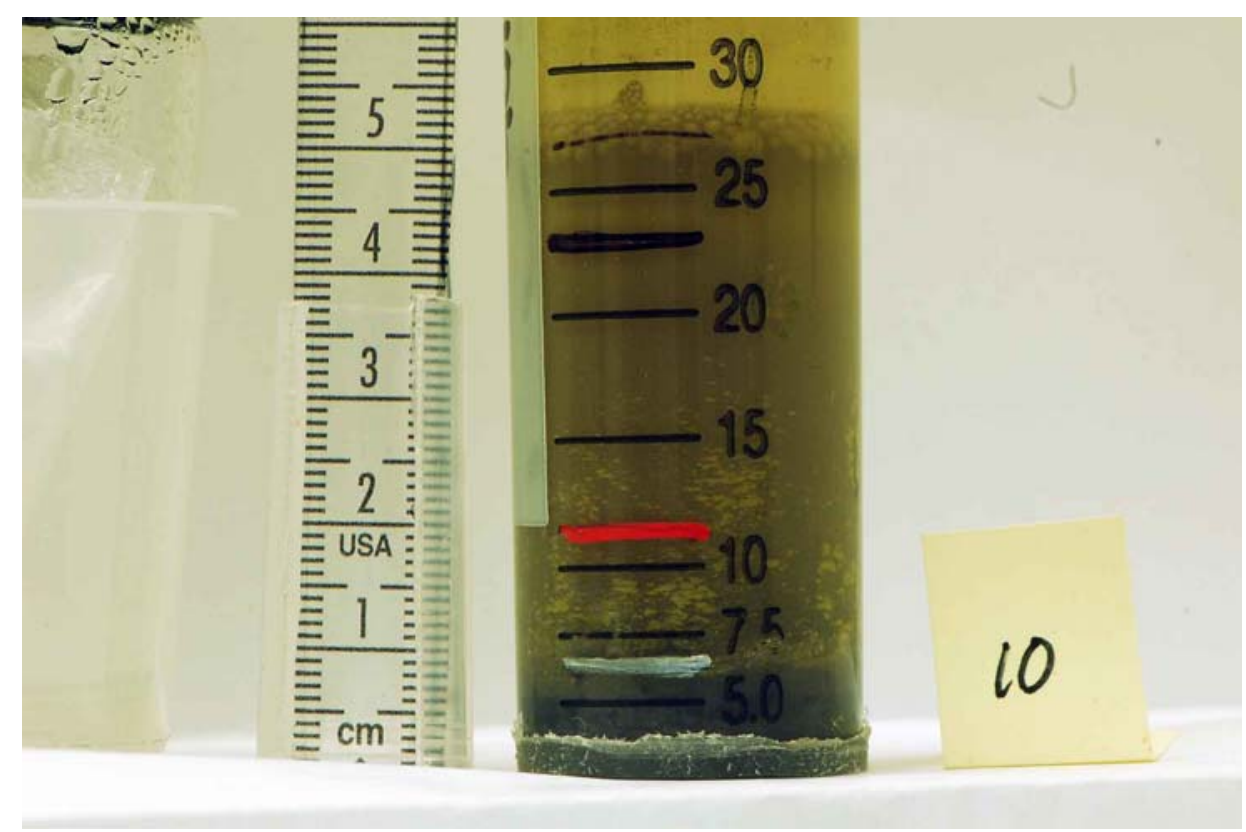

Figure C.11. Agitated- $-\mathrm{pH}$ Raised to 12 Using $\mathrm{NaOH}-50: 50$ Uranium Oxide Slurry

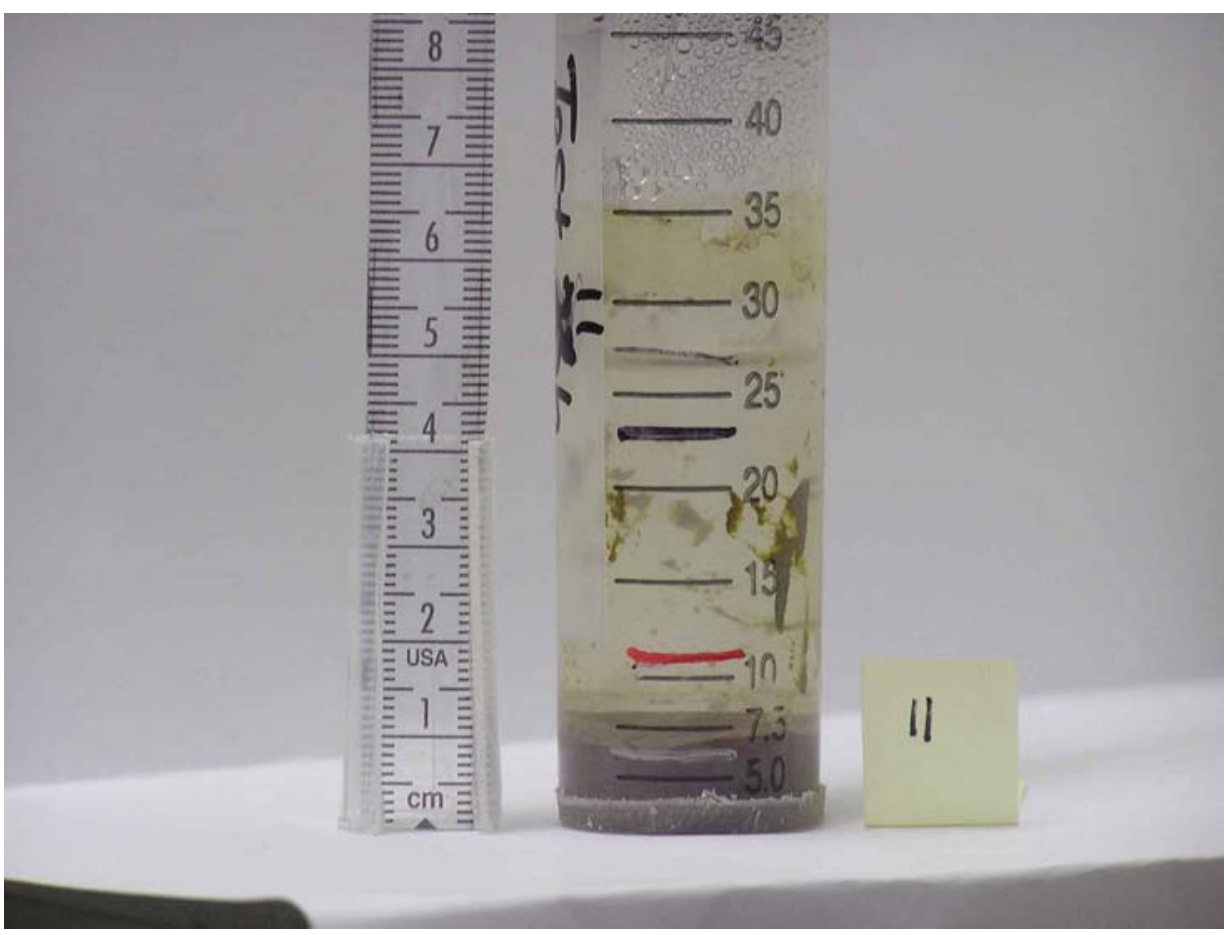

Figure C.12. Agitated—No pH Adjustment—50:50 Uranium Oxide Slurry 


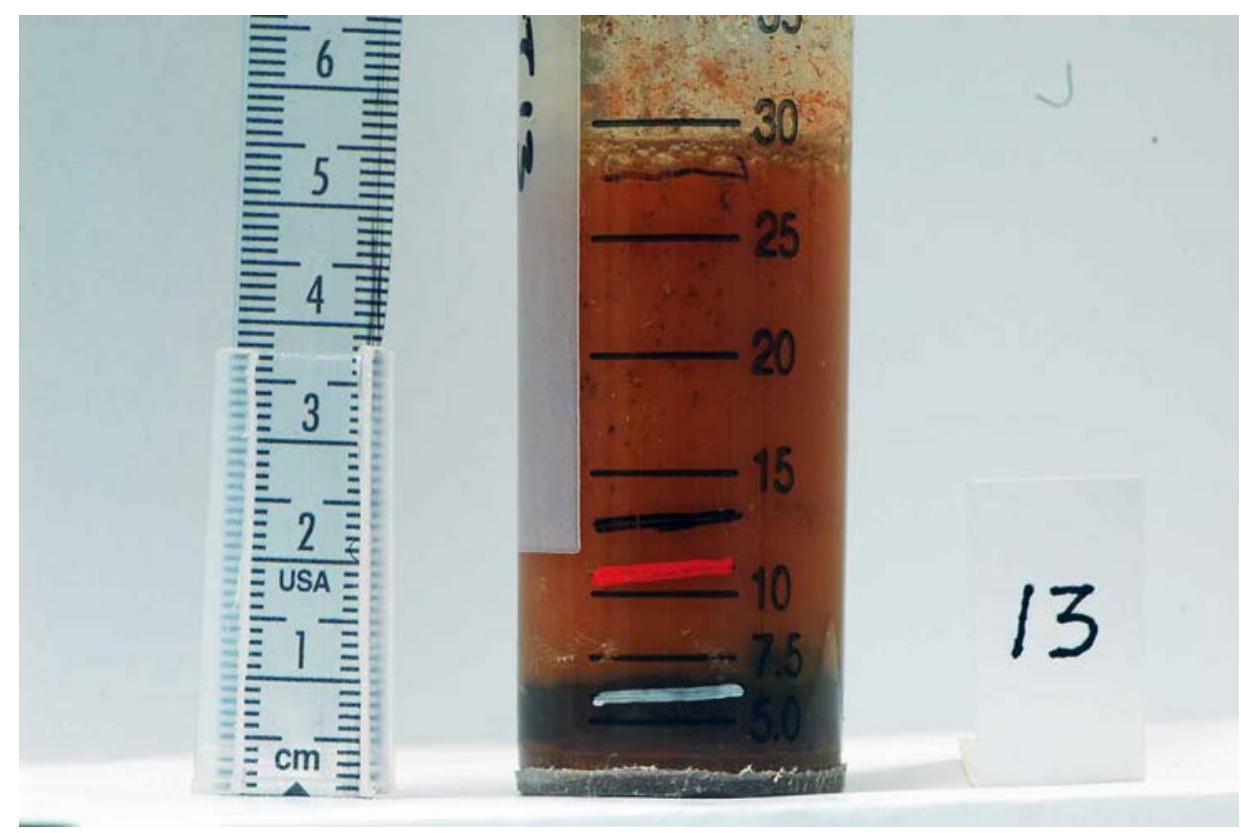

Figure C.13. Static - No pH Adjustment - KW Simulant

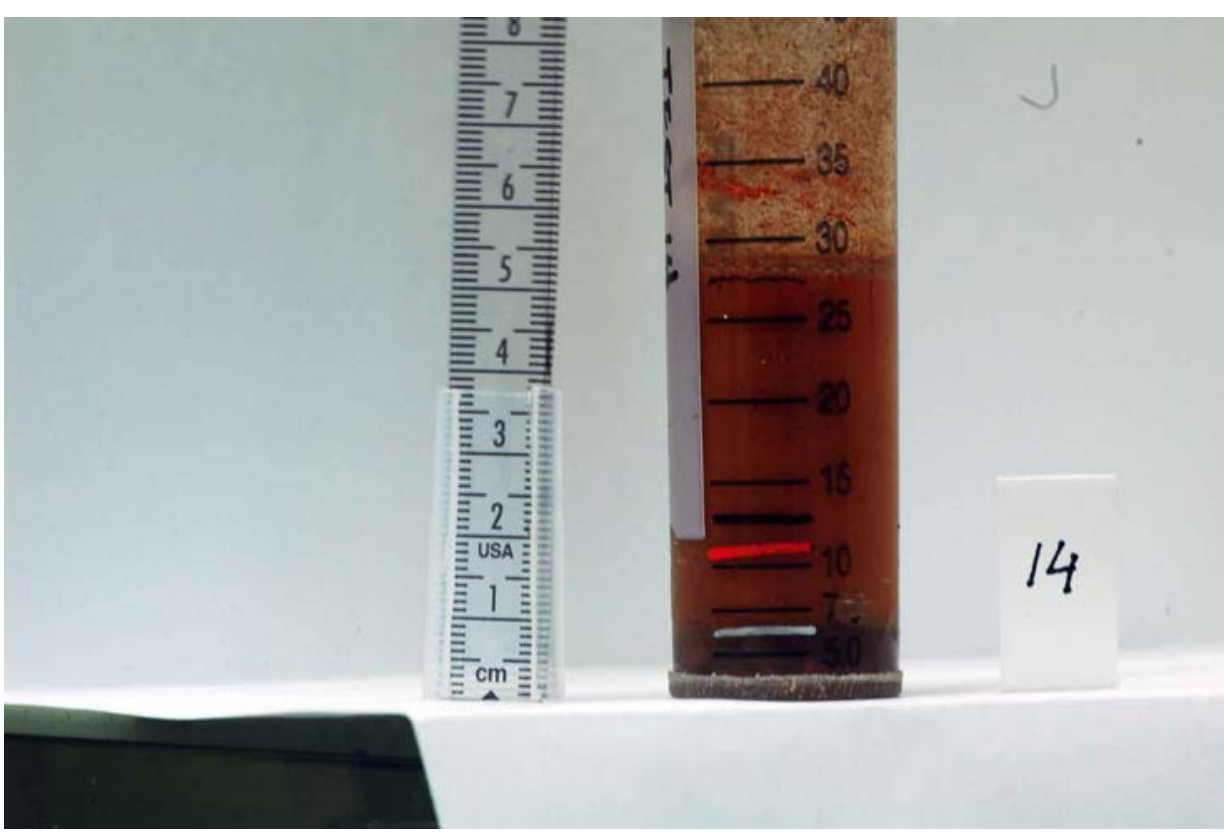

Figure C.14. Static-No pH Adjustment-KW Simulant 


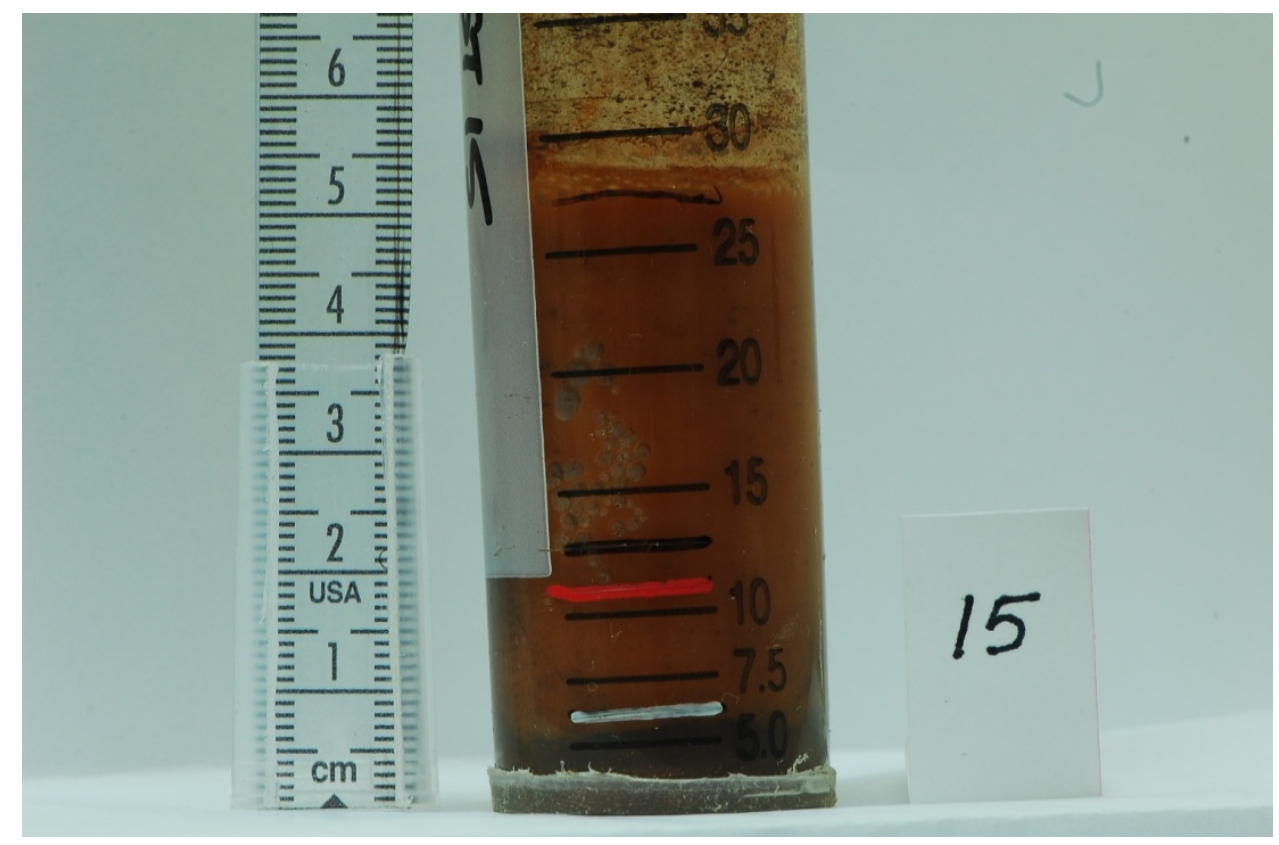

Figure C.15. Static - $\mathrm{pH}$ Raised to 12 Using $\mathrm{NaOH}-\mathrm{KW}$ Simulant

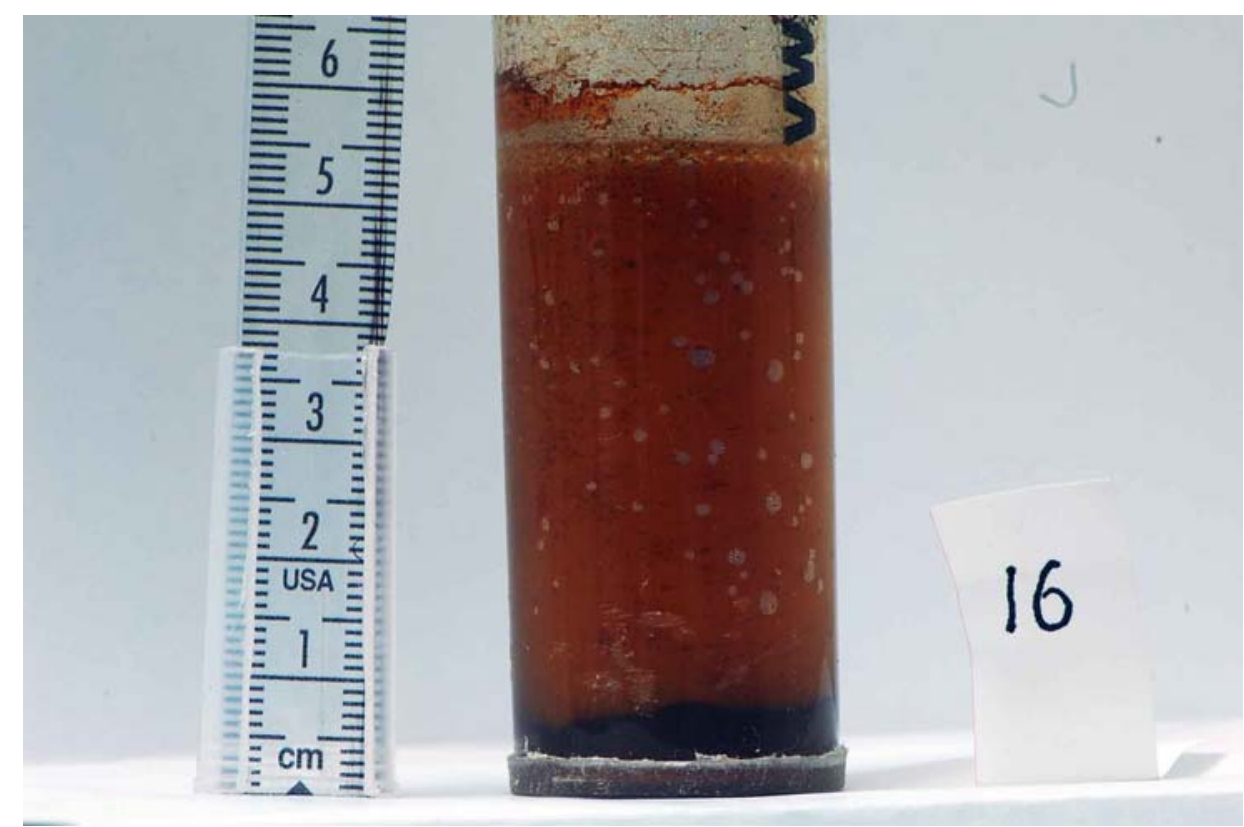

Figure C.16. Static- $-\mathrm{pH}$ Raised to $12 \mathrm{Using} \mathrm{NaOH}-\mathrm{KW}$ Simulant 


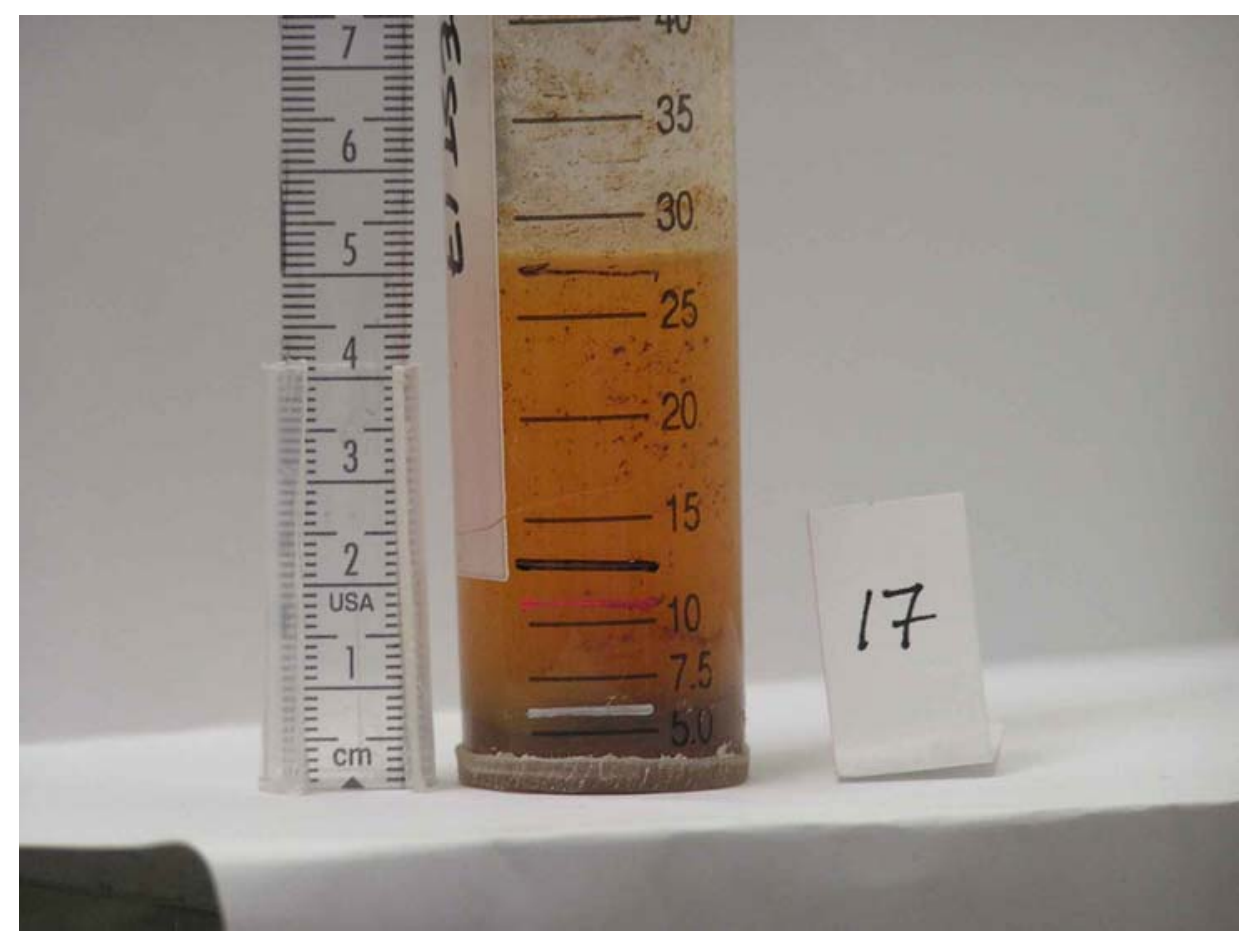

Figure C.17. Static—No pH Adjustment-KW Simulant

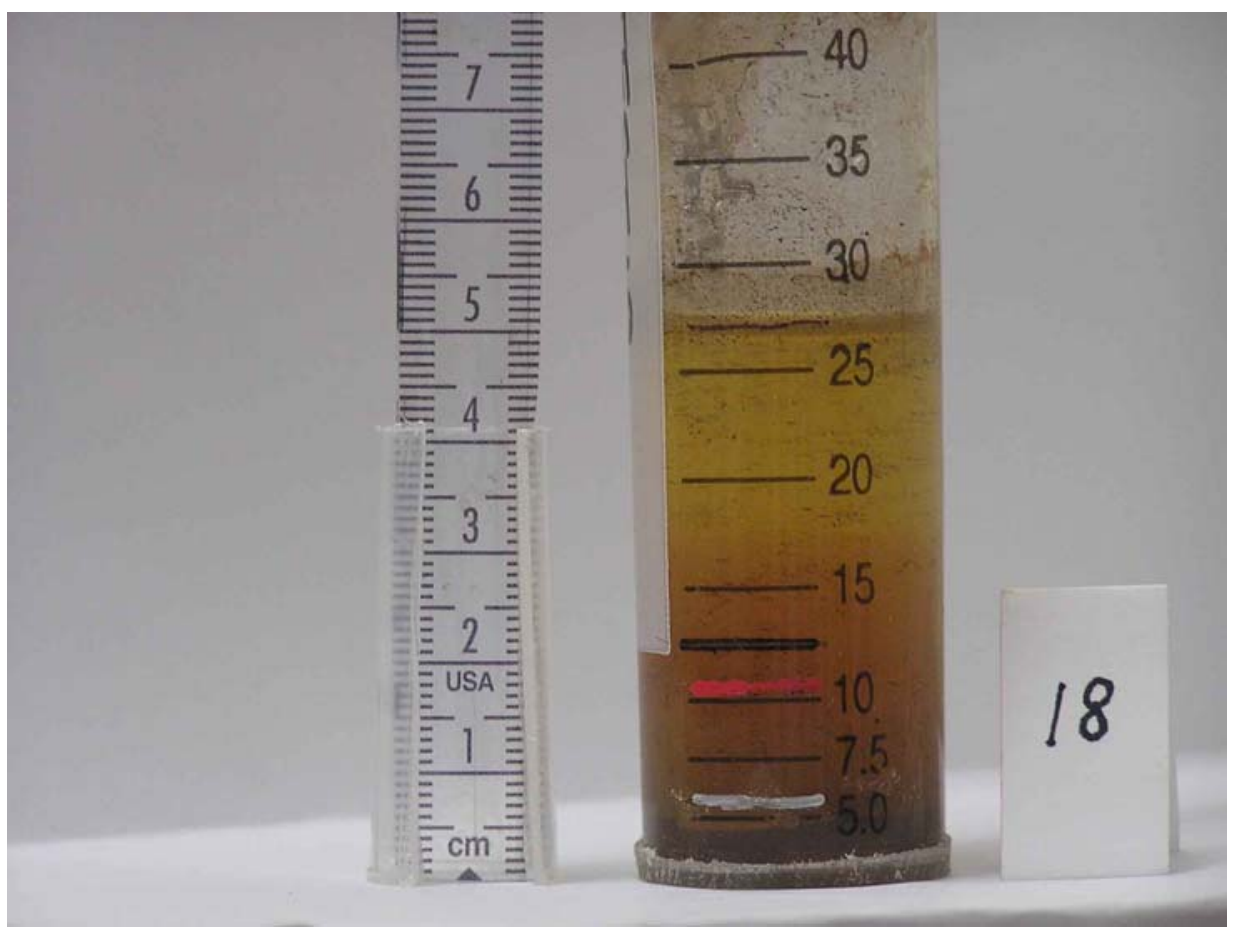

Figure C.18. Static- $-\mathrm{pH}$ Raised to $12 \mathrm{Using} \mathrm{NaOH}-\mathrm{KW}$ Simulant 


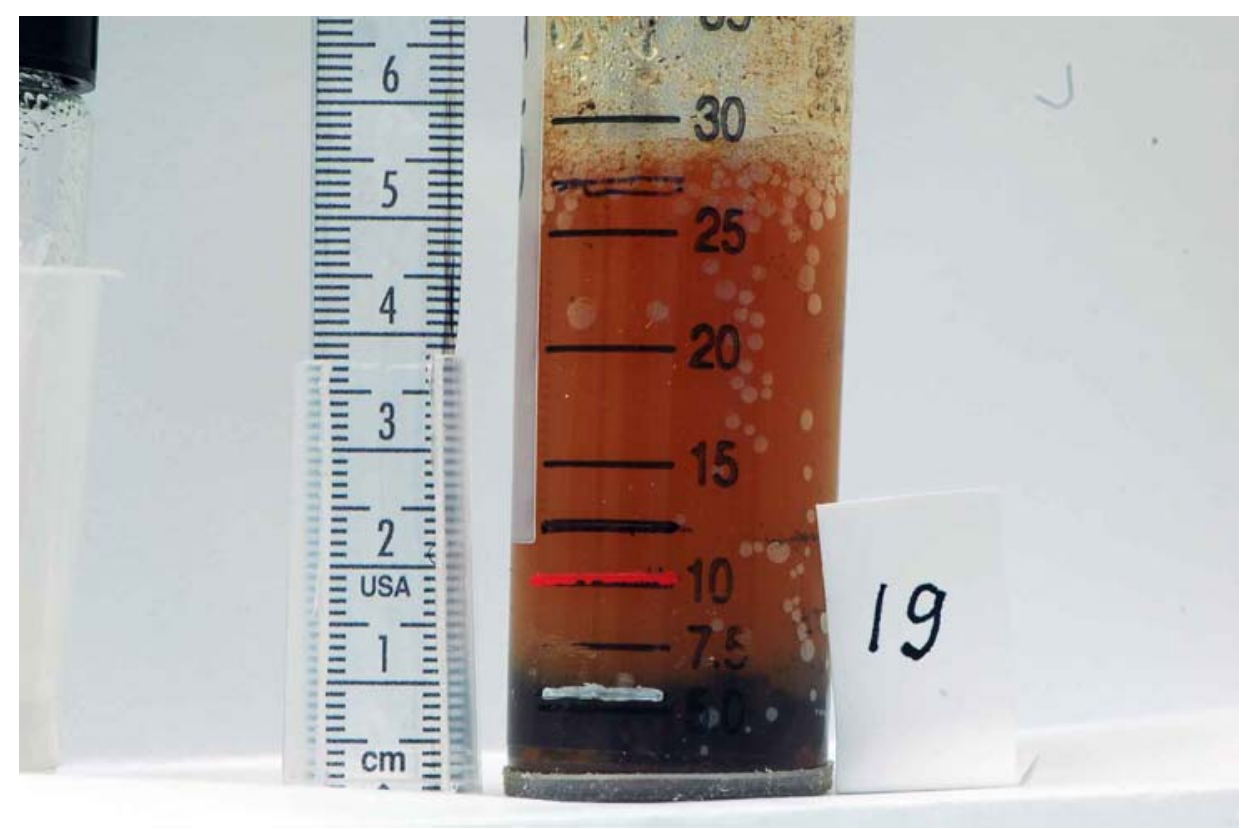

Figure C.19. Static- $-\mathrm{pH}$ Raised to $12 \mathrm{Using} \mathrm{Na}_{3} \mathrm{PO}_{4}-\mathrm{KW}$ Simulant

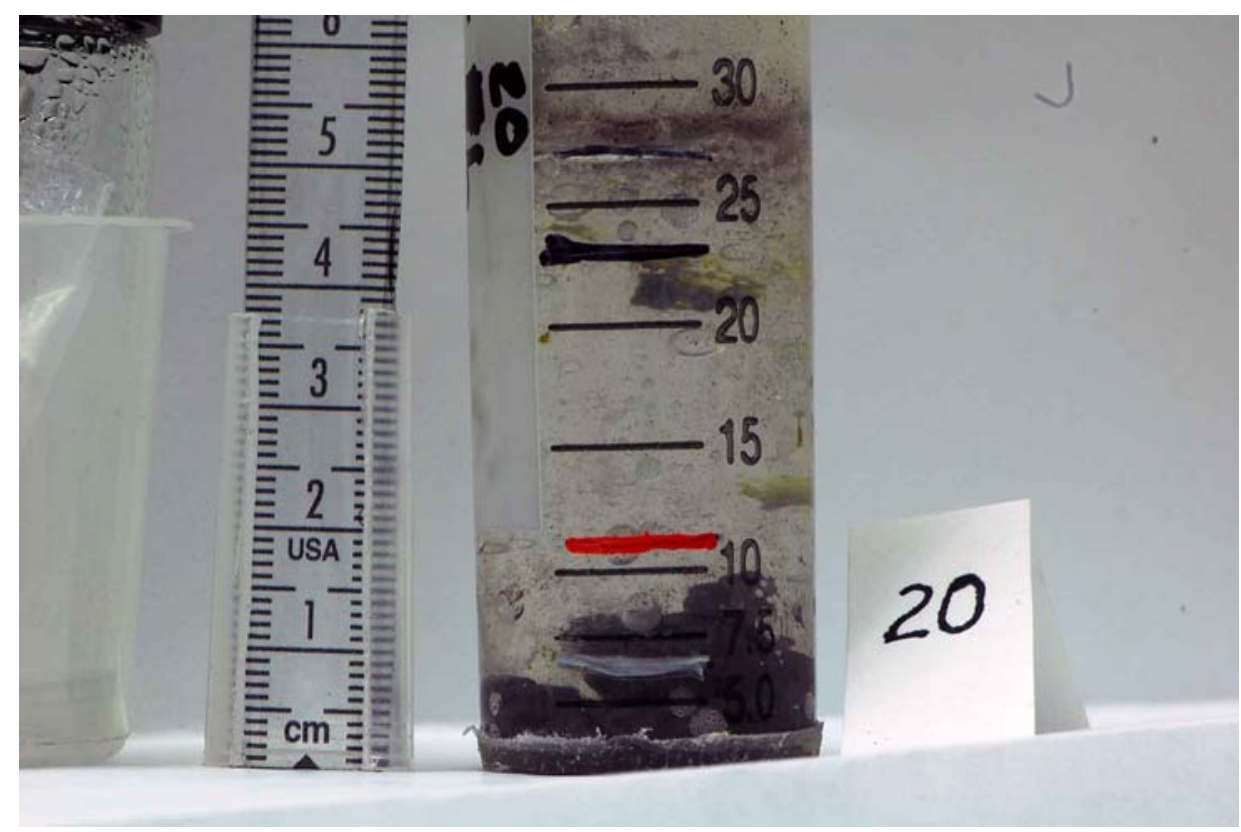

Figure C.20. Static - No pH Adjustment-50:50 Uranium Oxide Slurry 


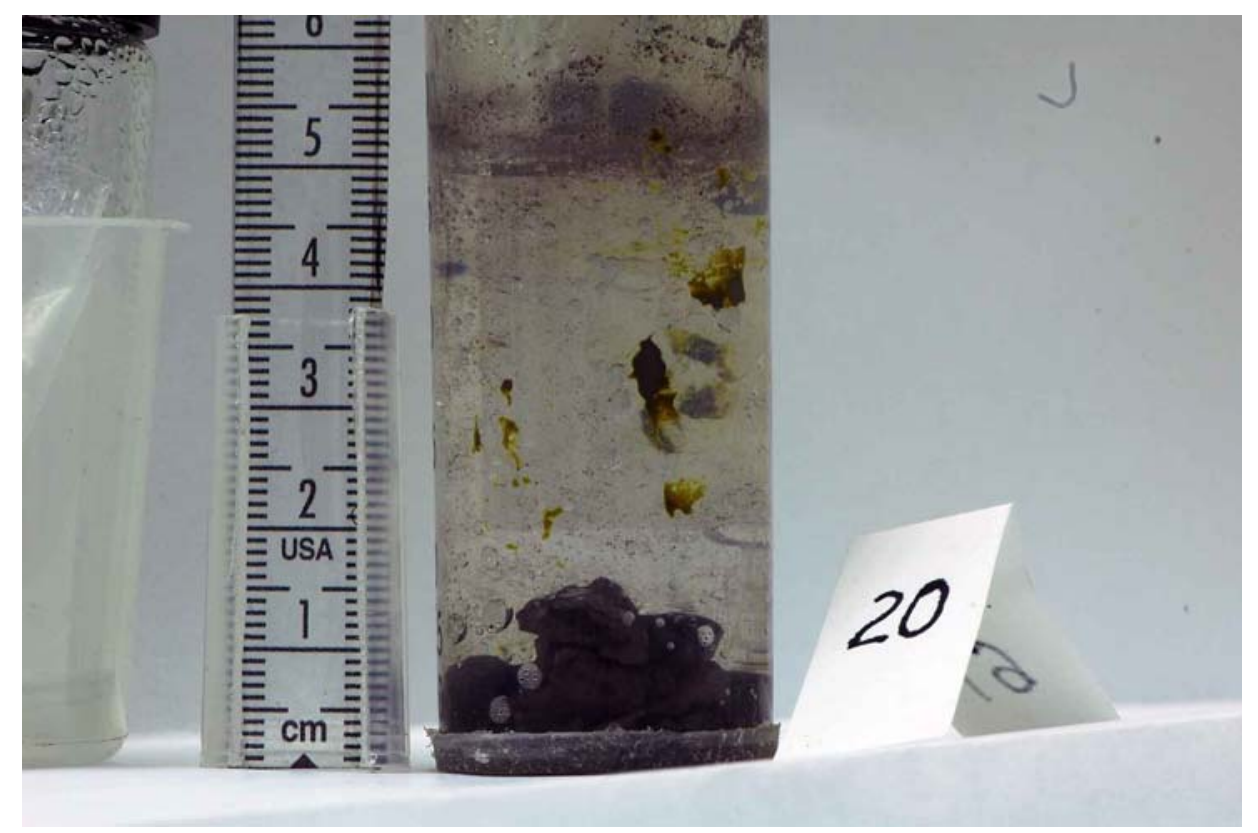

Figure C.21. Static—No pH Adjustment—50:50 Uranium Oxide Slurry

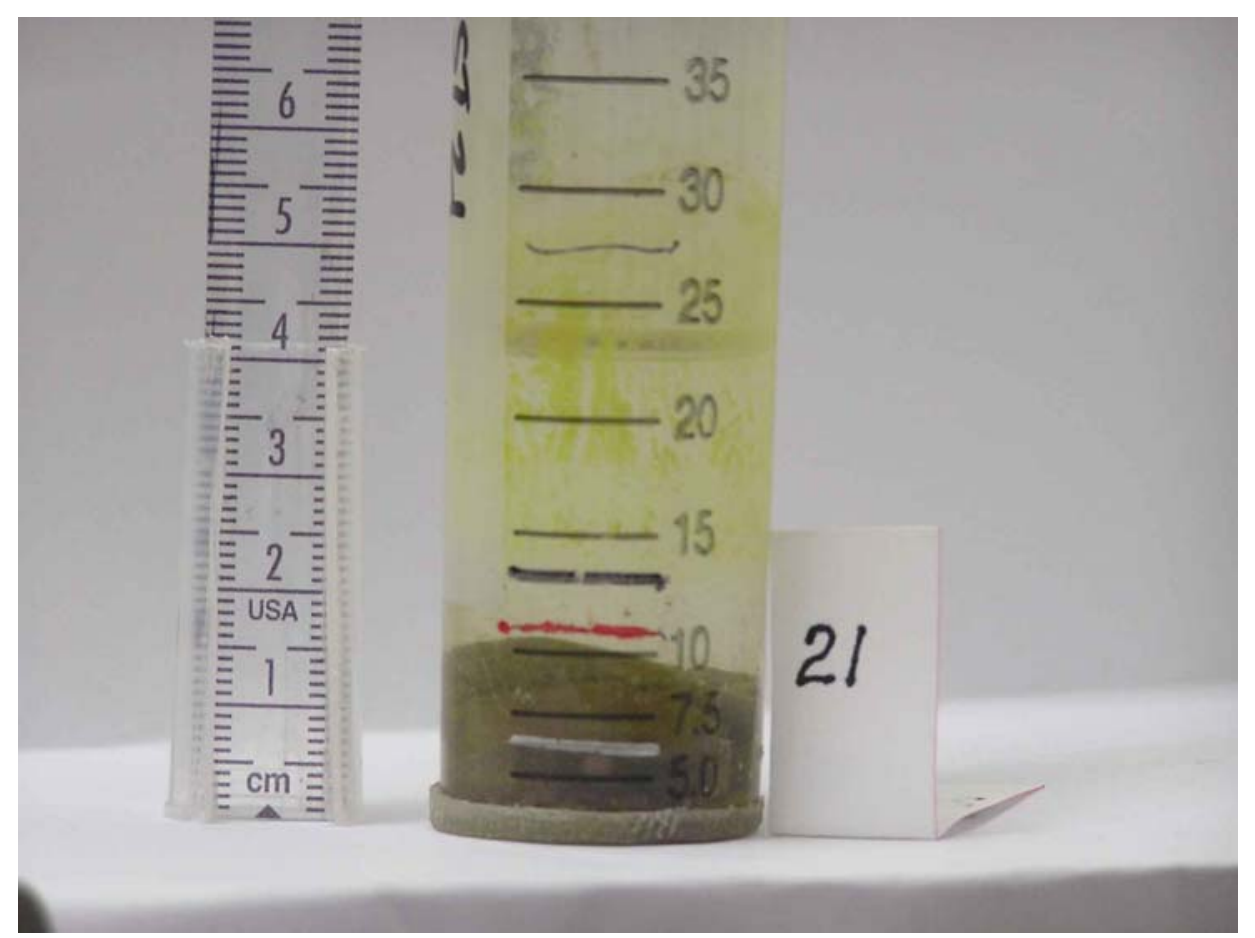

Figure C.22. Static — No pH Adjustment—50:50 Uranium Oxide Slurry 


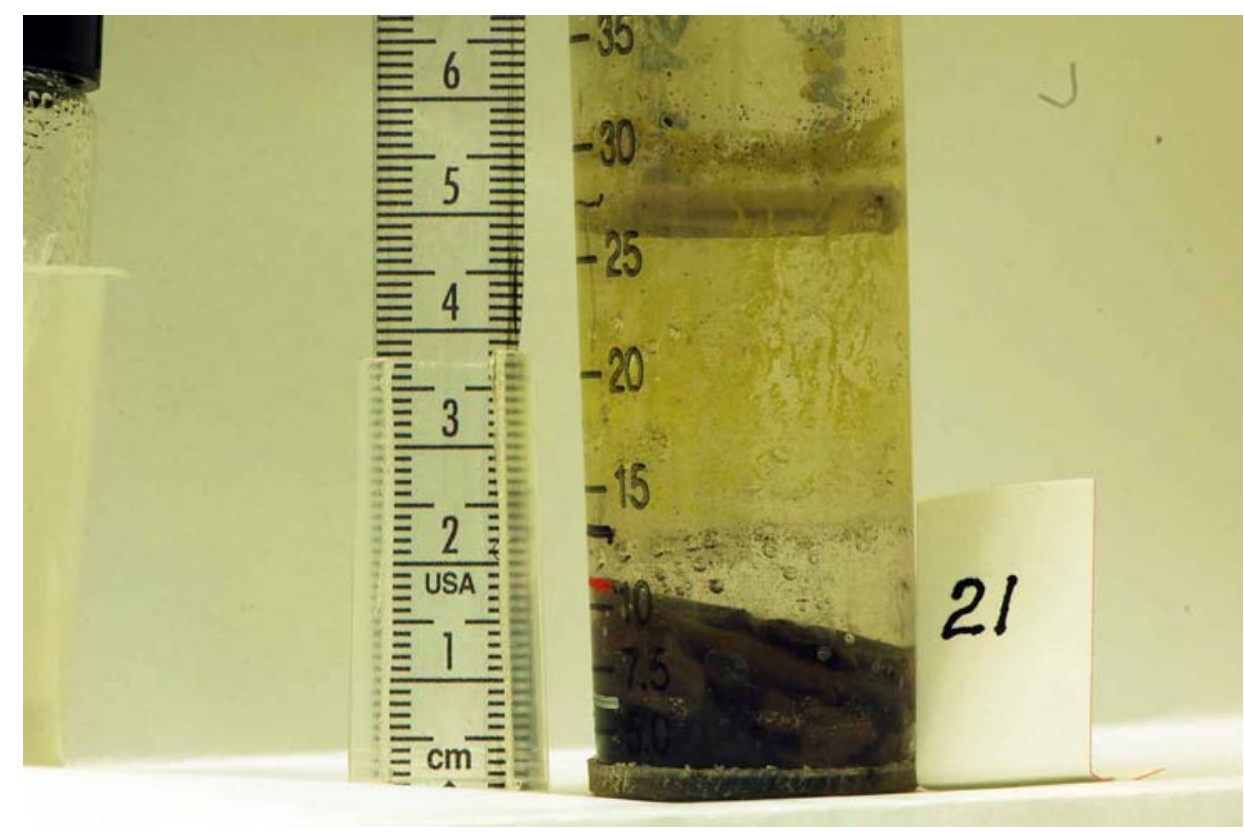

Figure C.23. Static-No pH Adjustment-50:50 Uranium Oxide Slurry

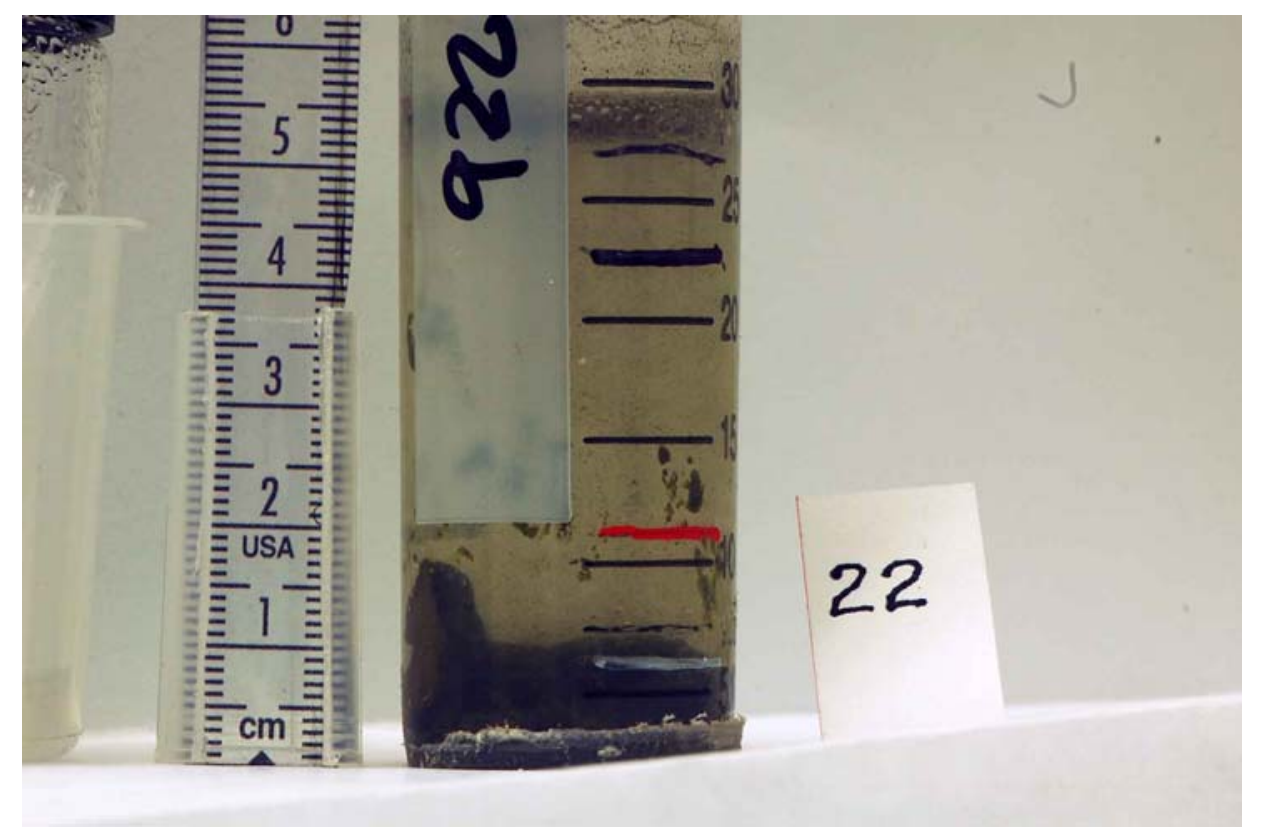

Figure C.24. Static - pH Raised to 12 Using $\mathrm{NaOH}-50: 50$ Uranium Oxide Slurry 


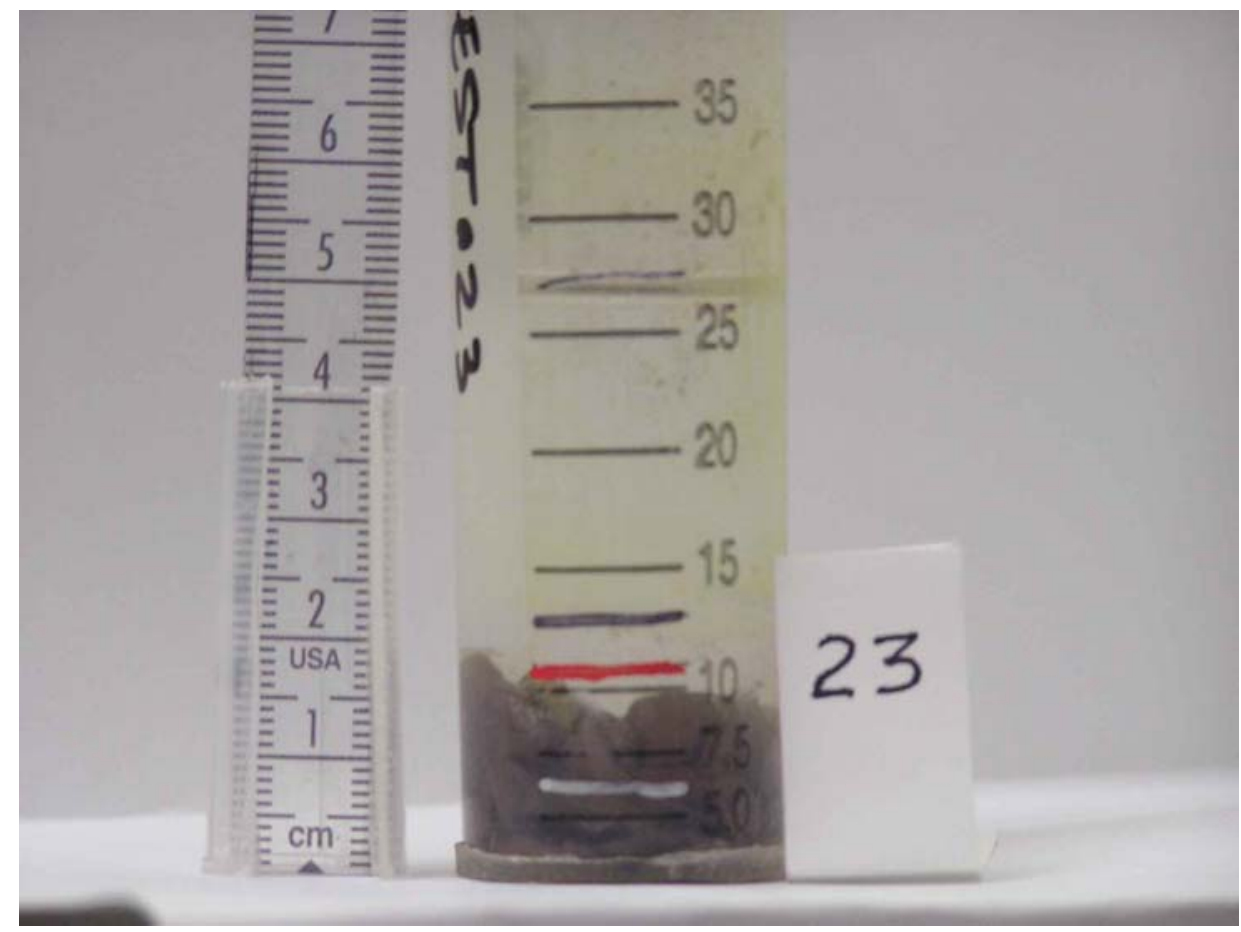

Figure C.25. Static—No pH Adjustment—50:50 Uranium Oxide Slurry

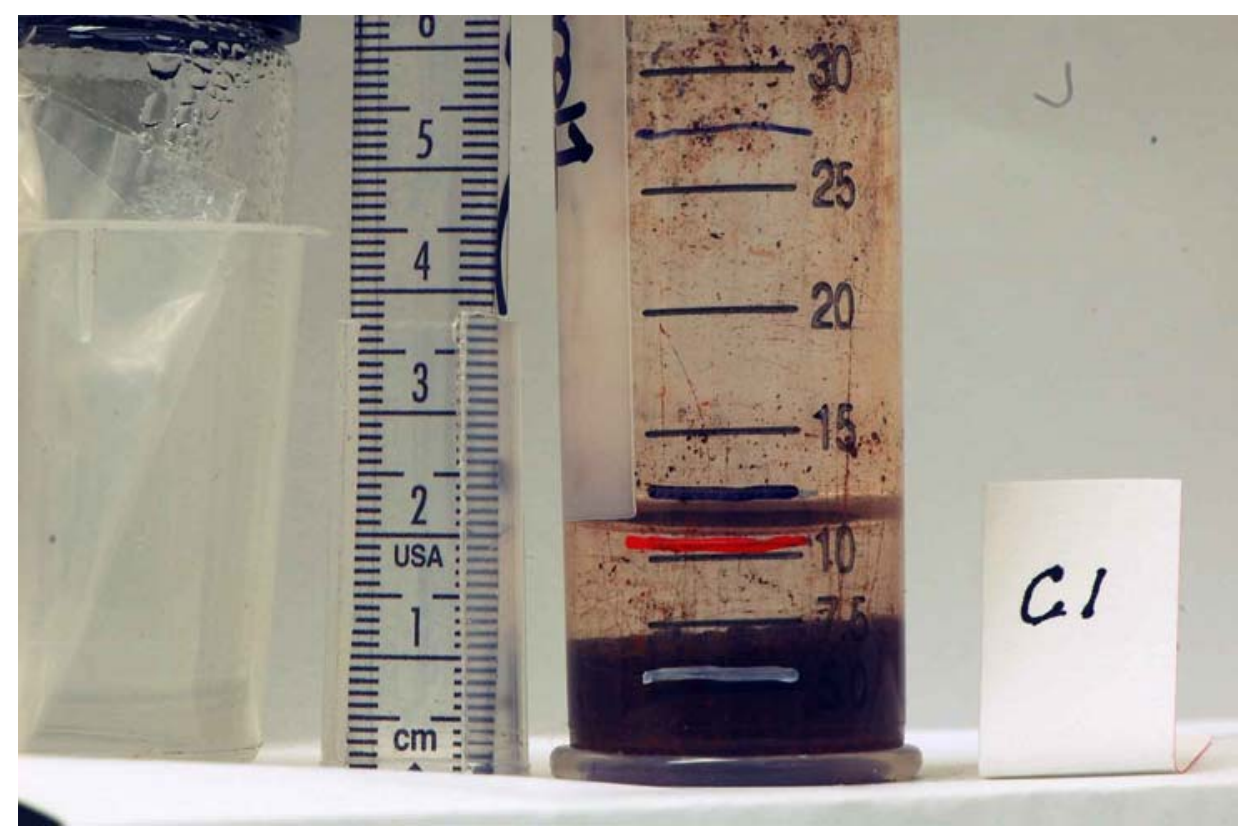

Figure C.26. Control—No pH Adjustment-KW Simulant 


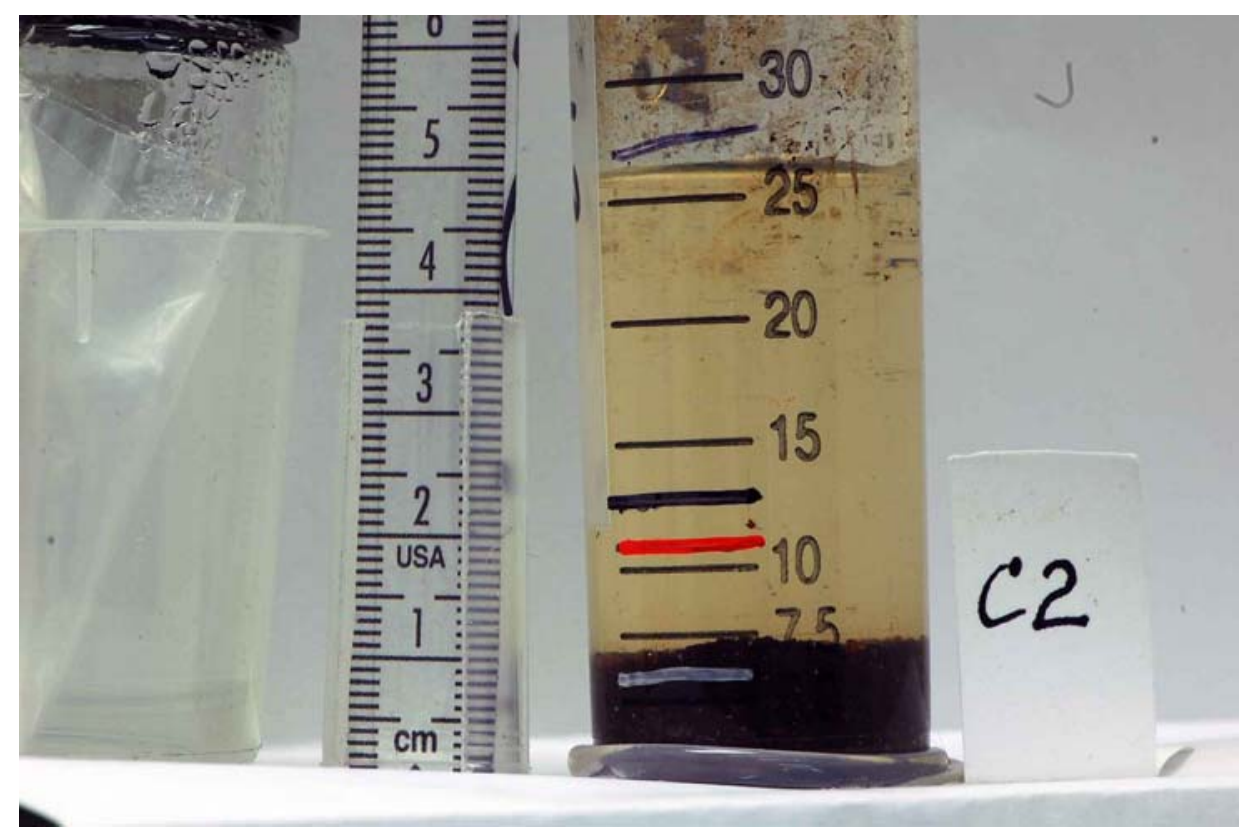

Figure C.27. Control- $\mathrm{pH}$ Raised to 12 Using $\mathrm{NaOH}-\mathrm{KW}$ Simulant

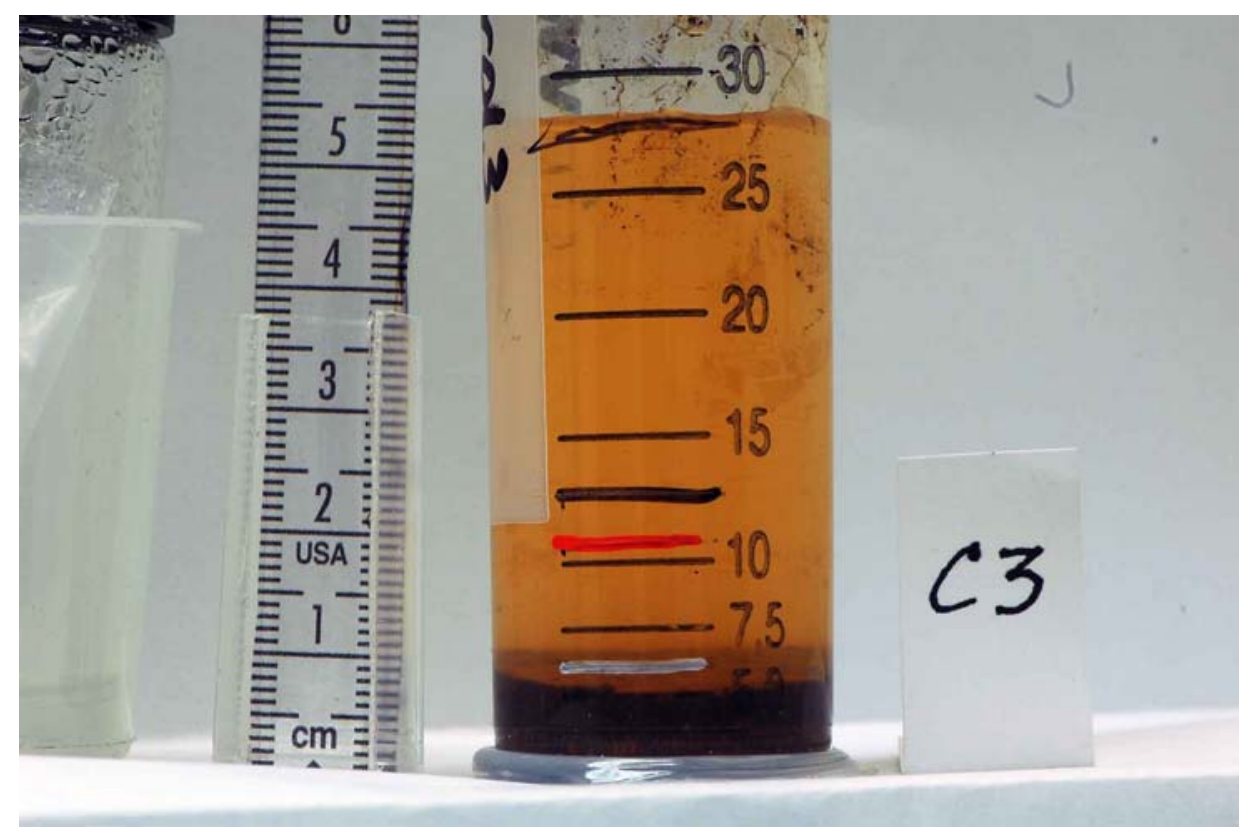

Figure C.28. Control $-\mathrm{pH}$ Raised to 12 Using $\mathrm{Na}_{3} \mathrm{PO}_{4}-\mathrm{KW}$ Simulant 


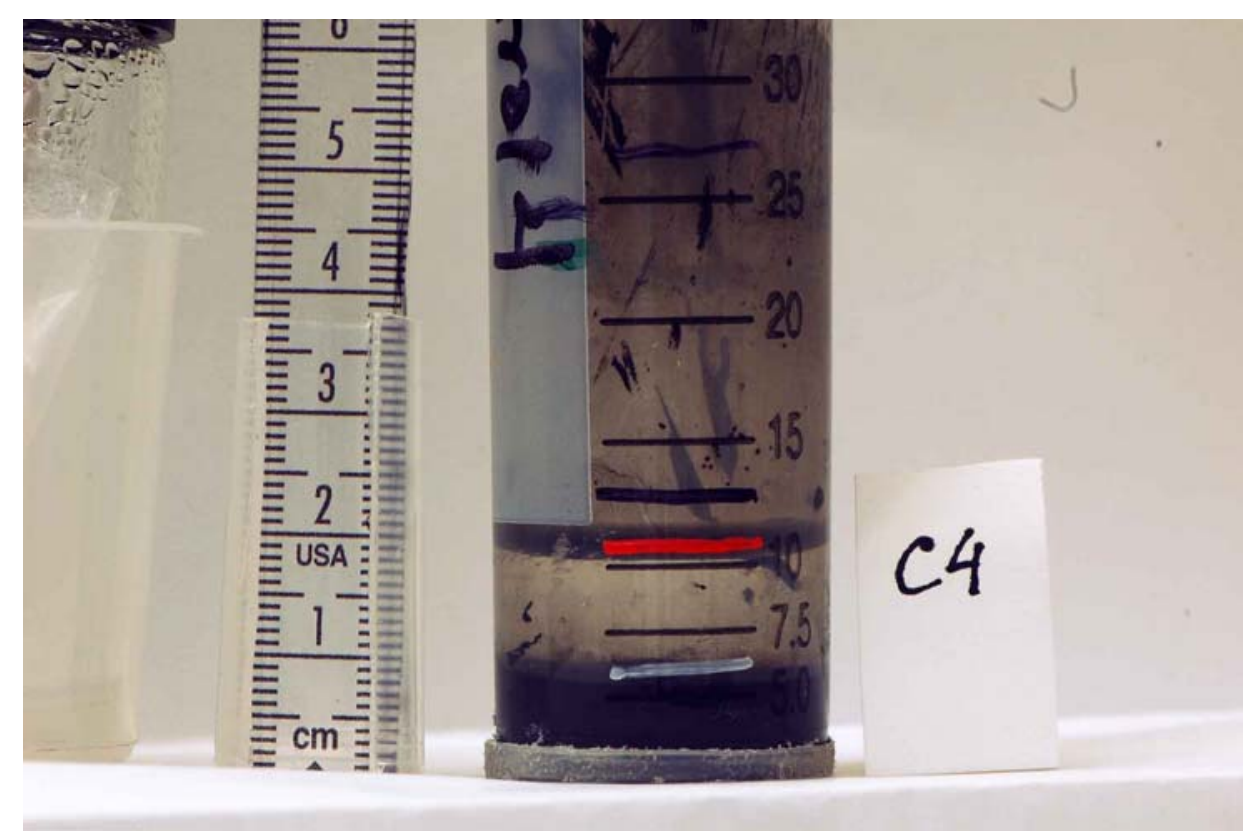

Figure C.29. Control—No pH Adjustment-50:50 Uranium Oxide Slurry

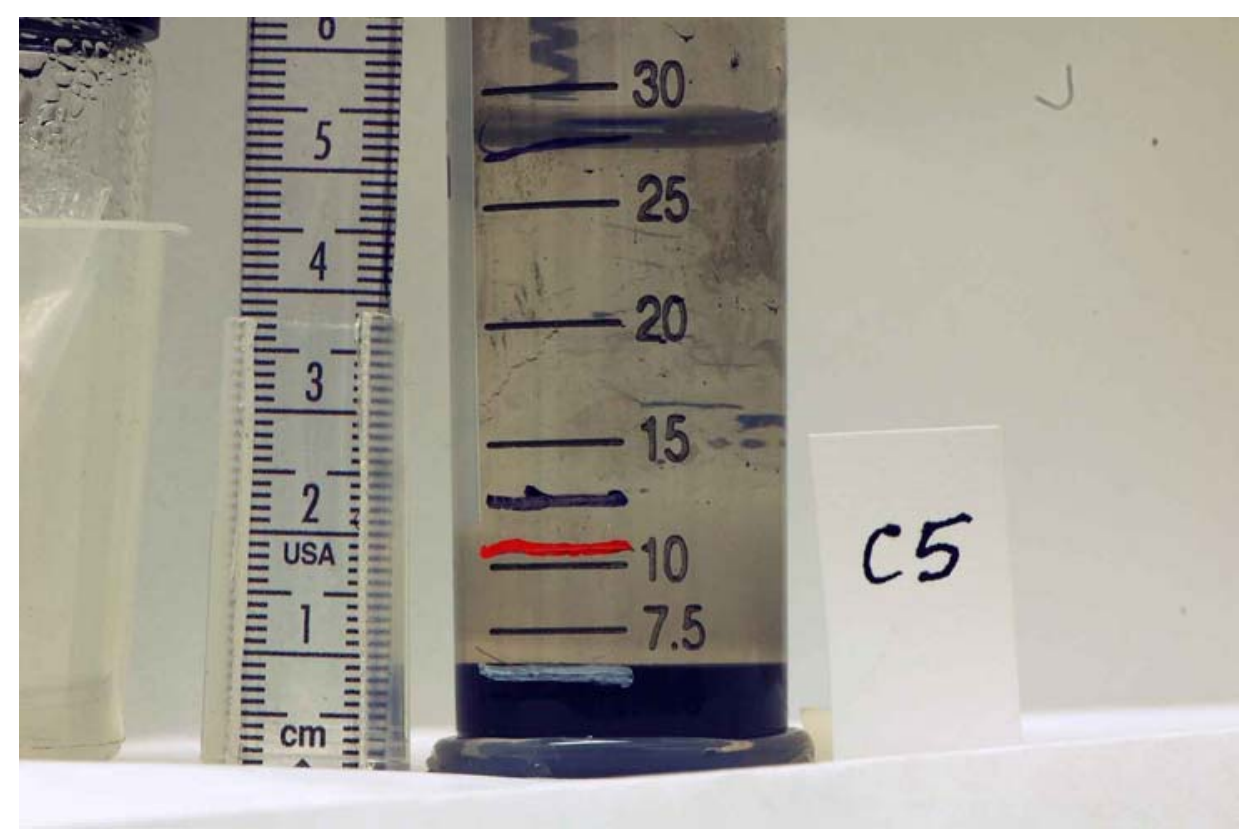

Figure C.30. Control— $\mathrm{pH}$ Raised to 12 Using $\mathrm{NaOH}-50: 50$ Uranium Oxide Slurry 



\section{Appendix D}

\section{Photographs of Test Items Following Completion of Two-Week Settling Period}

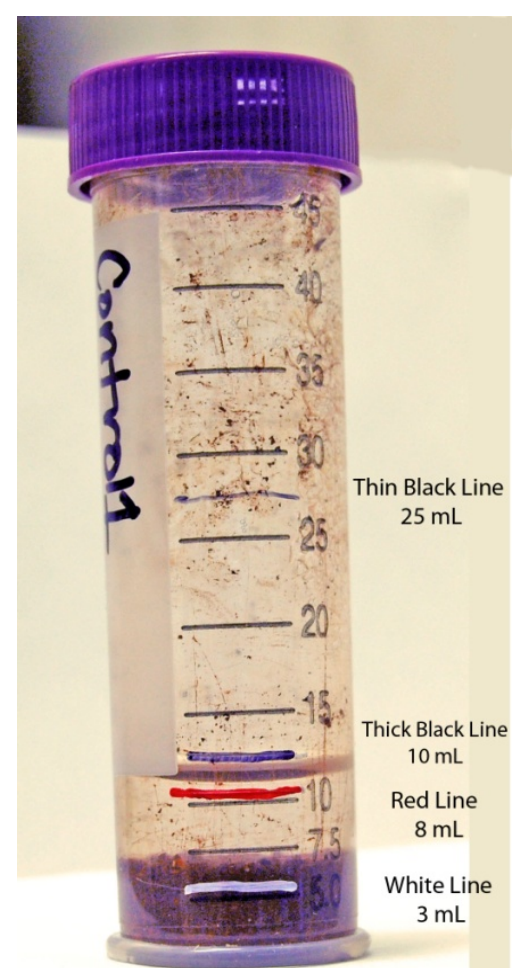

Note: The markings on the centrifuge tubes in these photos in this appendix indicate new calibration points for the vessel as determined with calibrated pipettes. The white line indicates the anticipated volume of the simulated sludge. The red line indicates the initial fill volume. The thick black line indicates the initial fill volume suggested for these tests. The thin black line indicates the final fill volume used. 



\section{Appendix D - Photographs of Test Items Following Completion of Two-Week Settling Period}

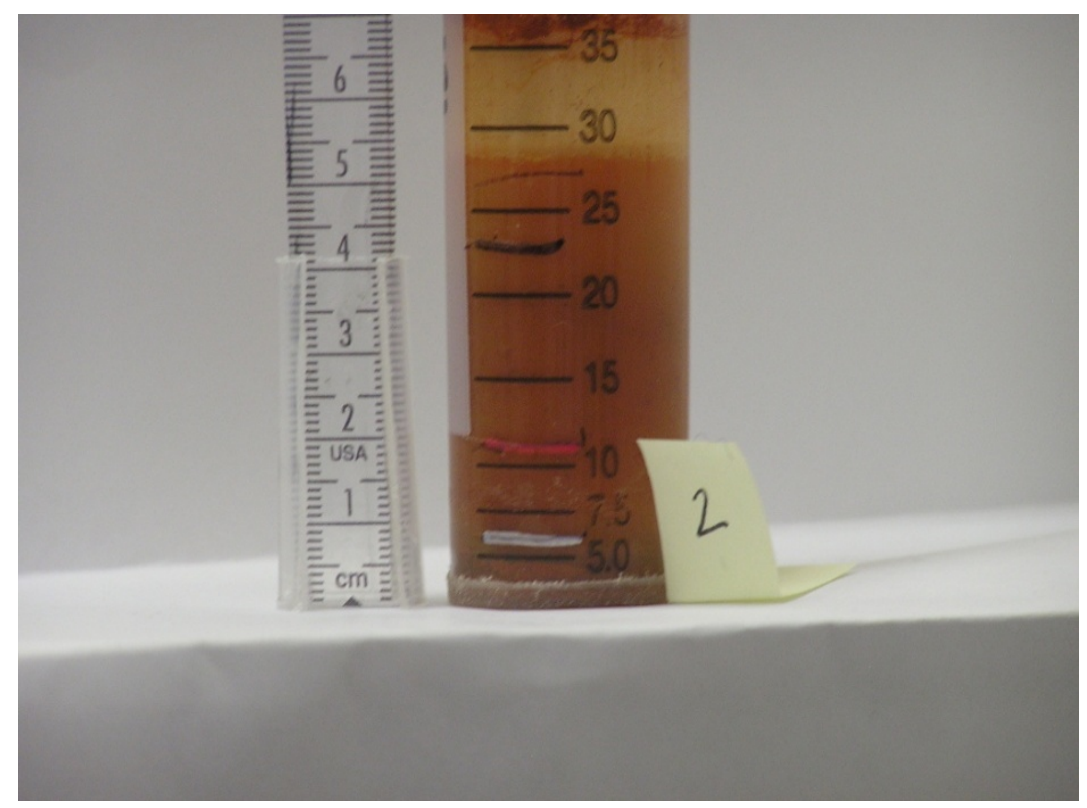

Figure D.1. Agitated—No pH Adjustment—KW Simulant—Additional Two Weeks Spent at $95^{\circ} \mathrm{C}$

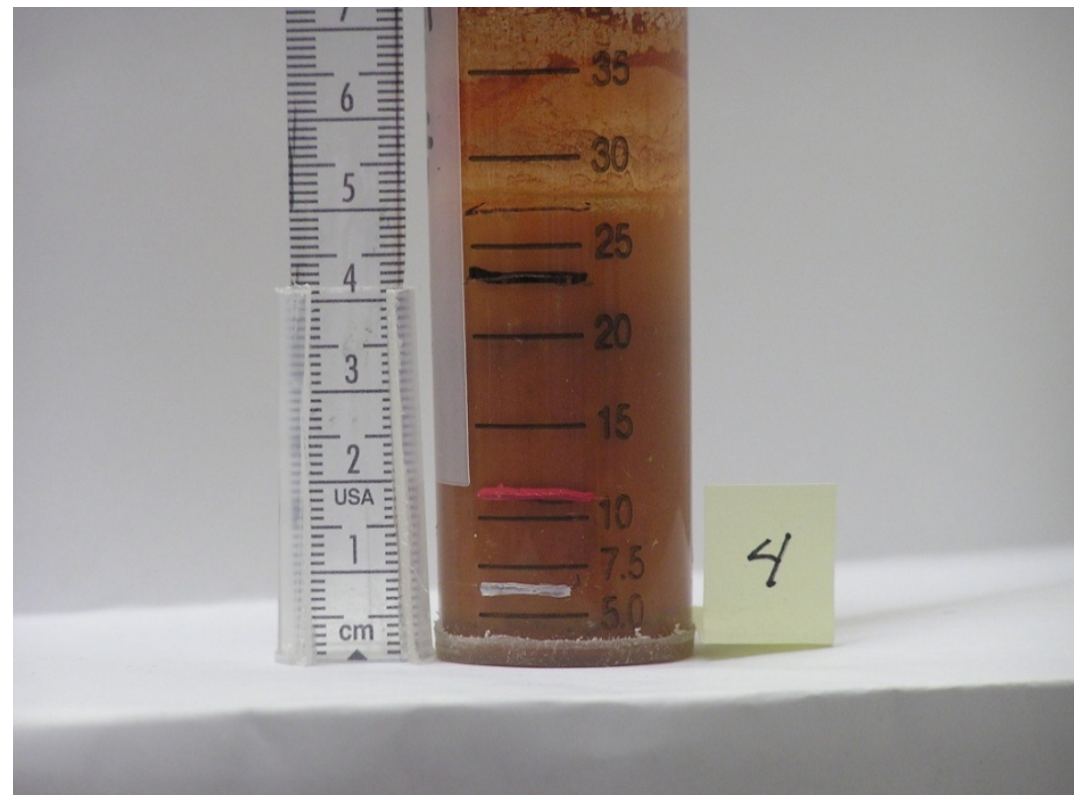

Figure D.2. Agitated - $\mathrm{pH}$ Raised to 12 Using $\mathrm{NaOH}-\mathrm{KW}$ Simulant—Additional Two Weeks Spent at $95^{\circ} \mathrm{C}$ 


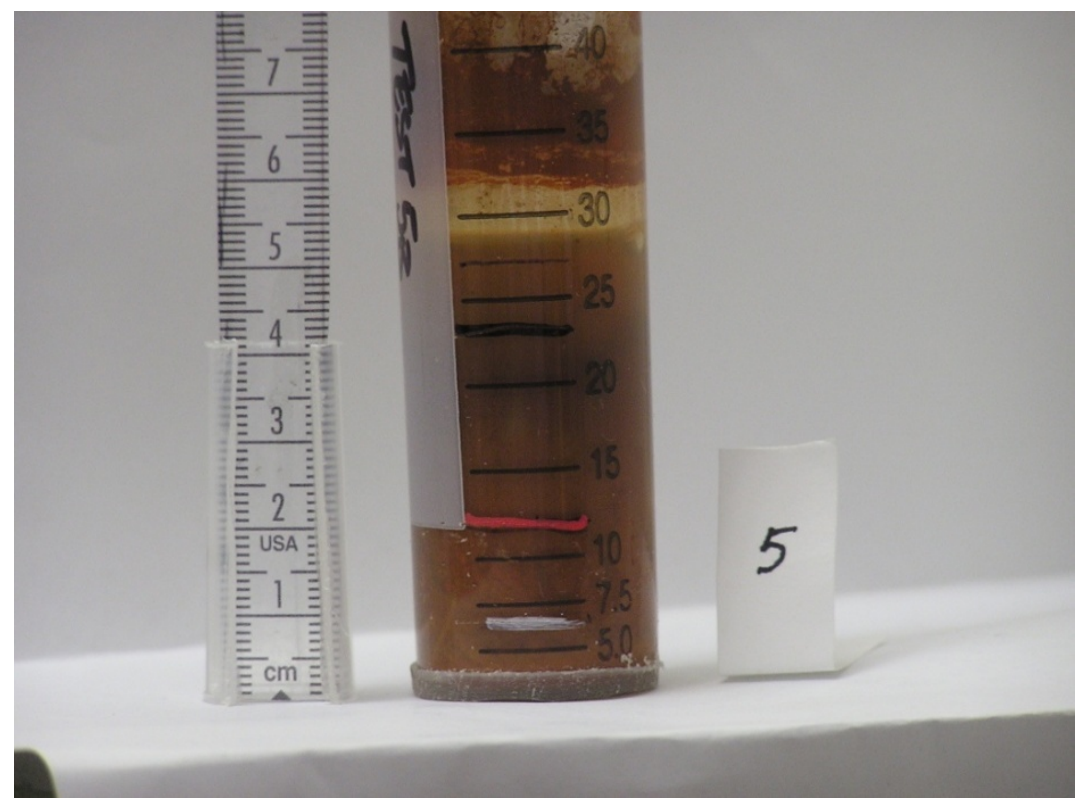

Figure D.3. Agitated-No pH Adjustment - KW Simulant—Additional Two Weeks Spent at $25^{\circ} \mathrm{C}$

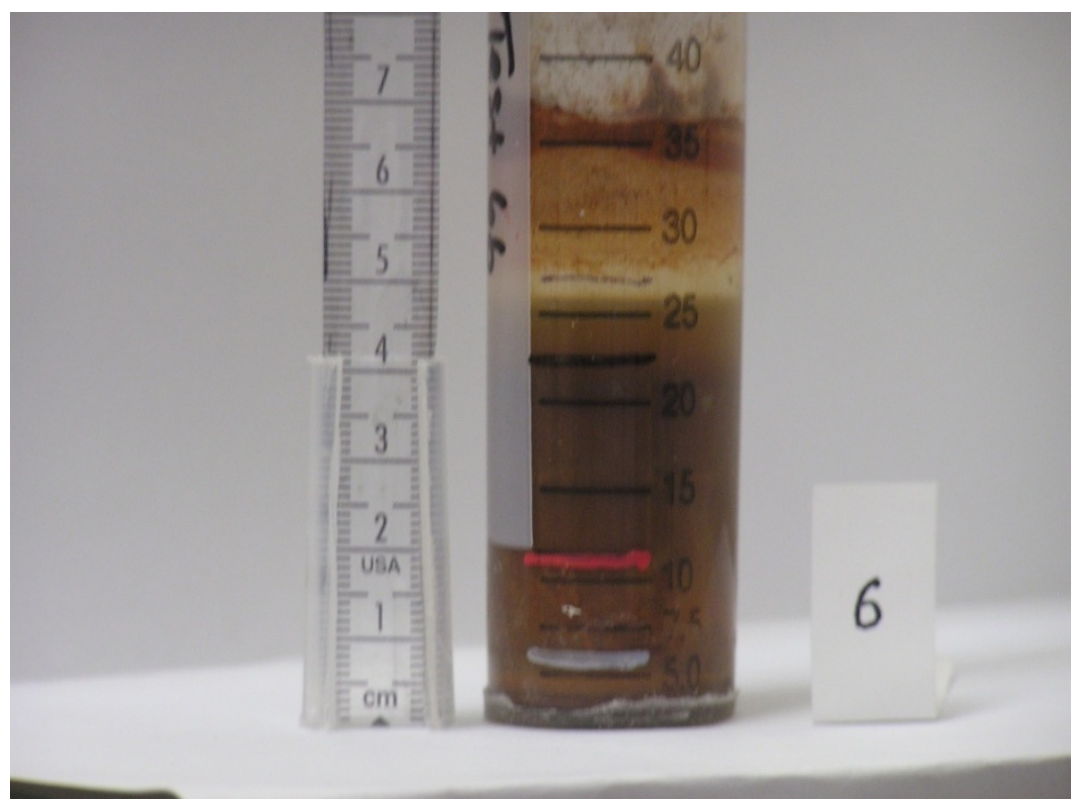

Figure D.4. Agitated- $\mathrm{pH}$ Raised to 12 Using $\mathrm{NaOH}-\mathrm{KW}$ Simulant—Additional Two Weeks Spent at $25^{\circ} \mathrm{C}$ 


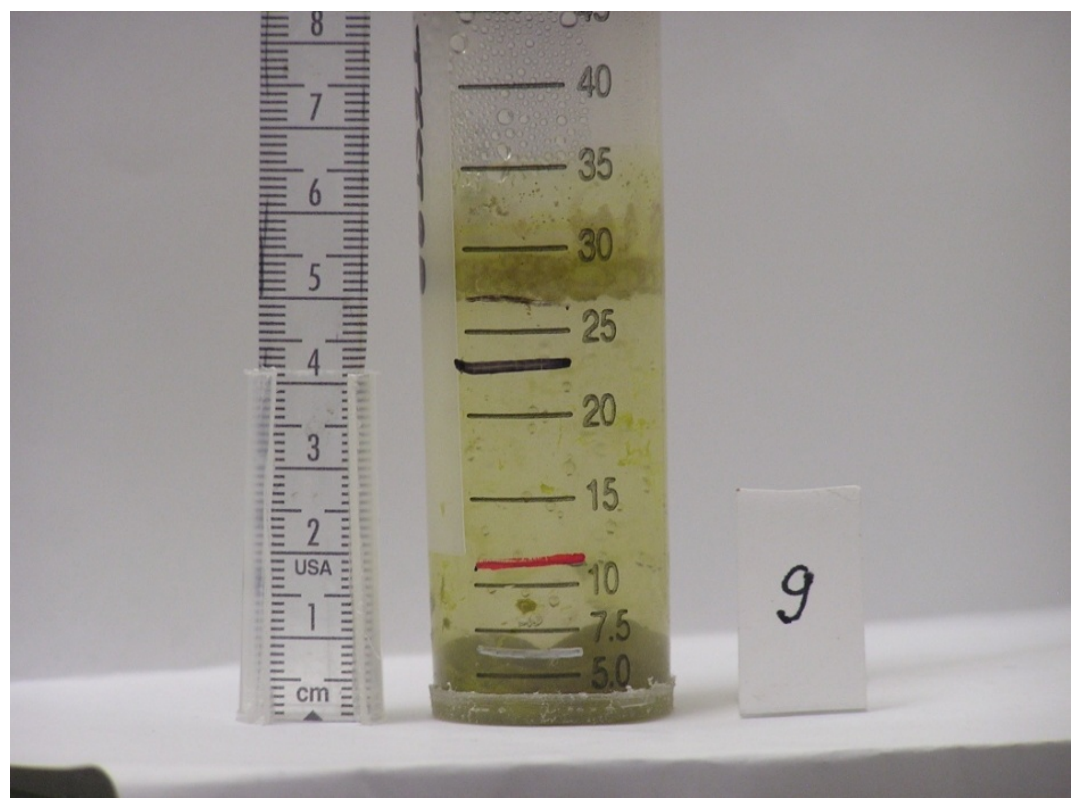

Figure D.5. Agitated-No pH Adjustment—50:50 Uranium Oxide Slurry-Additional Two Weeks Spent at $95^{\circ} \mathrm{C}$

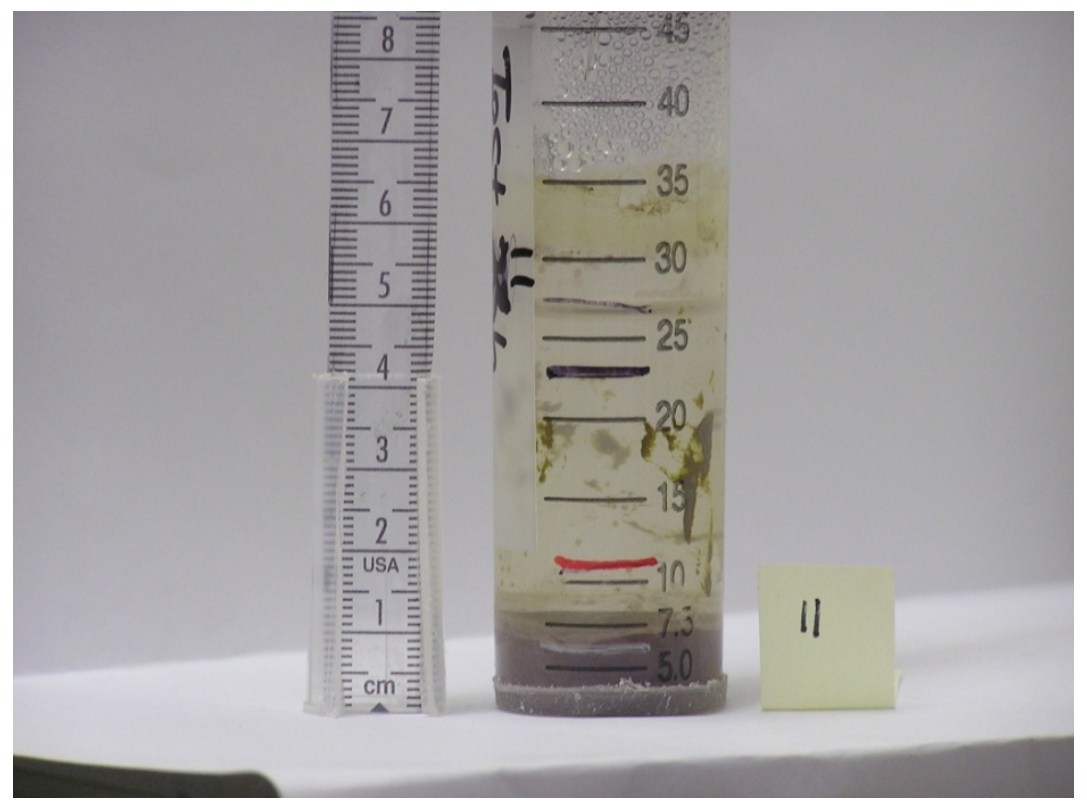

Figure D.6. Agitated - No pH Adjustment—50:50 Uranium Oxide Slurry—Additional Two Weeks Spent at $25^{\circ} \mathrm{C}$ 


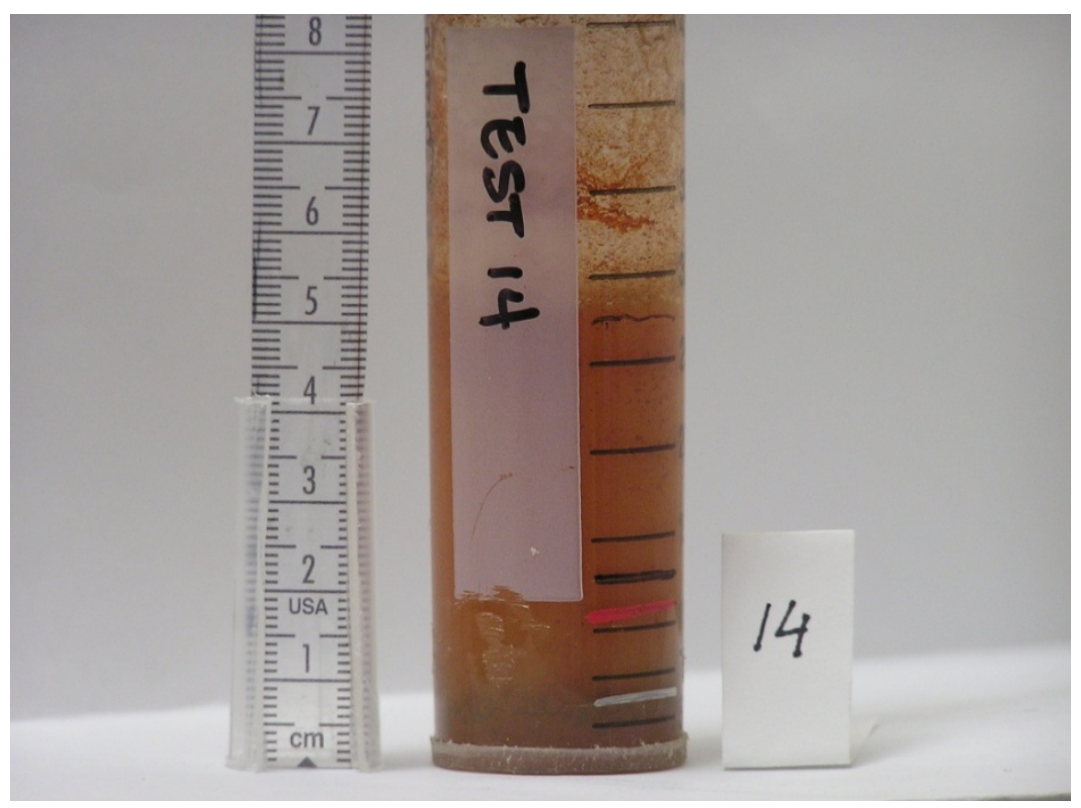

Figure D.7. Static — No pH Adjustment—KW Simulant—Additional Two Weeks Spent at $95^{\circ} \mathrm{C}$

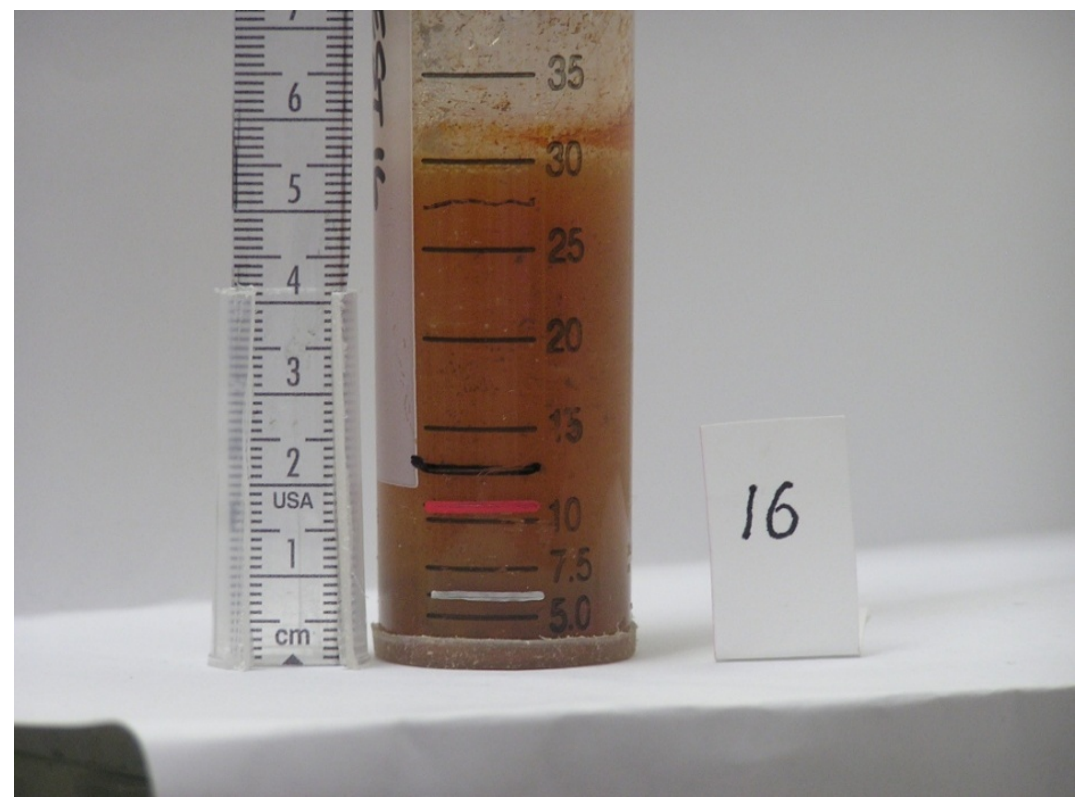

Figure D.8. Static - $\mathrm{pH}$ Raised to 12 Using $\mathrm{NaOH}-\mathrm{KW}$ Simulant-Additional Two Weeks Spent at $95^{\circ} \mathrm{C}$ 


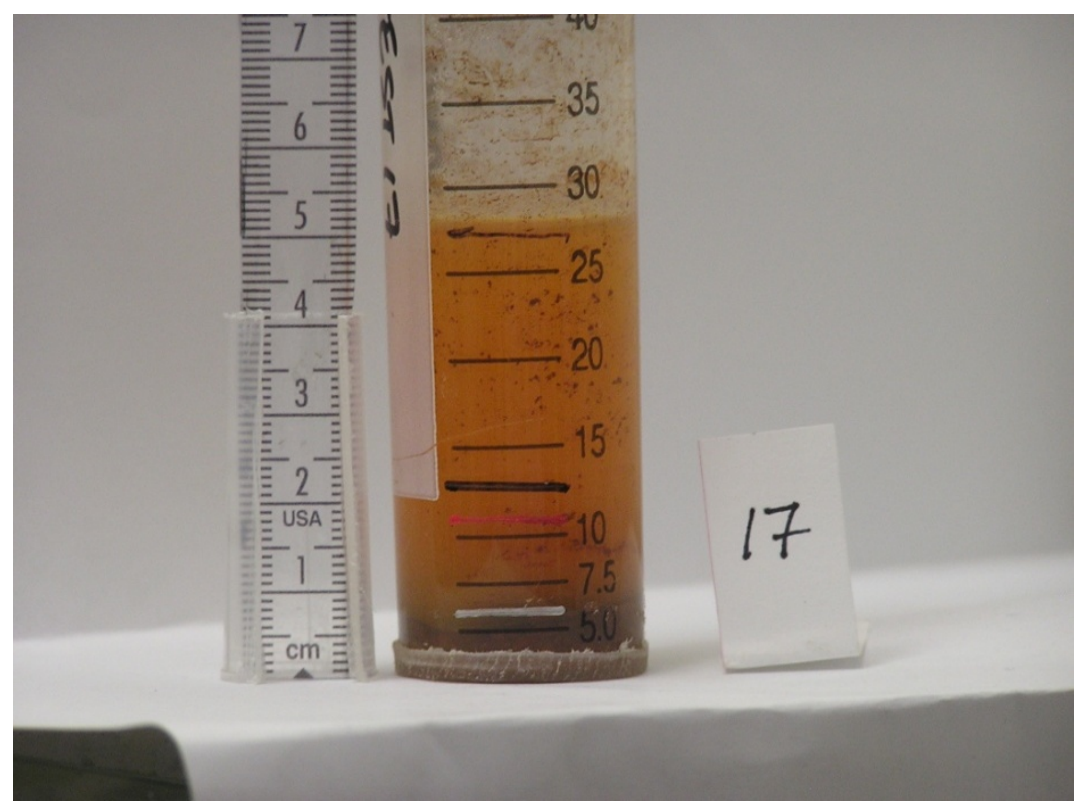

Figure D.9. Static — No pH Adjustment—KW Simulant—Additional Two Weeks Spent at $25^{\circ} \mathrm{C}$

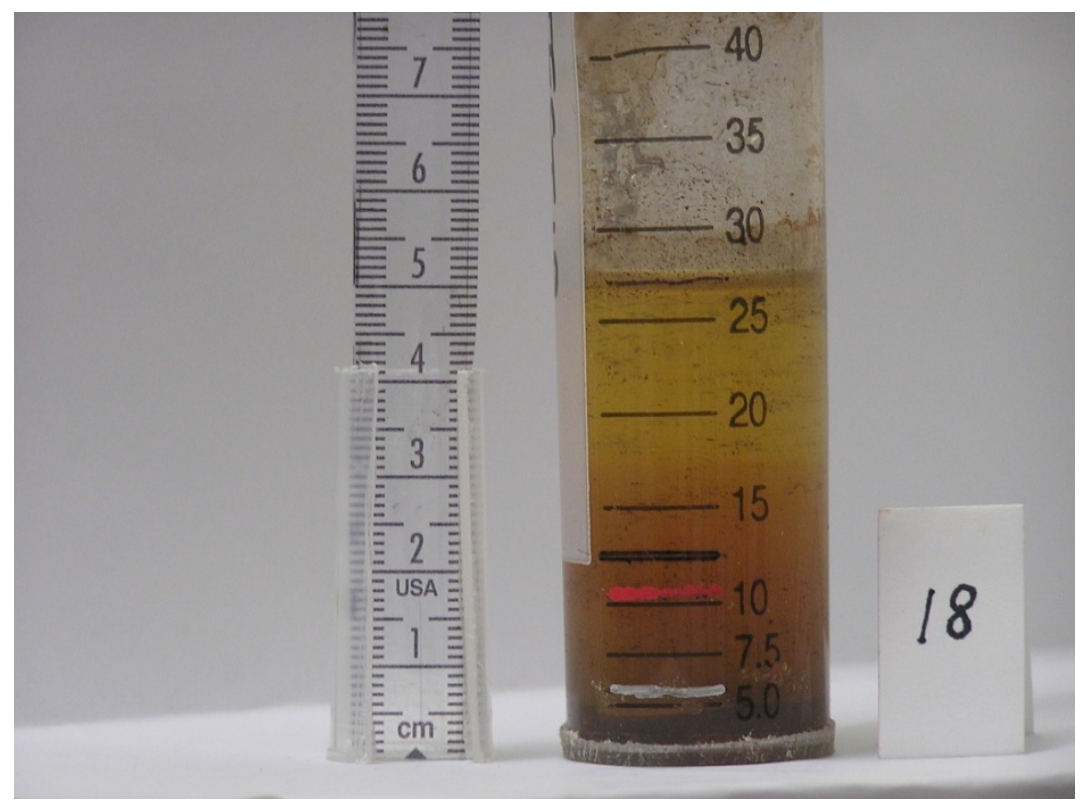

Figure D.10. Static - $\mathrm{pH}$ Raised to $12 \mathrm{Using} \mathrm{NaOH}-\mathrm{KW}$ Simulant-Additional Two Weeks Spent at $25^{\circ} \mathrm{C}$ 


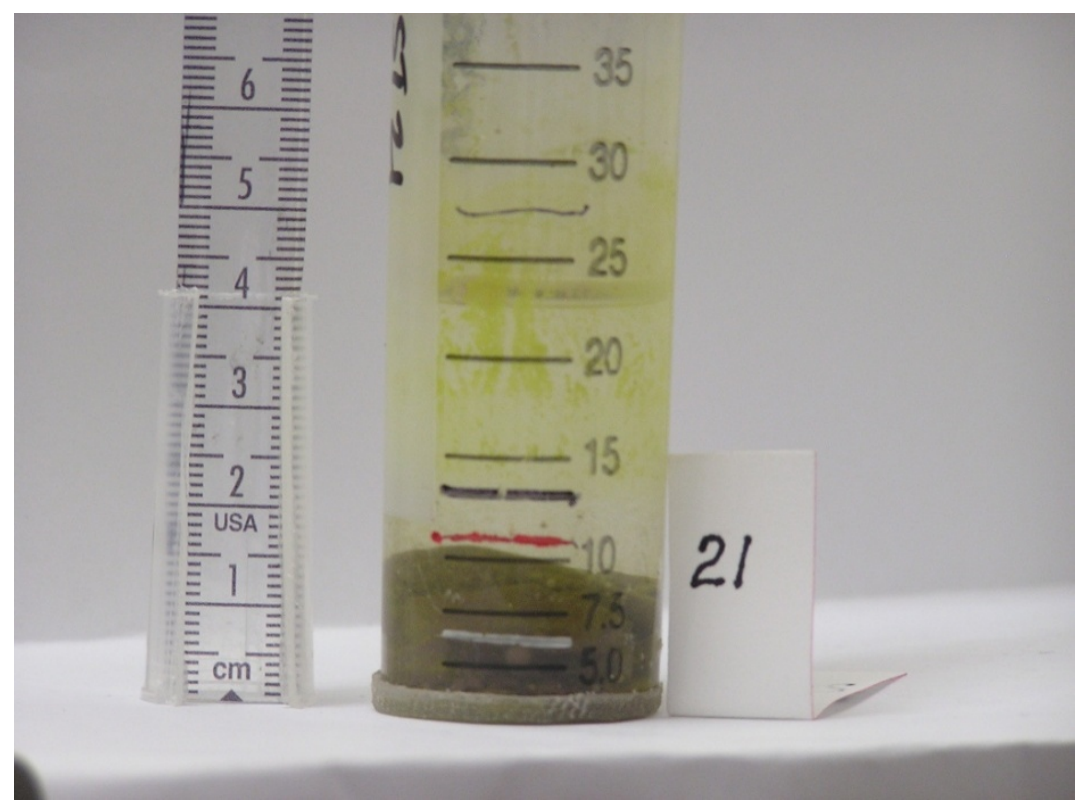

Figure D.11. Static — No pH Adjustment—50:50 Uranium Oxide Slurry—Additional Two Weeks Spent at $95^{\circ} \mathrm{C}$

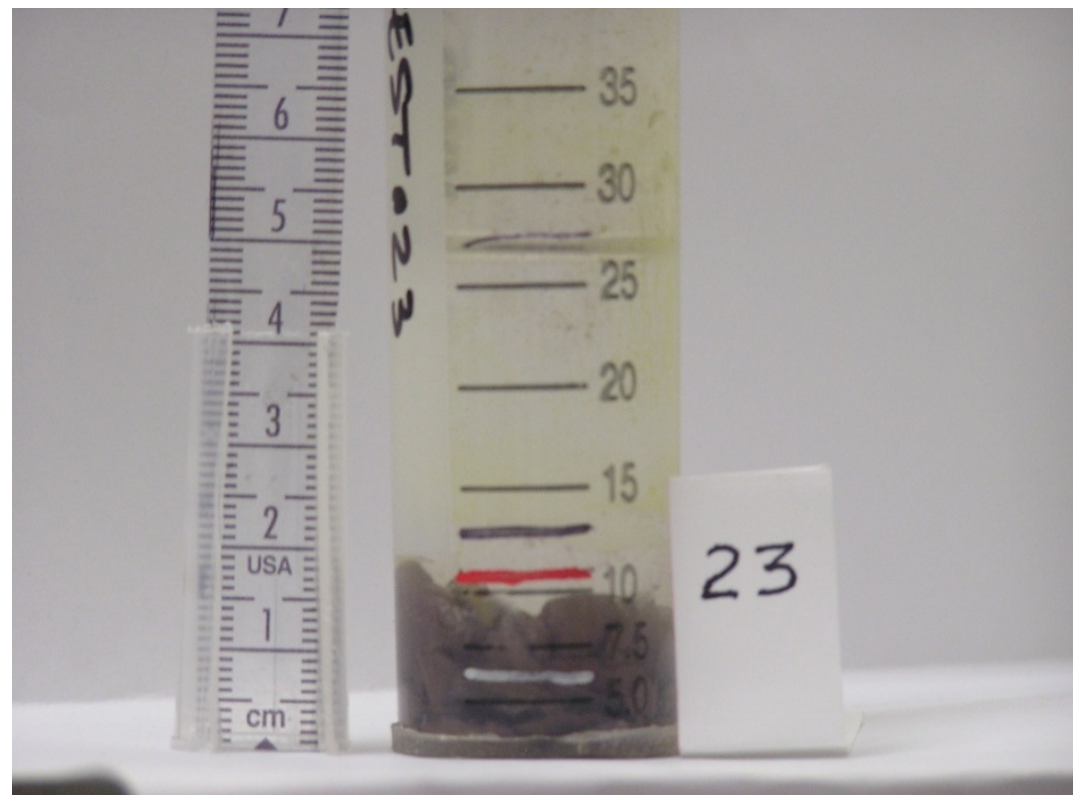

Figure D.12. Static—No pH Adjustment—50:50 Uranium Oxide Slurry—Additional Two Weeks Spent at $25^{\circ} \mathrm{C}$ 


\section{Appendix E}

\section{Scanned Electron Micrographs of Test Items}





\section{Appendix E - Scanned Electron Micrographs of Test Items}

\section{Initial Uranium Metal}

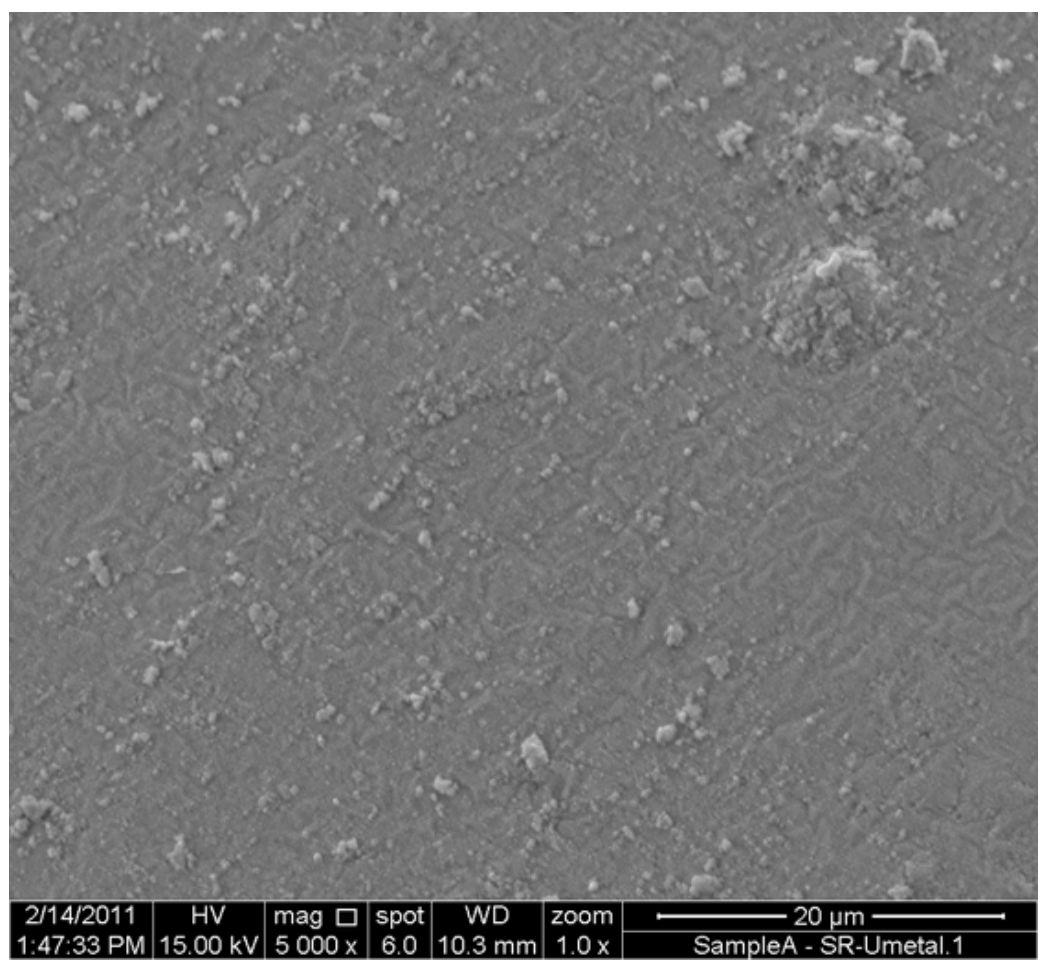

Figure E.1. Initial Uranium Metal - $20 \mu \mathrm{m}$ Window

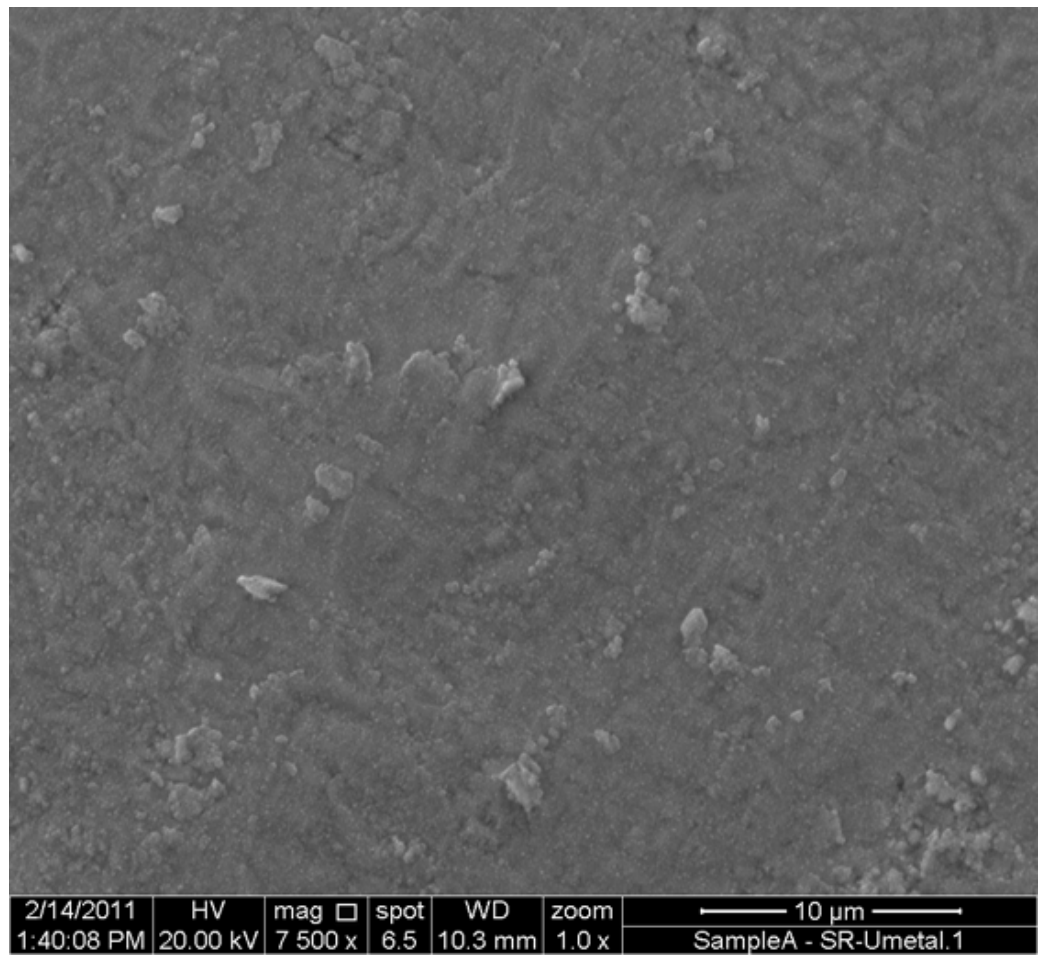

Figure E.2. Initial Uranium Metal - $10 \mu \mathrm{m}$ Window 
50:50 Uranium Oxide Slurry Contacted Uranium Metal/No $\mathrm{H}_{3} \mathrm{PO}_{4}$ Treatment

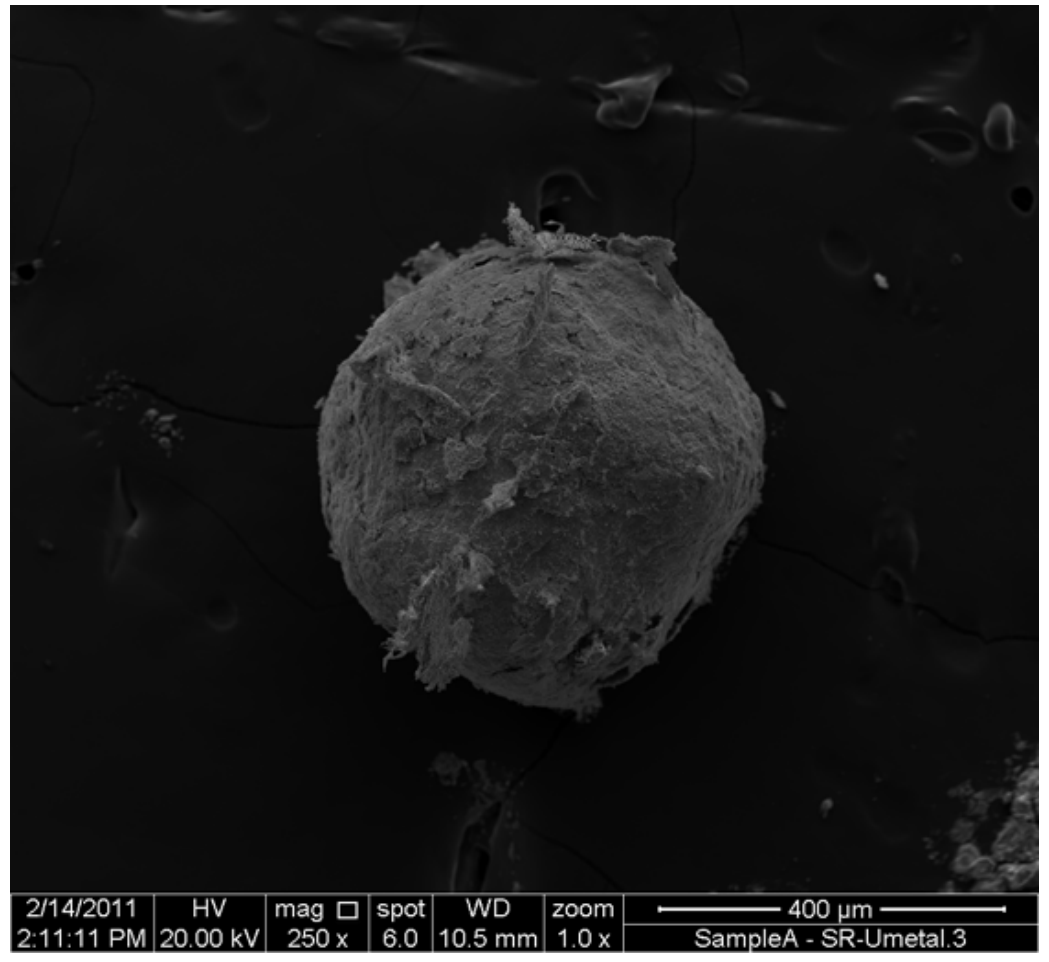

Figure E.3 50:50 Uranium Oxide Slurry Contacted Uranium Metal/No $\mathrm{H}_{3} \mathrm{PO}_{4}$ Treatment $-400 \mu \mathrm{m}$ Window 


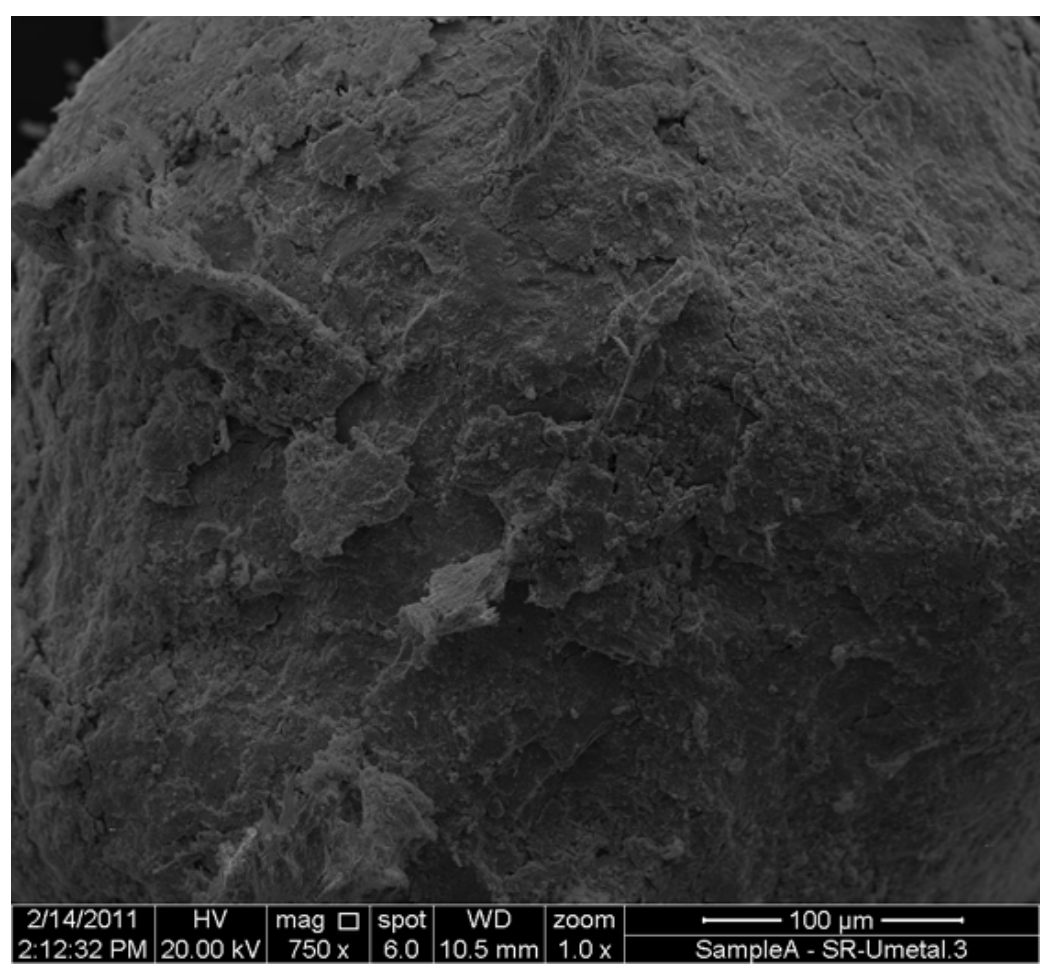

Figure E.4. 50:50 Uranium Oxide Slurry Contacted Uranium Metal/ $\mathrm{No}_{3} \mathrm{PO}_{4}$ Treatment $-100 \mu \mathrm{m}$ Window

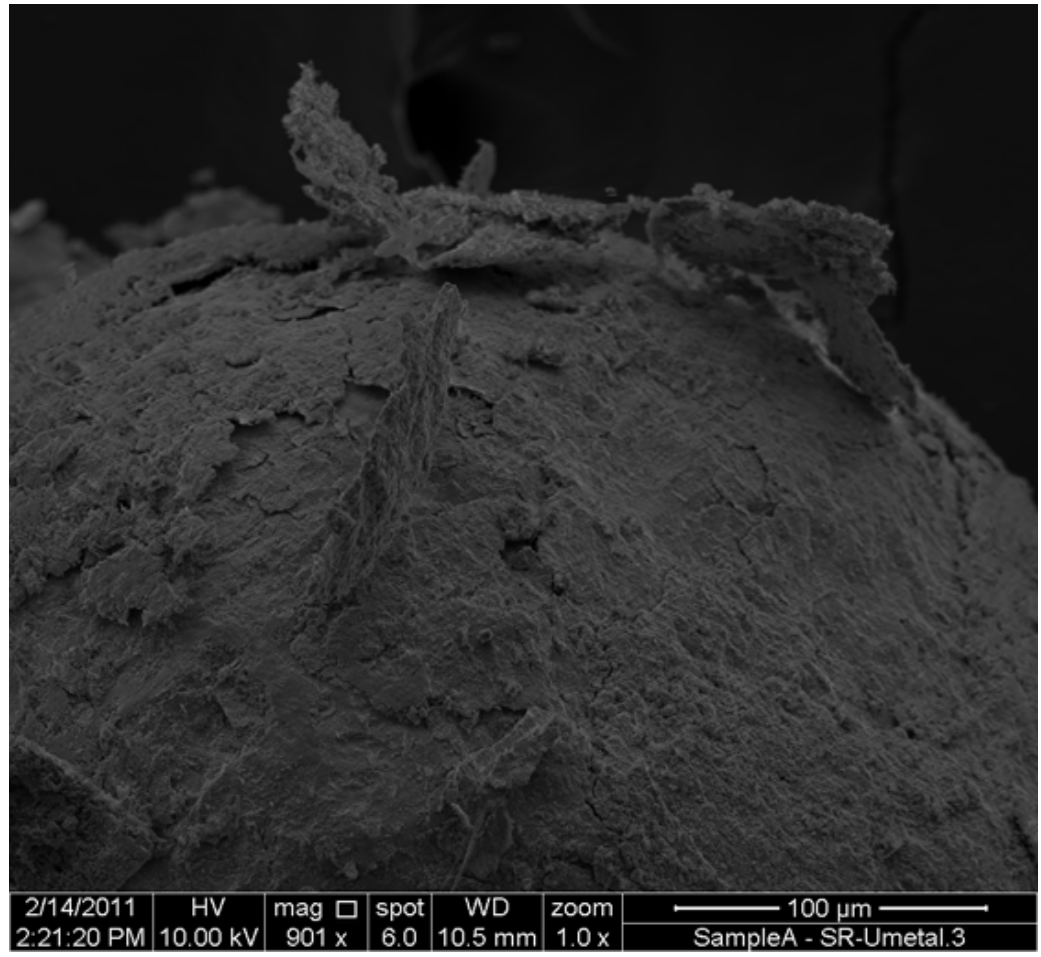

Figure E.5. 50:50 Uranium Oxide Slurry Contacted Uranium Metal/No $\mathrm{H}_{3} \mathrm{PO}_{4}$ Treatment $-100 \mu \mathrm{m}$ Window 


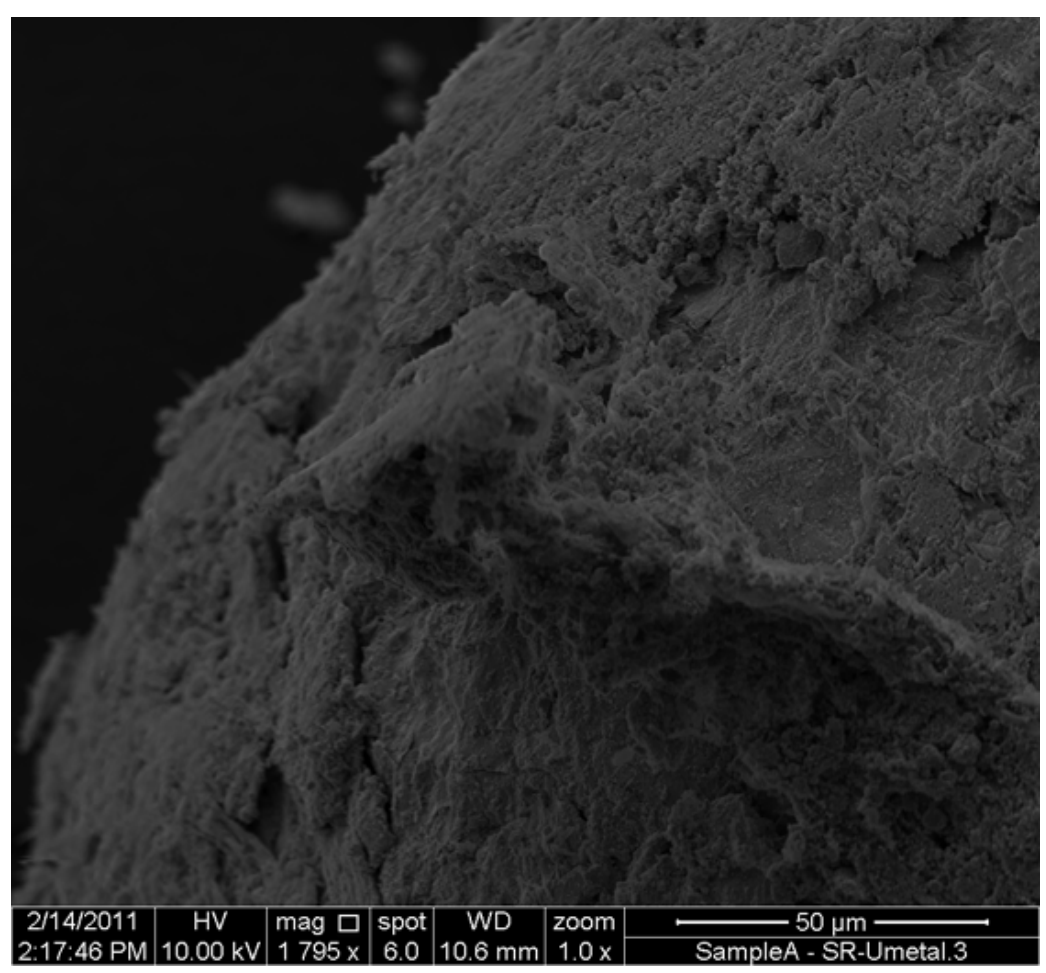

Figure E.6. 50:50 Uranium Oxide Slurry Contacted Uranium Metal/ $\mathrm{No} \mathrm{H}_{3} \mathrm{PO}_{4}$ Treatment - $50 \mu \mathrm{m}$ Window

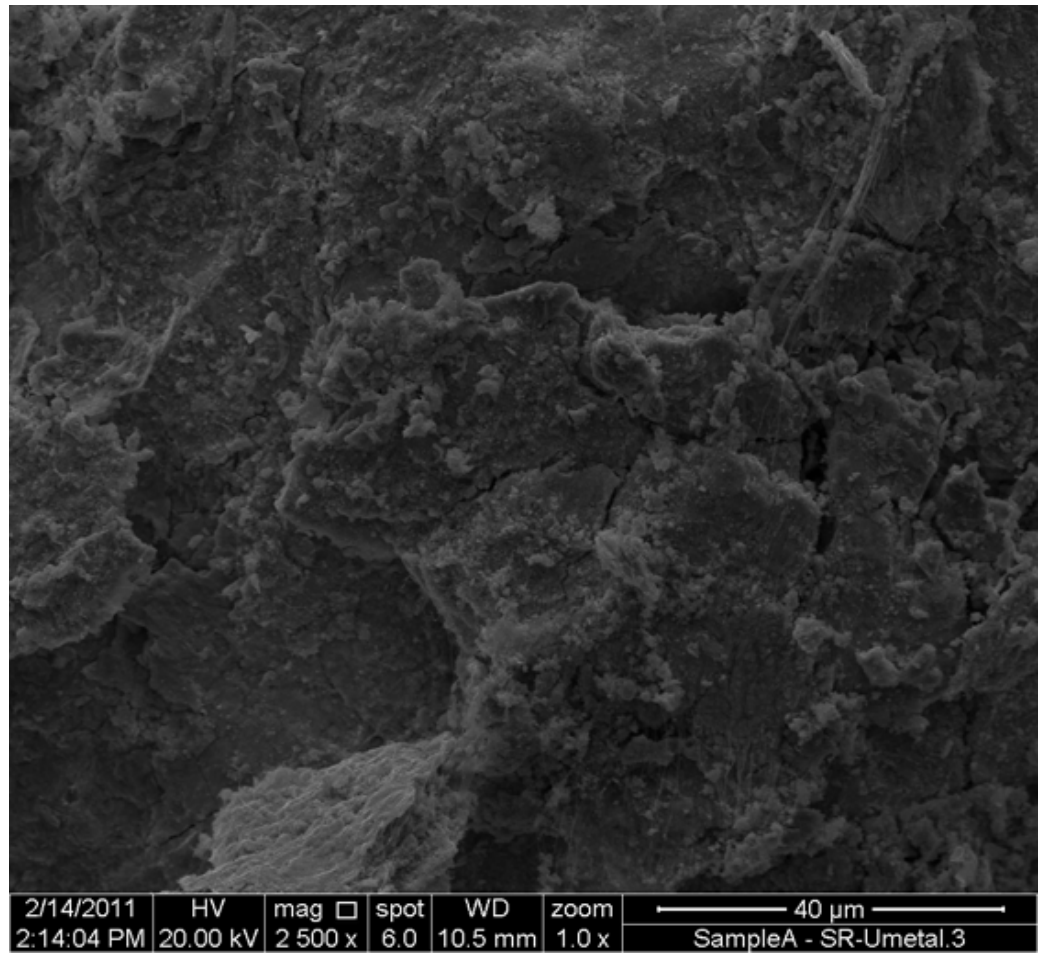

Figure E.7. 50:50 Uranium Oxide Slurry Contacted Uranium Metal/No $\mathrm{H}_{3} \mathrm{PO}_{4}$ Treatment $-40 \mu \mathrm{m}$ Window 


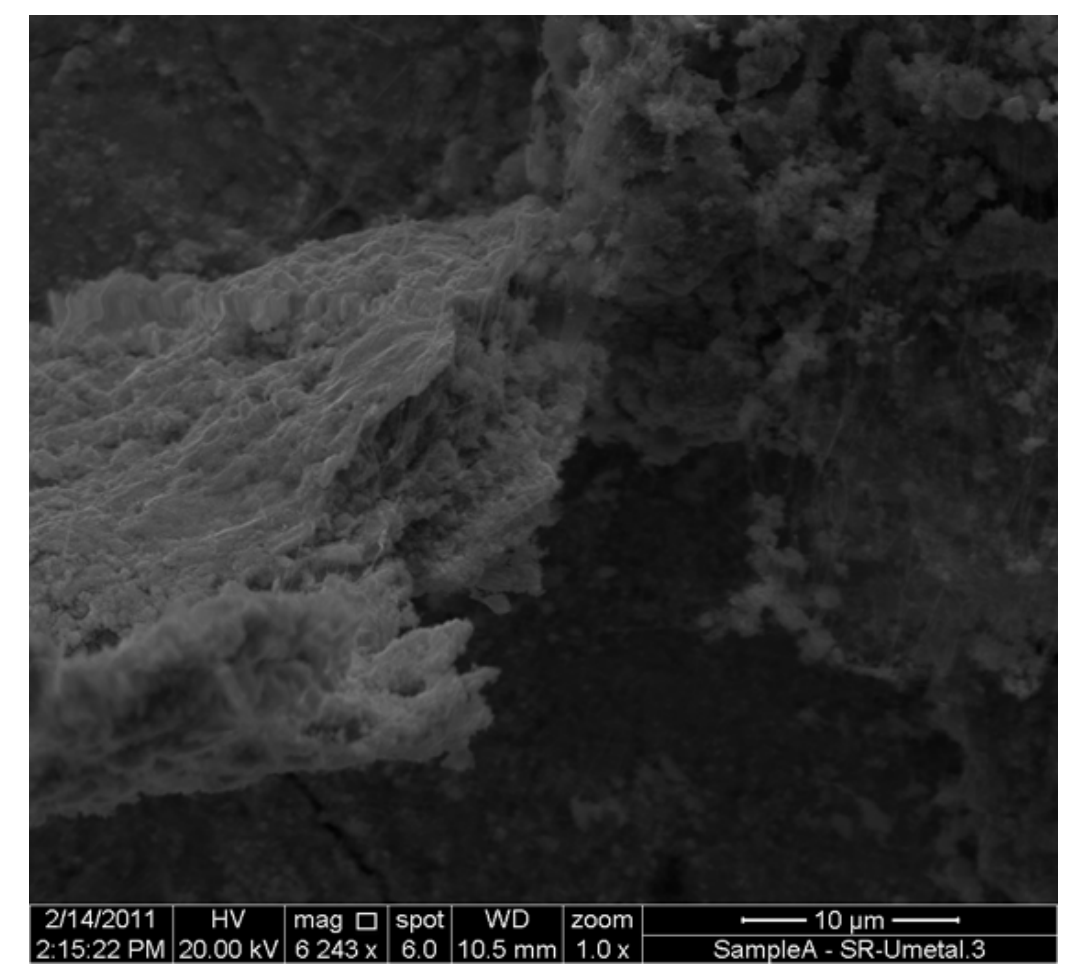

Figure E.8. 50:50 Uranium Oxide Slurry Contacted Uranium Metal/No $\mathrm{H}_{3} \mathrm{PO}_{4}$ Treatment $-10 \mu \mathrm{m}$ Window

\section{KW Simulant Contacted Uranium Metal / $\mathrm{H}_{3} \mathrm{PO}_{4}$ Treated}

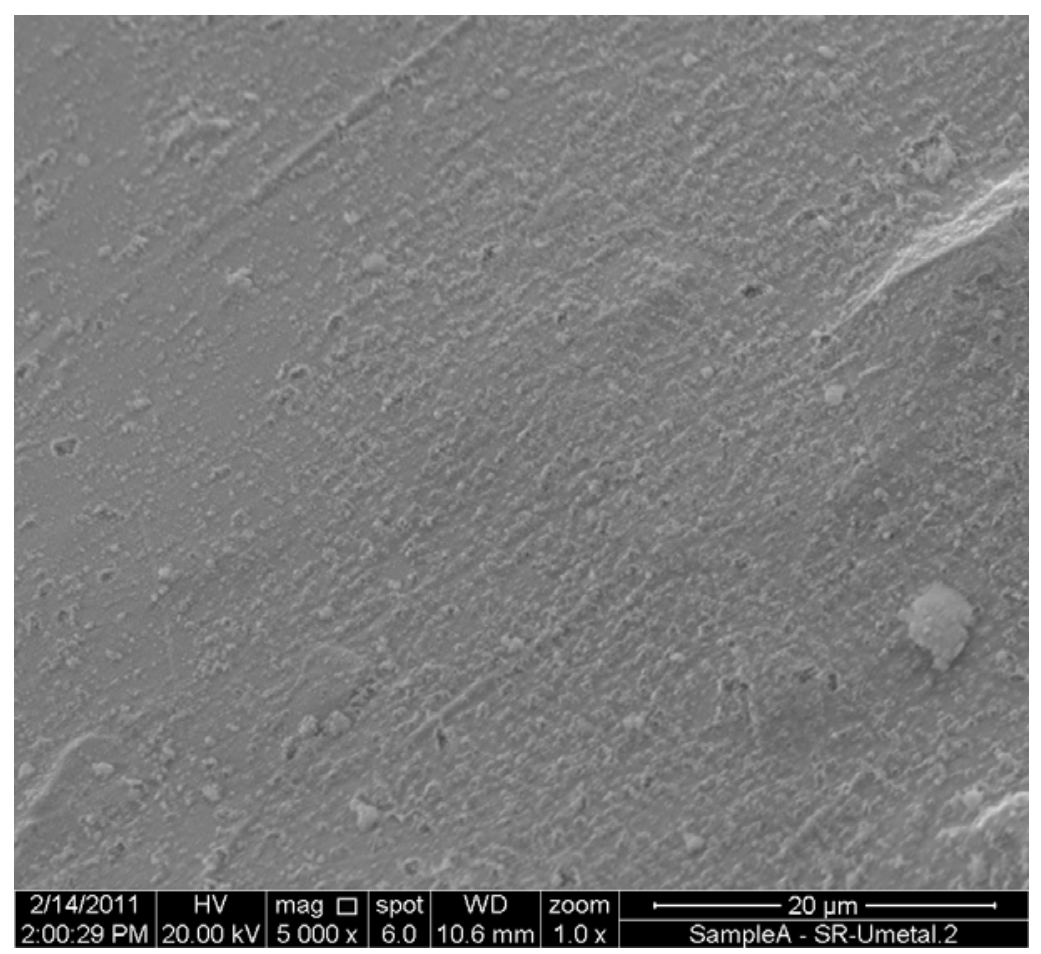

Figure E.9. KW Simulant Contacted Uranium Metal $/ \mathrm{H}_{3} \mathrm{PO}_{4}$ Treated - $20 \mu \mathrm{m}$ Window 


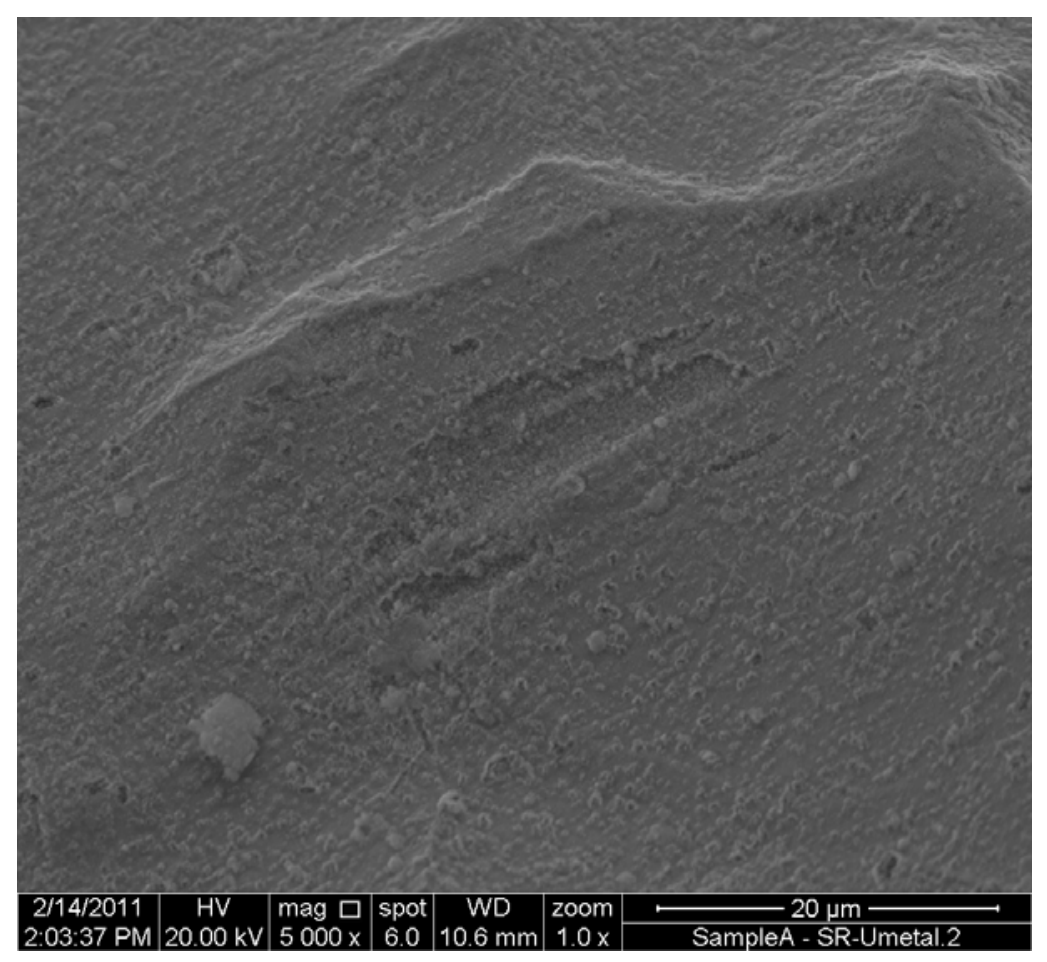

Figure E.10. KW Simulant Contacted Uranium Metal $/ \mathrm{H}_{3} \mathrm{PO}_{4}$ Treated - $20 \mu \mathrm{m}$ Window

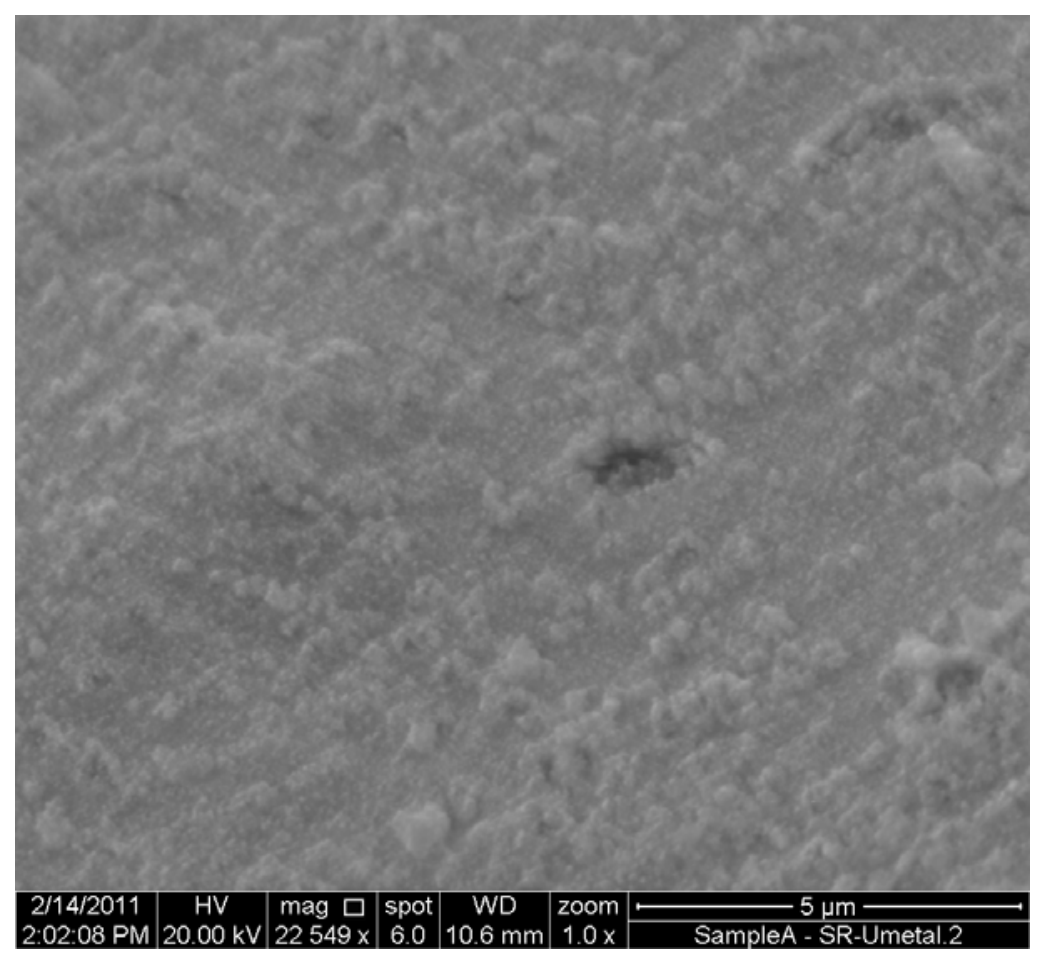

Figure E.11. KW Simulant Contacted Uranium Metal $/ \mathrm{H}_{3} \mathrm{PO}_{4}$ Treated $-5 \mu \mathrm{m}$ Window 


\section{0:50 Uranium Oxide Contacted Uranium Metal/ $\mathrm{H}_{3} \mathrm{PO}_{4}$ Treated}

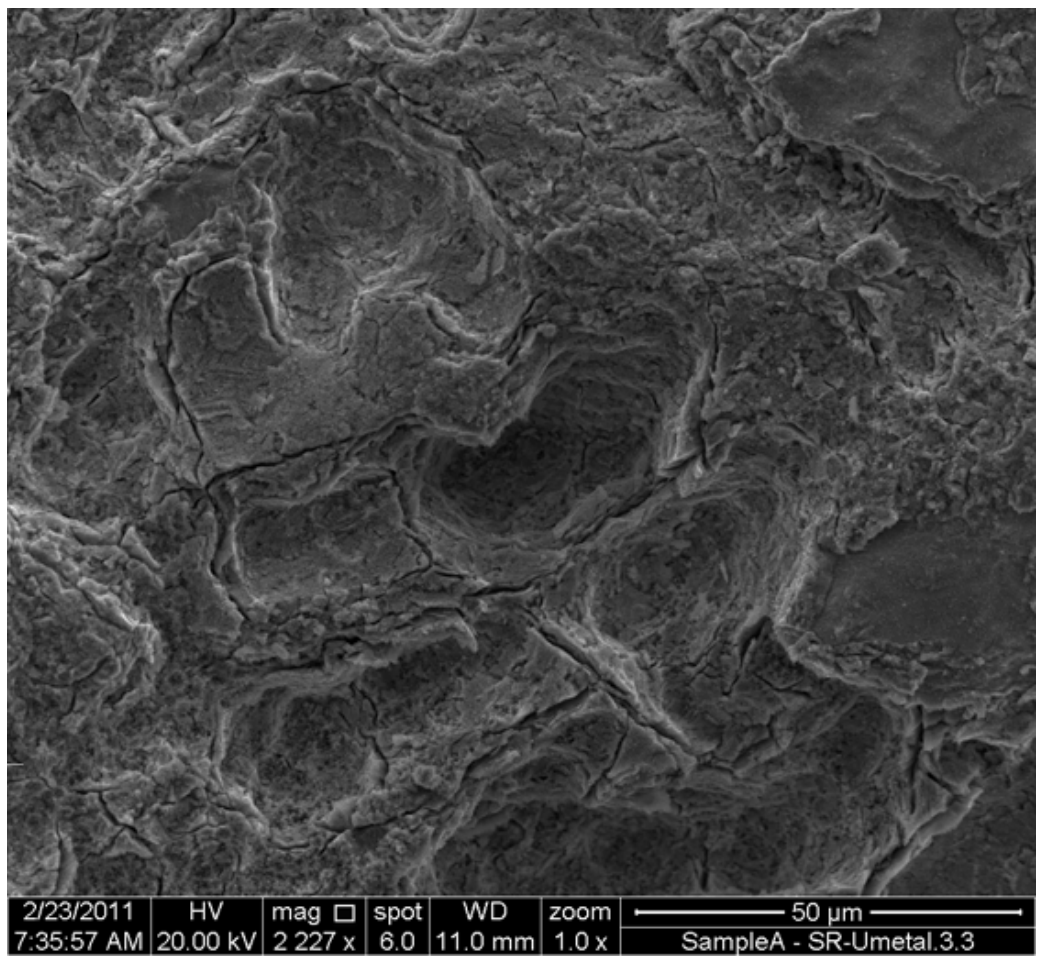

Figure E.12. 50:50 Uranium Oxide Contacted Uranium Metal $/ \mathrm{H}_{3} \mathrm{PO}_{4}$ Treated - $50 \mu \mathrm{m}$ Window

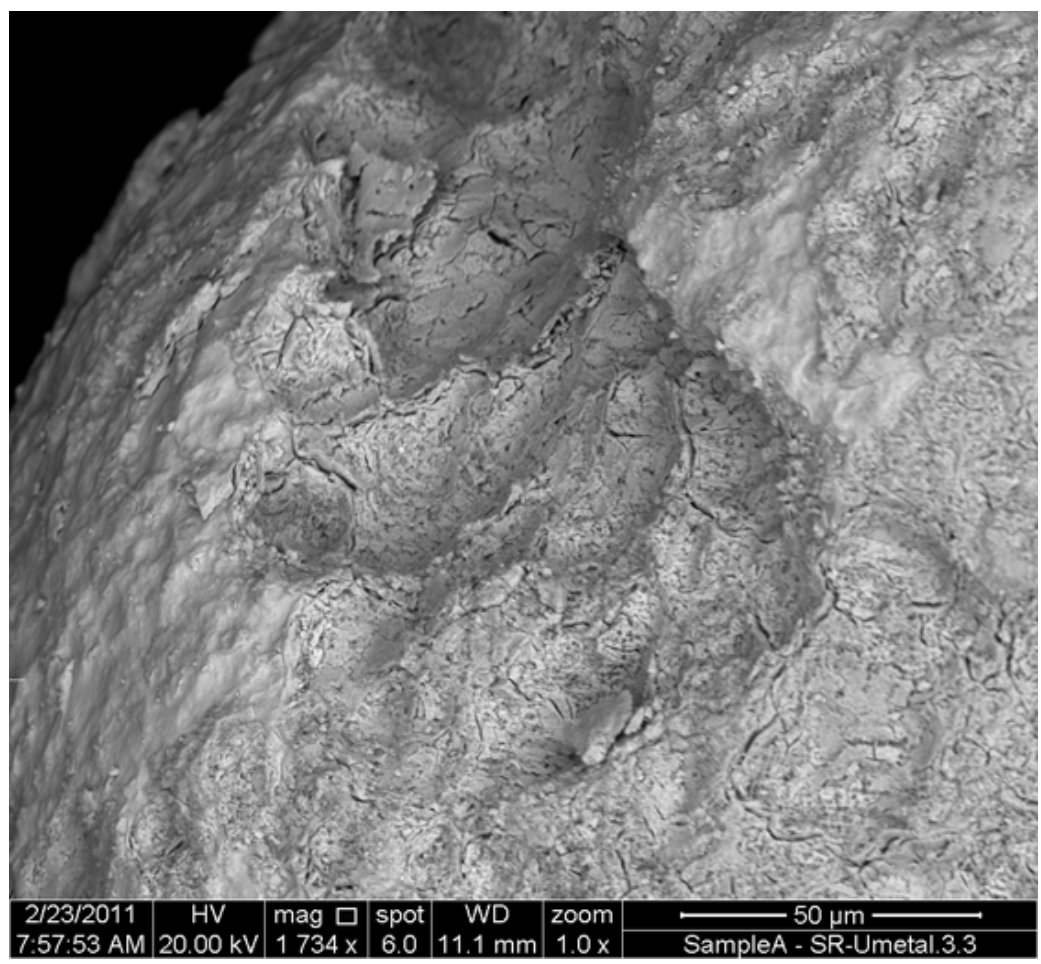

Figure E.13. KW Simulant Contacted Uranium Metal $/ \mathrm{H}_{3} \mathrm{PO}_{4}$ Treated - $50 \mu \mathrm{m}$ Window 


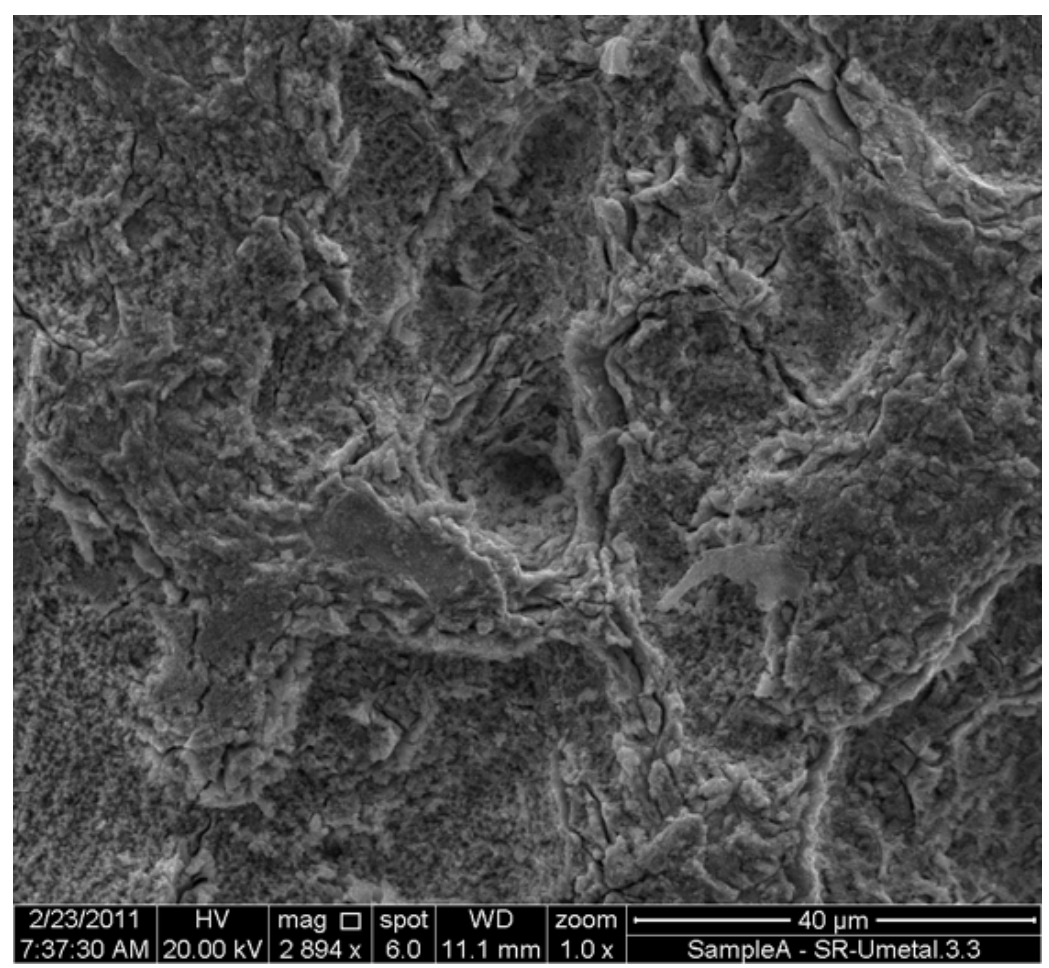

Figure E.14. KW Simulant Contacted Uranium Metal $/ \mathrm{H}_{3} \mathrm{PO}_{4}$ Treated $-40 \mu \mathrm{m}$ Window

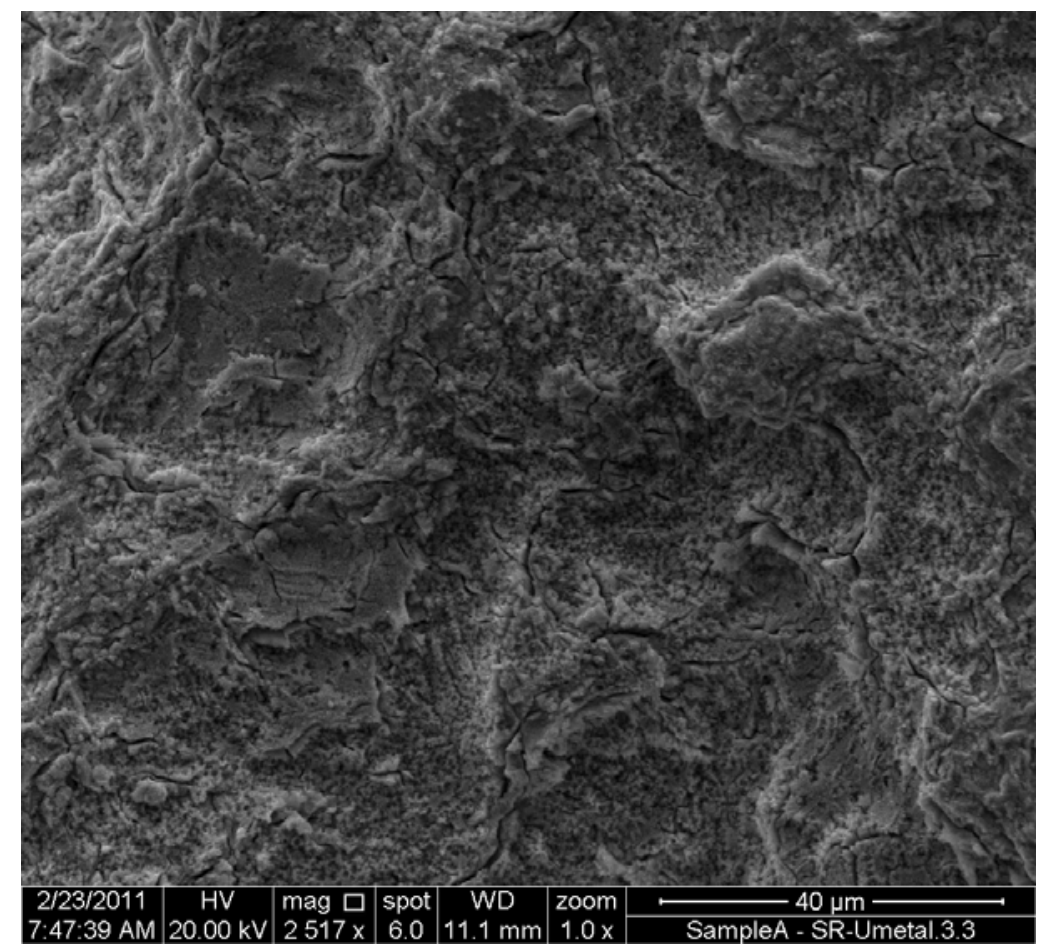

Figure E.15. KW Simulant Contacted Uranium Metal $/ \mathrm{H}_{3} \mathrm{PO}_{4}$ Treated $-40 \mu \mathrm{m}$ Window 


\section{Initial 50:50 Uranium Oxide S/urry}

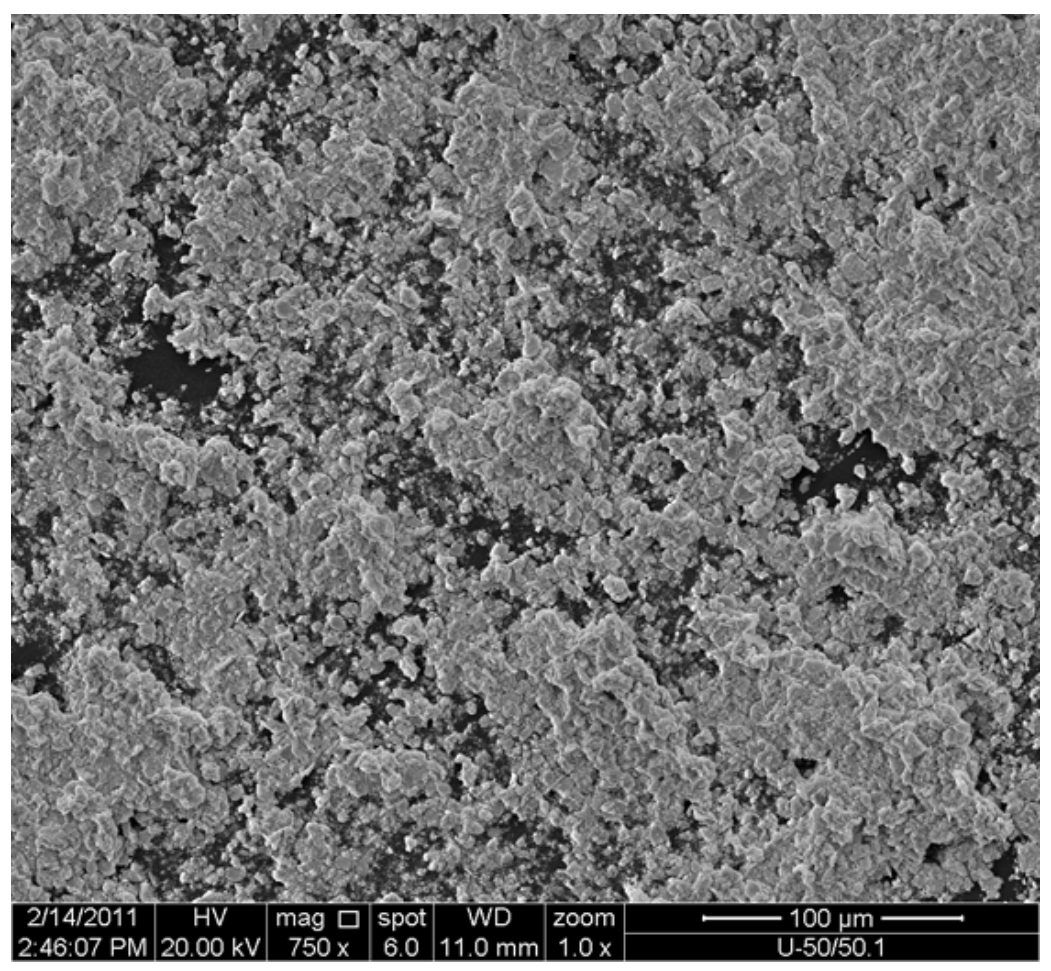

Figure E.16. Initial 50:50 Uranium Oxide Slurry - $100 \mu \mathrm{m}$ Window

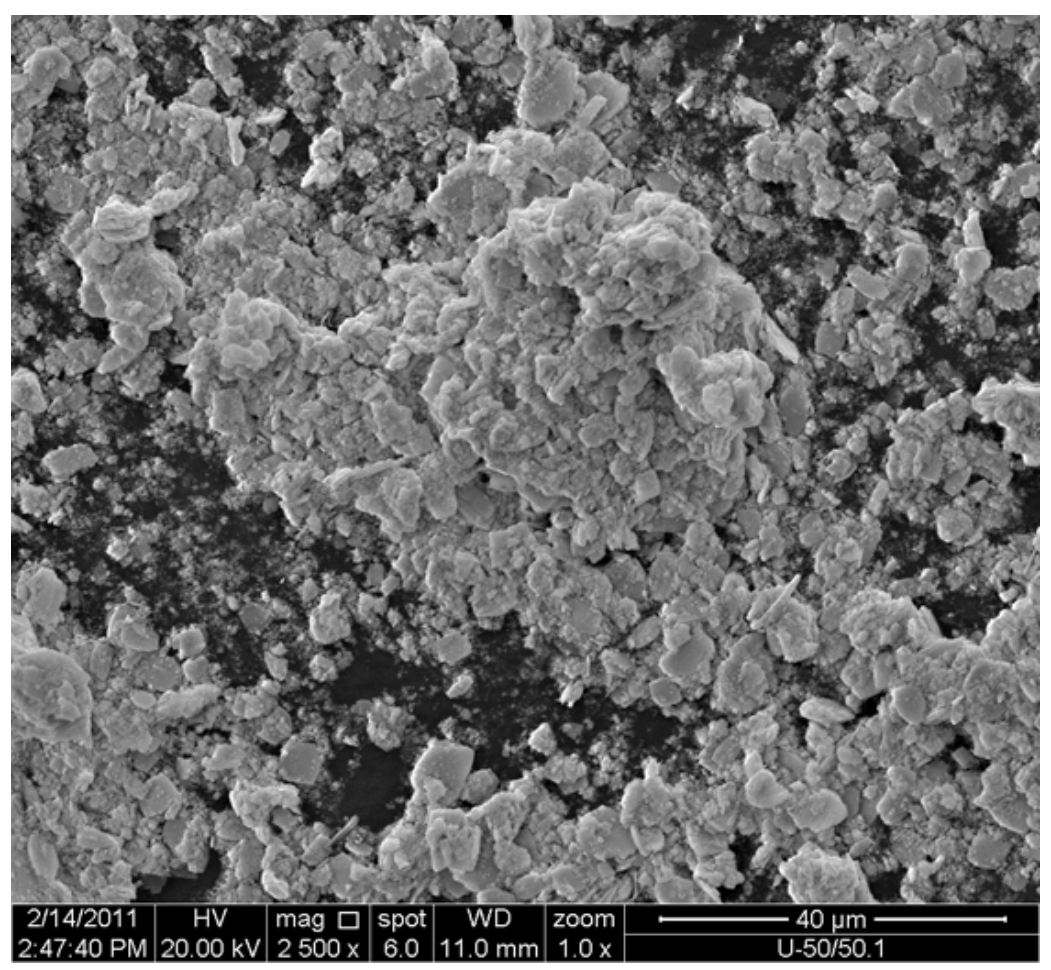

Figure E.17. Initial 50:50 Uranium Oxide Slurry - $40 \mu \mathrm{m}$ Window 


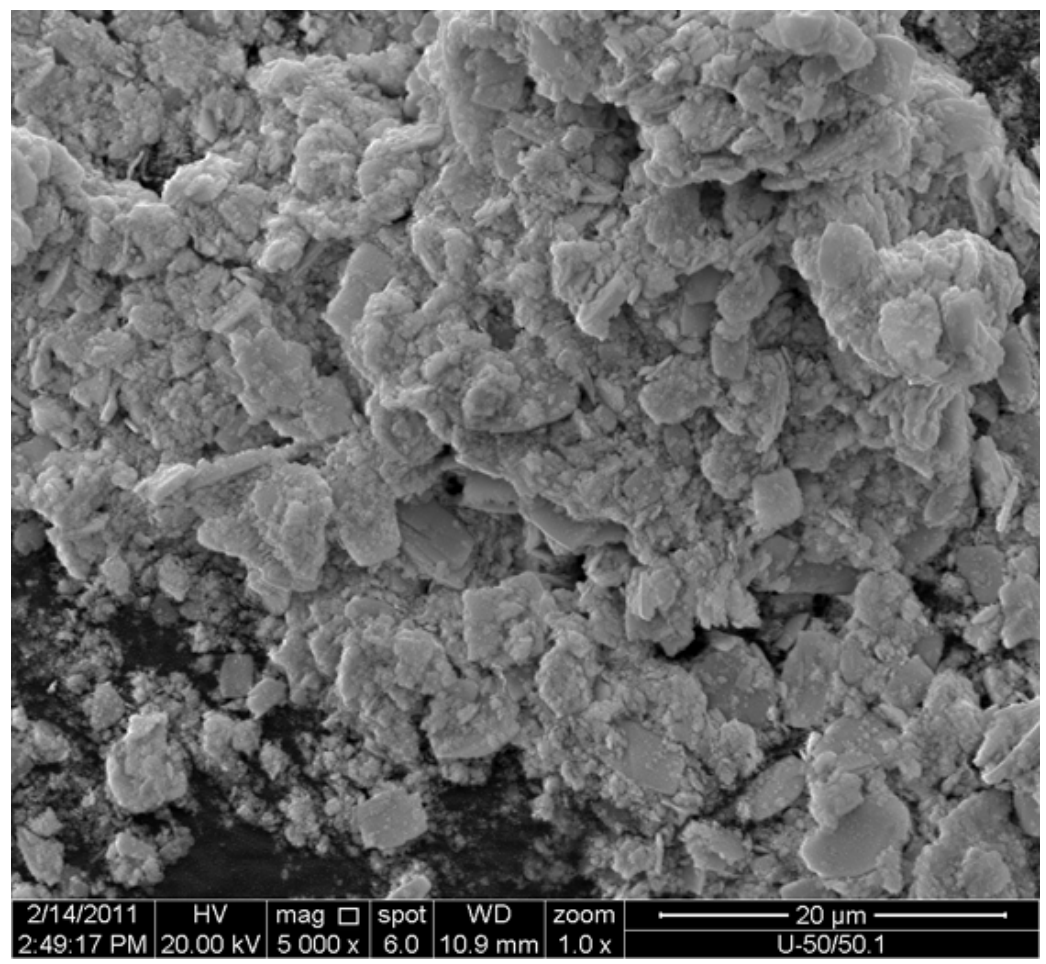

Figure E.18. Initial 50:50 Uranium Oxide Slurry - $20 \mu \mathrm{m}$ Window

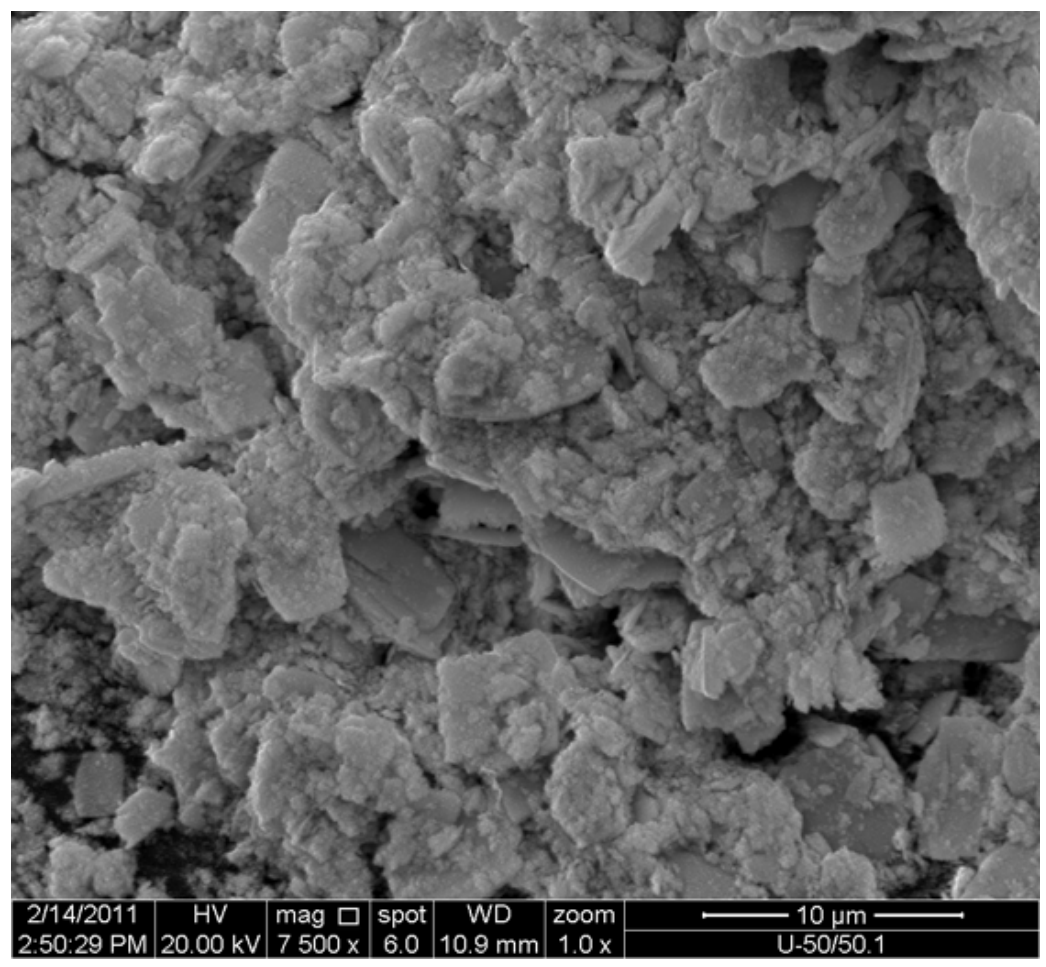

Figure E.19. Initial 50:50 Uranium Oxide Slurry - $10 \mu \mathrm{m}$ Window 


\section{Post-Heat 50:50 Uranium Oxide S/urry}

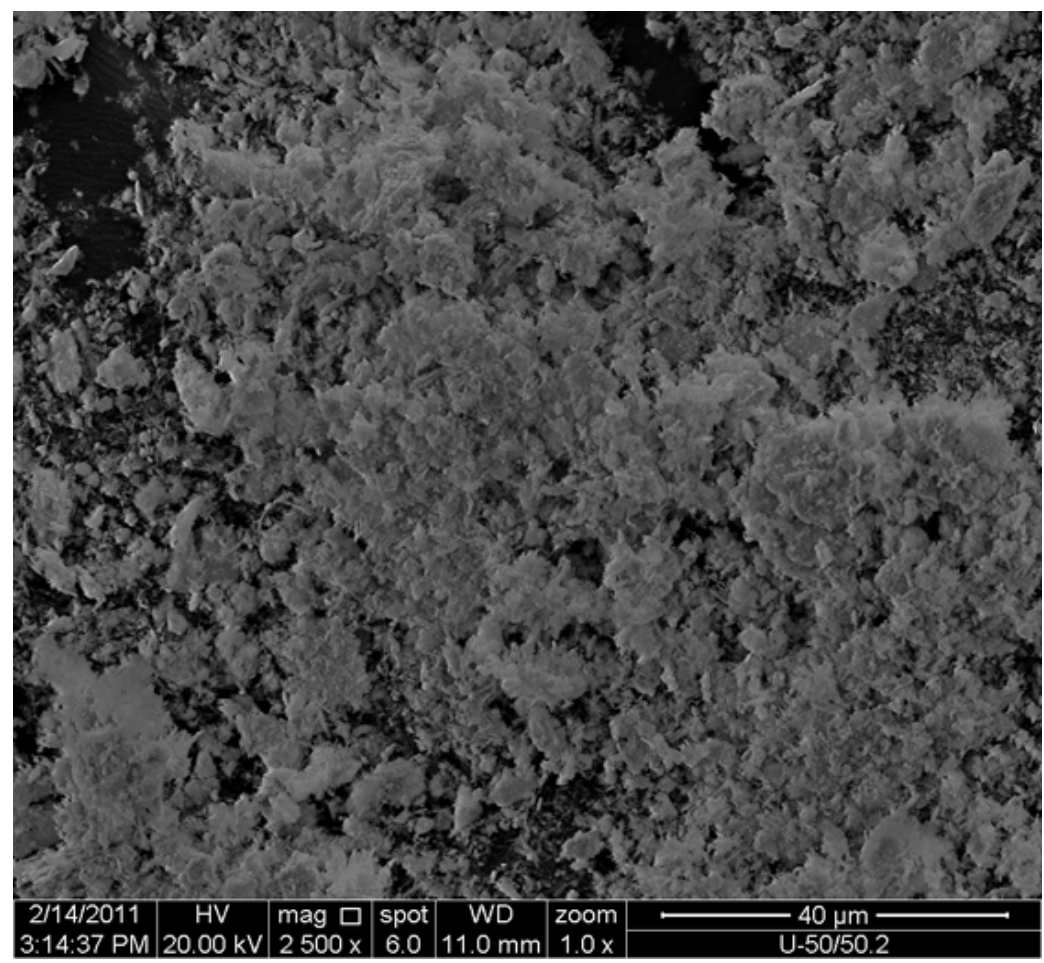

Figure E.20. Post-Heat 50:50 Uranium Oxide Slurry - $40 \mu \mathrm{m}$ Window

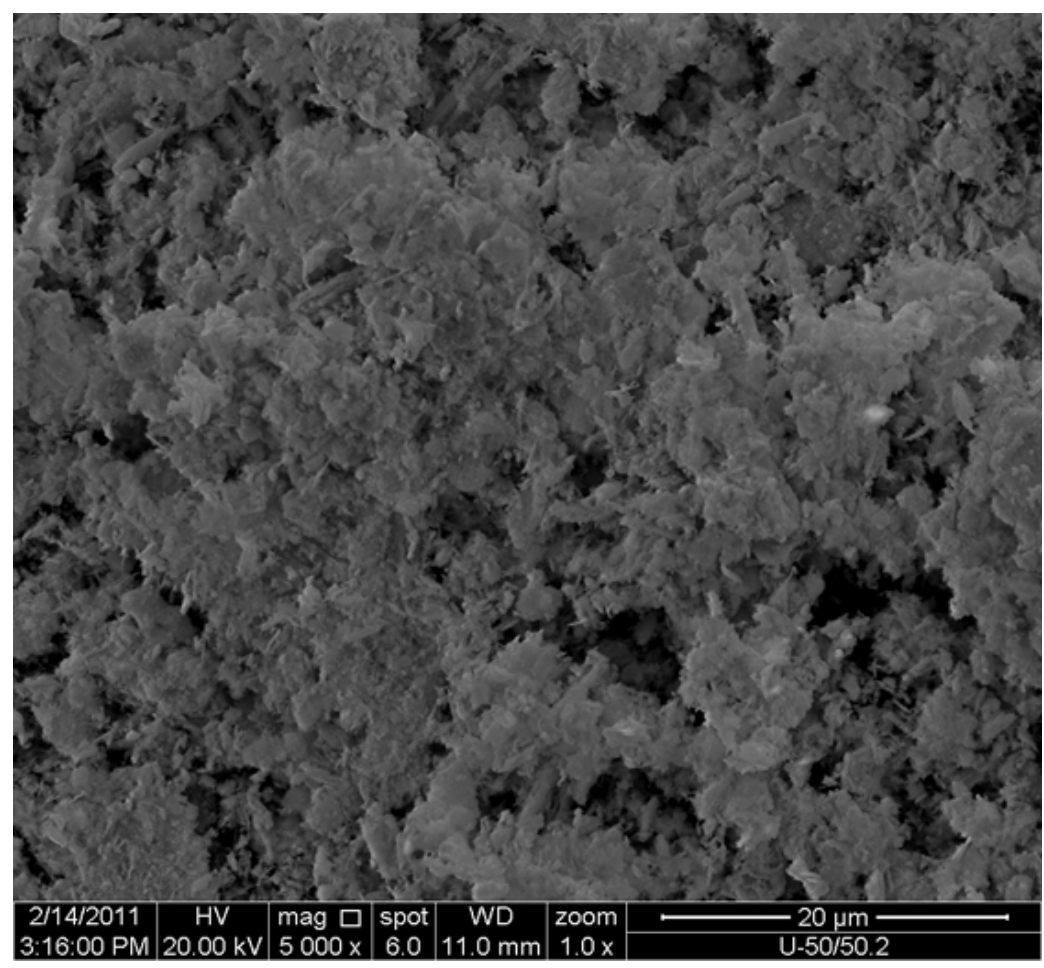

Figure E.21. Post-Heat 50:50 Uranium Oxide Slurry - $20 \mu \mathrm{m}$ Window 


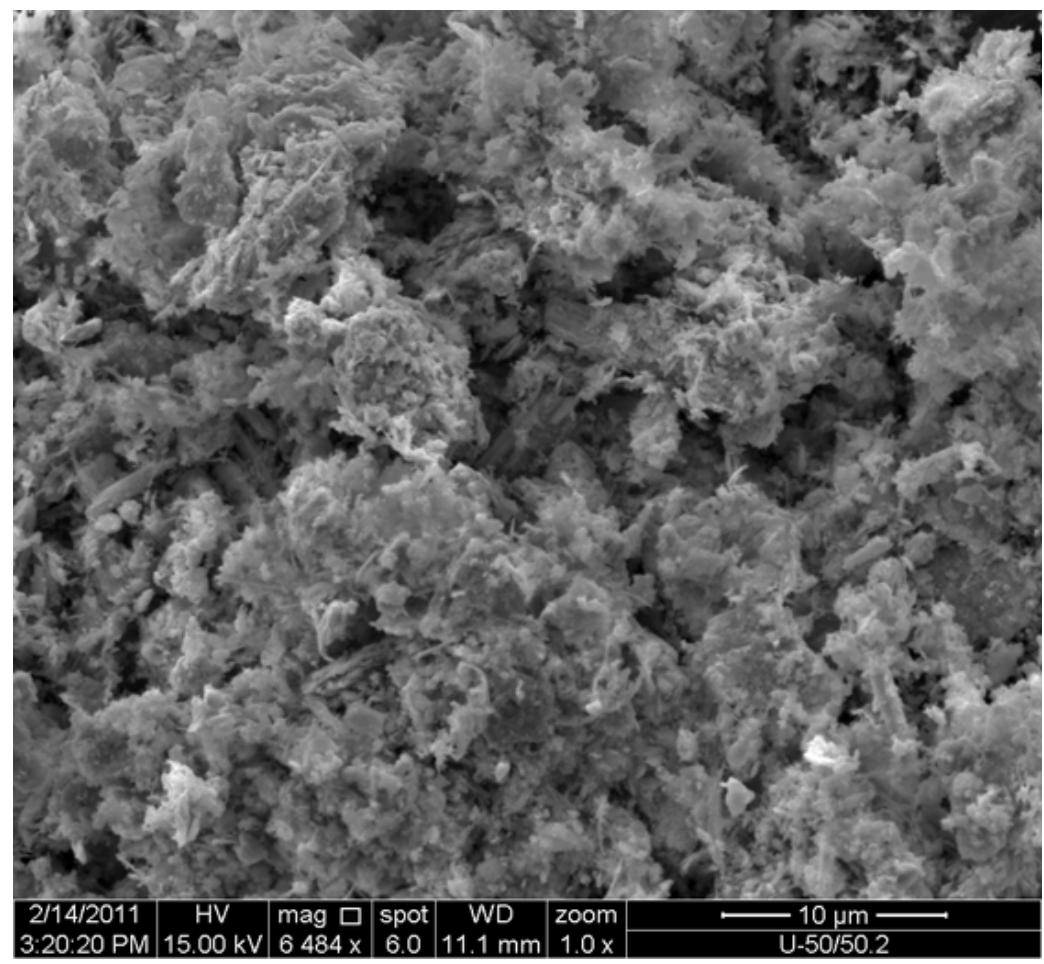

Figure E.22. Post-Heat 50:50 Uranium Oxide Slurry - $10 \mu \mathrm{m}$ Window 
PNNL-20070

53451-RPT16, Rev. 0

\section{Distribution}

No. of

Copies

7 CH2M Hill Plateau Remediation Company

RB Baker

JO Honeyman

ME Johnson

M Klem

WW Rutherford

JP Sloughter

F Wickstrand
A3-06

A3-06

A3-26

A3-06

A3-06

A3-06

R1-29
No. of

Copies

6 Pacific Northwest National Laboratory

JC Braley P7-25

CD Carlson P7-25

CH Delegard P7-25

SA Jones P7-25

SI Sinkov P7-25

AJ Schmidt P8-60

Information Release PDF 


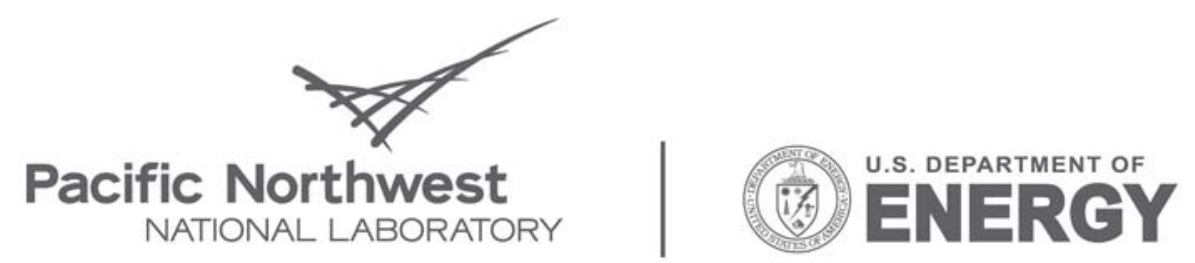

Proudly Operated by Battelle Since 1965

902 Battelle Boulevard

P.O. Box 999

Richland, WA 99352

1-888-375-PNNL (7665)

www.pnl.gov 